The Giving Trees: Community Orchards as New Urban Commons

by

\title{
Jennifer Barron
}

A thesis submitted to the Faculty of Graduate and Postdoctoral Affairs in partial fulfillment of the requirements for the degree of

Doctor of Philosophy

in

Geography and Environmental Studies

Carleton University

Ottawa, Ontario

(C) 2018

Jennifer Barron 


\begin{abstract}
This thesis explores community orchards through the lens of the commons. Grounded in extensive qualitative research at nine orcharding sites in three Canadian cities (Vancouver, Victoria, and Toronto) the author explores the meaning and purpose of community orchards to those who create and maintain them; the ways in which they can be conceived of as commons, and what community orchards can teach us about the challenges and potential of producing and sustaining new urban commons. The author advances the view that community orchards are much less about the fruits produced within them, and more about the production of urban space as new kinds of commons. The production of these food commons entails four main tasks: resisting enclosure, appropriating space for community, decommodifying exchange, and claiming power to shape the city, in collaboration with municipal administrations. As contributions to food security, community orchards work at deeper levels than might first be imagined, having less to do with what volunteer orchardists get in the way of free fruit and more to do with what they give through the medium of the orchards - to themselves, to each other, and to their communities.
\end{abstract}

Keywords: commons, community orchards, community gardens, decommodification, neoliberalism, food security, food commons 
COMMUNITY ORCHARDS AS NEW URBAN COMMONS

\section{Acknowledgements}

I have so many people to thank for their unique roles in helping me get to this point today. First, I thank Harjap Grewal, of the Council of Canadians, and Pat Cameron for inspiring me to start on this journey. It is possible that neither will ever know what a profound influence they had on me. I thank the Social Sciences and Humanities Research Council (SSHRC) for entrusting me with the generous support of a Bombardier doctoral fellowship; and Carleton University for the scholarships and research assistantship that were so helpful in supporting me and my family for the first four years. I also thank the Selkirk College Faculty Association (SCFA) for critical tuition support in years four and five. I thank graduate program supervisor Dr. Fran Klodawsky, who refused to let me quit in the first year of my doctoral studies when I desperately wanted to, and who wisely advised me not to make major irrevocable life decisions in the midst of grief.

I thank Phil Forsyth of the Philadelphia Orchard Project (POP), and Robyn, Bri, Lisa, Ryan, Alex, and Marian who shared with me their beautiful community orchards in Philadelphia. I thank those in Vancouver and Victoria to whom I also spoke but didn't formally interview, including Elise, Kerrie, Sarah, Mila, Eric, and Sage; and Sarah in Ottawa, who let me practise interviewing on her. I am most deeply grateful for the passion, enthusiasm, and articulate expression of all those I interviewed: Hartley, Susan, Jodi, Sherry, Linda, Hannah, Jane, Julia, Matthew, Lisa, Martin, David, Wayne, Melissa, Tom, John, Patti, Lynn, Yoshi, Augusta, Sara, Carmen, Tanya, Helen, George, Séan, Brian, Stephanie, Sylvia, Virginie, Joe, Zsuzsa, Jo, Cassandra, Betsy and Deanna. I thank you all for your time, care, and stimulating conversations - you are the heart of it all. 
I thank Joanne MacKinnon for putting me up at her condo in Vancouver many times when I came to town for research visits. In Nelson, I am so very appreciative of Randy, Mary Ann, Judith, George, and Cara-lee for giving me beautiful places to live and write between January and June 2018. I thank many dear friends who have seen me through the toughest times - Jocelyn, Allison, Janet, Dana, Joan, Bessie, Caroline, Karina; Erin for the constant reminder that "we can do hard things"; and the ever-generous Sarah, John, and Sue who were the first to celebrate with me when I finished.

I thank my mom, Lowell, and my sisters, Naomi, Julie, and Katie for offering encouragement, love, and moral support at critical moments. I thank my late father, John, who would have been so proud to see me finish but who only made it to the end of my first year of doctoral studies. I always felt his sincere encouragement, even while he had much bigger things on his mind. I thank my beloved children, Quinn and Felix, for their forbearance, and my former partner Erik, for maintaining a steady presence through it all. You were all such good sports moving to Ottawa for eight months; I hope at least that the great skiing made it all worthwhile!

Finally, I thank my committee members, Irena and Charles, for their insights and trust in me, and my wonderful doctoral advisor, Dr. Patricia Ballamingie, who showed such great empathy and always knew what to say in every meeting to motivate and inspire me to continue and do my best work. I chose Carleton to work with you, Trish, and your belief in me has made all the difference. 


\section{Table of Contents}

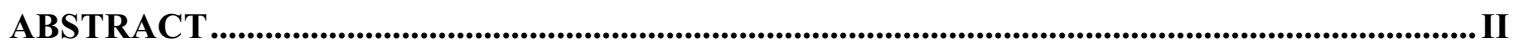

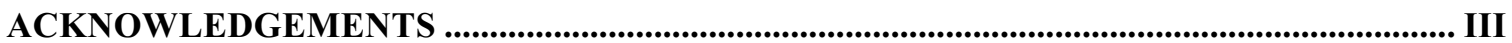

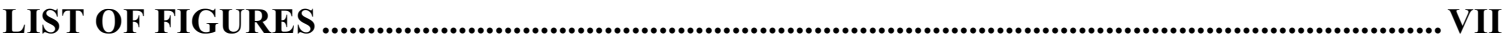

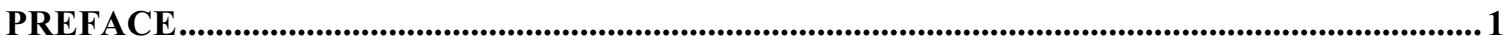

CHAPTER 1 - AN INVITATION TO COMMUNITY ORCHARDS ........................................5

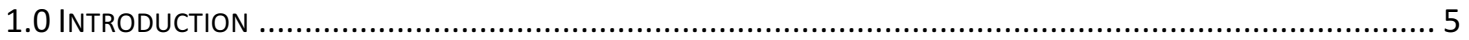

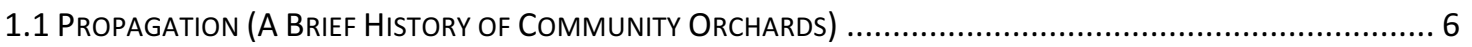

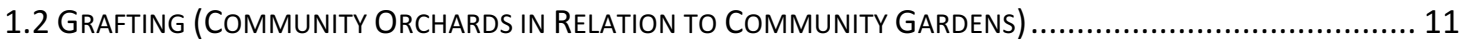

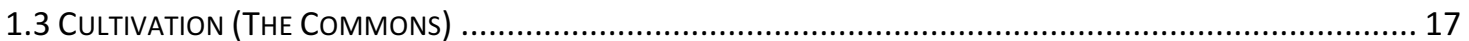

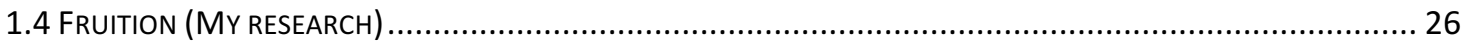

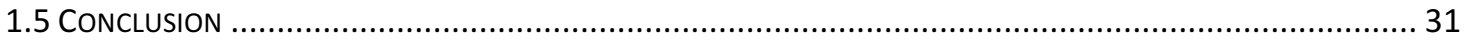

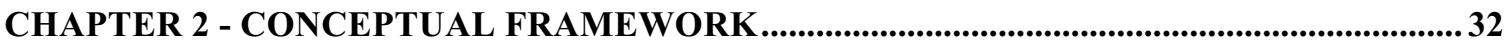

2.0 INTRODUCTION

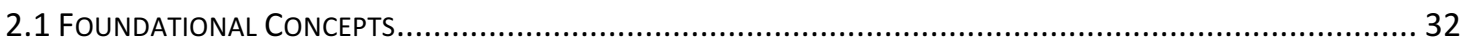

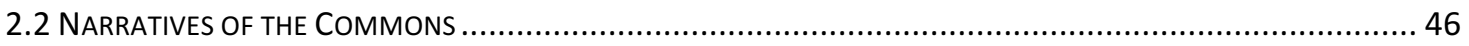

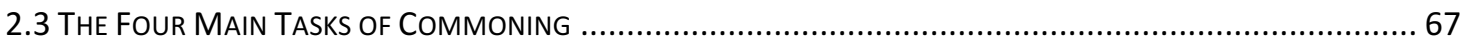

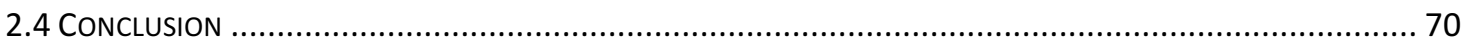

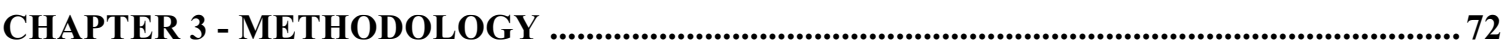

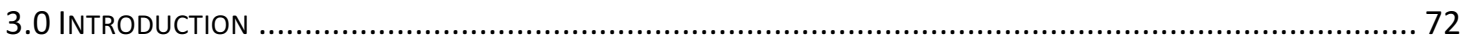

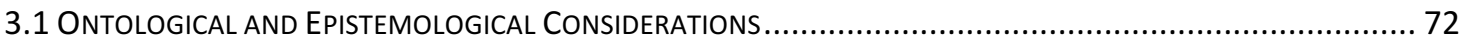

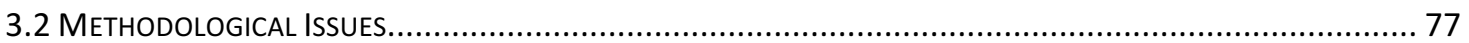

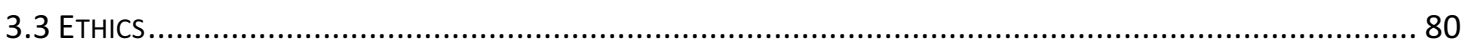

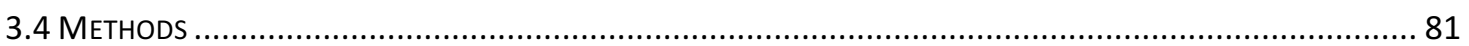

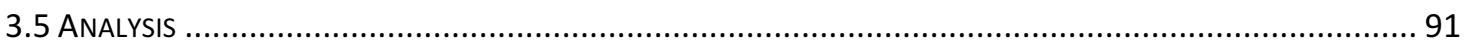

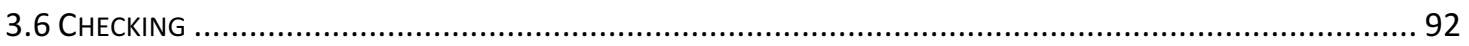

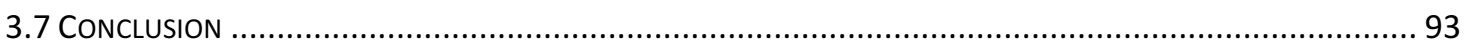

CHAPTER 4 - THE COMMUNITY ORCHARDS ................................................................95

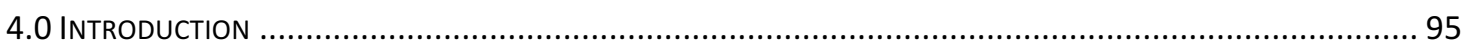

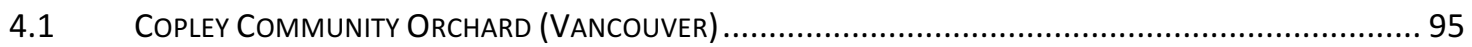

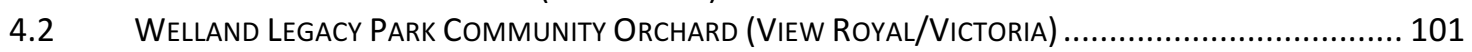

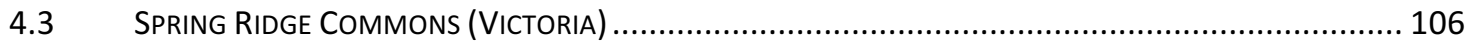

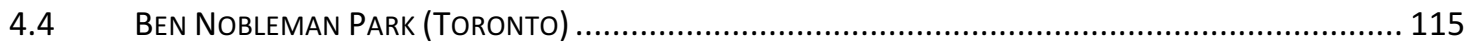

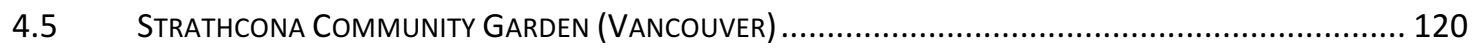

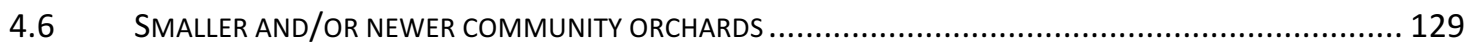

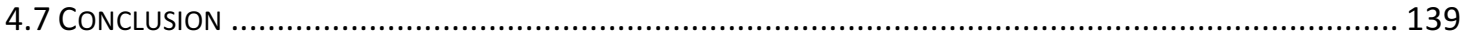

CHAPTER 5 - “IT'S NOT REALLY ABOUT THE FRUIT!” '......................................................140

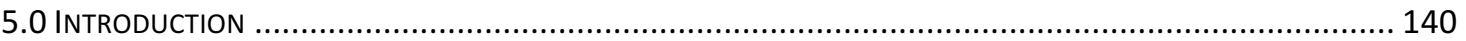

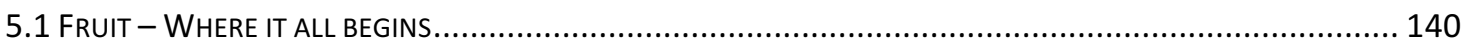

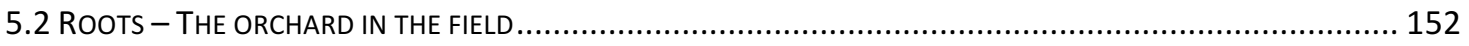

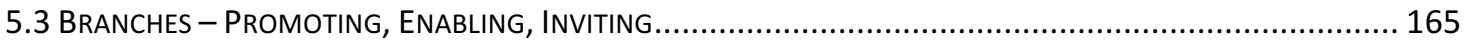

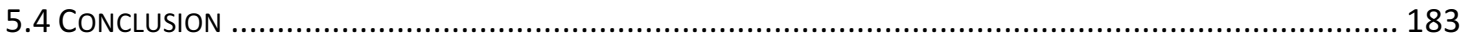


CHAPTER 6 - RESISTING ENCLOSURE ................................................................................ 187

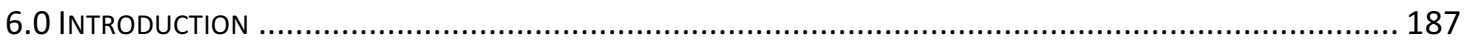

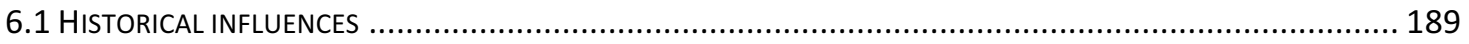

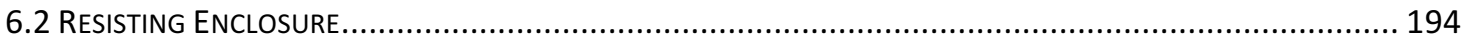

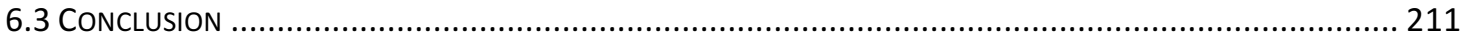

CHAPTER 7 - APPROPRIATING SPACE FOR COMMUNITY ..............................................2213

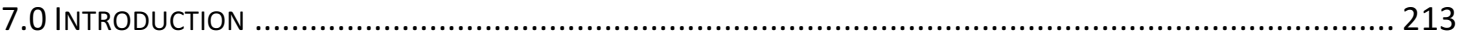

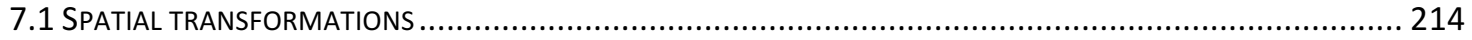

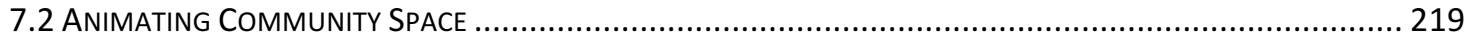

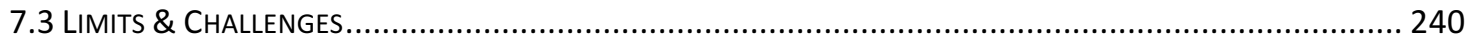

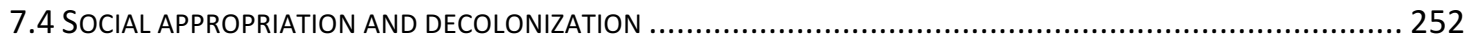

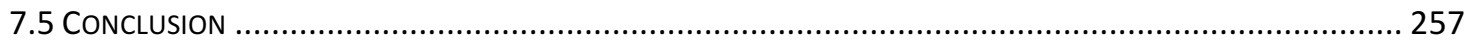

CHAPTER 8 - DECOMMODIFYING EXCHANGE: ....................................................................259

THE GIFT ETHOS IN THE ORCHARD ......................................................................................259

8.0 INTRODUCTION

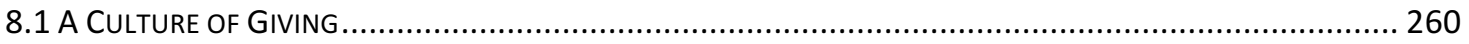

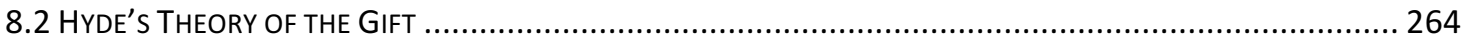

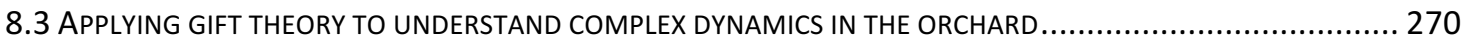

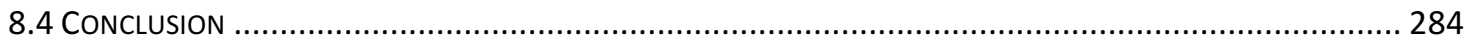

CHAPTER 9 - CLAIMING POWER TO SHAPE THE CITY .....................................................288

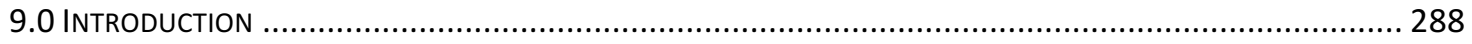

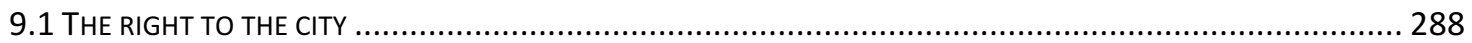

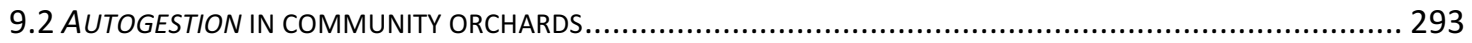

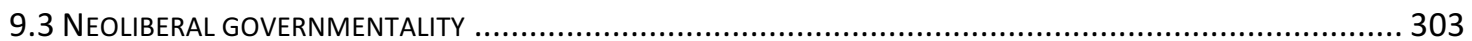

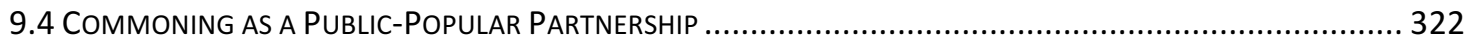

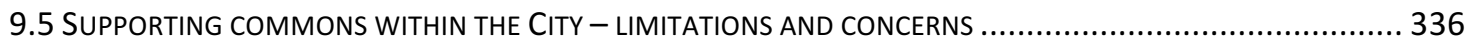

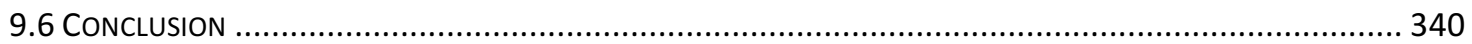

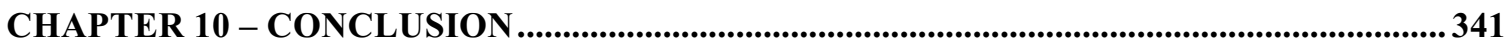

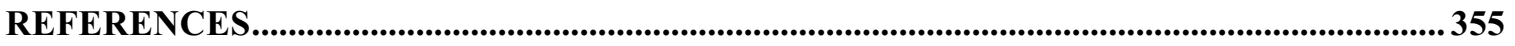

APPENDIX A - LETTER OF INTRODUCTION AND INFORMED CONSENT ......................393

APPENDIX B - QUESTIONS FOR INTERVIEWEES …................................................................. 397

APPENDIX C - COMMUNITY ORCHARDS BY PHYSICAL \& ORGANIZATIONAL

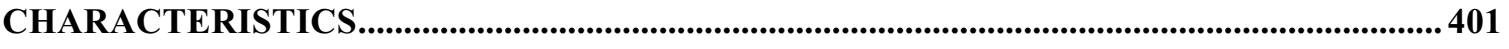

APPENDIX D - MAPS SHOWING LOCATIONS OF COMMUNITY ORCHARDS............... 404 


\section{List of Figures}

Figure 1 - Black raspberries at Copley

Figure 2 - EYA staffer helpfully pruning diseased branches on the community side of Copley Community Orchard

Figure 3 - Copley Community Orchard member Linda Lee

Figure 4 - Welland in early spring

Figure 5 - Native pollinator "condo"

Figure 6-Quince blossoms at Welland

Figure 7 - Winter pruning workshop at Welland

Figure 8 - Spring Ridge Commoners

Figure 9 - Spring Ridge Commons Welcome gate

Figure 10 - Partial view of Spring Ridge Commons, with camas field in foreground

Figure 11 - Welcome sign

Figure 12 - Mulberries!

Figure 13 - Volunteers Lynn and Alex at cherry harvest

Figure 14 - Ben Nobleman Community Orchard co-founder, Susan Poizner

Figure 15 - Ben Nobleman volunteers enjoying their harvest

Figure 16 - Strathcona Community Gardens espalier and grape arbor

Figure 17 - Apples at Strathcona Community Gardens

Figure 18 - Young apple tree, surrounded by perennials

Figure 19 - Espaliered area of orchard, Strathcona Community Gardens, with the Chinese Freemasons' seniors housing complex in behind 
Figure 21 - One of many informative interpretive signs at the Norquay

Learning Orchard

Figure 22 - Poster for community engagement event at Norquay Learning Orchard

Figure 23 - Fruit trees in Jonathan Rogers Park

Figure 24 - Signage in Jonathan Rogers Park

Figure 25 - Fernwood Community Orchard

Figure 26 - Welcome gate to Banfield Community

Figure 27 - Promotional poster for Banfield's annual Wassail

Figure 28 - Sign at Strathcona Community Gardens

Figure 29 - Sign at Strathcona (2)

Figure 30 - Members harvesting crabapples at Strathcona Community 


\section{Preface}

In 1992, when I was in the final year of my undergraduate degree, I met and became friends with a most inspirational teacher. Pat Cameron taught grade six at St Patrick Catholic Elementary School, an inner-city school in Hamilton, Ontario, where she was renowned for her innovative and adventurous pedagogical approach and her passion for environmental education. One of Pat's great accomplishments was starting a school garden, at a time when no one else was doing such a thing. Together with her students and many willing supporters in the community, she literally carved out an oasis of green abundance amidst an asphalt jungle, transforming her young students' experience of school and sense of community in the process. I was inspired to write up their story for an Ontario outdoor educators' journal (Barron, 1993) and it remains one of the pieces of writing I am most proud of today.

I also vowed that should the opportunity arise, I would like to follow Pat's fine example and start a school garden. Fast forward to 2005, when my oldest child was starting grade one in an alternative program in the public school system in Nelson, BC. The Wildflower program was innovative, progressive, and dedicated to nurturing the unfolding of each child's gifts through a holistic, empathic, community-oriented and experiential approach to education. Ironically (given its name), the Wildflower program, like St Patrick's School in Hamilton, was located downtown, with nothing but asphalt for the children to play on. It seemed the stars had aligned for me to follow through on my promise to myself, and so I did just that. Over the next eight years, I worked together with other 
COMMUNITY ORCHARDS AS NEW URBAN COMMONS

parents, teachers, students, administrators, school district operations staff, and enthusiastic community members to realize the dream of a school garden, and outdoor classroom, which eventually came to consist of 11 raised beds with built-in benches, a story circle, a stage, a shed, a compost area, a grassy playing field, and an herb and native plant spiral (the latter being an initiative of the Aboriginal Education program). In that garden, students have grown not only wildflowers, but also pumpkins, corn, scarlet runner beans, salad greens, beets, peas, chard, carrots, rhubarb, blueberries, Saskatoon berries, amaranth, and even buckwheat, which they have winnowed by hand, ground into flour, and made into pancakes.

Having fought for years previous in the trenches of peace and social justice activism against everything from low-level military flight testing and large-scale nickel mining in Nitassinan (Labrador) (Barron, 2000; 2002) to the crippling economic sanctions on Iraq, to the unnecessary use of pesticides in lawns and gardens - I had burned out. The school gardens project was, for me, a breath of fresh air. I desperately needed to do something in line with my values and desire for social change that would not bring me into so much conflict with other people. I was tired of facing opponents and fearing their animosity. I wanted to be for something, not just against things. And I wanted to lead and give in my community in a way that brought happiness and optimism to others, including my children, not to mention myself. Gardening - especially food growing - did this for me.

In the course of that project, I developed a deep and abiding interest in food security and, in time, the related constructs of food sovereignty and food justice. I came to feel part of 
the local food movement and even reoriented some of my own (college) teaching to use food as a focus or frame through which to teach environmental issues and peace. I joined the BC Food Systems Network and attended some of their annual gatherings, including one on Gambier Island in 2012 where I encountered the second major inspiration for this research. Harjap Grewal, a speaker from the Council of Canadians, gave a presentation on the renewal of the commons; it struck me with the force of lightning. His ideas about a collective, grassroots-based defense of public goods and the public interest as a route to sustainability and justice stimulated my intellectual appetite and awakened a dormant desire to return to school for a PhD. I was turned on by the hopefulness of this vision of the commons. I saw it as a third way, not wholly alternative to market and state but complementary, and capable, perhaps, of overcoming some of the limitations of each and the apparent stalemate between ideologies that have long privileged one or the other. I saw in this idea of the commons a way to deepen my interest in food security and alternative food institutions and to study a phenomenon that seemed to be imbued with a positive, constructive sense of empowerment. So, I undertook my doctorate with the goal of studying the ways that people were reclaiming the commons within the alternative or community food movement. I read extensively on community gardens - frequently lauded as prototypical or even quintessential commons - and later narrowed that focus to community orchards, which, being newer, are much less studied and therefore more inviting to research.

At the beginning of this journey, I harboured a niggling concern that over the long course of a $\mathrm{PhD}$, I might lose interest in my object of study. But both the commons and 
community orchards have proven to be very rich objects of study; they continue to intrigue and excite me even today, even as I have developed a more critical intellectual stance towards some of the complex political and social issues they raise. I hope that this dissertation may resonate with others who share my enthusiasm, not only for orchards, commons, and community gardens, but for the never-ending process of inquiring into what they may mean and may become. 


\section{Chapter 1 - An Invitation to Community Orchards}

\subsection{Introduction}

A community orchard is an orchard that is cared for, cooperatively, by some community of people, and that is managed for the benefit of members and/or the community at large, rather than for private profit (Ames, 2013). The apparent purpose of community orchards is to grow fruit and provide it, free of charge, to the community. ${ }^{1}$ Community orchards are then, quite literally, our "giving trees." 2 This research investigates community orchards in three Canadian cities by exploring: 1) how community orchardists understand, frame, and explain what they are engaged in and why; 2) how the practice of community orcharding fits in relation to theoretical writings on the commons (commoning); and, 3) how community orcharding affirms, informs, or challenges current scholarly ideas and debates about community, public space, neoliberalism, and urban governance. By synthesizing qualitative empirical analysis (primarily interviews with 35 orchardists at nine different sites) with theory, I have developed an understanding that

\footnotetext{
${ }^{1}$ We will come later to the intricacies of defining 'community'. For now, it is sufficient to note that unlike community gardens, where the produce is intended only for the gardeners, the fruits of community orchards may actually be intended for public consumption, though this is not always the case.

${ }^{2}$ The Giving Tree is the title of a book by famed American children's author Shel Silverstein. In the book, the apple tree gives of herself through her leaves, her limbs, her shade, her fruit, and finally, in being cut down, her wood, which is used to build first a house, and then a boat for the boy to sail away in. The story not only illustrates the many gifts an apple tree provides but also hints at the limits of selling apples for money, which does not make the boy happy. At the end of the boy's life, with the apple tree reduced to a stump, the tree is once again able to meet his needs, if only for a place to rest. Critics have expressed dismay at the tree's symbolic representation of self-abnegating motherhood and the pillaging of the environment the story also suggests. The book also has a sad and ambiguous ending, yet it has sold over 5 million copies worldwide (Margalit, 2014). I therefore don't intend the reference to be more than apple-skin deep. (:)
} 
COMMUNITY ORCHARDS AS NEW URBAN COMMONS

marries the insights of practitioners with those of academics; I hope it will lead to a more complex and more nuanced understanding of not only community orcharding, but also the related phenomena of community gardening and political gardening. I also hope that I have succeeded in writing up this research in a way that makes academic theory accessible to community orchardists.

In this chapter, I provide the substantive context for this research by first describing community orchards, and then defining and differentiating them from similar and related entities, including public produce, food forests, and community gardens. I then provide an overview of the relevant academic and grey literature. Because so little has been written about community orchards to date, this will include the extant literature on both community gardens and the commons, the two phenomena I deem most relevant to the study of this emergent phenomenon. The chapter concludes with a preview of the structure of the rest of the thesis.

\subsection{Propagation (A Brief History of Community Orchards)}

The community orcharding movement began in the United Kingdom (UK) in 1992 as an initiative of citizens who were concerned about abandoned orchards, and orchards that had already been lost to development, and who wished to preserve them out of concern for reviving heritage fruit varieties and historical community identities, as much as for enhancing green space and promoting healthy eating (Ames, 2013; Department for Communities and Local Government (DCLG), 2011; King \& Clifford, 2011). In addition to Friends-of-the-Orchard-type groups, set up for this sole purpose, entities that 
purchased or leased such orchards included local municipalities, charitable trusts, arts groups, food co-ops, and housing project residents (Ames, 2013). There are now hundreds of community orchards in England (King \& Clifford, 2011), located within existing allotment gardens, in previously under-used areas of parks, on privately owned farmland, municipally owned land, and land trusts (DCLG, 2011). The UK government regards them as a way of meeting community needs for open green space, a means of growing food and educating children, and a focal point for community activities (DCLG, 2011).

In North America, the development of community orchards has proceeded somewhat differently. Here, community orchards tend to be located in cities and to have been planted anew, rather than being reclaimed older commercial orchards in rural areas, as many are in the UK. Most are located in municipal parks or on other publicly owned lands. ${ }^{3}$ But community orchards may also be found on the grounds of housing co-ops, churches, group homes, food banks, and cohousing communities. In California, the allvolunteer organization Common Vision has planted orchards at over 180 low-income schools and community centres. ${ }^{4}$ North American cities with significant community orchards include Vancouver, Victoria, Toronto, Bloomington, Chicago, Philadelphia, Portland, and Seattle (Ames, 2013; Betz, 2014); other Canadian cities with community

\footnotetext{
${ }^{3}$ These include lands owned by school districts and lands owned by municipalities but not having the status of parks. These lands may be part of the City or school district's real estate holdings, held as investments or in anticipation of future property needs. In the cities this research concerns, particularly Toronto, community orchards and gardens have been established in parks as much as possible, in part to guarantee their longevity (J. Mihevc, personal communication, Aug 19, 2016).

${ }^{4}$ See http://commonvision.org/orchards.
} 
orchards planted in the last five years include Winnipeg, Halifax/Dartmouth, Kamloops, Guelph, Airdrie, Sackville, and Yellowknife.

Community orchards in Canada typically consist of fruit trees - both the familiar kinds, such as apple, plum, and pear (usually heirloom varieties, since they are less susceptible to pests and often taste better) and more "exotic" ones like persimmon, fig, and paw-paw (which grow in the relatively mild climate of Vancouver Island) - as well as berry bushes, raspberry canes, grapevines, hardy kiwi, and the like. Organizationally, community orchards may involve two or three parties: a local community group, which assumes responsibility for maintenance and for harvesting the fruit and distributing it; a landowner, which in most cases is a municipality and may be represented by a Parks Board or some similar entity; and possibly (though not always) a non-profit organization, which provides training and technical support to residents, and may provide the trees (shrubs, vines etc.). In addition to providing the land, municipalities may provide basic services such as mowing around the trees, such as is normally provided in public parks, and free or reduced water rates - although this is not always the case.

The academic and grey literature on community orchards is scant, consisting of a handbook produced by Common Ground, a UK-based environmental charity (King \& Clifford, 2011); one (excellent) masters' thesis about a community orchard in Portland (Becker, 2015); one graduate-level paper about two community orchards in Bloomington, Indiana (Betz, 2015); and a 15-page bulletin about community orchards, produced by the (US) National Sustainable Agriculture Information Service (Ames, 2013). Becker's thesis 
focuses on the community dimension of the community orchard and the ways in which a shifting locus of control over the orchard - from residents of a housing project to staff of a non-profit - redefined the community of the orchard and eroded locals' sense of psychological ownership and attachment. Betz's work is a detailed analysis of the Bloomington Community Orchard, using Elinor Ostrom's Institutional and Development (IAD) framework - a very different approach from my own. Ames' bulletin is largely descriptive but excellent. I also found one research article on urban food forestry that evaluates the substantial but untapped potential for urban food trees in Burlington, Vermont to contribute to community food security and landscape multi-functionality in that city (Clark \& Nicholas, 2013). The productivist bent of this article meant that it had little relevance to my research.

There does exist some literature pertaining to two concepts that are similar in many ways to community orchards: those of public produce and food forests. The idea of "public produce" comes from Darrin Nordahl's books of the same name $(2009,2014)$. As an advocate for better use of public space - he asks, If it nourishes democracy, can it not also nourish the body? (2014, p. 136) - Nordahl places the onus largely on municipal governments to employ all available and appropriate public lands to produce food. Nordahl does not explore community-based initiatives, and in fact describes community gardens as exclusionary, a form of enclosure (2009, p. 85-87). He outlines various models of municipally supported urban agriculture, illustrating with colourful examples. The essence of his argument is that cities should be able to manage and tend true public gardens with existing municipal resources; that food security is like the provision of 
water and fire/police protection, and that food should be available everywhere because unlike money, food does grow on trees. Community orchards could be considered a form of "public produce", however community orchards are foremost the products of community members acting collectively, with some degree of municipal support. The vision of public produce, on the other hand, as espoused by Nordahl, is more one of edible urban landscaping, in which fruit and nut-bearing trees, bushes, and herbs are provided and maintained by municipal staff, and/or individuals or private businesses operating in an ad hoc manner as individuals or disconnected entities. ${ }^{5}$

Food forests are areas of edible, perennial plants; community food forests are those located on public land and cared for by a community group. There are two main differences between orchards and food forests: the first relates to form and ecological function, and the second relates to maintenance. The visible form and structure of orchards make clear that they are typically geared toward production and are not trying to mimic natural conditions - fruit trees, sometimes bred as miniatures, are grown in rows, and sometimes espaliered (i.e., tied to frames such that they are almost two-dimensional), with many different varieties being grown in one space. Food forests, on the other hand, strive to mimic a woodland ecosystem; symbiotic inter-species relationships are intentionally cultivated through planting design (Jacke \& Toensmeier, 2005). The plants produce food at multiple levels - fruit and nuts from the canopy and low tree layers, currants and berries at the mid-level, vines running vertically, plus edible groundcovers

\footnotetext{
${ }^{5}$ The City of Victoria has toyed with this latter vision by running a pilot project in which individual community members are invited to plant, water, and harvest their own fruit trees in public parks. Details about the Urban Food Tree Stewardship Pilot Program are available at https://www.victoria.ca/EN/main/residents/parks/growing-in-the-city.html.
} 
and a root layer (Burnett, 2008) - but food production for people is not the food forest's only purpose. Food forests also grow medicinal plants and herbs, feed and shelter wildlife, and contribute to ecological restoration. And while an orchard is expected to require regular upkeep (annual pruning, insect and disease control, etc.) the goal with a food forest is for it to more or less take care of itself, at least after the first few careintensive years. That said, for the purposes of this research, community food forests can be quite similar to community orchards; in fact, one of my case studies, Spring Ridge Commons, in Victoria, BC, is a community food forest rather than an orchard.

\subsection{Grafting (Community Orchards in Relation to Community Gardens)}

Community orcharding in Canada and the U.S. can also be characterized as an outgrowth or evolution of the community gardening movement, in much the same way that a branch of a new fruit variety can be grafted onto the rootstock of an older one. In fact, some community orchards are contained within community gardens. One of my case study orchards for this research is part of Strathcona Community Gardens. The orchard is one of a few communally maintained areas within the gardens, the others being the pathways, seating areas, compost, and a naturalized area featuring a small seasonal pond. However, unlike the produce-producing parts of community gardens, which are typically divided into individually maintained plots, community orchards must be maintained through group effort and harvested in a cooperative manner; they cannot easily be subdivided. ${ }^{6}$ Community orchards tend, then, to be much more of a collective endeavour.

\footnotetext{
${ }^{6}$ I do know of one park in Vancouver where individuals each "adopted" a tree, but the experiment was short-lived and ultimately unsuccessful.
} 
In the coming chapters, I will at times distinguish between community orchards and community gardens, where differences are salient. However, as it is not possible to study an emergent phenomenon such as community orchards with reference only to the extremely small volume of extant literature on the subject, I will refer frequently in this paper to literature, assertions, and debates about community gardens with an understanding that they include community orchards. Wherever I do so, it is because I have deemed the ideas within those writings to be sufficiently generalizable to community orchards, despite the differences that sometimes separate the two. For that reason, let us move forward by expanding our purview to include community gardens.

Community gardens can be defined and understood in a great many ways. They are at once a form of urban agriculture, a claim to public space, a site of therapeutic recreation, socialization, and beautification, and, at least for some participants, a demonstration of radical democratic potential and environmentalist, socialist, and/or anarchist ideals. Community gardens, therefore, cannot be boxed into singular accounts of their meaning. In fact, the term 'community gardens' has been criticized as "richly connotative but inchoate" (Pudup, 2008, p. 1228) because it includes such a great variety of forms, which tends to confound analysis and general claims-making. The term is sometimes used to denote allotment gardening (a term and tradition coming out of the UK), seen largely, at least historically, as a form of self-help and/or leisure (Nettle, 2014; UK Government, n.d.), but also school, hospital, and prison gardening, forms that Pudup (2008) argues are better characterized as "organized gardening projects," having the purposes of education, 
training, healing, rehabilitation, and, some would say, social control (Guthman, 2008; Lawson, 2005; Pudup, 2008). The term may lump together those gardens actively promoted and supported by the state, ${ }^{7}$ often on private land (some, such as the Victory Gardens of WWII, being the product of a massive patriotic government campaign), with other, grassroots initiatives that have arisen quite outside of the state, often in defiance of it. Consider here the many gardens - most famously those in New York City - that have struggled constantly against local authorities just to maintain their existence (Eizenberg, 2012a; Schmelzkopf, 1995; Smith \& Kurtz, 2003). ${ }^{8}$ Many of these are (or were) located on vacant lots in blighted deindustrialized areas, which were reclaimed by local residents for the purposes of neighbourhood beautification, community safety, food production and socialization (Hynes, 1996; Lawson, 2005; Schmelzkopf, 1995, 2002). Vacant lot cultivation (sometimes seen as squatting) may be the dominant form in many American inner cities but it does not seem to be the dominant form in Canada, where most community gardens appear to be approved by their landowners (typically municipalities or school districts, but sometimes private developers) who tend to regard community gardens as an important component of community food security, particularly in light of

\footnotetext{
${ }^{7}$ The provision of allotment gardens in the UK is, in fact, legislated through several Acts of Parliament, the earliest going back almost two centuries (1819). Their purpose was the relief of rural poverty. At least half a dozen acts have been passed since to clarify rules and responsibilities both of allotmenteers and local governments (UK Government, n.d.).

${ }^{8}$ These NYC exemplars, despite their high profile, should not be assumed to be representative. Other big American cities, including Boston, Seattle, Denver, San Francisco and Philadelphia have given community gardens permanent status and funding (Gottlieb \& Joshi, 2010; McKay, 2011a; Wekerle, 2004). In Canada, many municipalities, including Toronto, Vancouver, Ottawa, and Montreal, have been strong supporters of community gardens for many years (even, in Vancouver, those planted extra-legally in railway corridors) (Cosgrove, 1998; Hyslop, 2014; St Jean, 2003; Welsh \& MacRae, 1998).
} 
COMMUNITY ORCHARDS AS NEW URBAN COMMONS

climate change and the need to increase community resilience (Kaethler, 2006; Wekerle, 2004).

For the purposes of this research, community gardens include those that are on public land, that are carried out with the permission of the landowners, and that are grassrootsinitiated - i.e., not affiliated with existing institutions such as schools, prisons, daycares, food banks, hospitals, or the like. This definition is in keeping with Nettle (2014), who notes the significant differences in design, management and support given to gardens started on institutional lands such as schools, hospitals, and prisons. The most salient difference is that community gardens are run with primarily voluntary labour (in the dual sense of being both unpaid and freely given), while institutional gardens are maintained by employees, students, patients, and prisoners, whose participation, while mostly unpaid, may be somewhat less than voluntary.

I also restrict my definition of community gardens to those that grow food - not just ornamentals, as can be the case in U.S. beautification gardens (Lawson, 2005; Nettle, 2014) - and those that do so outside of the market, meaning that the produce is not sold. ${ }^{9}$ While for-profit market gardening provides a meaningful focus in some urban agriculture projects, especially those oriented to community development or youth development, and especially in the U.S., (where there seems to be a greater emphasis on entrepreneurialism

\footnotetext{
${ }^{9}$ In later chapters, I explore the importance of decommodification to community orchard participants in my study. Interestingly, this characteristic does not seem to be shared with community orchards in the UK, where selling the produce - as well as value-added items such as jams, jellies, pies, and ciders - is encouraged, through green grocers, farmers' markets, and roadside stands (King \& Clifford, 2011).
} 
as a route out of poverty) such an emphasis makes for a very different style of management and ethos of participation from that of a garden that strives to exist outside the realm of monetary exchange. Finally, community gardening, as I use the term, includes neither boulevard gardening by individuals, nor guerilla gardening, which also tends to be carried out by individuals, often surreptitiously (e.g., by throwing "seed bombs" over fences onto private property). The individual basis of these forms makes them, almost by definition, not community endeavours. Circumscribing community gardens in these ways is consistent with common practice among food system scholars in Canada at this time. It is also critical for analytical purposes, especially when considering common critiques of community gardening, which may in fact be better directed at other forms and practices. ${ }^{10}$

The literature on community gardens is fairly robust but tends toward the laudatory and/or descriptive (Horst, McClintock \& Hoey, 2017). Driven, perhaps, by a desire to legitimize and support community gardens, much of the literature describing the benefits of community gardens presumes that their purpose is instrumental. These benefits are genuine and include poverty alleviation (Kurtz, 2001; Lawson, 2005; Meenar, 2012); community development and community building (Linn, 1999, Kurtz, 2001; SaldivarTanaka \& Krasny, 2004; Schmelzkopf, 1995); household food security; and health

\footnotetext{
${ }^{10}$ Here I am thinking most of the oft-quoted charge by Pudup (2008, p. 1228), directed at "organized gardening projects" where participants are enrolled in programs that she claims are designed to put them "in charge of their own adjustment(s)" to the privations visited on them by neoliberalism. Pudup feels that such projects contribute to neoliberal governmentality and absolve the state of its responsibility for social welfare. Such critiques do not apply equally, if at all, to community gardens as I have defined them, for reasons that I hope will become clear as I discuss the evolution of my research questions from their original formulation to their final form.
} 
promotion (Meenar, 2012; Schmelzkopf, 1995; Smith \& Kurtz, 2003; Wakefield et al., 2007). The resulting accounts are well suited to informing funders and policy-makers but can be criticized for a paucity of theoretical or critical engagement (Tornaghi, 2014). They can give the impression that what matters is what the gardens do for those who participate in them, and what gardeners, and their communities, get from them (Nettle, 2014). This is no doubt also a function of how the history of community gardens in both North America and the UK is typically narrated. The view that they have typically arisen as a response to crisis - e.g., the economic depressions of the 1890s and 1930s, and the two World Wars - while correct, tends to suggest that community gardens are reactive, simply products of shifting political winds and economic conditions (Nettle, 2014, p. 31).

In some accounts, community gardens are credited with advancing food citizenship and democracy (Baker, 2004; Hassanein, 2003; Levkoe, 2006; Wekerle, 2004); food sovereignty (Schiavoni, 2009); environmental justice (Milbourne, 2012; Wakefield, 2013); urban sustainability and resilience (Ferris, Norman \& Sempik, 2001) as well as environmental stewardship and civic engagement (Baker, 2004; Levkoe, 2006; Staeheli, 2008; Travaline \& Hunold, 2010) but it seems that these effects are regarded almost as by-products and not the primary purpose or motivation of those participating.

In contrast to this view, other scholars have positioned community gardening as a form of social action, a vehicle through which people proactively seek to bring about social and environmental change. Nettle (2014) applies social movement theory to convincingly position Australian community gardens as an effective part of a repertoire of collective 
action. Others have emphasized the agency of gardeners in creating insurgent space (Mares \& Peña, 2010; Schmelzkopf, 2002) and engaging in insurgent planning (Tornaghi \& Van Dyck, 2015); making critical social commentary (McKay, 2011a); asserting rights to the city (Schmelzkopf, 2002; Staeheli, Mitchell \& Gibson, 2002; Staeheli, 2008) and rights to land beyond private property (Wekerle \& Classens, 2015); and challenging neoliberalism (Eizenberg, 2012a, b; McClintock, 2014). The international journal, Local Environment, dedicated an entire issue to political gardening in 2015, and to the ways gardeners use land to "contest, transform and re-signify "the urban"” (Certomá \& Tornaghi, 2015, 1123). It is in this tradition that I position my own inquiry, as I see community orchards as very intentional efforts by practitioners to bring about social change.

\subsection{Cultivation (The Commons)}

The law locks up the man or woman Who steals the goose from off the common

But leaves the greater villain loose Who steals the common from off the goose.

- Old English Rhyme

Community gardens are frequently acknowledged to be commons (DeLind, 2002;

Eizenberg, 2012a; Johnston, 2003; Linn, 1999; Ristau, n.d.; Tornaghi, 2014). But authors who make that assertion tend to stop shy of exploring exactly what that means: What are the characteristics and practices that make something a commons? And what has commoning got to do with social change, community-building, public space, and urban 
COMMUNITY ORCHARDS AS NEW URBAN COMMONS

governance? This research tackles these questions head-on, and for that reason we must include here a primer on the commons.

At its most expansive, the commons can be thought of as those natural and cultural resources we collectively enjoy and hold in trust for future generations. Peter Barnes (2006, p. 4) describes commons as "all the gifts we inherit or create together", with emphasis on their gift nature (i.e., things received, not earned) and on sharing (i.e., we receive them as members of a community, not as individuals). James Quilligan (2012) defines commons as goods to which everyone has equal access and shares the same burden of costs, and which are life-enhancing for all. In their most tangible manifestation, "the commons" refers to natural resources that are jointly used and managed by local communities: pastures, fishing areas, forests etc. Such commons provide sustenance, security, and independence and are typically associated with subsistence more than commodity production. More abstractly, the term 'commons' can also refer to a set of common rights to use the fruits of a given natural resource - usufructory rights.

The concept of the commons originated first in Roman law (Nguiffo, 1998, p. 102) and then later, in the Anglo-Saxon context, within the fields, forests and pastures of preIndustrial Revolution Britain. ${ }^{11}$ According to Goldman (1998, p. 2), the concept of the commons grew with the expansion of the British empire, becoming associated with not just forests and pastures, but also fishing grounds, deserts and village spaces in the global

\footnotetext{
${ }^{11}$ The better-known commons of England had their counterparts in "run-rig" farming carried out in the Highlands of Scotland (later abolished by the Scottish equivalent of the English enclosures, the "clearances") and communal forms of land tenure in pre-conquest Ireland called "rundale" (Caffentzis 2004, p. 7).
} 
South - at least before they were violently colonized by conquistadors, settlers, and slave traders. In fact, the colonization of the Americas (and other continents) can be understood as the theft of other people's commons (a point to which I shall return later). It is this act - the theft of the commons, through enclosure or privatization - that gives rise to the act of reclaiming them today.

While we may most readily imagine the commons as a shared pasture or woods in Medieval England, upon which commoners, until about the $16^{\text {th }}$ century, grazed their sheep, and pigs fed on the mast (nuts) of beech trees, the 'commons' is simply the English word for a phenomenon that has taken many forms in different places across different periods of time, and has gone by many different names. Ostrom (1990) describes long-enduring systems of communal tenure of forests and meadows in Switzerland and Japan dating back to the 13th and 17th centuries respectively. In the present day, there are the oft-referred-to Mexican ejidos - communal areas attached to each village - and the comunidades agrarias - the more traditional communal holdings of Indigenous communities in Mexico. ${ }^{12}$ In Brazil, there is the faxinal, a term designating a part of a territory that is used as a commons for raising livestock (Bertussi, 2012). Communal irrigation systems exist in many places and go by many names: for example,

\footnotetext{
${ }^{12}$ The ejido system was actually used in Medieval Spain and colonial Mexico until the late 1600s. It was re-introduced by the Mexican government in its 1917 constitution as part of land redistribution prompted by the 1910 Mexican Revolution (Stephen, 1998). Most of the land redistribution did not occur, however, until after 1934, when Lazaro Cardenas came to power (Brown, 2004, p. 4). In the lead-up to the implementation of NAFTA, Article 27 of the Constitution was reformed (some say repealed) such that ejidos were opened up to privatization ejido land could be sold, leased, sharecropped or otherwise transferred. Comunidades remained protected, but the law allowed comunidades to enter into partnerships with private companies and to be converted into ejidos (Brown, 2004).
} 
COMMUNITY ORCHARDS AS NEW URBAN COMMONS

zanjeras in the Philippines, and huertas in Spain (Huron, 2015; Ostrom, 1990; Romero \& Melo, 2015).

Present-day commons found across the globe today include not only community gardens but also community farms, communal fisheries, and community forests - prevalent not only in North America, but also in countries as different as Cameroon and Nepal (Acharya, 2005; Nguffio, 1998; Teitelbaum, 2016). The Maine lobster fishery is regarded as a quintessential example of a successful, sustainable model of commons management in the global North (Coombs, 2011). And in the Outer Hebrides of Scotland, more than two-thirds of the population lives on land organized as another type of contemporary commons, the community land trust (Mackenzie, 2012). Beyond the realm of natural resources, the term 'commons' has been applied to community currencies, noncommercial approaches to housing and food, and other strategies of cooperative consumption (Bollier, 2012), as well as squatters' settlements, limited equity cooperatives, even homeowners' associations and gated communities (Blomley, 2008) showing that commons can be politically progressive or regressive (Mackenzie, 2012; McCarthy, 2005, p. 18-19). Today one often hears the terms 'cultural commons' or 'knowledge commons', which refer to the realm of immaterial or intangible resources that are understood to be in the public domain and are to be freely shared. The Internet is widely understood and referred to as a knowledge commons. All of these examples share 
collective ownership and/or forms of management or governance that are neither marketbased nor controlled by the state, but rooted in civil society, often in local communities. ${ }^{13}$ Some authors - for example, John McMurtry - make a distinction between natural commons and civil commons, but this is a hard separation to maintain because it depends on a false separation of nature and culture. ${ }^{14}$ Nonetheless, definitions such as McMurtry's have gained a following. In contrast to natural commons like water and air, he defines the civil commons as "human agency in personal, collective or institutional form which protects and enables the access of all members of a community to basic life goods"15 (McMurtry, 1999, as cited in Johnston, 2003, p. 16-17) and also "traditions that are cooperatively organized to give members access to the means of life" (Johnston, 2003, p. 17; Linebaugh, 2008). Gandhi's Salt March in 1930 was an effort to liberate the coastal commons when the British tried to monopolize them and tax their colonized subjects for salt (Cheria \& Edwin, 2011, p. 7).

\footnotetext{
${ }^{13}$ There are even looser conceptions of the commons, in which there is no sense of collective ownership, management or governance whatsoever. Examples include languages, holidays, outer space, mathematics, social trust or solar energy, all of which have been called commons but might better be thought of as manifestations of common wealth. Such uses of the term 'commons' illustrate the generalizability of the term and the expansive metaphorical uses to which it has been put. They also suggest an unfortunate potential dilution of meaning. To the extent that such endowments are part of our shared natural or cultural heritage, they are commons, to be sure. But if we want the commons to have any analytical value, not to mention political utility, we need to apply a more focused or discriminating logic to the ongoing task of defining them. The reasons for this will become clear as we consider the commons' relationship to property and to the state in Chapters 6-9.

${ }^{14}$ Barnes (2006) goes further and likens commons to a river with three forks: nature, community and culture. The difference between the latter two is hard to discern.

${ }^{15}$ McMurtry (2001, p. 827, 837) distinguishes between life goods and commodities on the basis of two criteria: 1) freedom from price barrier (while markets can be used for distribution, these goods cannot be restricted to those with resources), and 2) the property of enabling vital lifecapabilities.
} 
This view of commons as relations more than as things (Huron, 2015) stresses the importance of the social systems and the quality of relationships that commons represent. Commons express a social order based on cooperation and reciprocity, not competition; commoners define as common those things that benefit everyone. In a world increasingly marked by the staking of individual rights and the ascendency of private interests, the idea of the commons asserts the primacy of collective rights and the common good. ${ }^{16}$ This is not to pit one against the other, the individual against the collective. On the contrary, some have put forward the idea that in the commons, the two are inseparable; that no one can have a satisfactory life if he or she is not integrated into social relations because one's full personal unfolding depends on the unfolding of others and vice versa (Bollier, 2012; Mattei, 2012, p. 43). We might say the same of all social organization, not just commons. Nonetheless, it is particularly true in a commons that the borders between particular and collective interest(s) are blurred and fluid (Bollier, 2012).

To date, the commons have been constructed literally and metaphorically in relation to their opposite: enclosures. It was the Church and the nobility who first "enclosed" the English countryside, laying claim to exclusive private property rights on formerly communal pasturelands in the early 16 th century. ${ }^{17}$ These claims were often accompanied by a physical act of exclusion through which the new "owner" surrounded his land with fences or hedges and even employed armed guards to keep the commoners from

\footnotetext{
${ }^{16}$ Notwithstanding the difficulty of ascertaining what "the common good" may be!

${ }^{17}$ The enclosure movement is commonly located, historically, in the $16^{\text {th }}$ century, but historian Peter Linebaugh (2010) argues that the phenomenon began as early as the $13^{\text {th }}$ century and reached two peaks, one during the fifteenth and sixteenth centuries and then another during the $18^{\text {th }}$ and $19^{\text {th }}$ centuries.
} 
continuing to use lands that had previously been theirs to use for centuries (Caffentzis, 2010, p. 7). ${ }^{18}$ Historian Peter Linebaugh refers to the Enclosure Movement as one of the defining concrete moments of the "crime of modernism" along with the slave trade, the witch burnings, the Irish famine, and the genocide of Native Americans, all "limited in time and place but also immanent with the possibility of recurrence" (2010, p. 11).

Enclosure is generally associated with commodification and the elevation of commercial transactions and economic relations above basic needs. Enclosure generally entails a claiming of control over resources by actors outside the community, with the concentration of resources (particularly land) in fewer and fewer hands - two key mechanisms of socially produced scarcity. ${ }^{19}$ Enclosure also entails cordoning off aspects of the former commons that are most useful or profitable to the encloser and defining them, and them alone, as valuable. Instead of being a source of multiple benefits, the former commons become a one-dimensional asset to be used for a single purpose, reflecting the interests of the encloser (Goldsmith, Hildyard, Bunyard \& McCully, 1992). An example might be the appropriation of a site by a multinational company for the purposes of establishing a mine or quarry. Its value as a scenic landscape or home for

\footnotetext{
${ }^{18}$ Enclosures could also be accomplished by other means. George Caffentzis notes that in Ireland in the eighteenth century, enclosure was accomplished not one property at a time, but through the passage of discriminatory law - the so-called "penal laws" that "literally made it illegal for Catholics (the large majority of the Irish population) to own land" $(2004$, p. 8).

${ }^{19}$ David Harvey (2012, p. 70) has argued that enclosure can also be necessary as a means of protecting the commons, not from those who live there but from outsiders who might destroy it. He cites the Amazon rainforest as a case in point, due to its being under constant threat of deforestation and in need of some means of protection from those who seek to exploit its riches. However, I believe that Harvey is missing the point, given that enclosure refers to the act of exploitation for the private benefit (profit) of a few at the expense of the many. In the case of the Amazon, efforts to protect the rainforest from industrial exploitation ought not to be seen as enclosures but as a defense of the commons.
} 
wildlife is traded in for, or subordinated to, its commercial value as a production site for a profitable commodity.

Those championing the commons today identify myriad threats to them as metaphorical enclosures (Caffentzis, 2010; Dawson, 2010; Klein, 2001; Linebaugh, 2008). To some, contemporary enclosures include not just the acquisition of resources and/or occupation of lands customarily shared by identifiable groups of people, but also, in the words of Naomi Klein:

the way powerful ideas are turned into advertising slogans and public streets into shopping malls; new generations being target-marketed at birth; schools being invaded by ads; basic human necessities like water being sold as commodities; basic labour rights being rolled back; genes are patented and designer babies loom; seeds are genetically altered and bought; politicians are bought and altered. $(2001, \text { p. } 82)^{20}$

While it is true that much of the work commoners do today in the world is defensive involving rescuing, restoring and re-claiming the commons from the very large machinery that threatens it - much is also breaking new ground by creating actually existing new commons. The many experiments in commoning that are underway around the world illustrate the great diversity of forms it can take.

Recently, attention has turned to new urban commons, and what makes them distinct. Academics have studied the collective management of urban green spaces (Andersson, Barthel \& Ahrene, 2007; Barthel, Folke \& Colding, 2010); creative "independent spaces"

\footnotetext{
${ }^{20}$ We might well question the expansion of the enclosure metaphor to include all the threats Klein warns against, particularly the erosion of labour rights and the corruption of politicians. But whether we agree with her or not, we can easily see the many ways that the concept of enclosure, like the commons, has entered political and popular discourse.
} 
(Bresnihan \& Byrne, 2015) ${ }^{21}$; a women's library (Williams, 2018); neighbourhood governance in gated communities (Lee \& Webster, 2006) and even residual residential space (Rabinowitz, 2012). Going further, Foster \& Iaione (2016) imagine the governance of entire cities as commons by exploring two evolving models of urban commons governance - the sharing city and the co-city - as examples of scaled-up collaborative and polycentric governance. ${ }^{22}$ In the urban context, the focus is less on the stewardship of natural resources and more on the collective management of human-made resources and entities, including those in the "immaterial" realm of knowledge, culture, and ideas (Hardt \& Negri, 2004). For example, Bresihan \& Byrne (2015) look at independent spaces in Dublin that support events like film screenings, art exhibitions, meetings, rehearsals, gigs, and parties; as well as food sharing, skill sharing, bicycle maintenance, and group access to media production technology. It is the human-made nature of these commons that makes them new (Hess, 2000, as cited in Huron, 2015, p. 967). And what distinguishes them as particularly urban is the fact that they are being enacted in "saturated space" - i.e., "space that is already densely packed with people, competing uses, and capitalist investment" - and that they are "constituted by the coming together of strangers" (Huron, 2015, p. 963). Both are traits that make commoning more challenging in cities than in other environments - but also more necessary (Huron, 2015).

\footnotetext{
${ }^{21}$ Bresnihan \& Byrne define 'independent spaces' as "projects, located in buildings, which have a public dimension, operate beyond the auspices of public and private management and which have a grassroots, DIY ethos" (2015, p. 37).

${ }^{22}$ The idea of polycentricity in governance comes from Elinor Ostrom, and originally, from her husband, Vincent Ostrom. They define polycentric governance as involving multiple centres of decision-making that are formally independent of each other but may nonetheless function coherently (V. Ostrom, Tiebout, \& Warren, 1961, as cited in Ostrom, 2009, p. 411).
} 


\subsection{Fruition (My research)}

I have limited my focus to the urban Canadian context, choosing to study community orchards in three major Canadian cities - Vancouver, Victoria, and Toronto - where they are most established. Interviewees were mostly organizational leaders or long-standing orchard members/volunteers, although I also interviewed a representative of the municipal government in each city who was familiar with my case study orchards - one city councilor (Toronto), one town councilor (View Royal/Victoria), one municipal food systems coordinator (Victoria), and one planning analyst and community gardens liaison (Vancouver). In keeping with my definition of community gardens earlier in this chapter, I have selected as case study orchards only those that meet the following criteria: 1) they are maintained primarily by volunteers or membership-based community groups, acting collectively; 2) they do not involve selling the fruit; 3) they have been in operation for a minimum of five years. ${ }^{23}$ This leaves out orchards planted on school grounds or other institutional properties, orchards that are part of a working farm, and orchards that are maintained primarily by paid staff (e.g., food bank employees).

I have circumscribed my focus in this way for primarily analytical reasons. Defined in this way, community orchards share at least two important traits characteristic of most commons. ${ }^{24}$ First, they are non-commodified spaces (Eizenberg, 2012a, p. 779; Mares \& Peña, 2010), spaces of creation, production, regeneration, and not just consumption; they

\footnotetext{
${ }^{23}$ I should add that I have not yet come across any community orchards that $d o$ sell the fruit they produce, or exchange it in any form of non-commodified transaction. So, not selling the fruit might be more accurately described as a shared characteristic of my case study orchards rather than a criterion for exclusion.

${ }^{24}$ There are, of course, exceptions. Maine's famed lobster fishery, which is widely considered a commons, is also, clearly, commercial.
} 
are spaces where belonging or fitting in is not dependent upon ability to purchase or consume. As many authors have noted, it is common practice in community (and allotment) gardens to give away surplus produce and/or to produce food explicitly for the purposes of donating it (Crouch \& Ward, 1988; Eizenberg, 2012a; McKay, 2011b; Meenar, 2012). Social and economic behavior in community gardens is predicated on what Crouch and Ward (1988) call the "gift relationship". This characteristic will prove significant in explaining the behaviour and feelings of community orchardists about both their labour and its fruits (as we shall see in Chapter 8).

Second, community orchards as I have defined them are locally and communally managed spaces. In the commons, people co-manage through collaboration, cooperation and communication (Hardt \& Negri, 2004). In fact, it is through their collaboration and communication on the usage, production and maintenance of the commons that the community constitutes itself (not because members necessarily share a common living environment, belief or occupation) (De Angelis, 2003). That is, community orchards (and gardens) are commons as long as community members retain a central role in managing them on an ongoing basis. ${ }^{25}$

In my thesis proposal, I made several assumptions about the purposes and functions of community orchards and the extent to which they could be understood or analyzed as commons. I eventually questioned these underlying assumptions, as I came to see that what I had assumed was not necessarily the case. This resulted in a significant 
COMMUNITY ORCHARDS AS NEW URBAN COMMONS

metamorphosis of my initial conceptions of my research problem, and my guiding questions, which I will outline in the following pages.

Initially, the main objective of my research was to understand how community orchards in selected Canadian cities might be initiated, organized, governed, maintained and promoted to realize their potential as new urban commons; contribute meaningfully to food justice; and manifest effective resistance to neoliberalism. I sought to identify some best practices in community orcharding in relation to the realization of the commons ideal, and in relation to specific, preferred outcomes as articulated by the community orcharding groups themselves - which I assumed would include optimizing fruit production, enhancing equitable food access for identified food-insecure populations and/or community building.

On a more theoretical level, I hoped I might contribute to the ongoing conversation about the role of the emerging commons sector in relation to the state. I was particularly concerned with the problem of whether commoning should be seen as an emancipatory development and a novel way forward for progressive and radical food politics, or whether it was, as some would have it, little more than community-based charity (albeit dressed up for the $21^{\text {st }}$ century) in which those with the least means must compensate themselves for the losses visited on them by neoliberalism (see Guthman, 2008). In other words, I wondered whether commoning represented a new approach to justice, one that demands that the state move toward fulfilling the rights to which all citizens and residents 
COMMUNITY ORCHARDS AS NEW URBAN COMMONS

are entitled, or whether it represented an acquiescence to the neoliberal state's withdrawal from such responsibilities.

In short, the research problem as I originally saw it was to ascertain the potential of commoning initiatives within the food movement to achieve some measure of justice and sustainability, taking community orchards as exemplars of new urban commons. However, it became apparent through the course of my field research that all my assumptions were foundering on the shores of a very inconvenient truth: that in community orchards, as my interviewees told me (over and over) in tones either hushed or incredulous, "It's not really about the fruit!" This admission, which I could not avoid, forced a major re-thinking of my research questions. What if it's not about the fruit? I thought. What then?!? If it's not about the fruit, then it's not about self-reliance in food provisioning or making interventions to mitigate hunger. Do community orchards even have anything to do with food security? I wondered. If not, then there is little point in identifying best practices for optimizing fruit production and enhancing equitable food access. If it's not about the fruit (food), then a food justice framing isn't the best fit either. ${ }^{26}$ My assumptions about who benefits from community orchards, and in what ways, had to be tossed out the window! Consequently, my questions about the state's withdrawal from responsibility for basic social welfare no longer seemed relevant.

And so, taking this latter question - What if it's not about the fruit?? - as my revised starting point, I reoriented my research around three new sub-questions that are, I hope,

\footnotetext{
${ }^{26}$ I thank Charles Levkoe for first prompting this realization, as uncomfortable as it was for me at the time!
} 
less presumptuous, more tentative and exploratory, and more open to listening to what interviewees had to say. These sub-questions are as follows:

1. What is motivating participants in community orchards? (How do they see the meaning, value, and significance of what they are doing?)

2. In what way(s) might community orchards still be commons? (What are participants producing and sharing? What are they self-governing around, if not the fruit?)

\section{What can community orchards teach us about the challenges and potential of producing and sustaining new urban commons?}

This research advances scholarly understanding of community orchards (and by extension, many community gardens) by bringing theoretical literatures about the commons, community, and urban space to bear on them in new ways. It adds to the literature on community gardening (broadly conceived to include orchards) in Canada, which is currently much smaller than that on community gardening in the American context, and thereby contributes to understanding some of the similarities and differences between these two national contexts. Finally, it greatly expands our understanding of what community orchards (and gardens) are for, why people participate in them, and how they may be contributing to social and ecological change. In the following chapters, I show that the reasons why organizers and members of community orchards (and gardens) commit enormous time and energies to these projects go far beyond the taken-for-granted utility of producing food, and beyond the multiple other instrumental benefits frequently attributed to community gardens, and beyond community-building, too. I show that community orchards are not so much about what people get out of them, as gifts from the trees, as what they give to them, and through them - to each other, to their larger communities, to the city they live in, and to the land itself. 


\subsection{Conclusion}

In this chapter, I have described what community orchards and commons are, and presented my research questions. The remainder of this thesis consists of nine chapters. Chapter 2 details my conceptual framework by introducing the key concepts of community, space, and the gift; outlining the main narratives of the commons in contemporary discourse; and summarizing the four main tasks of commoning that I explore in relation to the community orchards I have studied. Chapter 3 outlines my methodological approach. Chapter 4 describes the main study sites for this research. Chapter 5 is a largely descriptive chapter made necessary by the dramatic shift that took place in my understanding of the meaning and purpose of community orchards midway through my research. It explains why and how community orchards are not what they first appear. Chapters 6-9 explore how community orchards manifest the four main tasks of commoning: resisting enclosure (Chapter 6); appropriating space for community (Chapter 7); decommodifying exchange (Chapter 8); and claiming power to shape the city (Chapter 9). Chapter 10 concludes the thesis with a review of the narratives of commoning I introduced in Chapter 2 and some thoughts on the potential of commoning in the context of food systems. 


\section{Chapter 2 - Conceptual Framework}

\subsection{Introduction}

In the first half of this chapter, I introduce three concepts that are foundational to my analysis of community orchards as new urban commons. These are community/space, and the gift. (The idea of community space is central to community orchards. For the purposes of conceptual clarity and building a foundation for that discussion, I discuss each component part of this term separately before bringing them together.) I explore the significance of these concepts for community orchards and provide an overview of the ways these concepts have been understood and applied in critical geographical scholarship generally. In the second half of the chapter, I outline eight narratives of the commons which incorporate these concepts; I will return to these at the end of the thesis. I then outline the four main tasks of commoning which set up the framework for the remainder of the thesis. These tasks are 1) resisting enclosure; 2) appropriating space for community; 3) decommodifying exchange; and 4) claiming power to shape the city. In Chapters 6-9, I discuss each of these in turn and demonstrate how they are manifesting in community orchards.

\subsection{Foundational Concepts}

\subsubsection{Community}

As mentioned in Chapter 1, these orchards' basis in community is what sets them apart from seemingly similar entities, including visions of public produce - in which municipalities or business owners replace ornamental plants with food-bearing ones, with 
no change in who is responsible for maintaining them (Nordahl 2009, 2014) - and food forests, which are expected to be more self-maintaining (i.e., not really needing a community to care for them after their initial establishment). While all community orchardists would probably welcome less disease and less need to cut the grass, complete orchard self-maintenance is not really the goal. Instead, most orchardists seem to recognize that the orchards' need for ongoing maintenance is essential to their success, for it is through such labours that orchardists deepen their connections to the non-human, and to each other. Without the ongoing need for maintenance, the community part of the orchard would wither. Community orchards are thus not only products of deliberately collaborative efforts by self-identified collectivities, but also self-conscious vehicles for building those collectivities or communities in the first place.

The term 'community' is significant to this research for another reason too, and that is because it connotes a liminal space between the public and the private (Nettle, 2014), a space in which it is not always clear what activities are permitted, nor who should be responsible. Tending a community orchard is private in two ways: 1) it involves the quasi-domestic activities of food-growing, caretaking, and eating; and 2) it invites escape and, sometimes, solitary retreat for those who engage in it. But community orcharding takes place in public space, a fact that can raise the ire of neighbours who feel that food growing is not an appropriate use of such space and should be relegated to the more private arena of the growers' backyards (presuming everyone owns property). The act of eating the produce underscores this point; indeed, some community gardens have faced criticism from people who feel that using public lands to grow food for some people's 
COMMUNITY ORCHARDS AS NEW URBAN COMMONS

private consumption detracts from the ability of such lands to serve the public good (City of Victoria, 2015). By bringing normally private activities and experiences into the public realm, community orcharding straddles a socio-spatial boundary, at times with ease and at times more uncomfortably, but in doing so, it is carving out the liminal space that is essential to the practice of commoning.

Community orcharding that takes place on public lands also invites questions of jurisdiction, authority, and responsibility for labour. In a world in which most urban spaces fall under the influence and control of either state (usually municipal administrations) or market (e.g., private or commercial property) the appropriation of community-maintained and freely accessible spaces like community orchards and gardens - where land and services are not provided by the state on behalf of the people, but by the people themselves - is still unusual. This is the realm of the commons - a liminal space, politically - and community is what drives it. In later chapters, I will explore questions about the promise and peril that co-exist when the responsibility for the provision of public goods (e.g., open green spaces) is located in communities. To build the conceptual framework for these later discussions, we first need an overview of the meanings and usage of the term 'community' in geography and in movements for social change.

The term 'community' is bursting with meanings. It combines moral and social values, spatial relationships, and collective identities and solidarities (Becker, 2015, p. 22; Blackshaw, 2010; Firth, May \& Pearson, 2011). It can be a resource, a discourse, a 
practice, and a site of action, and/or a source of identification. Writers speak of 'community' in both descriptive and normative "registers" (Nettle, 2014, p. 120), the latter tending to embody a range of desirable traits and idealistic visions - for example, those of harmony, mutual fondness, shared understandings, and solidarity. In this sense, 'community' is an aspirational term, much like 'family' - imbued with warm, fuzzy feelings despite the considerable experiential evidence we can all point to of the complex, messy, conflicted realities of each. More realistically, Everts calls community “a term that denotes situations in which people entertain a loose sense of 'being in it together', for better or worse" (2015, p.197). While the sense of community as locality-based and tied to place (suggesting fixed categories and stasis as well as parochialism) is widely regarded as outdated and romantic by academics (Bradshaw, 2008), in popular discourse it still holds sway in ways that no doubt contribute to the nostalgic appeal of community orchards.

In the social sciences, 'community' has been the subject of debate between those who praise it as an ideal and those who see in it the potential for exclusion, inequality, and suppression of difference (Amin, 2005; Massey, 2005; Young, 1990). Community is seen as constraining by some and enabling by others. Within critical geography, this is no less true. 'Community' has been read negatively as a locus of oppression and paternalism (Featherstone et al., 2012; Watts, 2004; both as cited in Everts, 2015) and consequently all but rejected as a category of analysis by many geographers. Others, however, see the concept of community as having the potential to resist larger forces that would otherwise dominate, homogenize, and privatize everything. In this sense, Everts acknowledges 
COMMUNITY ORCHARDS AS NEW URBAN COMMONS

critical geographers who invoke community as an "occasionally permissible strategic tool if suitably employed in the fight against global capitalism and exploitation (Castree, 2004; Coombes, 2007; Gombay, 2010)" (2015, p.197). Consequently, the concept of community remains an "imagined but nonetheless powerful discursive reality with material consequences too important to be ignored' (Rose, 1990, p. 425)" (Kurtz 2001, p. $661)$

The concept of community can be mobilized in many ways. It can be used to frame oppositions (e.g., the local vs. the global) and to lend projects legitimacy by denoting participation, collective action, collaboration, and agreement (Nettle 2014, p. 120). Often, the term 'community' is invoked to denote a collectivity that is more authentic, more personal than the general public. In this sense, it serves to differentiate between the public as the realm of government (as in public services, public money, public servants) and the public as the realm of the people - the "true" public, as some would say. This legitimating function is highly relevant when it comes to the act of making claims on urban space. For example, if a community orchard or garden is expressed as the will of "the community," those who might object to it are positioned as outside of the community and acting against the will of "the people".

Community is frequently used as a legitimating discourse for all manner of progressive aims and purposes, but it can be mobilized for socially destructive ends too. The classic debate about community in sociology concerns the distinction between the concept of community (Gemeinschaft) versus that of society (Gesellschaft) wherein the latter 
represents "all that is modern and alienated" and the former everything we need to return to (Biel, 2016, p.110). This construction of history, of the past/future dialectic, lends itself too easily to reactionary responses. Themes of wholeness, around land/nature or community, have disturbing historical expressions - e.g., in the fascist ideology of the Nazis (Biel, 2016, p. 111; McKay, 2011a, b). Consequently, Biel argues, we need always to be aware of the potential for co-optation that lies dormant in seemingly progressive ideas and ideals such as 'community'.

In sum, the 'community' in community orchards is much more than a descriptive modifier indicating where such orchards are located or by whom they are maintained. The term 'community' connotes a rich and complex socio-spatial location; and signals the orchards' very purposeful - some would say, political - intentions.

\subsubsection{Space}

Community orchards may be seen as a type or variant of community gardens, but there are ways in which they differ sufficiently to be thought of more like siblings - unique expressions of a desire that stems from common origins. One of these areas of difference concerns space. In community gardens, the individual plots or allotments are conceived as a kind of pseudo-private space for gardeners - in the sense that the gardeners alone are responsible for maintaining them and the harvest of each plot is theirs to keep or to share - to do with as they choose. In this sense, plots almost replicate private property by conferring some of the rights that inhere in private property. By contrast, the space of a community orchard is conceived of by orchardists - and by the municipal offices that 
promote them, by non-profits that support them, and by the general public - as being more public than the space of community gardens, if not entirely public. Community orchardists manage the orchard collectively and harvest from it together, with the understanding that the fruit should be shared among themselves and/or with the larger community. This understanding helps create a sense of community space that is neither private nor wholly public. ${ }^{27}$ However, the concept of common property as belonging to or being stewarded by - all members of a group, or everyone (as opposed to no one, or to the government) - is not well understood or typically recognized by the dominant society, as we shall see.

Space is also significant to community orchards in the sense that urban space and decisions over how it is used are unavoidably political. Appropriating, inhabiting, using, and transforming urban space raise questions of inter-group (class, "race", gender) relations, neighbour relations, and community-City relations. These spatial acts also spur debates about our fundamental values, including how we value and understand land - as a space in which to dwell, as an ecological community to belong to, as a canvas on which to express our creativity, as a resource for meeting our sustenance needs, and/or as something to exchange for money. For these reasons, space, too, is a critical concept in understanding community orchards.

27 In later chapters, I take up the question of whether it should be the case that community orchards are public and open-access to this degree, and what ramifications follow from this way of seeing them. 
Once again, our aims will be served by stepping back and looking at the bigger picture: the concept of space in critical geography. A starting point is with the assertion that space is a social product. That is, space is not merely a container or context for human drama. Rather, it is both the outcome of social, environmental, historical, cultural, political and economic forces, and a force itself (Lefebvre, 1991; Massey, 2005; Soja, 2010). In Doreen Massey's words, space is "constituted through interactions"; it is a sphere of multiplicity in which distinct trajectories co-exist...space is never closed, never finished, but always in the process of being made: a "simultaneity of stories-so-far" (2005, p. 9). As such, physical space is dynamic and developmental; it intersects with material (economic) processes to shape social life.

A second key point about the concept of space in critical geography is that the spaces that are generated or produced in cities (whether by community groups or by the faceless entity we call 'capital') embody and conceal both values and power (Balivé, 2011), both of which are sites of perennial struggle. Sometimes, in community gardens especially, the struggle is between exchange value - how much a piece of land can fetch when sold as real estate - and use value - the non-monetary needs it meets, and the enjoyment that those who use, maintain, and care for it get from doing so (Schmelzkopf, 2002; Eizenberg, 2012a; Mares \& Peña, 2010). In view of today's hot real estate markets, it is surprising that any urban land at all remains dedicated to growing food! Sometimes, space functions as a resource for the expression of dissent. Graffiti and the occupation of public squares provide two familiar examples. And sometimes, space is understood more generally to reflect the state of justice/injustice in the city, and in society generally, as 
evidenced by inequitable spatial arrangements and allocations (everything from apartheid and redlining to more subtle differences between neighbourhoods in the provision and quality of open green space, in the siting of hazardous facilities or highways, or in the attention and resources dedicated to infrastructure and related improvements).

Consequently, theorists and activists alike argue that any real and meaningful alternatives to the dominant social structure need to be rooted in the reworking of material space (Eizenberg, 2012a, p. 770). In the words of Bailey, Lobenstine \& Nagel, "If we demand the reworking of spatial arrangements, we are demanding the reworking of all other arrangements - those of nation, ownership, class, race, gender, etc." (n.d., 3). This conviction underpins the activities of many who claim urban space for counterhegemonic uses.

\subsubsection{Community Space}

In Lefebvre's view, space is essential to meeting a community's needs and realizing its rights: "groups... cannot constitute themselves, or recognize one another, as 'subjects' unless they generate (or produce) a space" (1991, p. 416). Likewise, Eizenberg writes that a community must do more than occupy a space and operate within it; to be a community, it must participate in the production of its own material environment according to its own culture, history, desire and vision (2012a, p. 776). Community spaces, therefore, can be thought of as socially produced spaces characterized by high levels of participation, expression and psychological ownership on the part of a more-orless defined group (Eizenberg, 2012a, b). While enjoying varying levels of support from municipal authorities (notwithstanding their concomitant restrictions), community 
gardens can be thought of as more or less autonomous community spaces - depending on the degree to which participants retain the right to design, use, maintain and benefit from them in ways they themselves determine (Staeheli et al., 2002). This being the case, community spaces tend to express a vernacular style, more concerned with practicality than grandiosity. As the lived spaces of users, not the conceived spaces of professionals, they are the realm of memories, symbols and personal history. Most of all, they are participatory landscapes (Saldivar-Tanaka \& Krasny, 2004, p.409), where users can see the mark of their own hands and their own work instead of just passively experiencing a space prepared by others without their input.

\subsubsection{The gift}

The gift theory to which I refer comes from Lewis Hyde, as articulated in his 1983 book, The Gift, now regarded as a modern classic. David Crouch and Colin Ward picked up on Hyde's theory in their landmark (1988) book, The Allotment: Its Landscape and Culture, where they observed that relationships in allotment gardens are predicated on a gift relationship - i.e., sharing of produce, mutual aid, and a general refusal to exchange produce for money. I believe this observation - of the centrality of the gift to community gardens - is at least as true, if not much more so, in the community orchard. Because community orchards are so often sited in public parks (or spaces treated as de facto parks by the public), and because they are maintained by unpaid volunteers, whose labour transforms what is often dead space into a community asset, community orchards can be understood as a gift to the community at large. In some orchards, the fruit itself is also 
COMMUNITY ORCHARDS AS NEW URBAN COMMONS

offered, or at least functions, as a gift. ${ }^{28} \mathrm{We}$ can also see the gift ethos in the ways community orchardists describe their ideal visions for the orchards, and the joy they express when community members - especially children - help themselves to a fruit and experience joy, wonder, and appreciation for it.

To understand why this theory is significant for understanding community orchards, we must first outline the basics of the theory, which begins with distinguishing gifts from commodities. If a commodity is something produced to be bought and sold, a gift may be thought of as something that is given away freely, with no assurance of anything being given in return. There are three obligations of a gift economy, as noted by anthropologist Marcel Mauss: ${ }^{29}$ 1) the obligation to give; 2) the obligation to accept; and 3) the obligation to reciprocate (Hyde, 2007, p. xxi). The gift exchange is governed by two ethical understandings: 1) the determination of the equivalence of any counter-gift is left to the giver; and 2) giving cannot be enforced by any kind of coercion (Hyde, 2007, p. 19). While in market exchange or barter, where the equivalence of two objects (money being one of them) is discussed, negotiated, and computed, the value of the gift is not discussed; the gift is given in silence.

Cultures practising a gift economy often engage in circular giving (not unlike the contemporary idea of "paying it forward") which is more complex than simple

\footnotetext{
${ }^{28}$ This way of conceiving of the fruit - as gift - does not always dominate, as we shall see. In the one case study orchard that is part of an established community garden (Strathcona), orchardists have taken great pains to try to communicate that the fruit is only for members, though they have not achieved much success in keeping the public from picking.

${ }^{29}$ Hyde's work is based on Mauss' influential book, The Gift: The form and reason for exchange in archaic societies, originally penned in French in 1925 and first translated to English in 1954.
} 
reciprocity between two people and seems to better illustrate the difference between giving and negotiated exchange. The circle is the structural equivalent of the prohibition on discussion. Writes Hyde,

When I give to someone from whom I do not receive (and yet I do receive elsewhere) it is as if the gift goes around a corner before it comes back. I have to give blindly. And I will feel a sort of blind gratitude as well... When the gift moves in a circle its motion is beyond the control of the personal ego, and so each bearer must be a part of the group and each donation is an act of social faith. (2007, p. 20)

Cultural practices of gift-giving tend in this way to involve some degree of reciprocity, but the emphasis is not on equilibrium, or paying to balance the scale. Instead, there is momentum - "the weight shifts from body to body" (Hyde, 2007, p. 11). Consequently, the gift must be kept in motion. Hyde calls this the paradox of gift exchange: "The gift that is not used will be lost, while the one that is passed along remains abundant... What is given away feeds again and again, while what is kept feeds only once and leaves us hungry" (2007, p. 26). Giving is the only way to assure abundance.

The social function of gifts is to establish social bonds. As Hyde notes, "It is the cardinal difference between gift and commodity exchange that a gift establishes a feeling-bond between two people, while the sale of a commodity leaves no necessary connection" (2007, p. 72). Referring to the custom, in some restaurants in the south of France, of having customers seated at a long communal table pour wine into each other's glasses, Hyde writes, "Spacial [sic] proximity becomes social life through an exchange of gifts" (2007, p. 73). A commodity, on the other hand, becomes a commodity by moving between two separate spheres without abolishing their separation. For that reason, says Hyde, "we do not deal in commodities when we wish to initiate or preserve ties of 
affection" (2007, p. 85). By contrast, gifts function as covenants, symbolizing an understanding and a desire regarding relationship. This is true whether they be gifts of incorporation (as in wedding rings), gifts of peace (abolishing division), or gifts of atonement (to re-establish broken bonds). At the level of a large group or community, gift exchange is less about bonds of affection between individuals than it is about constituting and affirming group membership. Gifts bring with them a sense of being obliged to others, a sense of cohesion. As agents of cohesion they provide "a kind of anarchist stability"; gifts act to make one body out of many (Hyde, 2007, p. 97).

It is not only tangibles like fruit that may be seen as gifts; knowledge can be seen and treated as a gift, to the extent that that it is allowed to move from person to person without a toll or fee. Imposing such a boundary means that the benefit or usefulness of such knowledge must then be quantified and paid for before it can be shared. When this happens, knowledge is turned into a commodity. ${ }^{30}$ Labour, too, may be given as gift, as is done by volunteers every day.

Giving is not confined to human actors. The birds are a gift of nature, so are the bees. These non-human actors - the land, the trees, the pollinators - can be seen to give too, by way of the ecological services they perform for us. It is common in many traditional

\footnotetext{
${ }^{30}$ As academics, we are all too familiar with this process. Whereas the tradition or ideal used to be one of academic communities advancing knowledge together through free exchange of ideas, the truth is that knowledge has been "enclosed" more and more in recent years, such that all ideas carry a price. Hyde writes, "In a free market, the people are free, the ideas are locked up" (2007, p. 107). Open-access publishing is one act of resistance to such enclosures.
} 
cultures to give back to the Earth, often in the form of animal sacrifice, or "first-fruits" rituals, to preserve or ensure the continued fertility and abundance of the Earth.

What we receive from nature... comes to us from beyond our sphere of influence...First-fruits rituals protect the spirit of the gift by making evident the true structure of our relationship to the sources of our wealth...To accept the fruits of these things as gifts is to acknowledge that we are not their owners or masters, that we are, if anything, their servants, their ministers (Hyde, 2007, p. 191).

When we come to see ourselves as actors in natural cycles, part of one large socioecological community or system, we finally understand that what we give to nature, and what nature gives us, are connected. As Hyde explains, "We come to feel ourselves as one part of a large self-regulating system. The return gift is literally feedback, as they say in cybernetics. Without it, that is to say, with the exercise of any greed or arrogance of will, the cycle is broken" (Hyde, 2007, p. 23-24).

As I will show in Chapter 8, gift theory provides a helpful lens for understanding the culture of the community orchard: how orchardists see the fruit, the Earth, their labour, and each other; as well as why they put so much effort into creating and sustaining these orchards in the first place. Gift theory also goes a long way to explaining orchardists' view of the knowledge exchanged by way of the community orchard, as well as some of the internal conflicts their organizations experience, and how they feel personally about what they do. Of course, the gift dynamic in community orchards is complicated for many reasons, one of them being that members of the public, not understanding themselves to be part of such a gift economy, do not always "play by the rules" - i.e., occasionally they will steal, or take advantage of orchards and take much more than orchardists would wish. Still, gift theory helps explain why, despite the complications 
COMMUNITY ORCHARDS AS NEW URBAN COMMONS

and challenges, community orchardists persist in giving of themselves, within and through the orchards of their making.

\subsection{Narratives of the Commons}

The commons, in addition to forming the substantive context for this research, is also a conceptual lens we must explore. It is an especially helpful one, too, in that it brings together the key concepts of community and space. In Chapter 1, I outlined what the commons are, what commoning entails, and why the phenomenon is worthy of study. In this section, I discuss the myriad ways that commons have been narrated, with brief comments about how they might relate to community orchards. These narratives include commons as socio-economic institutions for managing scarce natural resources sustainably and equitably; as spaces of sociability and community empowerment; as a means of creating wealth outside of the market and increasing the total stock of knowledge and creativity in the world; as a moral claim; as a public good (and the responsibility of the state to protect); as an activist phenomenon; a proto-political philosophy; and a new cultural outlook.

The word 'commons', barely in use ten years ago, has fast become ubiquitous in public discourse. One doesn't have to look far to find public and school libraries being rebranded as "learning commons." New housing developments and even shopping complexes are also co-opting the term. ${ }^{31}$ The power of this concept derives in part from

\footnotetext{
${ }^{31}$ See, for example, Nelson Commons (http://nelsoncommons.ca) and Walnut Way Development Corporation (http://walnutway.org/commons).
} 
its persuasive power as a "grand narrative" (Bollier \& Helfrich, 2012, p.166) but also its malleability - the many ways it can be spun or employed, to many different ends. In this section, I briefly review several of these. In my final chapter, I offer an assessment of the ways in which these narratives of the commons fit my analysis of community orchards.

\subsubsection{Commons as socio-economic institutions for managing scarce natural resources}

The largest body of literature on the commons is rooted in the study of common property and the management of common-pool natural resources on which a given community is dependent. Scholars studying commons of this sort began with a focus on rural communities and their defining livelihood practices; indeed, the "big five" issues in the field remain fishery, forestry, irrigation, water management, and animal husbandry (van Laerhoven \& Ostrom 2007, p.1). This literature presents a view of commons as institutions for the collective and sustainable self-governance of scarce natural resources; commons organize responsibility for ongoing maintenance using rules. This body of scholarship can be seen, largely, as a gigantic, collective repudiation of the still-dominant view that any resource held in common is doomed to ruin from overuse and lack of attention and care for its sustainable maintenance. This is the "tragedy of the commons" thesis, first advanced by Garrett Hardin with an article of the same name in the journal Nature in 1968. In it, Hardin conjectured, as a general rule, that users sharing any common resource (such as a pasture) would be unable to govern it themselves because individual interests would always win out over collective interest. Consequently, only the 
state or the market could effectively and efficiently allocate resources and ensure the maintenance of any given resource base over time. ${ }^{32}$

Those who have studied actual operational commons around the world in the decades since then have come to much different conclusions. Led by Nobel Laureate Elinor Ostrom, who won the 2009 prize for economics, this community of scholars synthesized years of detailed empirical work on communities that self-govern around the use of shared resources. ${ }^{33}$ They found that well-defined groups sharing dependence on a resource showed a much greater capacity to overcome collective-action dilemmas and create effective governance than expected. They put forward a radical proposal that departed in every way from Hardin's: that resource users are the best agents to design and enforce systems of governance and management of the commons because only they have the intimate knowledge of the resource and place, the continuous presence, and the incentives necessary to succeed. Essentially, they demonstrated the workability of collective self-interest at a time when most assumed it not to be viable. ${ }^{34}$

The now-sizable body of scholarship on natural resource commons provides a wellelaborated theory for the analysis of common property resources used by relatively small

\footnotetext{
${ }^{32}$ There are, however, some authors who begin with Hardin's premise (that common property regimes don't work and that commons will necessarily be degraded) and insist on its veracity, concluding that enclosure, privatization, and marketization is the best way to supply goods efficiently. See, for example, Lee and Webster (2006).

${ }^{33}$ The International Association for the Study of Common Property was established in 1989, and its name changed to the International Association for the Study of the Commons (IASC) in 2006 (van Laerhoven \& Ostrom, 2007, p.5).

${ }^{34}$ Even Hardin later qualified his assertion to read the tragedy of the unmanaged commons (Fairlie, n.d.)
} 
and homogeneous groups that are heavily economically dependent on a scarce renewable resource, and in situations where free-riding and shirking temptations are strong. ${ }^{35}$ The literature provides examples of diverse solutions to common property dilemmas involving mixtures of institutional forms and property types - e.g., private, public, communal. It provides insight into when and why users retain communal systems even where they may practice individual ownership in other realms, and under what conditions common property or communal tenure is the most appropriate and most workable mode of production and regulation - i.e., for meeting social needs and producing social wealth (as compared to the public/state mode or the private/market mode). ${ }^{36}$ Finally, it offers a set of principles, or best practices, that help explain why some common property regimes (CPRs) are more functional, efficient, equitable and sustainable than others (see Ostrom, 1990). I introduce these best practices in later chapters.

Along with these eight design principles, Ostrom and her colleagues made some critically important distinctions. The first is between open-access common-pool resources - in which there are no limits on who can use them and how much anyone can take from them - and limited-access common property, which involves a group with identifiable

\footnotetext{
${ }^{35}$ Not included in this research, then, are non-renewable common pool resources, situations where abundance is the norm, or situations in which users can produce major harm for others (e.g., asymmetrical pollution problems).

${ }^{36}$ Ostrom did not argue for common property to replace either private property or state ownership or control; she wrote that she saw her work as complementary to theories of the state and the firm. Rather, she argued for the recognition of contexts and conditions in which common property or communal tenure was the most appropriate and most workable mode of production and regulation. Ostrom noted that communal tenure often co-exists alongside private ownership. That communal tenure has persisted for thousands of years even alongside private tenure tells us that such arrangements cannot simply be dismissed as "primordial remains of earlier institutions" (Ostrom, 1990, p. 61). Rather, they have persisted because they work.
} 
membership that has the ability to exclude non-members from using the resource, and to apply sanctions for the misuse of the resource by members. Here it is useful to think not in terms of two distinct categories, but rather in terms of a continuum, from low to high excludability. As reflected in the design principles, the clearer the group membership and resource boundaries (the greater the excludability) the more likely the common property regime is to succeed. The significance of this distinction cannot be overstated, since the failure to distinguish between different types of commons has led to the widely held belief that all common property arrangements are fatally flawed. Failure to distinguish between open-access resources and common property can also tempt commons enthusiasts to assume, naively, the opposite: that all commons are inherently sustainable, no matter what.

What we might call the "Ostrom school" of commons theorizing, dominant in the field of natural resource management, sees commons as a property regime; as such, it lends itself well to institutional and economistic analysis. For example, Betz (2014) used Ostrom's Institutional Analysis and Development (IAD) Framework to analyze a community orchard in Bloomington, Indiana. This IAD framework allowed Betz to propose a method for analyzing the relationship of a single commons with local government. Where commons are looser - less institutionalized, with fewer (if any) codified rules - as in the community orchards I studied - different narratives of commoning seem more germane.

\subsubsection{Commons as spaces of sociability and community development/empowerment}

Karl Linn was a German-American landscape architect, psychologist, educator, peace activist, and leader in the field of community design from the 1960s through the 1990s. 
He is remembered widely for his efforts to create neighbourhood commons in many inner-city areas in Philadelphia, Washington, Chicago, Baltimore, New York, Boston and other large American cities. For Linn, neighbourhood commons were spaces of sociability where neighbours could interact, collaborate, and discover a sense of collective efficacy by participating in the design, construction, maintenance, and administration of projects that combined sitting areas, neighbourhood park/playgrounds and community gardens. Working in primarily low-income areas of already deindustrializing cities, Linn saw early on that commons were not so much about property improvement and the projects themselves as they were about "human renewal and the release of creativity and cooperation" (Linn, 2007, p. 70). He saw that the enclosure of formerly common public land resulted in detrimental consequences not only for people's (diminishing) rights to "their shared natural habitats of land, water and air" but also for people's ability to interact cooperatively with one another (Linn, 2007, p. 204).

Commons, for Linn, were about providing opportunities for those most affected by social and environmental problems to be involved in analyzing the issues, exploring strategies, leading meetings and developing solutions, while bonding socially and satisfying their deep craving for community (ibid, p. 208). This narrative of the commons is one that resonates strongly with many community gardeners, particularly at gardens that have grown up on vacant lots in formerly blighted neighbourhoods.

\subsubsection{Commons as a means of creating wealth outside of the market}

What excites many people about the commons is the idea that they may be able to transcend that long-standing dualism of market and state, and the limitations of each. The 


\section{COMMUNITY ORCHARDS AS NEW URBAN COMMONS}

popularity of the Occupy movement ${ }^{37}$ (at least for a time) was but one indication that there is a widespread hunger for such a "third way", for "alternatives to an increasingly remote, business-oriented and bureaucratized government on the one hand and the increasing corporatization of society on the other" (Menzies, 2014, p.165). Key to this vision is a focus on decommodification or removing common property or goods from the realm of market exchange (or at least private profiteering) as well as from government control. Concrete models are beginning to develop.

José Luis Vivero Pol has written extensively about the need to de-commodify and "recommonify" food by valorizing its non-monetary dimensions (as an essential resource, human right, cultural item and tradable asset) $(2013$, p. 20; 2015). He envisions a time when global and local food production and distribution systems will no longer be governed exclusively by market rules, but by "institutional arrangements based on collective actions, appropriate legal collective entitlements, adequate funding and political support... [with] due consideration by politicians and academics" (2013, p. 20). In what he calls a "food commons regime" self-regulated collective actions for food ("crowd-feeding") will represent the third pillar of governance, complementary to market and state $(2015$, p. 12$) .^{38}$

\footnotetext{
${ }^{37}$ The Occupy movement was a popular movement that sprang into existence in the fall of 2011 to protest the enormous economic inequality and runaway greed that are symptomatic of our current political-economic system, and the undue and unjust influence of corporations on democracy. It was first proposed by the Canadian group, Adbusters Media Foundation, and quickly became a global phenomenon.

${ }^{38}$ Vivero's vision of a food commons is not to be confused with a very different, more marketbased and programmatic initiative underway in the United States that calls itself "The Food Commons" and proposes a tri-centric governance regime. Its stated objectives are "to connect local and regional food system enterprises in a cooperative national federation that enhances their
} 
While Vivero Pol's ideas have yet to take physical shape, the commons form the conceptual model for other very practical efforts to create, retain, and share wealth outside of the market. Land trusts, for example - a legal commons framework - are being created in both urban and rural areas to establish collective land ownership and remove land from the speculative market and dedicate it permanently to community-designated purposes (e.g., affordable housing or agriculture) (Diacon, Clarke \& Guimarães, 2005). The land is held through an inheritable and renewable long-term lease, governed by a democratic, non-profit corporation according to a charter that specifies principles of sustainable and ecologically-sound stewardship and use. Individual leaseholders may own the buildings and other improvements on the land created by their labor and investment, but do not own the land itself. Resale agreements on the buildings ensure that the land value of a site is not included in future sales, but rather held in perpetuity on behalf of the regional community. Many land trusts, even in cities, include farms or at least community gardens (see Richer et al., 2010; Yuen, 2014).

\subsubsection{The commons as a moral claim}

It is not unusual to see the commons invoked rhetorically as part of a moral claim of one type or another. As noted above, Blomley (2008) has used the notion of the commons to explore the moral-political claim of the urban poor, including the homeless, to urban space as a form of commons or common property (based on their intensive use and habitation) and its relation to gentrification (as a form of enclosure). This narrative separates property rights from land ownership and asserts that the moral claim is an

profitability and sustainability while creating and supporting a robust system of local community financing, ownership, management and accountability" (The Food Commons 2.0). That is not to say that these visions are incompatible; that much remains to be seen. 
entitlement based on occupancy and notions of justice. Others speak of the commons as an enacted (moral) relationship of trust toward future generations and/or non-human species and/or the Earth (e.g., water). When they speak of the global commons, they are suggesting that all of us, as commoners, are entrusted with the responsibility of safeguarding the planet for others, both human and non-human, both now and in the future. Commoning in this sense contains within it an implied directive about what is just and "right" in terms of our claims on the Earth and the suggestion that commoners invariably act in moral ways, a claim that Heather Menzies denies when she acknowledges that commoners no doubt had "all the normal inclinations toward greed, spite and self-interest" $(2014$, p. 3$)$. Still, she writes that "the language of the commons is one of "empathy and engagement, of mutual recognition, respect and implicated participation. It's the (inherently ethical) language of relationships and felt connection with each other and with the Earth" (ibid), suggesting that the institution of the commons itself is an implicitly moral one.

Whether this view is historically accurate or not is moot. The point here is that this rhetorical construction of commons as sites of morality exists. In fact, David Harvey, writing in much less flowery language than Menzies', observes that the whole issue of commoning tends to be "laced with hefty doses of nostalgia for a once-upon-a-time supposedly moral economy of common action" (2012, p. 68). While he advocates the pursuit of the commons, noting that "[capitalist] urbanization perpetually tends to destroy the city as a social, political, and livable commons" (ibid, p. 80), he acknowledges that commoning always engages conflicting social and political interests. He writes, "At the 
COMMUNITY ORCHARDS AS NEW URBAN COMMONS

end of it all, the analyst is often left with a simple decision: Whose side are you on, whose common interests do you seek to protect, and by what means?” (2012, p. 71). In Harvey's view, there is nothing inherently moral about common action or commoning $-\mathrm{a}$ point we would do well to remember.

\subsubsection{The commons as a public good, and the responsibility of the state}

James McCarthy notes that many efforts to instantiate new commons are really efforts to defend or expand public space, public goods and the public domain, rather than to create commons, which by definition require some exclusion and boundaries (2005, p. 11). The conceptual equivocation of the two terms comes about in part because of the lack of precision around the term 'the commons' and in part because of the multiple meanings of the term 'public'. Consider 'public goods', 'public services', 'public employment', the 'public sector', 'public service', 'public power', 'public space', 'public life' etc. On one level, public means non-private. On another, it suggests an orientation to the common good. On a third level, it can imply government involvement as owner, trustee or administrator (e.g., public services, public employment, the public sector) although this is not always true of concepts like public life or public space. The commons share the first two meanings of public, but their relationship to the state is a point of contention or debate.

One way of understanding how the two concepts might be related is to imagine that the ethos of the commons implicates the state in protecting the commons without suggesting that the public and the state are one and the same. This seems to be the view of Canadian water-rights advocate and commons proponent Maude Barlow, who argues that part of 
recovering the commons is recovering and expanding the doctrine of public trust, "a longstanding legal principle which holds that certain natural resources, particularly air, water and the oceans, are central to our very existence and therefore must be protected for the common good; they must not be allowed to be appropriated for private gain" (2012, p. 163). Public trust doctrine obligates government to sustain these resources for the longterm use and enjoyment of the whole population, not just those privileged enough to buy access to them. But this is not the same as saying that the commons are the exclusive realm of the state. A close look at Anglo-American property law shows that the public trust doctrine makes a distinction between the public and the state. Citing Rose (1994), Blomley observes,

although the state may act as trustee, there is still a recognition of 'the public at large, which despite its unorganized state seems to have some property-like rights in the land held in trust for it - rights that may be asserted against the state's own representatives'. (2008, p. 319)

\subsubsection{The commons as proto-political philosophy}

The commons can be understood as a normative guide to governance, a way of administering a just and equitable state of affairs. Many assert that commons are inherently democratic; that all those who participate in a commons have the right to an equal voice in making decisions on the provisions and rules governing its management (Bollier, 2012). This may, of course, be an idealization of the commons, since collectivities at all scales contain within them differential power relations, particularly between men and women, and between wealthier and less wealthy members of a community (see Bakker, 2007; Brown, 2004; Ostrom, 1990). And when all are not equal, 
outcomes of decision-making are not necessarily just. ${ }^{39}$ Nonetheless, the sustainability of a commons does depend to some degree on the ability of users to participate in setting and changing the rules that affect their use (ibid). Moreover, in a well-functioning commons, there is a need to keep the power of any one sub-group or individual in check; this requires that everybody be subject to everybody else's personal scrutiny and sanctions (Goldsmith et al., 1992, p. 123-4). Management systems set up to promote mutual accountability thus offer a form of democratic control. In the commons, there is also an emphasis on equity, both in terms of equal access and equal burdens (e.g., cost, responsibility for maintenance). For these two reasons - the twin emphases on democratic control and equity - and because they are fundamentally about selfdetermination, the commons have recently gained recognition as a seemingly novel, nonstate, non-market model around which to organize politically (Ostrom, 1990; Menzies, 2014). ${ }^{40}$ Commons are seen to be more democratic than socialism (at least state-centred socialism) and more oriented toward the common good than the market. Consequently, the concept of the commons is frequently mobilized by those interested in promoting social and political change, often of the socialist or utopian-anarchist variety.

\footnotetext{
${ }^{39}$ In analyzing common property regimes that have not been successful, Ostrom (1990) identified, as one variable contributing to failure, the ability of wealthier users to control the resource or appropriate it using illegal or questionable strategies without working through the group toward a common solution.

${ }^{40}$ That the commons present an alternative should not be understood to mean that there is no need for market and state, or that all human endeavor should be re-conceived in terms of the commons. Rather, the commons offers a third way that can complement market and state and go beyond them. Part of the discussion around the emergence of the commons as a third sector involves figuring out exactly where and when a commons framework might be preferable to market or state-based frameworks, and how the commons might interact with both market and state. See Bollier and Helfrich (2012).
} 


\subsubsection{Commons as an activist phenomenon}

In the past twenty or so years, the discourse of the commons has gathered steam because of its embrace by a global movement of resistance to globalization and neoliberalism. Naomi Klein is one activist who has linked this movement's aims explicitly to the defense of the commons. She writes, "As our communal spaces - town squares, streets, schools, farms, plants - are displaced by the ballooning market-place, a spirit of resistance is taking hold around the world" (2001, p. 82).

It is in this narrative that we see the clearest distinction between the Ostrom school and a more Marxist autonomous tradition of the commons. The main difference between the two lies in the explanatory power they attribute to endogenous and exogenous variables when it comes to the success (or lack thereof) of a given commons. Ostrom and colleagues look largely to characteristics of the resource itself, the users, and their system of governance to determine why a given common property regime succeeds, fails, or changes into another type of regime. These include scale, renewability, costs of measuring resource units, characteristics of resource users (number, uniformity) as well as the institutionalized rules and norms of governance that limit the amount, timing and technologies used to extract individual resource units from a common pool. To those in the Ostrom school, good institutional design is the key to helping human groups avoid the tragedy of the commons. Because of its focus on the dynamics internal to commons, the Ostrom school does not tend to challenge the status quo allocations of resources, goods, 
and services, nor does it relate the emergence of commons to larger forces such as capitalism. $^{41}$

Those in what might be loosely called the Marxist autonomous school (represented by the alter-globalization activists), look more to exogenous factors to frame questions of the commons' emergence, defence, and sustainability over time. They consider the structure of the wider society, class relations, and other political economic forces within a particular region (e.g., the labour needs of the region or the stage of capitalist development) to explain the emergence, dissolution, or staying power of a commons or common property regime. They tend to embrace an explicitly anti-neoliberal agenda. The key questions for this group concern not the efficiency, sustainability and equity of a property regime, but its transformative potential - i.e., whether "a particular commons increases the power of workers to resist capital and to define a non-capitalist future" (Caffentzis, 2004, p. 27). While the Ostrom school, or CPR approach, focuses on local case studies, the Marxist autonomous approach takes a global perspective, often linking the North and South by articulating over-consumption in the former to scarcity and despoliation in the latter (Huron, 2015). According to Sylvia Federici (nodding to Peter Linebaugh), "the commons have been the thread that has connected the history of the class struggle into our time" (2011, n.p.).

\footnotetext{
${ }^{41}$ While the Ostrom school showed common property regimes to be compatible with markets, the CPR field is not explicitly pro-capitalist. Rather, it has been deemed so by critics like Caffentzis, if only because CPR scholars are not explicitly anti-capitalist and because they limit their analysis to the workings of the commons institutions they study, largely disregarding the political economic contexts in which they exist. A better distinction might be between anti-capitalists and new institutionalists.
} 
My own interest in how urban residents are creating commons and decommodified spaces in cities awash in neoliberalism; and how they relate to municipal administrations (as exogenous forces), suggest an orientation more aligned with the Marxist-autonomous approach than the institutional approach. But as I am also interested in the internal dynamics of community orchards, and how such commons may be maintained over time, I locate my own understanding and approach to the study of community orchards somewhere in between. ${ }^{42}$

The commons has become a politically useful concept for progressive and radical activists for two main reasons: As noted by George Caffentzis (2004, p. 1), the commons represented a missing link needed to connect the very diverse struggles that made up the anti- or alter-globalization movement, and provided a much-needed alternative model of social organization to "there-is-no-alternative" neoliberalism ${ }^{43}$, preconfiguring the kind of cooperative society the global justice movement envisioned. The commons/enclosures discourse also allowed global justice activists of the 1990s to distinguish themselves from defenders of state property (whether Keynesian, state socialist, or communist) and, according to Caffentzis, to recognize the fundamentally anti-capitalist position that they shared, the logic of which runs as follows:

[I]n order for capitalism to exist there has to be a working class to exploit; and the main condition for there to be such a working class is that workers are separated from the means of subsistence (Marx, 1909) (Federici, 2004; Caffentzis, 1995). As long as workers have the capacity to live well on the basis of their own labor

\footnotetext{
42 As Amanda Huron has pointed out, there is a theoretical gap between these positions that needs to be filled. I credit her with pointing this out and providing an example with her work on limitedequity housing cooperatives in Washington, DC (Huron, 2015).

43 "There is no alternative" was a slogan used by Conservative British Margaret Thatcher, who, along with George Bush, was one of neoliberalism's early and most adamant proponents through the $1980 \mathrm{~s}$.
} 
and keep control of the tools for subsistence and social reproduction, there would be no motivation to sell their labor power to capitalists so that surplus value could be created from it to be appropriated by capital. (Caffentzis, 2004, p. 6)

Historian Peter Linebaugh (2010) gives four of his own reasons to explain the ascendency of commons discourse among activists at this juncture. The first is the worldwide struggle of Indigenous peoples against enclosure of their traditional or communal lands brought on by the steady creep of neoliberalism and corporate capitalism across the globe. The most famous of these struggles is the Zapatista uprising in 1994 in Chiapas, Mexico, which was triggered by the Mexican government's reforms to Article 27 of the country's constitution, which effectively liquidated the state-created ejidos or communal lands attached to each village (Federici, 2011; Klein, 2001; Stephen, 1998). The reform or repeal of Article 27 was prompted by the imminent implementation of the North American Free Trade Agreement (NAFTA), which required that lands be open to private "investment" (acquisition) (Stephen, 1998). Not long afterward, new enclosures, or "land grabs," in Africa and Indonesia (also prompted by the needs or desires of international capital) brought forth waves of resistance and concern for the estimated two billion people who derive their livelihoods from the world's commons, and whose very existence is now threatened, not only by the "formalization" of land rights (which often results in privatization), but also by private extractive interests engaging in what David Harvey $(2008,39)$ calls "accumulation by dispossession", by state promotion of corporate-dominated export-commodity production, and by environmental conservation projects that privilege paying eco-tourists over those who dwell in the commons of the global South (George, 1998). 
Of course, it is not only Indigenous people and those engaged in subsistence modes of production who feel threatened by neoliberalism's drive to enclose everything. Many in the global North have also lamented the increase in privatization and commodification wrought by neoliberal governance regimes and the detrimental consequences, including increasing industrialization of food production, rampant resource-extraction, and the transformation of diverse ecosystems into landscapes of consumption. The value of land is no longer tied to what a farmer can afford, but rather to what an investor can make. This, in turn, leads to the rampant conversion of farmland into subdivisions, strip malls, and other development - the results of which we witness every day in the loss of beauty, productivity, and biodiversity from our landscape (On the Commons, 2011). In this context, commons represent a fundamentally different economic, social, and cultural logic - life before money! - a sensibility within which many activists find great hope. The second reason Linebaugh gives to explain why the discourse of the commons has become increasingly resonant since the 1990s concerns the collapse of the USSR and the communist countries of Eastern Europe. Decades of statist ideologies and centralized ownership of property had done as much to damage to the commons as capitalism had: physically, by denuding and polluting the earth, and socially, by inhibiting the development of the kind of coordination and cooperation that commons require. Ideologically, too, by bringing about a general disillusionment with state-centred remedies for the ills of capitalism (interpreted by some to indicate the triumph of capitalism), the demise of the Soviet bloc not only forced the Left to find a new counterweight to capital; it also severed the association between the commons and communism in a fortunate way. The statist model of revolution had been for decades like 
COMMUNITY ORCHARDS AS NEW URBAN COMMONS

a millstone around the neck of radical activists, sapping their efforts to build an alternative to capitalism; its loss was in many ways liberating. Writes Linebaugh, the demise of state communism "made it easier to discuss the commons without automatically being suspected of ideological intercourse with the national enemy" (2010, p. 13).

Linebaugh gives two additional reasons for the emergence of a politics centred around the commons, both of which I have already touched on: 1) the development of the Internet and the World Wide Web as a knowledge commons; and 2) the widespread pollution of our global commons - the planet's waters and the atmosphere. Identifying these two realms as commons has at least two obvious advantages for activists. The first is that the rhetorical construction of the commons immediately suggests access rights for commoners, and most people readily identify more as commoners than as any modernday version of nobility (in contemporary parlance we might say "the $1 \%$ "). The second is that the ready association of the commons with tragedy and despoliation positions these commons as being at risk and in need of our protection.

When we speak of activists' mobilization of the trope of the commons for the purposes of social justice, we must surely address a vexing problem: the discourse's universalizing use of the term 'commoner'. McCarthy (2005) points out that it fails to recognize that there can be competing claims on lands at different scales, by different populations and for different purposes, reflecting different values and historical engagement with those resources - i.e., different kinds of commoners. It is an injustice, he says, to designate 
national forests as protected areas and assume that this is of benefit to all Americans, because it overlooks the ways in which such forests were physically and discursively appropriated centuries ago when colonists stole them from Indigenous peoples and claimed them as a part of the United States.

On the other hand, thinkers like Nandita Sharma and Cynthia Wright (2008/9) argue in favour of the term 'commoner' as the most appropriate - non-ethnicized, nonnationalized, non-essentialized - term to describe and unite the many peoples and groups that currently seek liberation from various forms of oppression, especially Indigenous peoples. Sharma and Wright see colonialism as being fundamentally about capitalism, and critique as "neo-racist" those projects that seek to end the ongoing process of "accumulation by dispossession" by building alternative sovereignties based on Indigeneity and Aboriginal nationalism. Such attempts at decolonization are doomed to failure, they say, because the problem is not just who rules, but ruling relations themselves. And as with any nationalism, there is the fundamental problem of what is done to those who may be imagined as the nation's "others" (which makes solidarity between the descendants of African slaves and Indigenous people and new migrants, some of them Indigenous themselves, very fraught). What decolonization needs to challenge, they say, are capitalist social relations and those organized through the nation state, such as sovereignty. The only way to do this is to recognize that capitalism and nation-states are deeply intertwined since both arose from the bloody violence of expropriating the commons and exploiting the commoners (Sharma \& Wright, 2008/9, p. 131). Consequently, they say, the only way to decolonize our language and our minds is 
to understand colonialism as the theft of the commons, the agents of decolonization as commoners, and decolonization as the gaining of a global commons (ibid, p. 133). The subject identity of "commoner" can bring together all those who have struggled against historical relations of expropriation and exploitation and who struggle still against the identities of "race", nation and gender (ibid, 132). Menzies concurs, seeing in commoning the possibility of Indigenous and non-Indigenous peoples coming together as kindred spirits and allies to "articulate a new social contract that is simultaneously a covenant with Creation, replacing an ethic of domination with an ethic of mutual respect and coexistence" (2014, p. 65).

The "discovery" of the commons by social movement actors has breathed new life into radical and progressive politics by presenting an organizing concept that seems to have great potential as a rallying point around which so many movements can join in solidarity. That said, activists employing the discourse of the commons must reflect on the question of who exactly the term 'commoner' refers to and to what degree the use of that term might obscure rather than reveal the continuing colonial relationships between Indigenous peoples and settlers in our country. I will return to this point in Chapter 7.

\subsubsection{Commons as indicative of a cultural shift toward sharing, belonging, collaboration}

Finally, the increasing popularity of the concept of the commons can be understood as part of a larger cultural shift toward greater sharing, belonging, and cooperation. In recent years, there has been strong growth in the cooperative movement (Van Slyke, 2013) and community-supported agriculture (McCracken, 2012). The practice of sharing backyards 
to enable those without land to grow food is also becoming increasingly popular (Chaker, 2012; Wekerle \& Classens, 2015). Other community-supported ventures - including community-supported breweries, art, medicine and publishing, to name a few - are also taking off (Drugmand, 2014). What all of these have in common is that they encourage both sharing (of goods, services, risks, and benefits) and collective subjectivities - i.e., an identity as a member, someone who belongs to and promotes something larger than his or her own personal interest. This cultural shift also extends to the ways we see ourselves in relation to the planet, or, more commonly, local ecosystems. The Great Lakes Commons initiative is a grassroots environmental effort to establish the Great Lakes as a living commons - shared waters that those living around take care of and protect in perpetuity. ${ }^{44}$ The mobilization of the concept of the commons in such contexts is rooted in the idea that commoning entails a deep connection with the Earth, based on an understanding that humans are not separate from, but a part of nature. In this tradition, commons are said to require and produce a more vibrant kind of ecological citizenship, one that emphasizes belonging to and identification with one's community (Menzies, 2014). The framing of these initiatives as commons demonstrates, in the words of Julie Ristau "a shift in thinking from the prevailing ethic of "you're on your own" to "we're in this together" (n.d., p. 20).

Clearly, "the commons" can be narrated in many ways. Scholarly conceptions of common-pool resources and common property regimes (CPRs) - what we might call the Elinor Ostrom tradition - are only the beginning, albeit an important one. The more

\footnotetext{
${ }^{44}$ To learn more about the Great Lakes Commons, go to http://www.greatlakescommons.org/
} 
popular and political discourses of the commons that are circulating today among thinkers and activists and policy-makers outside the domain of resource management and governance are only loosely related to the CPR literature, and they expand beyond its scope to embrace a far wider array of resources, domains and scales (McCarthy, 2005). This adoption and metaphorical expansion of the concept of the commons has enlarged the scope of commons scholarship beyond the study of institutions, economics, and governance, to include its cultural and moral dimensions. The social movement embrace of the commons has also shifted commons discourse beyond instrumentality and rules and toward an engagement with the social, ethical, and political dimensions of commoning. It is to these dimensions that we now turn, with the goal of understanding how community orchards are engaging in commoning and how the lens of commoning can shine a light on what is going on at the deepest level in community orchards.

\subsection{The Four Main Tasks of Commoning}

Whether defensive or generative, the act of commoning typically involves four main tasks: 1) resisting enclosure; 2) appropriating the commons for the community; 3) decommodifying exchange; and 4) claiming political power. To set the stage for the remainder of the thesis, I introduce each briefly here.

First, resisting enclosures. There is a very long history of commoners resisting enclosures through various means: sabotaging machinery, blockading roads, satirizing and threatening landlords and officials, lampooning experts, testing bureaucratic defenses, and using local traditions as an arsenal (Goldsmith et al., 1992, p. 196). Resistance can be 
overt or subterranean, repressed or resurgent. The struggle often involves demands for recognition of collective territorial rights, and/or a stop to certain kinds of development that threaten the commons, such as mega-dams, mines, timber extraction, energy projects, plantations, large-scale agriculture, and the dumping or incineration of toxic and noxious wastes. At other times, it is a struggle to create new commons through such means as land take-overs - occupations of large tracts of land held by absentee landowners (a frequently used tactic of Brazil's MST, or Landless Workers' Movement) - and the creation of legal land trusts (more common in North America and the UK). Resisting enclosure also represents a struggle to reclaim vernacular knowledge - i.e., traditional ways of growing foods, saving seeds, conserving water, curing the sick - and to resist the appropriation and patenting of such knowledge by corporations. In community orchards and gardens, the mere act of growing food in urban spaces that have high exchange value is intrinsically an act of resistance to enclosure and a challenge to private property. I explore this theme in Chapter 6.

Secondly, commoning entails the appropriation of space for community. According to Rainer Rilling, people transform themselves into commoners "when they make into common cultural symbols and take into their symbolic or real possession something that previously was 'private' or 'only' public property" (2011, p. 1). The New York commoning organization, 596 Acres spells out this process in four steps: Believe it is ours, create ownership, engage in stewardship, establish the right to governance. ${ }^{45}$ Similarly, in 2011-2012, the Occupy movement grabbed headlines by engaging in social

\footnotetext{
${ }^{45}$ To learn more about 596 Acres, go to http://www.596acres.org.
} 
appropriation (at least symbolically) and asserting common rights of all sorts of spaces through their presence in public squares and on streets, bridges, and college campuses around the world. Appropriating space for community is not simple or easy. Mackenzie (2012) notes that it is a complex, sometimes contradictory, and contingent process, always subject to negotiation. I explore this theme in Chapter 7.

Third, commoning is about decommodifying exchange and re-valorizing the informal sector, including the unpaid labour of social reproduction - e.g., volunteering, childrearing, food production, etc., as a way of limiting the scope and penetration of the market in people's lives (Bollier, 2012). What Josée Johnston (2003) calls "commons praxis" is about subordinating market/state modes of regulation to community modes that maximize access to life goods. This does not mean that commoners reject all forms of commodities and markets or focus on an entirely subsistence-oriented way of life, but they do favour access over ownership and frequently defend autonomous ways of accessing life goods against commodification. Johnston writes, "Struggles for the civil commons are struggles for a world where markets might exist, but where they do not dominate all social relations, or become the exclusive way of accessing the means of subsistence" (2003, p. 40). ${ }^{46}$ This re-valorizing of unpaid labour and non-commodified exchange is strongly evident in community orchards in the form of a pervasive gift ethos; I explore this theme further in Chapter 8.

\footnotetext{
${ }^{46}$ One trending example right now is a project called "Food is Free" (http://foodisfreeproject.org). People around the world are setting up free, help-yourself food gardens and stands to offer food to neighbours and strangers, to demonstrate that food does not have to be obtained only through market transactions, and to build a stronger sense of community through sharing.
} 
Fourth, commoning is about claiming political power to shape the city, but not at the expense of others' rights to do so too. At a societal level, it means redistributing wealth and transforming relations of power (Bollier, 2012) and asserting that no culture, gender, "race", class, or other group has the right to assert privileged status over others (Goldsmith et al., 1992, p. 202-3). At the community level, it means regaining or engendering the mutual support, responsibility and trust that are necessary to sustain the commons (Goldsmith et al., 1992, p. 205) and re-instituting the checks and balances that limit power within the local community. It is about redefining conventional enactments of public space/property and re-negotiating the usual roles and responsibilities of the community or voluntary sector, vis-à-vis municipal governments. I explore this theme in Chapter 9.

\subsection{Conclusion}

In this chapter, I have outlined the conceptual framework for my research, beginning with the foundational concepts of community/space and the gift. Secondly, I have presented the commons as a complex idea that can be narrated in many different ways, within which there is a clear divide between the inward-looking institutional-analysis approach of the CPR field (Ostrom school) and the outward-looking Marxist-autonomous approach to the commons. I have asserted that commoning, at least in the latter tradition, consists essentially of the four main tasks just described. Before turning to my examination of these tasks as I see them unfolding in community orchards, I must first outline my methodology (Chapter 3), introduce my study sites (Chapter 4) and clarify the role of the 
COMMUNITY ORCHARDS AS NEW URBAN COMMONS

fruit itself - the ostensible purpose of community orchards - in order to situate the stillimportant act of food growing in this larger project of commoning (Chapter 5). 


\section{Chapter 3 - Methodology}

\subsection{Introduction}

In this chapter, I discuss my methodology by first situating myself within the normative lens of the political project that is this doctoral research. This research is about a social innovation, its political undercurrents, and the reasons interviewees have for taking part in it - the social-change aims they are advancing, and the often-political visions they are enacting and bringing to life. I am interested in validating and sharing narratives that may resonate with others who are just starting, or thinking of starting, community orchards because I see them as worthwhile undertakings. In that sense, mine is an action orientation. But this is not action research per se insofar as I am working alone and not testing and tweaking a particular intervention into a social problem following the actionobservation-reflection cycle. ${ }^{47}$ My ambitions are, consequently, quite modest; I seek an understanding that I feel - and hope - may be of interest to others, and that may help to advance similar social innovations by different actors in other places.

\subsection{Ontological and Epistemological Considerations}

Ontology is the branch of metaphysics that concerns the nature of reality; as such, it informs all approaches to inquiry. As a researcher, I begin with an ontological orientation toward social constructivism - the belief that reality is socially constructed, and therefore cannot be viewed as independent from those who have constructed it (Creswell, 2007).

\footnotetext{
${ }^{47}$ Action research begins with an immediate problem to which the researcher, working in collaboration with actors "on the ground," seeks a practicable solution. Action research follows a process of planning, taking action, observing, reflecting, and tweaking the action, and then repeating the cycle (O'Brien, 1998).
} 
This stands in contrast to a realist (or modernist) paradigm which views reality as separate and distinct from humans (Lincoln \& Guba, 2000), but knowable by us from the outside. If reality is socially constructed, then researchers and participants are co-creators of knowledge, and the most a researcher can claim to do is to offer an interpretation of the phenomenon studied, not an exact picture of it (Charmaz, 2006).

Epistemology concerns how we know what we know. Epistemologically, I take the position that there exist multiple, competing, incomplete perspectives on any given phenomenon. My particular viewpoint derives from my unique life experiences and values, and, significantly, from my positionality, relative to both the phenomenon at hand and to those with whom I speak. As a feminist, I believe it is important to take explicit note of that positionality. I am a white, English-speaking, middle-class, highly educated female settler (non-Indigenous person). My power and privilege derive from my social status as someone who belongs to a dominant social group in this country (white Englishspeaking settlers) with access to the luxury of higher education, and perhaps greater economic security than some interviewees. ${ }^{48}$ In the research context, my privilege is also to have "the final power of interpretation" (Gilbert, 1994, as cited in Rose 1997, p. 307); although I invited others to contribute to shaping my understanding, I was, ultimately, the one who decided what questions to ask, who directed the conversations, who decided what was significant, and how and where to use it.

\footnotetext{
${ }^{48}$ Initially, I imagined I would be interviewing many people who were food insecure at the household level, which I am not. However, with one or two possible exceptions, it turned out that this did not seem to be the case; interviewees appeared to be from a similar socio-economic background as me - i.e., largely middle-class, as broad a category as that may be. Moreover, as I was not gathering household demographic data on either interviewees or the general membership of the community orchards studied, I am not in a place to infer very much about our relative economic locations.
} 
What, then, is to be done about the privileges that attend who I am and the power I have as an academic researcher? It may be that all I can do is to acknowledge their existence. Pratt (2000) writes that the attempt to situate oneself in the research process "serves the purpose of stabilizing the process and removing bias in order to uncover the truth" (as cited in Rose, 1997, p. 21). But is this even possible? Reed and Peters note that it may be paralyzing to try to reach the (unobtainable) goal of "ascribing and eliminating the biases associated with the power of academic researchers" (2004, p. 31-32). As much as I may strive to be reflexive, and aim for nuance and attention to detail, there will always be a bit of $m e$ in the way I understand and reflect (if not represent), the understandings of those whom I have interviewed. This bit of me will invariably come through in the way I have constructed my understanding of the issues, in how I have made sense of what interviewees shared with me, and how I communicate it through this thesis and any publications I may author in the future.

Consequently, say Reed and Peters, the attempt to eliminate one's own biases may amount to little more than what Rose calls a "goddess trick" (1997, p. 311). ${ }^{49}$ In other words, it is a fiction, because, as Reed and Peters write, "we cannot know all of the ways our position affects how people respond to us, or how our histories and experiences affect what we notice and how we interpret our results" (2004, p. 21). The only correctives I am aware of are to resist "ironing out" or writing away contradictions and uncertainties, and

\footnotetext{
49 This is Rose's reference to Donna's Haraway's concept of the "god-trick"- the belief (conceit) that a researcher, in aspiring to the ideal of scientific objectivity, can actually succeed in eliminating personal biases, commitments, emotional involvement, or partial perspectives. Haraway (1991) says that this is impossible, and that only partial and situated knowledges exist. Rose's contribution is to question the subsequently articulated feminist ideal of complete reflexivity or transparency in knowing exactly where one is situated and what sort of partial knowledge that perspective confers.
} 
to thereby acknowledge the gaps or fractures in my interpretive authority (Larner, 1995; Miles \& Crush, 1993; both as cited in Rose, 1997, p. 318); and to remain as sensitive as I can to potential power relations between myself and others - especially research participants (Ballamingie \& Johnson, 2011, p. 713).

Another aspect of my epistemological position was my desire to approach my research questions in an inductive, iterative, and open way. I knew it was important to maintain an openness to modifying elements of the research design where feedback indicated that changes were necessary. Even prior to beginning interviews, it started to become clear that my definition of the research problem, and my idea of its salient features, would need to shift to account for my changing understanding of the phenomenon at hand. I had begun the research thinking that Elinor Ostrom's commons theory might explain some of the successes or difficulties encountered by community orchards and help provide guidance for them. My hope was to try it out, experiment with it, perhaps, and interpret both the input of interviewees and the relevance and value of that theory to community orchards. My initial strategy of inquiry involved specifying in advance the type of information I was seeking, rather than simply waiting for it to emerge from participants. I was, however, committed to remaining flexible and willing to change if my research strategies did not seem to be leading to the most accurate, useful, or salient results.

This commitment to what Reed and Peters term "adaptive research methodology" (2004, p. 27) turned out to be a good thing. As the process unfolded, I found myself asking more open-ended questions (still guided by the same research instrument) - essentially, talking 
less and listening more. What began as a somewhat theory-driven approach evolved into something more resembling a grounded-theory approach, in which the purpose of inquiry is to inductively generate a novel theory having to do with how interview subjects interpret or make meaning of the world. The investigator does not begin with (or seeks to move beyond!) any hypotheses or assumptions about how phenomena or their characteristics may be correlated; rather, s/he looks for understanding and meaning to unfold authentically from the shared interpretation that is constructed by the researcher and the interviewees together (Charmaz, 2006, p. 5; Cresswell, 2009, p. 8). Because I did not begin with completely open-ended questions, I cannot call this grounded theory exactly. However, I did allow the answers to my initial questions to loop back and modify those initial research questions quite significantly.

In doing so, I was engaging in what Reed and Peters call "reflexive research practices," which allow us to "adapt research methods to meet unexpected outcomes" (2004, p. 2426). These unexpected outcomes or surprises include "the possibility that our understanding or definition of a research problem may be inappropriate or partial" (ibid, p. 27). While we can try to correct as we go, it may well be the case that this condition is permanent; our understandings of the research problem can only ever be partial. And so the research "findings" will be, unavoidably, inconclusive, more of an expression of our understandings at a certain point in time, a moment in an ever-unfolding process of learning that is fixed or limited by the time constraints of the PhD process, but could otherwise continue well beyond. 


\subsection{Methodological Issues}

Methodologically, I have taken a case study approach, which is to say that I explored a limited number of community orchards, mainly through in-depth exploration of the perspectives of the individuals who have created and maintained them, with the goal of bringing together a mix of different narratives that collectively illustrate the complexity (and possible ambiguity) of community orcharding as a social phenomenon. Doing case studies involves "moving from empirical observation to concepts/theory" in multiple loops, involving both induction and deduction to understand the concrete and practical aspects of community orcharding as a phenomenon, while also expanding and generating new explanatory concepts (Baxter, 2010, p. 90). What I like about the case study approach is that it acknowledges the context-dependency of all knowledge and privileges the richness of in-depth understanding over the breadth that might be had with farreaching but relatively superficial inquiries (Flyvberg, 2006). A case-study approach also asserts that naturalistic observation is really the only route to knowledge-generation in the social sciences - "noisy, fallible, and biased though it may be" (Campbell, 1975, as cited in Flyvberg, 2006, p. 224). Flyvberg's assertion fits with my own view of how we learn what we think we know.

As cases are "neither entirely unique nor entirely representative of a phenomenon" (Baxter, 2010, p. 86), I wanted to look at a moderate number of cases to balance the particular and that which might be generalizable. However, this was not a comparative case study approach. I felt that to compare orchards in that way would have required a higher minimum number of research participants from each orchard, to make reliable and 
COMMUNITY ORCHARDS AS NEW URBAN COMMONS

appropriate comparisons, as well as an explicitly comparative aim - i.e., research questions that made the similarities and differences among orchards the focus and tried to explain them by reference to characteristics they either had or did not have in common. I chose instead to focus on community orcharding as the phenomenon requiring explanation.

Realizing that comparison and explanation of differences between them was not the point of my research (particularly after my questions shifted), I recognized that it was not necessary for me to focus solely on the small number of sites that might be considered appropriate comparators. Rather, if my interest was to generalize about community orchards, to understand them as an emerging phenomenon, I decided that an embrace of many orchards would be more desirable because it would bring in greater potential diversity of individual viewpoints (assuming that there would be greater diversity looking across orchards rather than just within them, which I believe is true). This choice allowed me to include the voices and perspectives of interviewees whose orchards do not have many active members, and where I might be granted access to only one or two as interviewees (an insufficient basis on which to derive comparisons of the orchard as a whole to other orchards, but legitimate as individual perspectives). Embracing the diversity among orchards was most important because it kept me from over-generalizing; many times when I thought I might be able to characterize all community orchards in a certain way, I would notice that at least one of them didn't fit that (putative) pattern. In fact, this recognition led directly to one of my key learnings, which is that community orchards and their proponents are not easily boxed into types and must not all be painted 
COMMUNITY ORCHARDS AS NEW URBAN COMMONS

with the same brush. Their development and meaning is very context-dependent and situation-specific.

I have, nonetheless, chosen to write up the stories of five exemplars - Copley Community Orchard (Vancouver), Strathcona Community Garden (Vancouver), Spring Ridge Commons (Victoria), Welland Community Orchard (View Royal/Greater Victoria), and Ben Nobleman Community Orchard (Toronto) - to draw a picture of this emergent phenomenon and to create a sense of what interviewees are involved in and speak about. I chose these five because I wanted to study orchards that were relatively well established (at minimum, five years old) and where there was a solid core group of people who were actively and regularly using the space and/or contributing to its upkeep. I felt that without this degree of longevity or continuity of membership, any conclusions I might draw could be very tenuous; after all, emergent phenomena are notoriously difficult to study. That said, I also spoke to a small number of people at four other orchards - Banfield Community Orchard (Victoria), Fernwood Neighbourhood Orchard (Victoria), Norquay Learning Orchard (Vancouver), and the orchard affiliated with the Elizabeth Rogers Community Garden, in Jonathan Rogers Park (Vancouver). These four are newer and/or smaller and/or more limited in terms of the degree of community ownership and engagement they seem to have. Still, I wanted to acknowledge their existence as a way of representing more comprehensively the diversity of community orcharding in these centres. I also wanted to retain in my analysis the voices and perspectives of the interviewees associated with them because I felt that each added something valuable and unique. 


\subsection{Ethics}

This research followed Tri-Council guidelines and was approved by the Office of Research Ethics at Carleton University. All participation in this research was strictly voluntary. I began by sharing information about the nature and purpose of the research and gaining participants' informed consent (see Appendix A for the Letter of Introduction and Informed Consent). Participants were told both orally and in writing that they were free to refuse to answer any questions I asked, and that they would have a chance to review the transcript of their interview, at which time they would be free to edit or revoke any statements they had made.

Before conducting interviews, I also thought hard about confidentiality and anonymity. I felt it important to reveal the identities of the orchards and their locations. Concealing them would mean extracting them from their contexts, which would disallow meaningful analysis. Full anonymity would also make it impossible for me to share stories among community orchards in a way that could be of value to them. That said, I did offer interviewees some degree of individual anonymity, if requested. One final ethical consideration had to do with working with vulnerable populations. Once again, my expectations proved misplaced. As it became clear that orchard members/participants were not in it for the food, and that household food insecurity was not going to feature into our conversations (I can think of only one interviewee who ventured into that area) it also became clear that vulnerability (at least due to poverty) was not such a salient concern for these interviewees, in relation to their interactions with me. 


\subsection{Methods}

\subsubsection{Environmental Scan}

I began with a broad environmental scan over the Internet, which turned up community orchards in the UK, the US, and Canada. Having already determined that going to the UK would be beyond my means (and subsequently also learning that community orchards in the UK have quite a different focus, as previously described in Chapter One), I identified as many community orchards in North America as I could. My goals were: 1) to find out how extensive this emergent phenomenon was, where other similar projects had been established or were coming into being, what scale(s) they were operating on, and what information-sharing networks I could join; 2) to identify a subset of community orchard sites that I wished to study more deeply; and 3) to identify contact people at these sites. In doing so, I encountered many people from whom I learned, but whom I did not ultimately choose to interview, including a woman who had studied community orchards in Portland, Oregon and whose master's thesis I had read and found quite insightful (see Becker, 2015). I also discovered that a North America-wide Community Orchard Network had been established in January 2015 and learned that it holds monthly webinars with guest presenters, which are recorded and made public on YouTube. While these turned out to have little direct bearing on my work (their focus being mostly on the horticultural aspects of maintaining community orchards), they did give me a sense of where community orchards exist in North America, and how I might tap into that community in the future as a way of disseminating my research. 


\subsubsection{Site Visits}

In the spring of 2015, I conducted preliminary site visits in Toronto, Vancouver, Victoria, and Philadelphia. I chose to go to Philadelphia because it is the site of the most established and extensive community orcharding organization in North America - the Philadelphia Orchard Project (POP) - which has been in operation since 1997. I thought it might teach me what to look for elsewhere, and that it might be a fairly easy way to see a large number of different orchards, highly concentrated in one city. The Philadelphia Orchard Project (POP) lists over 50 community orchards on their website, almost all of them in low-wealth neighbourhoods where household food insecurity is not unusual. (At the time of my visit, I was still framing my research in terms of food justice, so this seemed particularly germane.)

I chose to do site visits early on because there is not a great deal of information available on the Internet about community orchards generally, and also because I wished to avoid making cold calls, seeking a great deal of information from people who didn't know me at all and who might be wary of a researcher's motives or feel resentful of the "ask" from a stranger. I felt that if I made the effort to go to community orchards early on and meet people in person, not only would I be able to determine which sites and how many seemed best suited to deeper exploration, I would also have a much better chance of establishing the rapport needed to request extended interviews and time from people. ${ }^{50}$ Preliminary visits also helped me evaluate how appropriate the interview format and

\footnotetext{
${ }^{50}$ While I think these in-person visits helped establish that rapport, they were probably more important for building my confidence. Once I was well into the interviewing phase, I found it quite easy to contact strangers and gain their trust and willingness to be interviewed.
} 
COMMUNITY ORCHARDS AS NEW URBAN COMMONS

questions I had formulated might be - basically whether I had the endorsement of the various actors to do the research and whether the orchards they were involved in seemed like a good fit for my research.

In the end, I decided not to include the community orchards in Philadelphia (or elsewhere in the US) and to restrict my focus to community orchards in Vancouver, Victoria, and Toronto. I did so not only for pragmatic reasons (expense, time) but for reasons having to do with my own positionality. I realized, in Philadelphia, that the US context (especially in the large deindustrialized cities of the east coast) is very different from the Canadian one because of the unique history of race relations and the much more racially segregated patterns of residential settlement that prevail in the US. Moreover, from what I could see in my short time there (only four days), I was not sure that I, as someone who has not studied American history or critical race theory, would be well enough equipped to negotiate the layers of complexity necessary to fairly interpret the meaning of community orchards in that context. This just added to my feeling that it was not wise to try to include examples from the US, unless my interest was to be explicitly, cross-nationally comparative, and to connect differences between the community orcharding movements in each country to national historical/socio-economic/political differences. It was not my intent to undertake a cross-national comparison and doing so would have re-directed the whole undertaking. Moreover, it would have entailed research with an unmanageable scope, given my relative immobility as a researcher who also has children at home. 
Within Canada, I chose to study orchards in Vancouver, Victoria, and Toronto, mostly for substantive reasons. That is, these were the ones I identified as being the most established. ${ }^{51}$ These also, conveniently, suited my purposes for logistical reasons. I live in Nelson, BC, which is an eight-hour drive from Vancouver, and approximately 12 hours from Victoria (including the ferry crossing to Vancouver Island). While my study sites are not as accessible as they might be if I lived in Vancouver or Victoria, they are not that difficult to visit. (We in the $\mathrm{BC}$ interior are quite accustomed to making such long drives for social, medical, sport, and work-related reasons.) Moreover, I had friends and/or family members in both cities with whom I could stay for brief periods. I also have immediate family in Toronto, and because I travel there to see them at least once a year, I felt I could also include Toronto's Ben Nobleman Community Orchard in my purview quite easily. In short, it was a happy coincidence that the orchards that I most wanted to study in Canada were also the ones most conveniently located for me.

\subsubsection{Document Review}

In Chapter Four, I narrate the histories of the five main orchards. My sources for these narrations (and my subsequent interpretation of the interviews) included the following: 1) documents and materials generated by each community orchard (e.g., mission statements, blog posts by organizers, internal member surveys, Facebook pages, on-site signage, video clips, etc.); 2) articles in newspapers, magazines or other public media; and, 3) my

\footnotetext{
${ }^{51}$ I had originally included Calgary on my list, based on a newspaper article that indicated that the City of Calgary was undertaking a five-year pilot project involving orchards under three different modes of management. However, upon closer investigation, I could not identify any actual orchards in Calgary nor find anyone who could explain why they had not materialized. From those I was able to speak to, I got the sense that the orchards were aspirational at the time of the article, and that the staff person who had the vision had since moved on, and the pilot project never materialized.
} 
own observations, gleaned from site visits and limited participation in work parties. A couple of the orchards (Strathcona and Spring Ridge Commons) had also been studied previously by graduate students, and I found their work an extremely insightful addition to my understanding (see Mallet, 2012; Rodgers, 1995).

\subsubsection{Semi-structured Interviews}

Where I had made strong and positive personal connections through preliminary visits, I was able to proceed directly to the interview stage without making a return visit (i.e., by using phone or Skype). At other sites, I began by identifying orchard organizers, support organization staff, and municipal government representatives through their websites and/or publicly available emails. I then asked orchard organizers for recommendations and/or introductions to people who had been involved as participants or volunteers in the orchards for a significant time and whom the organizers felt would be amenable to being interviewed. As I did more interviews and my confidence grew, I became comfortable emailing people whom I had never met in person and arranging for interviews by phone or Skype. ${ }^{52}$

Because participation was so voluntary, and in fact required these interviewees to take some initiative to get back to me, as well as give of their time, this research no doubt reflects some selection bias: those who wanted to speak to me all felt quite strongly, thoughtfully, and more-or-less positively about what they were doing. (Conversely, there

\footnotetext{
${ }^{52}$ In fact, Skype proved to a wonderful tool. I felt that those interviews were just about as warm and personal as any I conducted in person.
} 
were a handful of people whom I contacted on multiple occasions to request interviews who did not respond. I took this as an indication that they did not wish to be interviewed. However, without any knowledge of their reasons, I cannot venture what that says about their involvement.) Being aware of this selection bias, I also asked orchard organizers if there were any people with dissenting views that they could suggest for me to interview. It was my intention that any critical views would be presented in an aggregated and anonymized way in my write-up, to avoid damaging interpersonal relations or the reputations of any community orchard. However, in all cases where interviewees had spoken of significant conflict (usually with neighbours), they also told me that they felt the conflict was in the past, and that they would prefer that I left well enough alone. Naturally, I did.

In total, I conducted in-depth semi-structured interviews with 35 people, representing a variety of perspectives and roles relative to nine community orchards. ${ }^{53}$ These included orchards both large and small, very established and quite new, thriving and struggling, located within and outside of city parks, with varying degrees of tenure security and incorporation into City operations. They also included one food forest and one orchard that seems almost more like a botanical garden (because its purpose is largely to demonstrate and propagate as many different varieties of fruit trees as possible); one orchard that is part of a community garden, and one that doesn't call itself an orchard (but explicitly calls itself a commons); orchards that are overseen by non-profits and orchards that are completely community-run.

\footnotetext{
${ }^{53}$ In addition, there were about 20 community orchardists I spoke to informally whom I did not end up interviewing.
} 
Of my interviewees, 23 were female, 12 male. I interviewed ten people from Copley Community Orchard, five people associated with each of Strathcona, Welland, and Ben Nobleman, three people from Spring Ridge Commons, and one or two from each of the secondary sites, plus two who work for the City administrations in Vancouver and Victoria and who are not associated with any particular orchard or garden. (The City representative I interviewed in Toronto is associated with Ben Nobleman).

I used slightly different sets of questions for those in different positions vis-à-vis the community orchards (e.g., members/volunteers, or coordinators, or representatives from City administrations - see Appendix B). Interviews in general took approximately an hour each, with many going as long as 90 minutes. Interviews were audio-recorded and transcribed verbatim, then returned to the interviewees for approval, at which time I offered them two months to make any changes they wished to make, and/or to indicate if there were sections that they would not like to see included (or included only anonymously) in my write-up. Nearly all interviewees read their transcripts and got back to me, most of them with unconditional approval to use their words and quote them by their real names. However, at certain places in my write-up, I have made an independent choice not to identify interviewees due to the sensitive nature of their comments.

The concept of reciprocity, which features in some feminist methodological literature, encompasses an acknowledgement of the gifts given by research participants through some form of compensation, and a commitment to share the benefits of the research (see Diver \& Higgins, 2014; Ybarra, 2014). It was important to me that I give back to my 
interviewees to thank them for what they were giving to me. Where possible (i.e., when I met with them face to face) I offered a token of my appreciation in the form of a small jar of local specialty honey, the significance of which was always immediately apparent to orchardists and appreciated with a grin. I also accepted an invitation to make a short presentation to a gathering of neighbourhood organizers who were planning a new community orchard/garden in Vancouver's Riley Park neighbourhood. As important as these small gestures were, I also heard from many of those I interviewed that there was something inherently rewarding for them in simply speaking to me about their passion. Thus, while some critics construe academic research as "taking" from those interviewed (see Robbins, 2006), I do believe it is possible to see it in a different, more positive light - that in some cases, research can offer interviewees an opportunity to share their story with a very interested listener (see Janzen, 2014). ${ }^{54}$ This was indeed what I found; interviewees seemed to relish talking about their experiences and reasons for being involved, and genuinely thanked me for listening. (Rarely does someone listen as intently as a researcher!)

Interviewees were also very eager to hear my thoughts, and many of the interviews morphed into extended conversations (and even some standing invitations to stay with the interviewees whenever I was next in town). I was delighted by their interest, so I put

\footnotetext{
${ }^{54}$ I would qualify this statement by adding that it is certainly much more possible in situations of relative power balance, where there is no history of colonization or other exploitative/oppressive relationships between the groups to which the researcher and the interviewees belong. Robbins (2006) does a thorough job of detailing the historical entwinement of colonialism and research across many disciplines and the ways in which the arrangement and definition of that data suited colonizers' goals and helped create or uphold an elite class who made decisions that were, at best, paternalistic, and often pernicious. Mine was a very different context and power dynamic.
} 
together a reading list of works on the commons and other concepts related to community orchards (e.g., public produce) which I circulated to those who expressed an interest in learning more about those ideas. And because many indicated a strong desire to learn more about what other community orchards were doing (and an almost baffling lack of awareness of other community orchards' existence), I committed to sharing with participants a written, plain-language summary of what I produce (which will be much shorter than the full thesis).

It may be, though, that what I have written will not answer their questions at all, and for that I am sorry. In part, this is due to institutional limitations on university research. Early on, I did want to ask community orchard members what they would most like to learn about, and from, other community orcharding groups, but I soon realized that I couldn't design a research proposal that was this vague and open-ended, nor could I first find out the answers to those questions and then design the research, because just asking those questions would constitute research, which isn't allowed prior to ethics clearance, which in turn depends on a fully fleshed-out research proposal having already been written and submitted. Moreover, there would still have been the problem that community orchardists' needs and interests might not match my own, or meet the test of having conceptual or theoretical significance (e.g., How do other community orchards manage coddling moth? How do they share the work of writing grant proposals?) Ultimately, then, we return to the inescapable fact that while I have elicited input from others, this is ultimately my research, reflecting my priorities and my interpretations, my insights and 
COMMUNITY ORCHARDS AS NEW URBAN COMMONS

my limitations. Nonetheless, I think the need for reciprocity will be satisfied, if not necessarily in the strictly transactional way I originally imagined.

\subsubsection{Research site visits}

I made three research trips to explore the research sites themselves and to interview people on location. I travelled to Vancouver and Victoria in late March, mid-July, and early August 2016; and to Toronto in late August 2016. My goals in doing site visits were: 1) to develop familiarity with each orchard and its context (especially the socialgeographic context - i.e., the neighbourhood); 2) to help establish a foundation of trust and sharing that would facilitate my carrying out meaningful interviews; and 3) to develop ideas in situ about these gardens' functions relative to their larger communities, to the commons ideal, and to the shaping of public space in cities. Sites visits allowed me the opportunity to engage in some participant observation, which I did while volunteering for work parties - e.g., harvesting green plums and crabapples at Strathcona, and helping with pruning at Copley. ${ }^{55}$ Site visits also gave me a chance to encounter people whom I might not otherwise have met, and to gather more serendipitous input that, again, I might not have encountered if I had tried to do all my interviewing and data collection by telephone or computer.

As explained above, I chose to make multiple short site visits to a moderate number of sites instead of spending prolonged periods at fewer sites. I made this decision not only because my family responsibilities preclude spending weeks or months at a time away

\footnotetext{
${ }^{55}$ I was not able to participate in work parties at all sites, but nor was I depending on participant observation as a major source of input.
} 
from home, but also because I believe that such extended involvement, however exciting it might seem, is neither truly necessary, nor would it serve my needs or purposes.

Community garden researchers Saldivar-Tanaka and Krasny report from their work in New York City: "we discovered that spending prolonged periods in a few gardens did not necessarily lead to a better understanding of their impacts relative to spending shorter periods of time in multiple gardens" (2004, p. 401). ${ }^{56}$ Like Saldivar-Tanaka and Krasny, I felt that my time would be better spent building an understanding of a larger number of cases and gaining a broader perspective.

\subsection{Analysis}

Because my research questions had shifted mid-course, my analysis did not proceed as I initially expected it to. It was when my research questions changed that I found myself moving more toward grounded theory as an analytical strategy, because it wasn't initially clear to me just what to do with the thoughts and words people had shared with me. My old questions didn't seem such a good fit for the phenomenon I was studying (based, as they were, at least loosely, on Ostrom's eight principles of successful commons), but it

\footnotetext{
${ }^{56}$ Saldivar-Tanaka and Krasny also reported that they tried to do participatory action research but couldn't find people interested in being co-researchers. I have the same hunch: I don't expect that many people involved in community orchards would really want to participate that deeply in this research, as I have defined it. It would be an entirely different matter if I were already a member of their community and we co-instigated a project based on a shared sense of priorities. That not being the case, I wanted to be sensitive to the value of the research to the participants (which I presume is considerably less than it is to me). Another doctoral researcher, Sherrill Johnson, wrote of her own efforts to "democratize the research process" by inviting members of the community of concern to her research to work with her on the analysis: "In spite of the many attempts on my part to encourage a participatory approach, this offer was met with little enthusiasm and even less uptake" (Ballamingie \& Johnson, 2011, p. 721). Consequently, I think it would be disingenuous to claim that I was trying to be more than minimally participatory.
} 
COMMUNITY ORCHARDS AS NEW URBAN COMMONS

wasn't yet clear to me what new questions my data was answering. So, I went through the transcripts and coded them for themes, and then grouped these themes in ways that seemed logical, looking only at the data itself. I arrived at my revised (and retrospective) research questions through a process of moving back and forth between my old questions and my coded themes, cracking open the embedded assumptions in the old questions, which had been invisible to me before.

\subsection{Checking}

While interviewees indicated to me that they had felt heard and understood, and while I did give them the chance to edit their own transcripts, I also wanted to build in a further process of verification to see whether my interpretations of the significance of their words resonated with them. (While my interpretation is ultimately my own, there would be something wrong if interviewees felt that I had not understood their meaning, in which case I would be wrong not to seek to harmonize our understandings.) Researchers Bailey, White, and Pain call for such checking as part of the dual need for 'critical thinking' and 'reflexive response' (1999, p. 28). It is also an act of necessary humility to acknowledge that "participants often have critical insights into local situations that may escape researchers who are not community members" (Reed \& Peters, 2004, p. 29). Beginning in early February, 2018, I reached out to all interviewees with an invitation to anyone interested in reading my drafts. Of my 35 interviewees, 13 indicated an interest in reading. To them I sent selected chapters - the ones they had indicated interest in reading (at the time, I had drafted only the first five); some chose only one or two chapters, while several volunteered to read all five. Disappointingly, I heard back from only about five interviewees; I surmise that the rest were daunted by the sheer volume of reading. 
However, the feedback I did receive was very positive. In my final stage of writing, once I had drafted the remaining five chapters, I once again reached out to offer those chapters to anyone interested in reading. I also let them know that I hoped to travel to Vancouver, Victoria, and Toronto this summer and would be very happy to get together with interested community orchardists to see the orchards and/or discuss my ideas. Several interviewees in Vancouver and Toronto responded to this invitation and I very much enjoyed meeting with them and giving hard copies of my thesis to these orchard groups in person. (Unfortunately, I have not yet made it back to Victoria so I am sending hard copies in the mail to Welland, Banfield, Fernwood and Spring Ridge Commons). Much as I would like to get feedback from everyone, to learn how my ideas are being received by those I interviewed, I can only extend the offer; the rest is up to them.

\subsection{Conclusion}

What follows is a qualitative inquiry into nine community orchards in three Canadian cities, conducted mostly by way of in-depth interviews with 35 active community orchard participants, site visits, document analysis, and participant observation. I have approached my research questions in a very iterative, adaptive and reflexive way, modifying them as it became necessary to reflect my growing understanding of the phenomenon, as well as my ontological and epistemological commitments to constructivism, interpretation, and feminist positionality. In the end, my interpretations are my own, and they are provisional, insofar as I humbly acknowledge that further engagement with community orchards and those who maintain them could very well alter my perspective even more. Just as community orchards are always growing and 
COMMUNITY ORCHARDS AS NEW URBAN COMMONS

changing, in response to weather, seasons, and ecological/human dynamics, so, too, is my grasp of them bound to continuously evolve. I invite you to share in this season of my understanding. 


\section{Chapter 4 - The Community Orchards}

\subsection{Introduction}

In this chapter, I locate my research in the actual spaces and places of the case study orchards. I draw from media reports, research by others who have studied the orchards, the orchards' own internal documents, ${ }^{57}$ and the interviews I conducted, to paint a picture of each orchard: its geographical location, physical characteristics, mission, property ownership, social history, and activities to date. For maps showing the locations of the orchards within their respective cities, please see Appendix D.

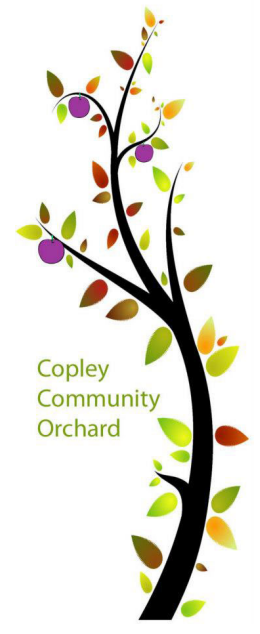

\subsection{Copley Community Orchard (Vancouver)}

"Connecting to food, the land, and each other" http://www.copleycommunityorchard.com

Located a stone's throw from the Nanaimo Skytrain Station in East

Vancouver, the 1.2 acre Copley Community Orchard was initiated in 2011 and broke ground in 2012 with 65 trees and 100 shrubs planted in the first season alone. ${ }^{58}$ The full list of species that have been planted in the first five years includes 23 varieties of apples, cherries, pears, plums, walnuts, and figs, as well as strawberries, blueberries, Saskatoon berries, currants, grapes, honeyberry, elderberry, goji berry, haskap, sea buckthorn, jujubes, goumi berry, pomegranate, raspberry cane, kiwi vines, rhubarb, and even asparagus! The land on

\footnotetext{
${ }^{57}$ Groups' internal sources include websites, promotional videos, Facebook pages, member surveys, messages posted to member list serves, and records of public meetings. The amount and types of material available to me varied greatly from one orchard to the next.

${ }^{58}$ For a wonderful short video that conveys the community's shared excitement on planting day in 2012, see https://www.youtube.com/watch?time_continue $=339 \& \mathrm{v}=\mathrm{hfDnfVI}$ _mso
} 
which the orchard grows is part of the traditional territories of the Musqueam, Squamish, and Tsleil-Waututh First Nations - a fact noted on the large sign that greets visitors entering the site from the west. Prior to the $20^{\text {th }}$ century, the site was swampy (owing to the presence of beaver dams up to 37 metres long!) and perfect for cranberries, which flourished there for many years. When non-Indigenous settlers moved in and drained the bogs, around the turn of the 20th century, fertile organic soils remained. Today, owing to its location near a busy Skytrain station, the site sees lots of pedestrian and bike traffic; project initiators incorporated this facet into their design, placing their plantings around and along the well-trod, preferred path of those who pass through daily, which runs diagonally through the centre of the now-thriving orchard.

Copley Community Orchard was named after Richard and Marie Copley, immigrants from England who bought the property in 1905 and held it until 1940. During the heyday of Copley Ranch (as it was then known), the site grew cherries, walnuts, plums, and apples, of which Richard Copley

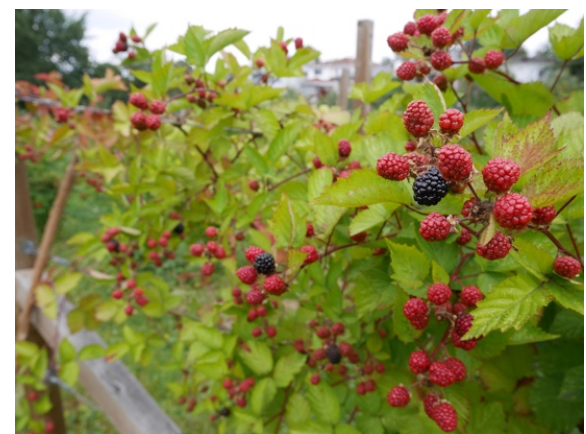

Figure 1: Black raspberries at Copley Community Orchard Photo credit: Jennie Barron cultivated no fewer than 120 different varieties. Nine of these now-very-large, original apple trees remain on the site; they have been dubbed the "heritage trees" to acknowledge that their presence pre-dated the community orchard per se, and to recognize that neighbours have been freely harvesting from them for many years, a practice the community orchard organizers did not want to interfere with. After the Copleys sold the site, it remained vacant for decades, considered "undevelopable" because of the very 
large sewer line the City had placed underneath it, where Gladstone Creek flows (underground) to Trout Lake. The City had hoped to use the property for social housing, but abandoned those plans in 2011, when it was determined that the site would be too costly to develop (Rayner, 2012). As the property is still owned by the City's real estate department - not the Parks Board - it faces an uncertain future. The community orcharding group signed a second 5-year lease in 2016, but the City reserves the right to take the land back at any time, if and when the City deems it to be economically feasible to develop.

Copley Community Orchard was the brainchild of Hartley Rosen, executive director of the Environmental Youth Alliance (EYA), who saw it as a way to promote food re-

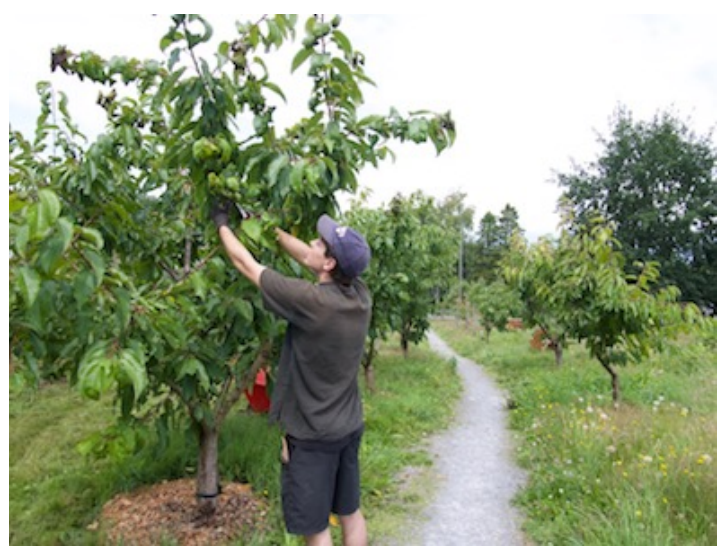

Figure 2: EYA staffer helpfully pruning diseased branches on the community side of Copley Community Orchard Photo credit: Jennie Barron localization and urban food production.

Hartley was especially inspired by the idea of promoting perennials as a relatively underutilized food resource (compared to annuals, such as grow in most community gardens).

Cresting the rising wave of public excitement around such trends as the 100-mile diet, ${ }^{59}$ the project also sought to reach youth and connect them to the Earth (this being the EYA's primary goal), and to build awareness and appreciation of trees, as well as greater attachment to the places in which residents

\footnotetext{
${ }^{59}$ This trend was made popular by a book of the same name, written by Vancouver-based authors Alisa Smith and J.B. MacKinnon in 2007.
} 
live. ${ }^{60}$ Initially, the space was divided into two sections: one for the EYA and one for the community group. The EYA's area was dedicated to youth education and apprenticeship through intensive fruit production. The focus of the community area was up to the community group. However, members of that ostensibly separate group relied heavily in the early years on the capable leadership of EYA project coordinator, Jodi Peters, who provided energy, drive, permaculture knowledge, and an ability to inspire others, which brought many people into the project in the early years. This imbrication of the EYA and the community group would prove challenging later on (when Jodi moved away), as the EYA sought to transfer leadership to the community group, which desired greater autonomy but had limited capacity, as volunteers, to provide what Jodi, and other EYA staffers, had been supplying.

Hartley's vision for Copley was also unique in moving away from the allotment design of most community gardens, preferring instead to engage neighbours, community organizations and school groups in communal tending of trees, vines, and shrubs. Hartley saw this as a more innovative approach, one that suited his desire for Copley to be a collaborative project, a space where decisions were made collectively and where participants could learn about larger democratic structures by participating in a microcosm of society. All residents within a two-block radius of the site were delivered invitations to participate in a collaborative design process, led by The Community Studio, a group of landscape architects, planners, architects, and engineers who do pro-bono work for nonprofit community-based projects (Rayner, 2012). Not all, however, were

\footnotetext{
${ }^{60}$ The mandate of the EYA is "to provide meaningful work and volunteer experience for children and youth working on community food and ecology projects" (Rosen, in Poizner, 2014).
} 
happy about the proposal. A small but vocal minority of neighbours living on the street west of the orchard expressed a strong preference that the land be kept in its current state, as the idea of fruit trees didn't match their vision of appropriate land use in urban areas "That's for Chilliwack," they said. ${ }^{61}$

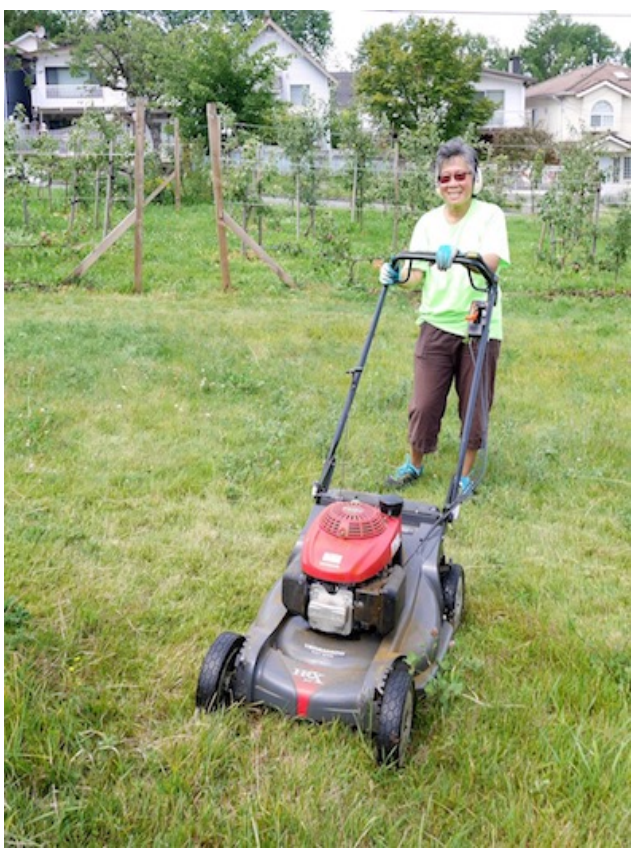

Figure 3: Copley Community Orchard member Linda Lee.

1.2 acres is a lot to mow!

Photo credit: Jennie Barron
Other neighbours were concerned about the construction of a toolshed beside the oft-used path to the Skytrain, some seeing it as ugly (before it was finished) and others fearful that someone might hide behind it and attack people coming along the walkway. Opposition didn't stop the project, and most neighbours have come onside since, but others maintain a stance of suspicion and criticism, with one even blaming the orchard for bringing bad luck that she believes caused her uncle to die. ${ }^{62}$

${ }^{61}$ Chilliwack is a historically agricultural municipality in the Fraser Valley, which lies approximately $100 \mathrm{~km}$ southeast of Vancouver, and is known for its large dairy, poultry, and pig farms - and the odours they produce. These neighbours' objections are to be expected. As Domene and Sauri (2007) explain, a cultural separation of the urban and rural spheres that developed following WWII led to a common preference for urban natures to be either completely "natural" (unmanaged) or completely produced (tamed or "manicured"), thus rendering agriculture, as a hybrid landscape, a seemingly "backward", inappropriate or frequently unwanted use of urban space.

${ }^{62}$ In keeping with certain Chinese beliefs, this neighbour attributed the planting of a tree directly opposite her doorway for the family's misfortune. The tree was not, in fact, part of the orchard, but was planted by the City along the edge of the property, as part of a big push to increase urban forest cover in Mayor Gregor Robertson's bid to become the world's greenest city by 2020. 
Copley began with a membership structure $-\$ 20$ per household, annually. ${ }^{63}$ Membership was not limited to those in the immediate neighbourhood; rather, organizers sold memberships to anyone interested in joining and lending their labour and ideas to the project. During the first two years, so many people were joining, and the project was so popular that the organizers felt compelled to create elaborate systems - to manage as many as 100 people showing up all at once for work parties - and a hierarchy of committees responsible for site management, communications, finances, membership, education, and a core committee, to which all the others would report. Two years into the project, with only periodic maintenance to do and no appreciable volumes of fruit, member numbers were down from 85 (in 2012) to about 30-35 (Rosen, in Poizner, 2014). In 2017, facing a threat from the City, which was considering rezoning the land for modular housing, and another group that expressed interest in sharing land use, the Copley community group formally established itself as a not-for-profit society. Keeping the vision alive now - ensuring that the mowing, water, pruning, organic pest treatments, pathway repair, shed and tool maintenance get done - depends on about a dozen enthusiasts, with no regular funding. ${ }^{64}$ But what they lack in size, they make up for in sheer dedication.

\footnotetext{
${ }^{63}$ Technically, because they were not a registered non-profit society, this was not a membership fee, but a requested donation, in exchange for membership.

${ }^{64}$ Financial support in the past has come from the EYA, the City of Vancouver, Vancouver Parks and Recreation, VanCity Credit Union, the Toronto Dominion Green Streets program, and individual donors. But as with most community development projects, the kind of funding that is available to maintain existing projects pales in comparison to that available to initiate them.
} 


\subsection{Welland Legacy Park Community Orchard (View Royal/Victoria) A new model of public park stewardship http://lifecyclesproject.ca/our-projects/welland-community-orchard/}

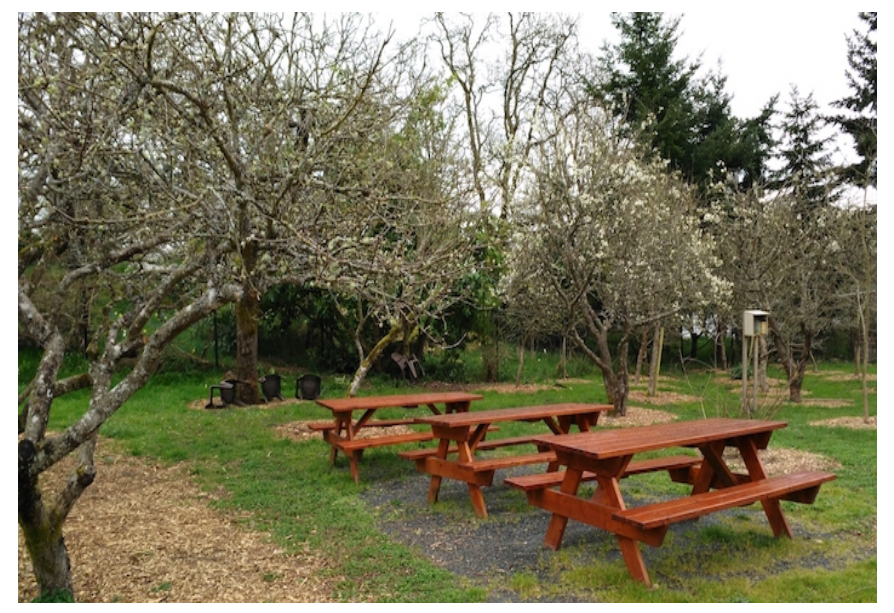

Figure 4: Welland Community Orchard in early spring. Photo credit: Jennie Barron
Welland Legacy Park is located in the town of View Royal, one of 13

municipalities that make up the region of Greater Victoria, on Vancouver Island. As such, it is part of Coast Salish Territories, specifically of the Lekwungen (aka Songhees) and W_SÁNEC

peoples. ${ }^{65}$ Known as "the Garden City", Victoria was established by British colonialists, beginning in 1843 ; its daily newspaper is still called the Times Colonist. ${ }^{66}$ Owing to its temperate climate, the region is well suited not only to gardening but to fruit growing. In fact, the first apple tree in BC was planted by the Hudson's Bay Company on the site that would later become Fort Victoria (Martin, 2006). ${ }^{67}$ The region was soon awash in orchards, some of which survive to this day, even at 160 years old (McCulloch, 2013). Apples provided early settlers with not only a sweet and healthy addition to their sometimes-meagre diets, but also ample quantities of delicious, hearty cider. During the

\footnotetext{
${ }^{65}$ The term 'Coast Salish' refers to a number of Indigenous peoples, including Esquimalt, Hul'qumi'num, Klahoose, Lekwungen (Songhees), MALAXEt, Musqueam, OStlq'emeylem, Pentlatch, Scia'new (Beecher Bay), Sliammon, Shishalh, Skxwú7mesh-ulh Úxwumixw, Stó:lo, Straits, Tsleil-Waututh, T'Sou-ke, W_SÁNEC (Pauquachin, Tsartlip, Tsawout, Tseycum), and Xwemalhkwu (LifeCycles, 2017).

${ }^{66}$ Victoria was not actually incorporated as a city until 1862.

${ }^{67}$ Martin's fascinating history of the apple also includes the birthplace of apples - Kazakhstan and the fact that they were brought to Canada by explorer Samuel de Champlain in the early $17^{\text {th }}$ century.
} 
gold rush era, the $\mathrm{BC}$ government required that every prospector come through Victoria, where tens of thousands of prospectors stocked up on much-needed supplies, including, of course, dried fruit (J. Rogers, personal communication, July 11, 2016). ${ }^{68}$

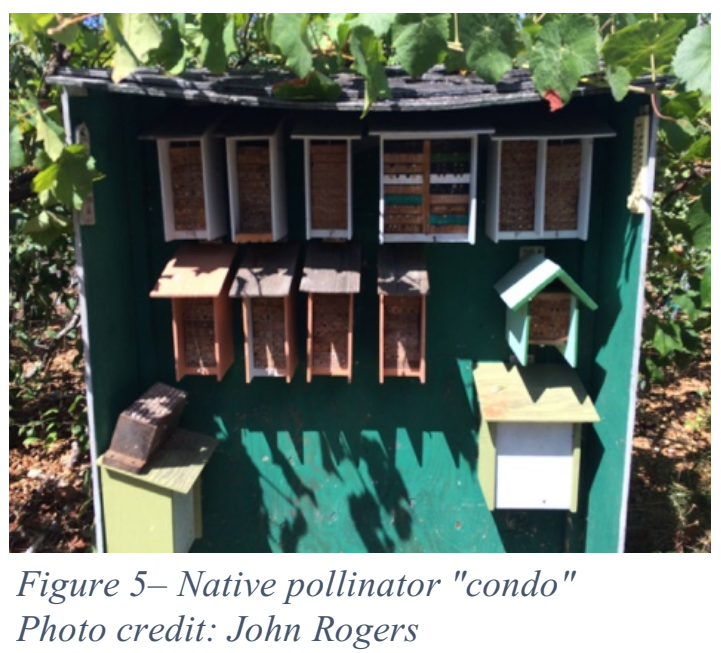

The 2/3-acre property of what is now Welland Legacy Orchard was formerly the backyard of a well-loved community member by the name of Rex Welland. A gentle and patient man who cared deeply about his community, Rex was a highly respected conservationist, well known for the extensive private collection of fruit tree varieties that he propagated and developed over decades of painstaking research, observation, and documentation. The site today contains over 200 fruit trees and vines, including many rare heritage varieties of apples, as well as pears, plums, figs, hazelnut, medlar, quince, persimmon, pluot (a cross between plum and apricot), grape, pawpaws, hardy kiwis, sour cherry, and shipova (a hybrid of the European pear and the common whitebeam). Rex was equally passionate about supporting native pollinators and promoting local bee populations; as a meticulous observer of their habits and life cycles, he developed innovative methods to help native pollinators survive mite infestations and other dangers.

\footnotetext{
${ }^{68}$ The other, more geographically likely point of entry into Canada for travel up to the Yukon would have been Bellingham, Washington, which, being on the mainland, would have been far more convenient.
} 
Rex Welland's vision was to have his land utilized as a public resource, where generations could come to be nourished and to learn. Upon Rex's death in 2008, his family placed the land under a covenant with The Land Conservancy and gifted the property to the Town of View Royal. Knowing they could not manage the intensive maintenance required for 60 mature trees, 100 espaliered (oblique cordon style) heritage apple varieties, a dozen fruiting vines, and 50-100 seedlings, the Town partnered in 2013 with LifeCycles, a local non-profit, to maintain the orchard. LifeCycles' mandate is to "cultivate

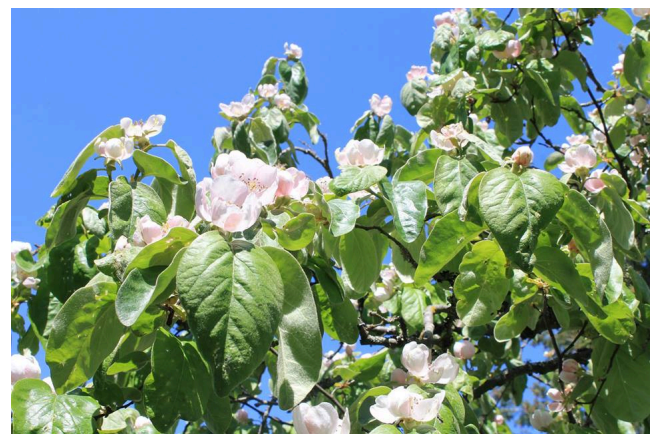

Figure 6: Quince blossoms at Welland Photo credit: Julia Ford community health by connecting people to the food they eat and the land it comes from [and to] support the region in growing, accessing, and eating local food in ways that foster diversity and enhance our urban environment" (LifeCycles, 2018). A sign posted at the entrance to the park from the popular Galloping Goose bike trail explains the park's goal: to produce the "food, soil, plant materials, and knowledge to feed a re-localization of our region's food system". To meet this goal, LifeCycles actively propagates the orchard's many varieties by grafting and growing out new trees in an on-site nursery, and then giving them to other public parks and community gardens in the region. LifeCycles also hosts free community workshops at Welland on pruning, grafting, cider-making, mushroom-growing and supporting native pollinators; the workshops, and the skills participants gain through engaging in them serve as a way of thanking volunteers for their labours, though there is no formal requirement to volunteer in exchange; everyone who wants to come and learn is welcome. Rapport between the town, its parks staff, and 
LifeCycles is very good, and is aided by the fact that View Royal town councilor John Rogers is also an ardent supporter of Welland; it was Rogers who, as the Parks liaison for Council and a member of the local water commission, arranged for Welland to get the agricultural water rate.

Welland Legacy Park's community orchard seeks not only to educate the community through interpretive signage and demonstration, but to involve residents in actively caring for a diverse orchard system. LifeCycles' Julia Ford organizes work parties at Welland on the first and third Sundays of every month, from March to October. The high degree of volunteer participation in caring for the park makes the partnership between the Town of View Royal and LifeCycles unique. It also makes Welland unique as a public park,

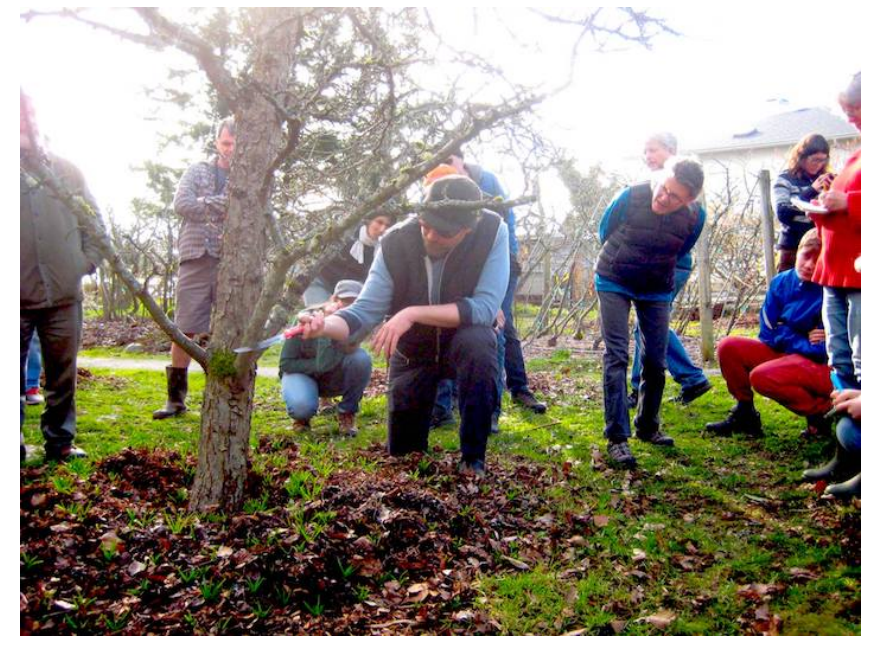

Figure 7: Winter pruning workshop Photo credit: Julia Ford insofar as the maintenance of the park as a public resource is dependent on the involvement of volunteers. To some extent this is enabled by status of View Royal as a non-union town, which means fewer restrictions on the activities of volunteers, who do all the tree care, mulching, weeding, fertilizing, pruning - pretty much everything except mowing the grass. It was also volunteers who took it upon themselves to demolish Rex's old shed, replacing it with another, and to install new irrigation connected directly to city pipes, instead of to Rex's former house. In return, the town gives LifeCycles a grant in 
the amount of $\$ 13,000$ each year (plus a $2 \%$ annual increase), as part of a five-year (2016-2020) contractual agreement for maintaining the park. ${ }^{69}$ This investment is much greater than for any other parks in Greater Victoria, but the town of View Royal seems happy to be playing this unique role in fostering heritage preservation and holding what Welland Community Orchard Coordinator Julia Ford describes as "a really interesting piece of the food security puzzle in the region."

Where most other community orchards are still a long way from reaching their full potential, in terms of the volumes of fruit they can produce, Welland is enviably mature. Says Julia,

Because there's such variety, people's minds get blown! Welland has the sensual experience - the beautiful site, the incredible variety, and the flavour. There's such potential for engagement, in terms of getting people to really care about their local food. The orchard is there. It's not like we're building it. We just have to bring the people in.

In 2016, Julia recorded $400 \mathrm{~kg}$ of produce coming off of the trees, and she estimates the little orchard probably produced another 50-100 kg that was not weighed. Since she started in the job in 2015, Julia has been bringing more people in and building the volunteer base, which she hopes will one day operate on more of a membership model, similar to a CSA (Community Supported Agriculture), but in the public realm. Like all visitors to Welland, Julia is inspired by the generosity and example of Rex Welland: "Look at what an incredible resource this is. Look at what we can do in a lifetime, with some careful attention and care to a piece of land... That's really powerful to me. It's cool."

\footnotetext{
${ }^{69}$ Note that LifeCycles also has other significant sources of funding, including a $\$ 25,000$ grant
} from Toronto Dominion Bank, which they won in part for Welland Legacy Park. 


\subsection{Spring Ridge Commons (Victoria) A community urban food forest}

http://fernwoodnrg.ca/fernwood-nrg-programs/urban-sustainability/spring-ridgecommon/

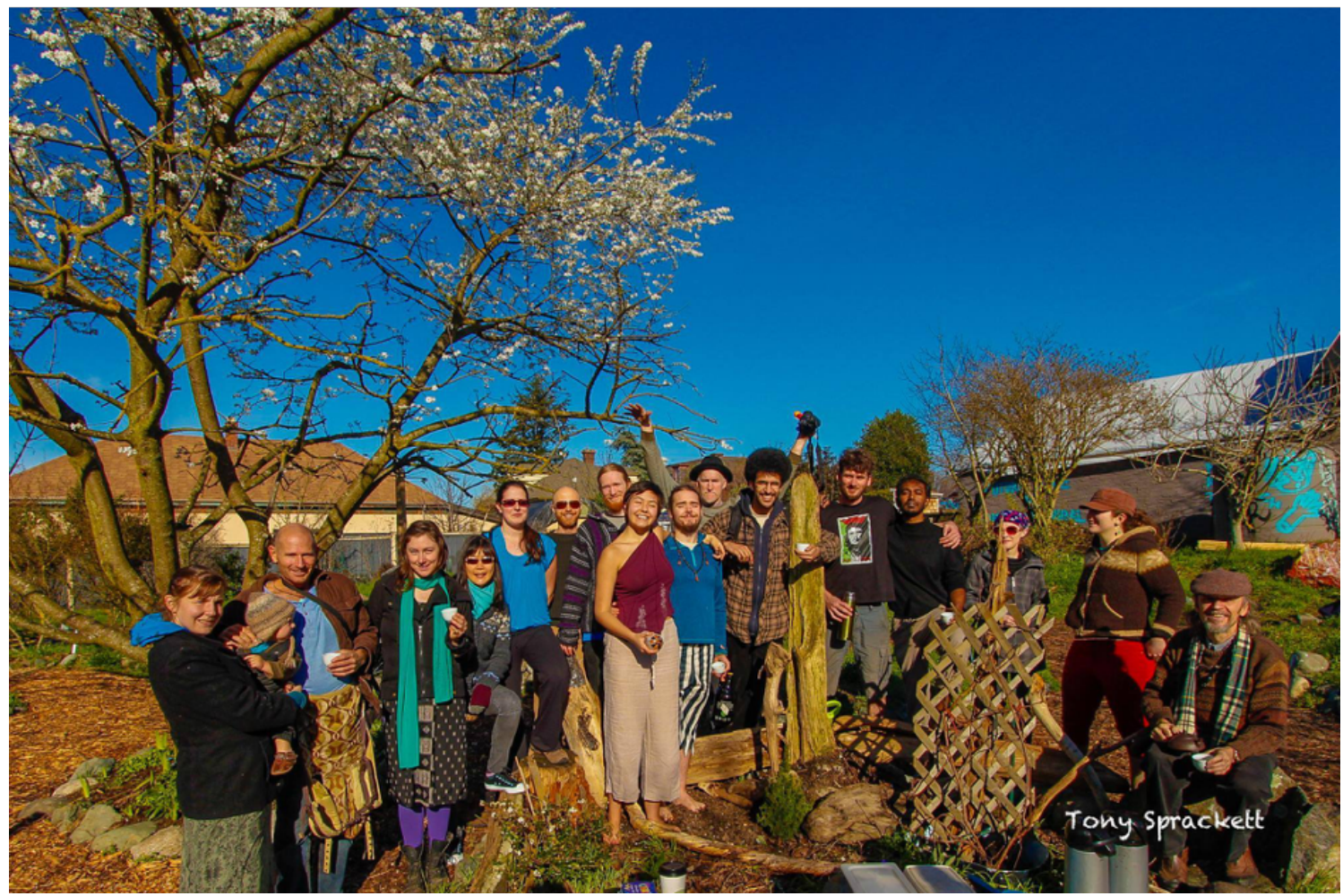

Figure 8: Spring Ridge Commoners Photo credit: Tony Sprackett

Spring Ridge Common(s)(SRC) ${ }^{70}$ is located at the corner of Chambers St. and Gladstone

Ave. in the Fernwood neighbourhood of Victoria, within the traditional territory of the

Songhees First Nation. In the right season, a person passing through the commons may

delight in harvesting herbs, goumi berries, pie cherries, sea buckthorn, damson plums, medlars, or, if they are very lucky, a coveted desert king fig. As a food forest (not an orchard per se), Spring Ridge Commons was developed according to permaculture principles, which means (among other things) that the fruits of the land are not just for

\footnotetext{
${ }^{70}$ There appears to be some disagreement among stewards of the site about whether it is to be referred to as a 'common' (singular) or a 'commons'. In fact, in the large welcome sign at the entrance to the site, one can see that an 's' originally inscribed into the driftwood at the end of the word in question was later scratched out, almost successfully.
} 
humans; the site exists also to provide food and shelter for birds, bees, and other wildlife. And, in keeping with the site's Indigenous history, organizers have planted camas bulbs (once eaten in abundance by First Nations) as part of a small Garry Oak restoration site.

The 1/2-acre property on which SRC grows is owned by Victoria School District 61. From 1887-1968, it housed one of the first schools in Victoria (Spring Ridge School). When the schoolhouse was torn down, a gravel lot remained and the school district used it as a parking lot for their school buses. In 1999, the site was appropriated as a common(s) by a group of Victoria residents under the leadership of local food-forest enthusiast Geoff Johnson. Johnson envisioned his project as a manifestation of resistance to enclosure and economic globalization, which he described as "the merger of the state with corporations" (Mallet, 2012, p. 42). Having been very involved in the anarchist scene and as an anti-globalization activist through the 1990s, Johnson eventually got burned out, and came to see permaculture as an alternative way to have an impact that was smaller but real:

[F]or me, permaculture, and especially urban permaculture, is closer to real autonomy or real sovereignty. We can talk about political sovereignty and decentralization and all this stuff but unless there is a biophysical aspect to it it's just thinking and talking. Unless we can actually grow more food and the things that we need closer to where we live then it's not real sovereignty is it? (Johnson, as cited in Mallett, 2012, p. 42-43)

Johnson, together with other activist gardeners, expended enormous energies

transforming the site into a permaculture demonstration site containing over 100 species of plants. Original design goals included teaching people about local food and permaculture; creating a local gathering space, and increasing regional diversity and sustainability (Kemshaw, 2011). Poor soil and the warm, dry conditions of the site have 
favoured some of these species more than others, but the site continues to be a place for experimentation, not only with edible and medicinal plants, but with social relationships and organization.

Spring Ridge is described on the Victoria and Region Community Green Map as "a living laboratory...a source of free food, a learning environment, and most importantly, a place of beauty, nature, and solitude., ${ }^{71}$ It attracts high school students and business people, hippies

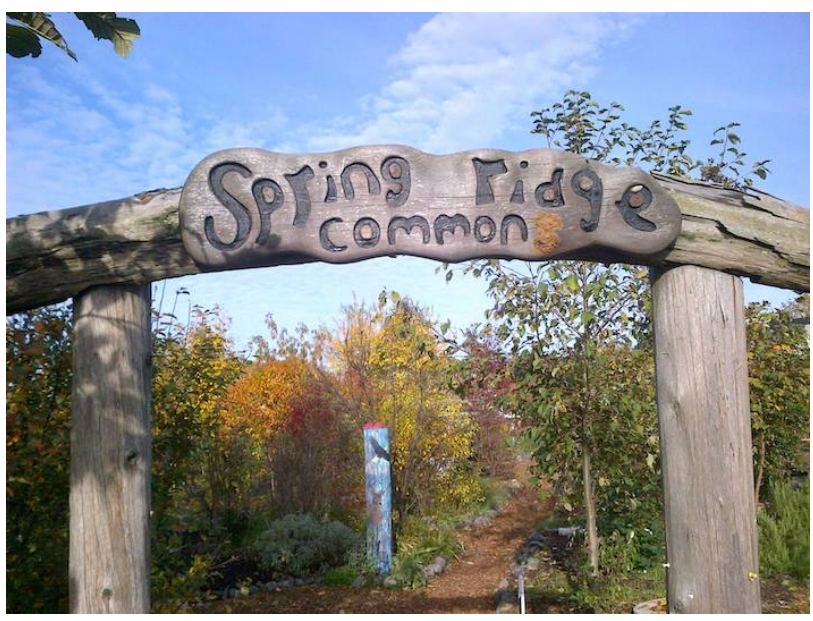

Figure 9: Spring Ridge Commons Welcome gate. Photo credit: Jennie Barron

and retired seniors, addicts and new mothers, anarchists, artists, and people who have no homes. Former SRC steward Matthew Kemshaw, narrating a video about Spring Ridge, describes it as being "at the crossroads of several community groups... where the rich interact with the poor, the homeless with the housed, the yuppie with the hippy, and the young family with the mentally ill” (Kemshaw, 2011). ${ }^{72}$ He envisions Spring Ridge as a common space where people can experiment with novel relationships to land and other people - a social oasis as much as a natural one. The learning that arises from their interactions is thus cultural as well as ecological; the novelty of the environment at

\footnotetext{
${ }^{71}$ The Community Green Map is available at http://crdcommunitygreenmap.ca/location/springridge-common

${ }^{72}$ That lovely 8-minute video of Spring Ridge is available at https://www.youtube.com/watch?v=IBEHwoV5zzA\&feature=player_embedded
} 
Spring Ridge helps people step out of "fabricated social roles or hierarchies"; it helps them "construct new meanings and identities in true community" so they can become instead, "simply human" (Kemshaw, 2011).

Since 1999, the School District has leased the land (three city lots) for $\$ 1 /$ year. From 1999-May 2007, the Fernwood Community Association held the lease; from May 2007 to Fall 2010, LifeCycles Project Society held the lease; and since Fall 2010, the Fernwood Neighbourhood

Resource Group

(NRG) has held the

lease. Fernwood NRG

is a social enterprising

non-profit that is run

$b y$ and for the

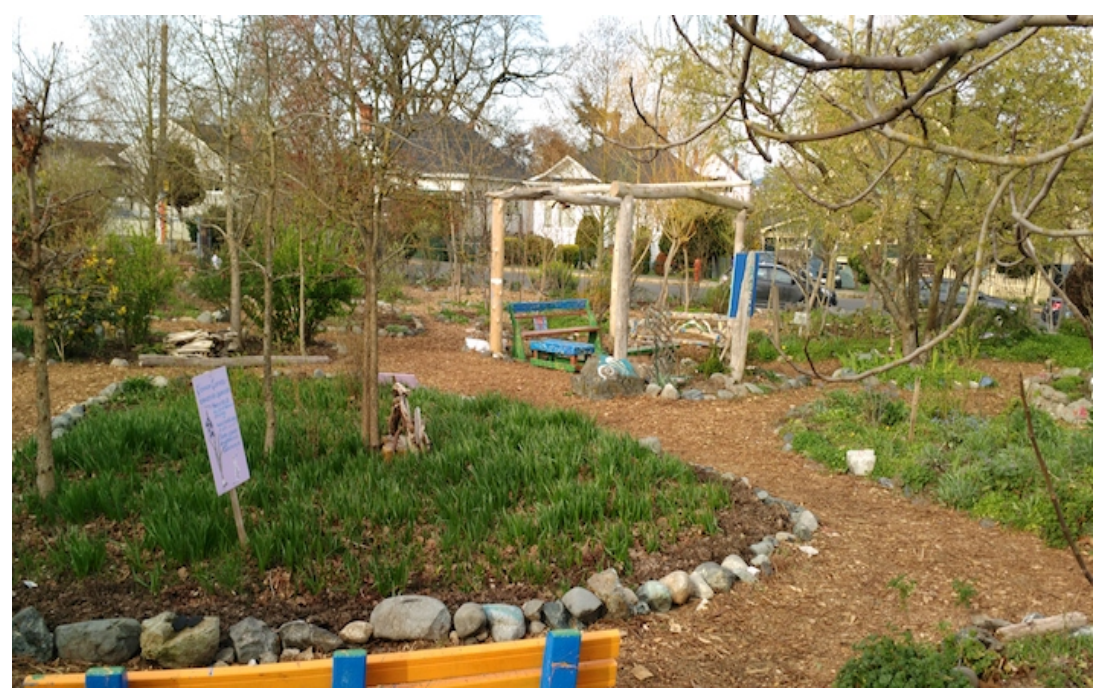

residents of

Figure 10: Partial view of Spring Ridge Commons, with camas field in

Fernwood. ${ }^{73}$ It offers foreground. Photo credit: Jennie Barron

family programs, including a Good Food Box, and regular by-donation Monday night community dinners from which no one is ever turned away for inability to pay. In support of their food programs, they cultivate a kitchen garden and a young community orchard

\footnotetext{
${ }^{73}$ Fernwood NRG also offers childcare services and operates two apartment buildings providing affordable housing to a total of ten local families, as well as the Cornerstone Café, a beautiful and popular coffee shop/bakery described on the organization's website as "Fernwood's living room". In addition, the NRG organizes an annual music festival; an annual celebration of local food and drink; and numerous sustainability initiatives across all the NRG's sites.
} 
planted just outside the Fernwood Community Centre (one of the four secondary research sites I profile briefly at the end of this chapter).

Historically, relations between the leaseholder and the main stewards of SRC, and between the stewards, some users, and some neighbours have been marked by conflict. Starting out as a guerilla gardening project, SRC did not have the full support or explicit permission of the site's leaseholder (the Fernwood Community Association, or FCA) when it began, and the volunteer initiators/stewards were well aware of that (Mallett, 2012, p. 84-85). It was only through the development of a personal relationship between Geoff Johnson and one of the board members of the FCA, an ally, that a bridge was built between the stewards and the leaseholders, allowing the project to continue through those first seven years (ibid, p. 82-83). Between 2007 and 2010 there was a period of relative calm while LifeCycles held the lease. Then, in 2010, LifeCycles determined that they could no longer afford to pay the water bill to the City, and the Fernwood NRG took over the lease and associated responsibilities. With the transfer of the lease to the Fernwood NRG came a division of labour between the leaseholders, who had authority over what would happen at the site, and who were now legally responsible, and the volunteer stewards, who did all the work on the ground.

A good deal of conflict through the years has related to site maintenance and safety - or the lack thereof. Organizers of the Commons had initially hoped that those who enjoyed Spring Ridge's relaxing atmosphere and who harvested from its many edible and medicinal plants might spontaneously lend a hand to maintaining it, too. According to founder, Geoff Johnson, the organizational structure was intentionally left open "as a 
social experiment in cooperation" (Mallett, 2012, p. 72). Specifically, stewards believed that the space should be maintained on the basis of "covenantal services" - i.e., those that are done for free and are not commercialized - because they associated any notions of exchange with corporatism, and written contracts with a lack of trust (ibid, p. 69).

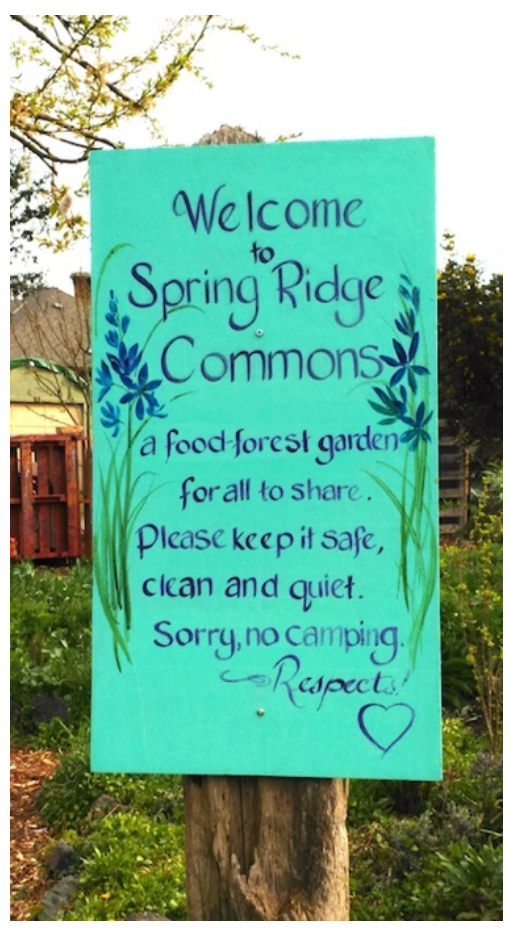

Figure 11: Welcome sign. Photo credit: Jennie Barron
After the departure of LifeCycles' Matthew Kemshaw ${ }^{74}$ in 2009, a steering committee of seven people took over at SRC, all of them food activists or growers with some training in permaculture. They shared a goal of distributed leadership - sharing power and responsibility and making decisions as a group. This was understood to be in keeping with sharing land in common, as steering committee members rejected the authoritarian leadership they associated with private property ownership (ibid, p. 74). While the shared leadership vision worked well initially, it did not stand the test of time. In the words of one steward,

\footnotetext{
${ }^{74}$ Matthew Kemshaw has been associated with Strathcona Community Gardens, Spring Ridge Commons, and most recently, since being hired as LifeCycles' Executive Director in 2017, Welland Legacy Park \& Community Orchard. The soft-spoken Kemshaw has had a remarkable influence on the community orchard/gardens and larger food scene in Vancouver and Victoria. This points to the impact that key individuals can have on the development of not only individual projects, but movements - in this case, the community orcharding movement, which appears to be more highly developed in Vancouver and Victoria than elsewhere in Canada. Something similar could be said about Geoff Johnson, who, while not directly associated with other community orchards, is probably the person most responsible for the development of the concept and vocabulary of "commons gardens" in Victoria, which are now widely recognized in that city, if not elsewhere.
} 
Tamara, "it kind of dissolved because nobody really had the responsibility and people had all these other commitments where they had to show up" (Mallett, 2012, p. 74).

Currently, stewards host monthly "Bee in the Garden" work parties on Sundays, at which they share tea made from the plants grown on the Commons, while gently recruiting volunteers. While a great many people have come through the site, and many have had a hand in caring for it over the years, Spring Ridge has relied greatly on the extreme dedication of a handful of self-appointed stewards to carry most of the burden of ongoing site maintenance. ${ }^{75}$ The all-too predictable result has been burnout, leading to what Fernwood Neighbourhood Resource Group Executive Director, Lee Herrin, has described as a "long-term boom-bust cycle of volunteer energy and resources" (in Howard, 2014). During low-energy times, the garden has become overgrown and almost unmanageable, leading to all manner of social ills and high conflict between neighbours, especially those whose properties face or border the Commons, and stewards, who are driving the vision for the permaculture food forest. While the former share a sense of neighbourly pride in the space and property they use and look upon daily, the latter tend to be more ideologically driven, "motivated by their belief in the site's potential as a food source, a learning environment, and a community space" (Mallett, 2012, p. 66). Between these groups, there have been differences of opinion over not just how much maintenance gets done, but also how much maintenance is needed at the Commons. In part, this is attributable to the ethic and ecological principles underlying permaculture (and its

\footnotetext{
${ }^{75}$ SRC's Facebook page has over 2100 followers! Many volunteers come via other programs e.g., the Greater Victoria Green Team, University of Victoria geography students, Transition Victoria, etc.
} 
COMMUNITY ORCHARDS AS NEW URBAN COMMONS

different, less ordered, less human-centric aesthetic). As one Commons user, Trevor, remarked about the appeal of permaculture, "You don't have to maintain it; you just harvest" (Mallett, 2012, p. 54).

The most notable conflict occurred during the spring and summer of 2014, when the tolerance of neighbours for the seemingly intractable problems reached a breaking point. The site was exuberantly overgrown, with some trees having grown from 4 to 40 feet tall in the years since they were planted and bushes now so large and unruly that they were providing hiding spaces for covert, even criminal, activity. At least once, an unconscious person was found lying in those bushes, too. Unsurprisingly, the site had accumulated a great deal of garbage and junk, which in turn was attracting rats. Then there was the open use and trade of street drugs, with their associated dangerous paraphernalia (i.e., needles) posing threats to other garden users and passersby, and the fear that users might be selling drugs to children. The presence of overnight campers also caused serious hygiene problems because of the accumulation of hazardous combustible materials and the lack of toilets on site.

The School District, City Council, City staff, Victoria police, and staff of the high school just down the road had all expressed concerns about Spring Ridge Common, generating substantial negative media attention. Finally, a group of neighbours took it upon themselves to act, coming in with their own tools to prune back the site, remove the garbage, and dismantle the main building structure (which was in poor shape). One neighbourhood resident, a middle-aged man by the name of Ed, took it upon himself to 
work from dawn until dusk, every day for many weeks, actively remediating the site, repairing irrigation and removing weeds and grass. But not everyone was happy. Some people associated with the gardens felt that the neighbours had gone too far, and they were outraged. ${ }^{76}$

Among the principles of the Fernwood NRG is a commitment to "ensuring neighbourhood control or ownership of neighbourhood institutions and assets" (Fernwood NRG, 2014). At the time, it is probably fair to say that questions were in the air about the degree to which Spring Ridge Commons really was a neighbourhood asset, and about who was in control. So on September 24, 2014, Lee Herrin, the Executive Director of Fernwood Neighbourhood Resource Group (FNRG), the legal leaseholder, hosted a public meeting at the Fernwood Community Centre. In less than a month, the lease with the School District was to expire, and the FNRG's board of directors needed to determine whether the will existed in the community to keep Spring Ridge Commons alive, or, if not, what alternate uses the community might want for the site.

Approximately 50-60 people attended the public meeting, speaking with remarkable selfrestraint, compassion, patience, and mutual respect. ${ }^{77}$ Collectively, they expressed the desire to have safety and order in the commons, while still maintaining it as a foodproducing shared green space, open to all. While many people no doubt felt relieved at the outcome of the meeting, the question remained: What to do to ensure the ongoing care of the Commons?

\footnotetext{
${ }^{76}$ Comments from this period have since been deleted from the SRC's Facebook page.

${ }^{77}$ The video of this nearly two-hour meeting is available on YouTube (see Howard, 2014).
} 
In the spring of 2015, the NRG hosted a second public meeting to discuss a fresh start for Spring Ridge Commons. In the intervening months, the City of Victoria had agreed to provide a small amount of funding (\$6,000 each) to a half-dozen existing community gardens and orchards in the city, to support part-time volunteer coordinators to oversee and ensure maintenance of the various sites. When I first visited Spring Ridge Commons in 2016, the site appeared beautiful, well maintained, and safe.

Interpretive signage was abundant and the site was

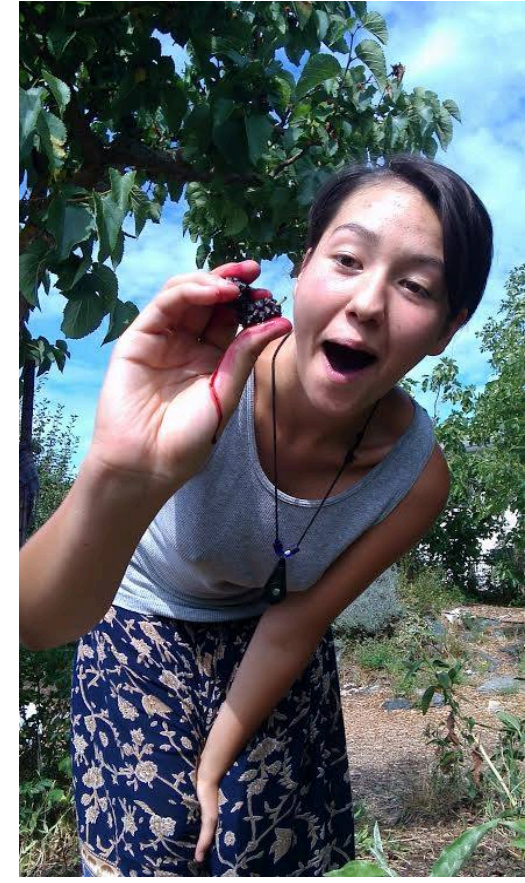

Figure 12: Mulberries! Photo credit: Linda Chan being regularly frequented by music-making young people, gardeners offering peace prayers, and neighbours engaged in meditation. As to the future sustainability of Spring Ridge Commons, only time will tell.

\subsection{Ben Nobleman Park (Toronto) "And we became a park!" http://communityorchard.ca/}

In June of 2009, a little orchard of 14 trees took root in an underused city parkette across the street from the Eglinton West subway station in Toronto. In the nine years since then, this little orchard has survived many challenges, including disease infestations so serious that many of the trees had to be torn out and replaced, followed by large-scale theft (on the eve of the first large harvest of disease-free cherries, no less!). But the Ben Nobleman Community Orchard has endured and now thrives, thanks to the persistence of a small 
group of plucky volunteers, recognizable in their matching, royal-blue, work-party Tshirts.

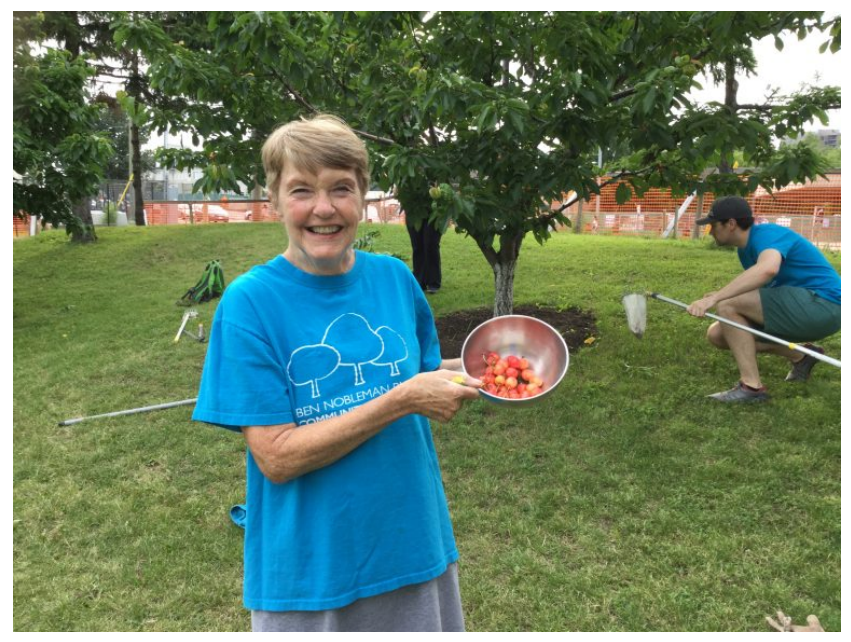

Figure 13: Volunteers Lynn and Alex at cherry harvest time. Photo credit: Susan Poizner

Initiators of the Ben Nobleman orchard have always seen their project as being about much more than fruit or trees. In addition to producing food, their other worthy goals included recognizing and educating locals about the site's history; enhancing neighbourhood social bonds; and bringing life to the park itself. The establishment of apple, apricot, plum, and cherry trees on the site recalls one chapter in the site's history, in the early decades of the $20^{\text {th }}$ century, when commercial orchards flourished in the now-residential neighbourhood. ${ }^{78}$ These were lost gradually in the post-war years to encroaching development, and while many local streets bear names recalling the area's orcharding history, community orchard organizers sensed that few residents were aware of the connection. Also aware that many neighbours did not know each other, and that Ben Nobleman Park was seriously underutilized, organizers Susan Poizner and Sherry Firing aimed to revitalize both the park and the neighbourhood; to that end, they have organized and hosted blossom and fruit festivals, neighbourhood picnics, potlucks, educational workshops, and other highly successful social events. The first Harvest Festival drew an astounding 400 people! The park is now a unique and colourful place: a brightly painted

\footnotetext{
${ }^{78}$ There are also paw-paws now in Ben Nobleman Park, though it is highly unlikely that any pawpaws were planted over a century ago!
} 
concrete bunker with a green (growing) roof acts as a toolshed, and a heavy 20-foot harvest table made from reclaimed historic lumber from Toronto's original dockyards welcomes young and old to feast together.

While the social dimension of the Ben Nobleman Community Orchard has always been of primary importance - the fruit trees being a vehicle for developing community - Susan Poizner's attention to the horticultural needs of the trees is unrivalled. A beginner when she and Sherry started the project, Susan educated herself on fruit tree care to such a great extent that within a few years she had started a blog and podcast, written a how-to book on the subject, and had begun consulting and offering trainings to others, both in person

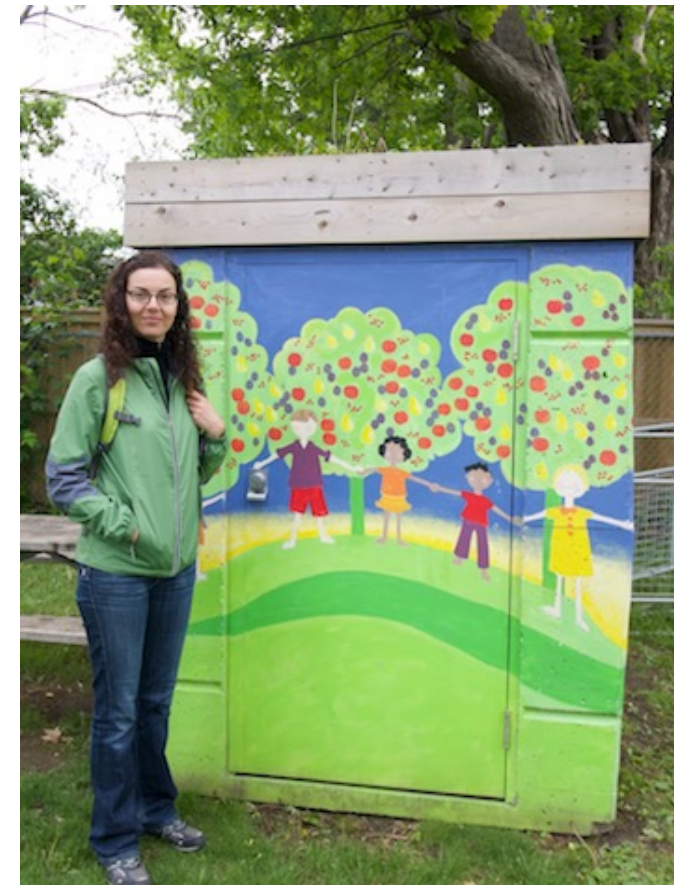

Figure 14: Ben Nobleman Community Orchard co-founder, Susan Poizner Photo credit: Jennie Barron and online, as part of her not-for-profit organization, Orchard People. ${ }^{79}$ Since 2014, Susan's book, website, podcast, radio show and online fruit tree care courses have earned her many awards - from the North American Association for Garden Communicators and the Garden Writers' Association - as well as the Queen Elizabeth II Diamond Jubilee Medal for community service. Ben Nobleman Park has been Susan's incubator, her lab, her inspiration, and her legacy.

\footnotetext{
${ }^{79}$ To learn more about Susan's organization, see https://orchardpeople.com/
} 
What sounds like a wonderful success story now did have a rocky beginning. Organizers had taken pains to distribute flyers to homes within several blocks in all directions, and to organize a meeting, hosted by City Councilor, Joe Mihevc, to explain the proposal and answer questions. Still, a small handful of neighbours resisted the idea of fruit trees in their local park and spread misinformation about what they feared would transpire if Poizner and Firing were allowed to go ahead with their project. Alluding to the potential for messiness and voicing an unfounded fear that the fruit trees would leave no space for other park uses, these three or four angry neighbours started a petition to try and stop the project. A second community meeting was called, this time held at the local synagogue (this being a largely Jewish neighbourhood). According to Poizner, it didn't start off well: "[T]he synagogue had security and they had to check your bag as you went in. But people thought it was not because it was a synagogue but because people were so angry about the fruit trees that they might bring in a weapon or something!"

Fortunately, things improved. Organizers had listened to the petitioners' concerns and brought in experts to this second community meeting to speak to each of those concerns and see that critics' questions were answered. The original plans for 40 trees were scaled

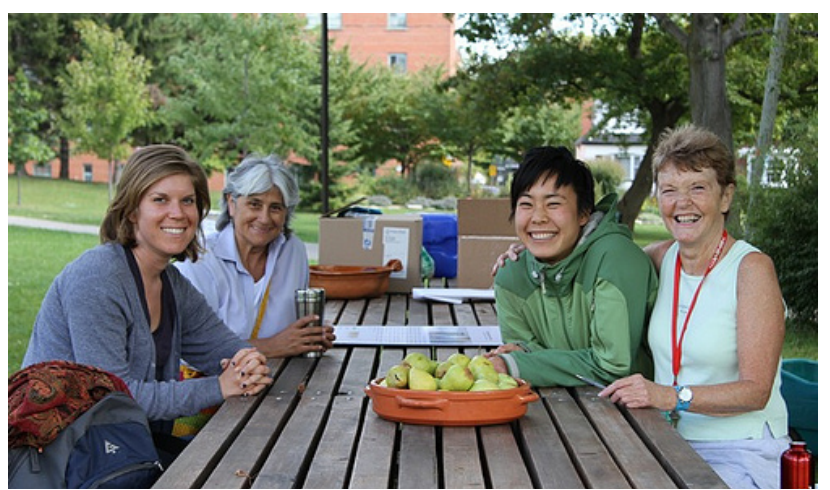

Figure 15: Ben Nobleman volunteers enjoying their harvest table. Photo credit: Susan Poizner back to 27 (and later, just 14) and relegated only to the park perimeter (Porter, 2009). But in the end, Poizner credits the opposition by this small but very vocal group for helping ensure the long-term success of the orchard: "I 
have been so meticulous with those trees! I don't want to prove those opponents right. So those trees have been beautifully cared for. If there's a diseased tree, we dig it out, we throw it away." Ironically, one of the first local residents to make use of the 20 -foot harvest table was one of the project's fiercest opponents, who used it for her child's birthday party. Even that small symbol of reconciliation has been validating for Poizner: "You know...just a little bit of approval shows that we did manage to work through it. It was bitter and ugly, but we did work through it."

Like many other community orchards, Ben Nobleman's is a story of transformation. Once a "dog-poop park", used mostly by local apartment dwellers as a place to take pets to do their business, as well as by drug dealers and their customers, Ben Nobleman has come to life in the past nine years. In fairness, the park's revival is not all due to the efforts of a few community orchardists; the City of Toronto also installed a new playground. But the orchardists - who also took over maintenance of a large garden bed, replacing tired, diseased junipers with vibrant, colourful perennials - have certainly played a key role in improving the site and making it meaningful for residents, an asset to the neighbourhood. Poizner recalls a man thanking her for her many long hours of hard work, saying, "You know, before the orchard, this park was nothing, and now it is everything." 


\subsection{Strathcona Community Garden (Vancouver) A green oasis in the city http://strathconagardens.ca/}

The nearly 3.5-acre Strathcona Community Garden is a volunteer-managed, public-access, beautifully verdant growing space in East Vancouver. It exists to provide a place for urban residents to grow food; to improve wildlife habitat in the city; to educate the community on organic food-growing, composting and sustainability, through demonstration, workshops, and tours; and to offer a nurturing green space for area residents to enjoy.

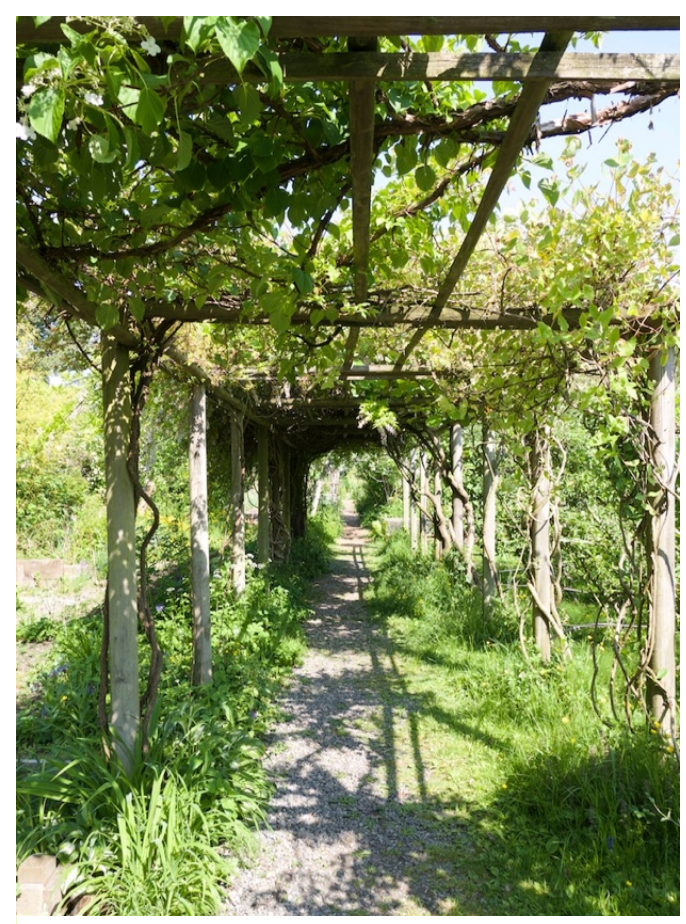

Figure 16: Strathcona Community Gardens espalier and grape arbor.

Photo credit: Jennie Barron

Bordering the poorest section of the city, the site was once an informal dump where decades of industrial and domestic waste accumulated. Today, it is testament to the power of citizens to wholly transform blighted land into a cherished urban oasis. A study of the site's history tells a tale of complex and contested power relations in the city, as documented by UBC graduate student Nedjo Rodgers in his outstanding 1995 masters' thesis. Having begun his research with curiosity about why the site had sat apparently undeveloped for so many years, Rodgers writes about what he subsequently learned, as follows:

Far from being the casual outcome of accumulated neglect, the vacant and degraded state of the future gardens sites reflected decades of intense struggles over the definition of place. These struggles involved questions of capital, class, ethnicity, and gender and drew in various and conflicting interests within the local state...But throughout we see also the strength of marginalized communities, 
challenging those powers or acquiescing to them, but participating actively in the shaping of place. The resultant geography bears the obvious scars of decades of abuse and neglect. If we look more closely, however, it reveals also the now hidden work, dreams, and struggles of generations of local citizens. (Rodgers, 1995, p. 72).

In the following few pages, I briefly re-present some of Rodgers' excellent history of Strathcona, to illustrate what he means by these words.

Two hundred years ago, the site where Strathcona Gardens now flourishes was composed of tidal flats and an estuary, surrounded by coastal rainforest; it formed part of the unceded traditional territories of the Musqueam, Squamish, and Tsleil-Waututh First Nations - a fact recognized by Vancouver City Council in 2014 (McCue, 2014). In spite of ongoing Indigenous occupation and use, British colonizers moved in during the midlate $19^{\text {th }}$ century and established the townsite of Granville. By 1885, the Canadian Pacific Railway had reached the coast, transforming the little townsite into a bustling urban centre. Intent on promoting industrial development, the colonial government conferred title to the land on two railways: the Canadian National Railway (CNR); and Great Northern Railway (GNR).

Beginning around 1915, the flats were mostly drained (to create more land for the railways) but were still used as a dumpsite for waste; dumpers simply counted on the ocean tides to carry it all away, though eventually these would not be enough. Observers of animal activity at the dumpsites referred to it as "a sort of rat theatre" (Marlatt and Itter, 1979, as cited in Rodgers, 1995, p. 77). As Rodgers notes, pumping and filling was to continue for decades, with areas of bog and open water remaining stubbornly resistant 
to men's efforts to reshape nature $(1995, \mathrm{p}$. 76). The open, stagnant water pools were well known for their "rank odour" - and one was vernacularly named "Chocolate Pool" for its dark colour - yet local children still regularly swam in them (Rodgers, 1995, p. 77). Noting that Vancouver's mayor, G.G. McGeer, described Strathcona as "a cesspool" in 1938, and comparing descriptions of Vancouver's East End in the 1930s to those of industrial England in the 1840s, as cited by Engels (1953[1844]. Rodgers writes,

The putrification of the False Creek Flats is the cultural hegemony of a British elite etched in urban space. The East End becomes a literal sewer in the same way that it is designated the repository of moral "filth"- prostitution, gambling, bootlegging, and so on.” (1995, p. 78)

Amidst and in spite of the wastes, the area developed into a vibrant working-class residential neighbourhood, where settlers picked wild mushrooms and pastured livestock on the land. Strathcona, as a neighbourhood, became home to "diverse immigrant communities: Italians, Jews, Chinese, Slavs, Japanese, African Americans [sic]” (ibid, p. 76). The neighbourhood's multicultural composition was no accident, but a product of deliberate efforts to keep non-British residents out of

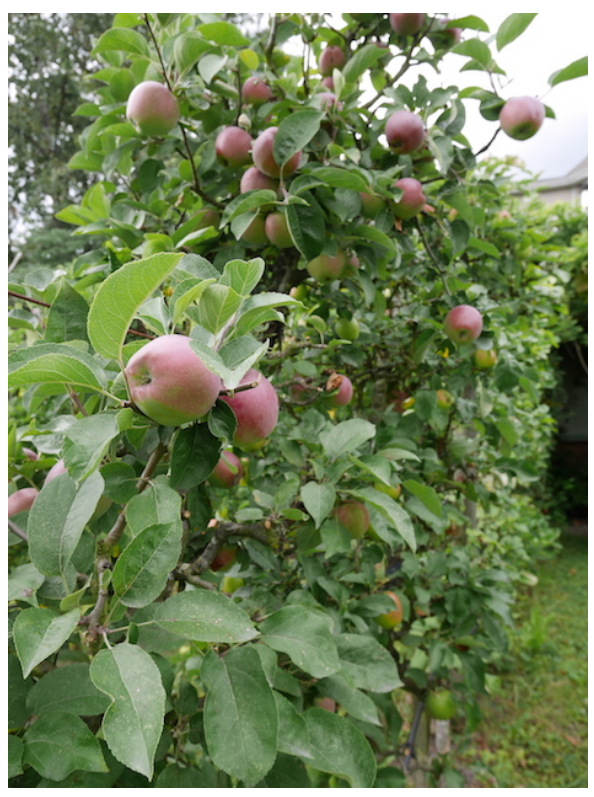

Figure 17: Apples at Strathcona Community Gardens

Photo credit: Jennie Barron the more affluent areas to the west (e.g., Shaughnessy, Point Grey, the West End).

Strathcona Park, as a public green space, had many starts, hit many walls, and took many years to come into being. As early as 1928 , local residents were using the land for allotment gardening, which expanded greatly during World War II, though a large section 
of the site was also taken over by the Canadian government for use as a military training field. The first initiative to establish a city-sanctioned recreational park on the site began in 1936, when the GNR fell on hard times and was unable to pay back-taxes it owed to the City. The ratepayers of Ward Three proposed that the City forgive the outstanding taxes in exchange for GNR donating the land in between the railway lands proper and the residential neighbourhood (Rodgers 1995, p. 79). The City agreed, but in 1940, on the verge of the park's apparent realization, the country entered WWII, and plans for the park were shelved.

Following WWII, the work of filling and drying the land resumed, with alternating layers of soil and garbage used as fill. By 1950, the area once reserved for the park had been halved, but ballfields had at least been developed - a cause for celebration, even if not all were open to the public. ${ }^{80}$ The 1960 s saw rampant urban redevelopment - solving poverty by eliminating the poor - and two waves of "slum clearance" in Strathcona, an undertaking that had strong and distinctly racist overtones as the area had seen increased settlement of Chinese since the repeal of the Chinese Immigration Act in May 1947 (Rodgers 1995, p. 85).

In the 1960s, the City sought to use the site as a public works yard, but local residents, growing ever savvier in fighting for their rights, resisted and won. Their success was repeated in 1971, when protesting residents halted plans to route a new highway through

\footnotetext{
${ }^{80}$ The best ballfield was reserved for the BC Electric Employees' Softball League, because they paid for the lights and bleachers (Rodgers, 1995, p. 84) - just one example of capital shaping public space in Vancouver.
} 
the southern edge of the park. In 1974, the potential, not-yet-realized park was reduced in size, when the City built a fire station on the west side. But in 1977, local children were finally granted the playground the community had been demanding for over four decades. In 1982, the land was designated as a permanent city park.

In 1984, in recognition of the City of Vancouver's upcoming centennial in 1986, and in

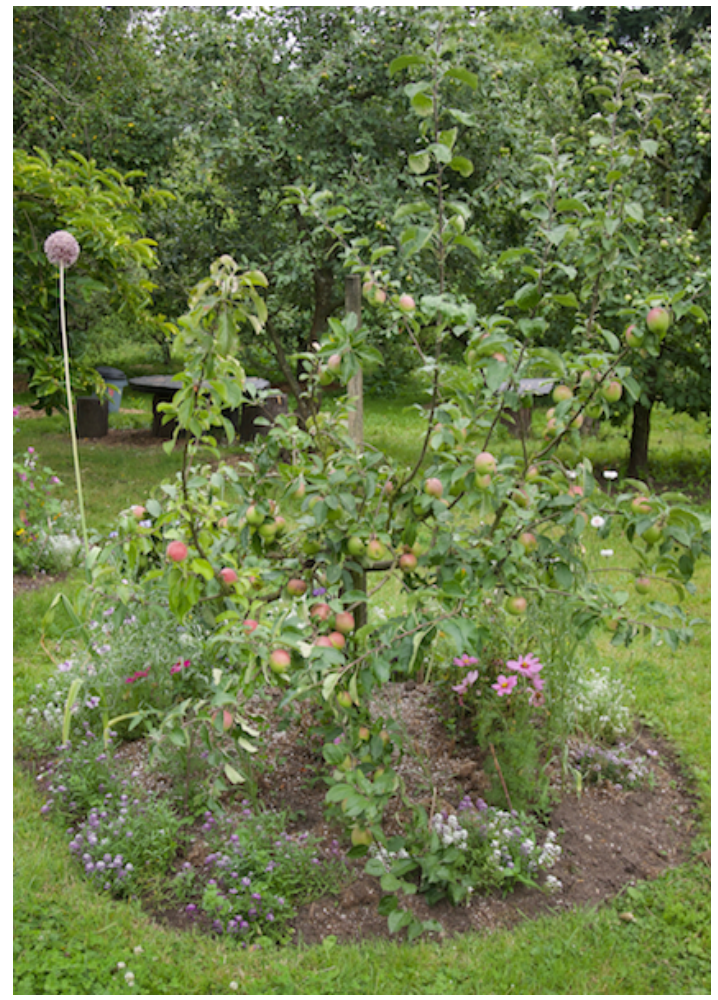

Figure 18: Young apple tree, surrounded by perennials. Photo credit: Jennie Barron

response to a proposal by local urban agriculture group, City Farmer, the City of Vancouver endorsed the creation of a network of community gardens, intended not only to promote environmental values like saving energy and recycling, but "to preserve "the people's common interest in the land they live on and use' via 'the physical intermingling of town and country" (Rodgers 1995, p. 94) (a direct reference to Ebenezer Howard's seminal 1902 work in the field of urban planning, Garden Cities of To-Morrow, which I discuss in Chapter 6). In 1985, work began on what would eventually become Strathcona Community Gardens. A West End resident by the name of Leslie Scrimshaw was hired by City Farmer; she proved helpfully naïve to the local politics of the East End neighbourhood (ibid). She was joined in this work by UBC landscape architecture students and their professor, Dr. Moira Quayle. Local residents also moved mountains to 
realize the dream. Early garden originators included Ellie Epp, a young mother; Mr. Li, a mathematics-professor-in-China-turned-butcher upon immigration to Canada; and Henry Westergaard, a reclusive senior who lived in a notoriously skanky $\mathrm{SRO}^{81}$ in the Downtown Eastside (DTES) and who had already gardened the area by stealth, planting potatoes by the railroad tracks. More intrepid garden enthusiasts soon joined them, landscaping the space with the help of rain gutters, bricks, joists, and greenery salvaged from nearby house demolition sites (ibid, p. 96-97).

In 1987, the City moved to take back one quarter of the gardens for a seniors' facility, to be built by the Chinese Freemasons. It was the section of the garden worked by Mr. Li, Ellie, and Henry, the first and most established garden plots. Against the gardeners' moral claims to property ${ }^{82}$ through their thousands of hours of sweat equity, City Council (dominated by the business-friendly Non-Partisan Association) evicted the gardeners (whom they regarded as squatters and vagrants) and gave the land to the Freemasons, a group made up mostly of merchants from Chinatown (Rodgers, 1995, p. 101). Through that winter, work parties of up to 50 gardeners laboured steadfastly to move years of painstakingly built-up soils to new plots, and to re-locate their irrigation systems and the newly planted orchard of 45 young fruit trees. One weekend in early May of 1989, some 350 volunteers showed up to accomplish the massive re-location, with the aid of many neighbourhood service agencies and generous donors of everything from lumber, to catering, to childcare services. Writes Rodgers,

\footnotetext{
${ }^{81}$ SRO stands for "single-room occupancy" - jargon understood by all in the Downtown Eastside to refer to residential hotels that provide long-term housing to very low-income residents. ${ }^{82}$ This concept of the poor having a moral claim to property comes from Nicholas Blomley (2008).
} 
The volunteers [dug] thousands of meters of irrigation trenches and [laid] pipes. They haul[ed] twenty-two dump truck loads of gravel by wheelbarrow and [laid] it over the paths and irrigation lines. They edge[d] pathways with wooden borders and construct[ed] raised beds for gardeners in wheelchairs. And then, at the end of the second day, they [came] to the RayCam Community Centre to celebrate. (1995, p. 104)

Threats to the park's existence continued. In 1990, the City threatened action under the Untidy Premises bylaw, owing to the accumulated garbage and junk on the garden's southeast corner, where wild blackberry bushes frequently harbour not only vermin but homeless humans, drug paraphernalia, used condoms, and other detritus of human misery. In 1991, the City again threatened eviction so they could develop part of the park as a heavy equipment training ground. But the gardeners, wise now to the workings of the municipal machinery, armed themselves with a legal opinion from the City's Housing and Properties Department which said that the Parks Board had exclusive jurisdiction. City Council had little recourse but to agree, and finally allowed the gardeners to be. A period of relative calm followed. In 1993, the City granted the Strathcona gardeners a 10year lease, which was followed by a 25-year lease in 2005.

Notable features of Strathcona Community Gardens today include the demonstration Eco-Pavilion (incorporating solar power, rainwater collection, greywater cleansing and compost toilet), which was built by young women learning trades in a job training program in the late 1990s; the bee works, where honey is harvested and sold to gardeners; a greenhouse and nursery; an herb garden; a seasonal pond; some 200 garden plots; and a one-acre orchard. The orchard consists of an espaliered area, where dozens of centuriesold heritage fruit varieties grow in a highly managed and very compact form, their limbs pruned and trained to supportive two-dimensional wood-and-wire frames; as well as 
some 30 types of open-grown trees, producing apple, pear, plum, quince, fig, and other delectable fruits. The orchard, pond, bee works, greenhouse, and other common areas are testament to Strathcona gardeners' desire to go far beyond the usual community garden emphasis on individual plots, and to make the community gardening experience an experience of community, shared labour, and shared rewards. While not all gardeners get involved in the orchard, there is a requirement at

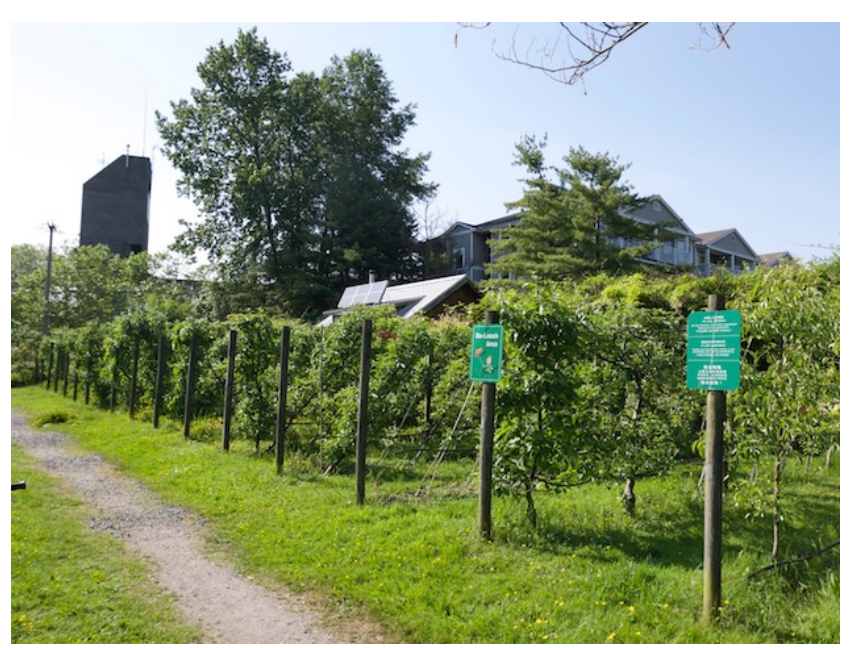

Figure 19: Espaliered area of orchard, Strathcona Community Gardens, with the Chinese Freemasons' seniors housing complex in behind. Photo credit: Jennie Barron

Strathcona that gardeners dedicate a

certain number of hours to actively maintaining common areas; this can also mean weeding and mulching the pathways, taking care of the compost, or repairing the irrigation system, which is highly prone to breakage. The garden's relatively short waiting list suggests that not all would-be gardeners in Vancouver are interested in signing on for this additional responsibility (and indeed, a small number have found this membership requirement too onerous and have chosen to leave). But for other Strathcona gardeners, the emphasis on communal areas and communal work is precisely what attracts them to join, and to stay.

As a teaching orchard, Strathcona experiments with growing methods, and orchardists share what they learn. In 2013, Strathcona's dedicated orchardists undertook a comprehensive tree inventory that identified (with Latin names) and mapped roughly 300 
trees on the site, tracing the origins of each, some of them going back several centuries (e.g., Malus domestica 'Red Gravenstein' which was traced to Denmark in 1669!). The community orchardists currently endeavour to record yields from all trees, but of course, given their high-traffic location, a fair bit of fruit does get taken (a problem not at all unique to this orchard). Community garden members are divided on what the proper response to theft should be, and even on what constitutes theft, given the public nature of the space (another widely shared problem across all orchards). I shall return to this issue in later chapters.

As of early 2018, Strathcona Park is facing a new threat, in the form of a City of Vancouver proposal to provide a new arterial road and railway overpass through False Creek Flats. Three options are currently under consideration by City Council, two of which directly encroach on the south boundary of the park. No matter which option Council chooses, the history of the park, the neighbourhood, and the gardens suggests, hopefully, that residents, gardeners, and orchardists will be resilient in the face of change, and that this little oasis in the city will endure, albeit perhaps in altered

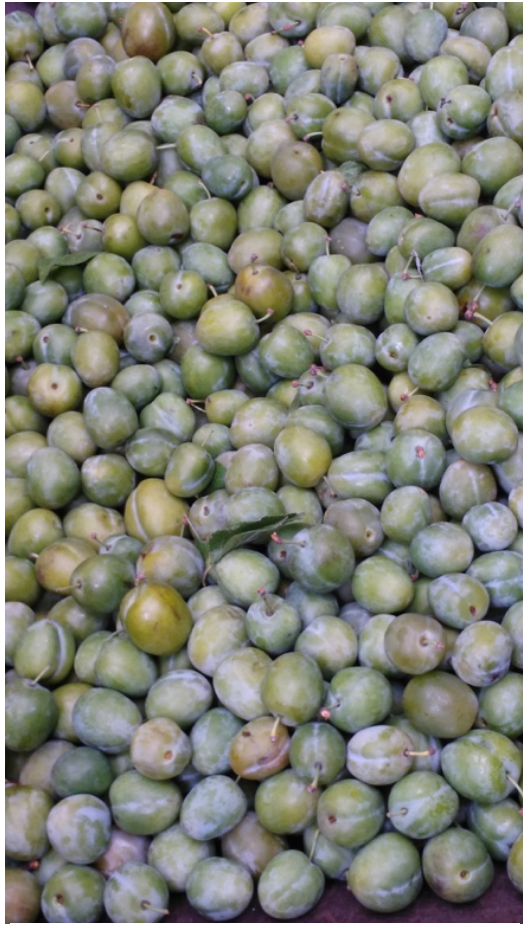

Figure 20: Wheelbarrowful of green gage plums

Photo credit: Jennie Barron form, and will continue to be a cherished and iconic piece of the geography and social history of Vancouver's East End. 


\subsection{Smaller and/or newer community orchards}

- Norquay Learning Orchard (Vancouver)

- Jonathan Rogers orchard (Vancouver)

- Fernwood Neighbourhood Orchard (Victoria)

- Banfield Park Community Orchard (Victoria)

In addition to the five main community orchards from

which I have drawn most of my interviewees, I also

visited and learned about four others, all of which are

smaller, both in size and in numbers of people

involved (at the time I visited them in 2016). Here, in

this final section of the chapter, I provide a brief

sketch of each, as a way of providing context for the

words of the one or two interviewees I spoke to from

each of these sites, and of further demonstrating the

diversity of community orchards I have studied.
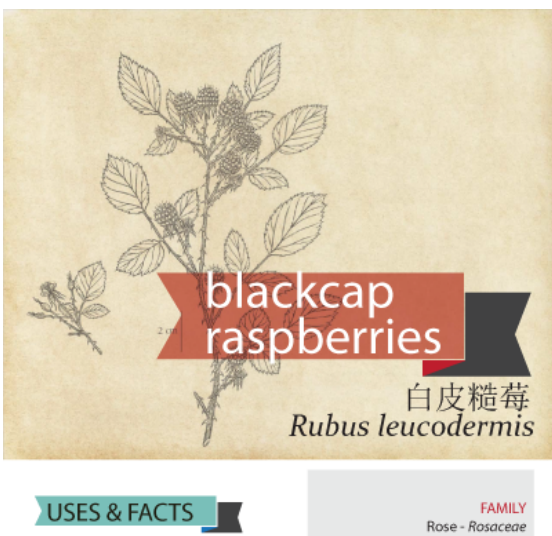

Coast Salish peoples mostly ate the fruit fresh

The Sto'lo dried the raspberries like raisins,

and the Bella Coola used it with wild raspberries to make jams

The young shoots were peeled and eaten by the Comox in the spring

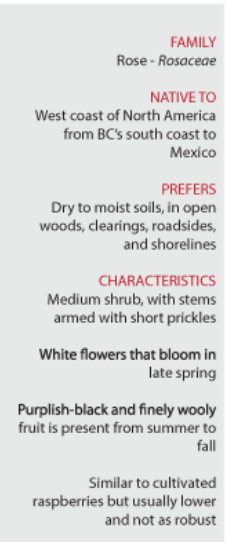

Figure 21: One of many informative interpretive signs at the Norquay Learning Orchard

\subsubsection{Norquay Community Orchard}

Norquay Community Orchard is located on a vacant lot in a residential area of southeast Vancouver, not far from Copley Community Orchard. It was established in 2010 by the Renfrew-Collingwood Food Security Institute (RC-FSI), a project of RenfrewCollingwood Neighbourhood House, located several blocks east on Joyce Street. ${ }^{83}$

\footnotetext{
${ }^{83}$ Neighbourhood Houses are a unique feature of Vancouver's social service sector. Part of the settlement house movement, they arose to meet the needs of immigrants and migrants to cities for day nurseries (childcare), English-as-an-additional-language classes, adult literacy support, social work services, and community development. Vancouver's seven neighbourhood houses now offer a wide range of social supports and recreational programming for all ages, and in many languages. The RC-FSI strives to "foster strength in our community by sharing knowledge around sustainable growing, urban agriculture, multicultural food traditions, Native plants, and issues of Aboriginal food sovereignty" (Renfrew-Collingwood Food Security Institute, 2017).
} 
COMMUNITY ORCHARDS AS NEW URBAN COMMONS

Similar to Copley, the site had been considered undevelopable, owing to the presence of an underground stream (now captured in a large pipe). Consequently, it was the City that approached the RC-FSI for help turning the site into more of a neighbourhood asset. City staff suggested it as a possible community garden, but RC-FSI Food Security Coordinator, Elise Barber, had a more innovative idea: to grow a learning orchard, a place to showcase native fruit-bearing plants and to demonstrate innovative and sustainable growing methods.

Before the RC-FSI got involved, there was already a cherry tree, two plums, a laurel tree, and a blackberry bush on the site. Since then, organizers have planted two heritage varieties of apple, and five varieties of pear, as well as fig, blueberry, kiwi, kiwiberry, red and white grapes, black and white currants, and a dozen varieties of edible berries native to western Canada. In keeping with this emphasis on teaching the public, organizers have carefully researched all featured species and created beautiful interpretive signs that highlight not only the plants' characteristics, but their traditional uses, as foods and medicines, by various Indigenous peoples, in recognition of the historical use and occupation of the area by the Skwxwú7mesh sníchim, (Squamish), $\mathrm{x}^{\mathrm{w}} \mathrm{m} ə \theta \mathrm{k}^{\mathrm{w}} ə \mathrm{y} \partial \mathrm{m}$

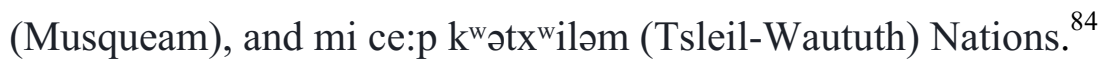

\footnotetext{
${ }^{84}$ The orthography of Indigenous languages is still evolving as language revitalization continues and technologies are developed to accommodate Indigenous languages on keyboards and in computer fonts. The spellings I have used come from the First Peoples' Language Map of British Columbia http://maps.fphlcc.ca/first_nation_index.
} 
Unfortunately, it is not clear that very many people are visiting Norquay to take in all that is offered. The Food Security Institute's other programs - i.e., Collingwood Community Garden, and the Neighbourhood House's community kitchen, food skills classes, roof-top garden, food-related films and special events - are popular, but as the orchard is not on-site, getting folks involved in maintaining it, or even just regularly enjoying it and making it "theirs", has been a challenge. For one event, CR-FSI staff bussed

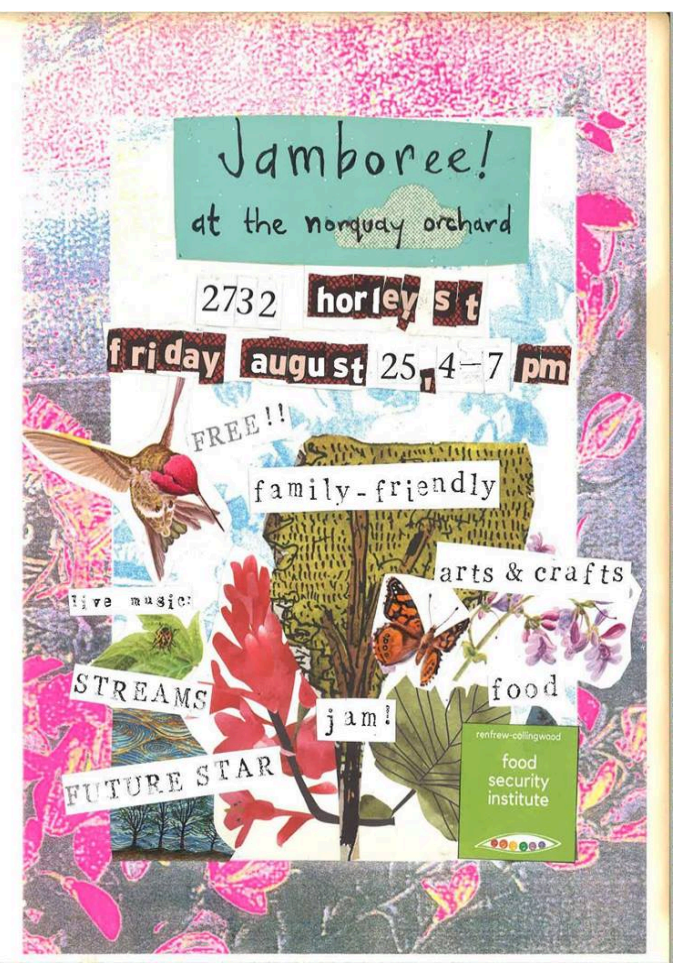

Figure 22: Poster for community engagement event at Norquay Learning Orchard, August 2017

in participants from the Neighbourhood House's other programs; at other times, they have made arrangements to involve summer program participants and school classes in site maintenance. But the initiative is all coming from RC-FSI's two staff people and a small handful of enthusiasts who have a passion for trying to make the orchard work. Significant community engagement, especially from residents of the immediate neighbourhood, still seems to elude the orchard. Still, RC-FSI staff and volunteers persist in organizing new plantings and special events that encourage social gathering in the community orchard. 


\subsubsection{Jonathan Rogers Park Orchard (Vancouver)}

Vancouver's Mount Pleasant neighbourhood is a mix of craft breweries, fashion shops, outdoor expedition stores and art studios set amidst older industrial buildings, and the 2010 Olympic Village, now turned into one of Vancouver's many housing co-ops.

Today, Mount Pleasant has a handful of open green spaces, but historically, it was one of the city's under-served neighbourhoods in that regard. ${ }^{85}$ Jonathan Rogers Park owes its existence to its namesake who died in 1945 leaving a $\$ 100,000$ bequest to the City specifically for the purpose of creating a park in a poorer part of the city. Within a fenced-off area of the park is the Elizabeth Rogers Community Gardens, named for Jonathan's wife, in recognition of her long and active contributions to the city. It was members of the community garden who planted eight fruit trees, just outside the gardens, in the open grassy part of the park, where visitors picnic, and play Frisbee, and push their children on swings.

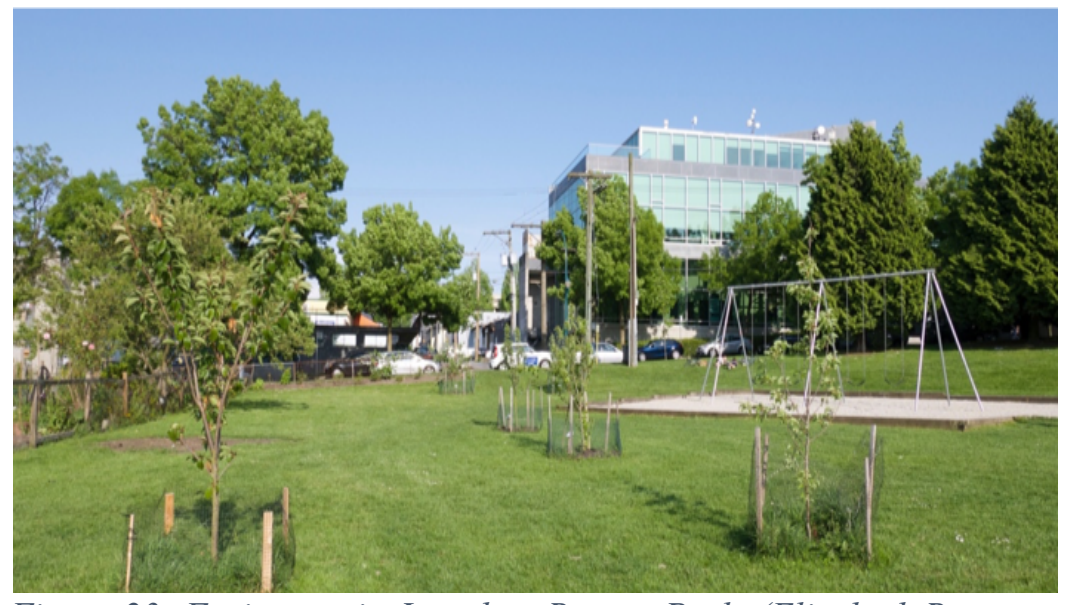

Figure 23: Fruit trees in Jonathan Rogers Park. (Elizabeth Rogers Community Garden is just to left.) Photo credit: Jennie Barron
The idea to plant fruit trees in the park came from Augusta Lokhorst and one of her fellow community gardeners, but the City was more than willing to let them

\footnotetext{
${ }^{85}$ Many in Vancouver allege that there is a significant East-West disparity when it comes to public green space. Common opinion (among those in the East End, at least) holds that the West End has always had bigger and better parks, with better facilities, and that West End parks get more attention because the population on the West side of Vancouver is more affluent. I have little doubt that this is historically accurate, but whether it is still demonstrably true today, I do not know.
} 
give it a try, as long as the gardeners agreed to water and care for the young trees - which they have done, faithfully. (Lokhorst estimates that between 12 and 18 people have had a hand in caring for the trees, at one point or another). The City's enthusiasm can be explained in part by the fortuitous timing of Lokhorst's request; it was (and still is), a key priority of the City to plant thousands of urban trees, which meant that all possible locations and ways of meeting this goal were of interest to City staff. So, in 2010, Jonathan Rogers Park joined a list of about a dozen city parks and golf courses to feature fruit- and nut-bearing trees. Since then, they have also planted a handful of blueberry bushes. Results of this municipal experiment have been mixed, with tree survival rates being generally correlated with the degree of active stewardship assumed by community groups. As of 2017, the apple, plum, and pear trees in Jonathan Rogers Park are alive, but often threatened by pests, a challenge the trees' volunteer stewards did not fully appreciate at the outset. Orchard initiator Augusta Lokhorst comments on her learning,

"Now I do see why it's not done [more often] is because you do need the resources to

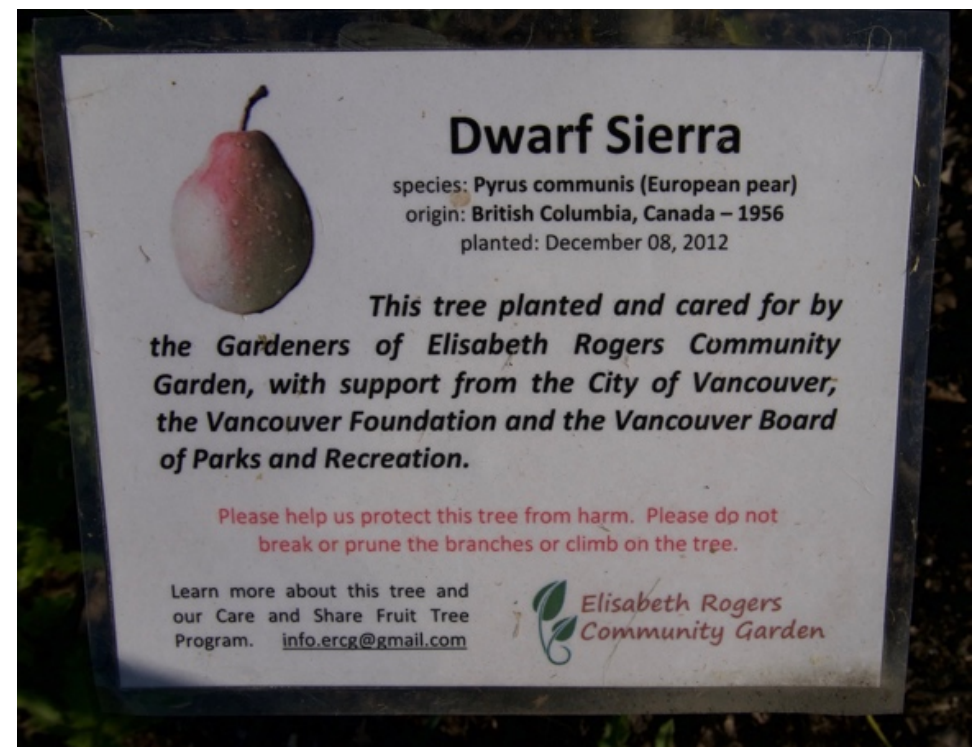

Figure 24: Signage in Jonathan Rogers Park. Photo credit: Jennie Barron maintain it, too."

It may be a stretch to call this a community orchard, with the number of caretakers and the number of trees both so small.

But Augusta sees its value in more abstract terms, as providing a metaphorical bridge between different park 
users who previously had nothing to share. Observing that Jonathan Rogers Park is frequented by many homeless people, who come because of the nearby bottle depot and the availability of bathrooms where they can wash up, Augusta observes that the trees provide something to talk about, and thereby break down barriers between people like herself and those who are frequently marginalized by society. Talking to transient people in the park has also taught her that they, too, appreciate improvements made to the park: "One man told me... that this was his park, this was his home, this was his paradise. So, he really appreciated that other people were contributing and doing work. He was all for it." Augusta has also observed homeless people displaying a sense of psychological ownership, defending the trees: "When I was being harassed by somebody in the park, when I was watering the trees, I had [a homeless person] come to my help and tell them to stop harassing me, and [say] how well we were taking care of his trees."

\subsubsection{Fernwood Community Orchard (Victoria)}

http://fernwoodnrg.ca/fernwood-nrg-programs/urban-sustainability/fernwoodcommunity-orchard/

Just outside the Fernwood Community Centre on Gladstone Avenue in central Victoria,

grow the 25 trees that

comprise the Fernwood

Community Orchard. From

their perch on three raised

benches of City-owned

land, the neat rows of

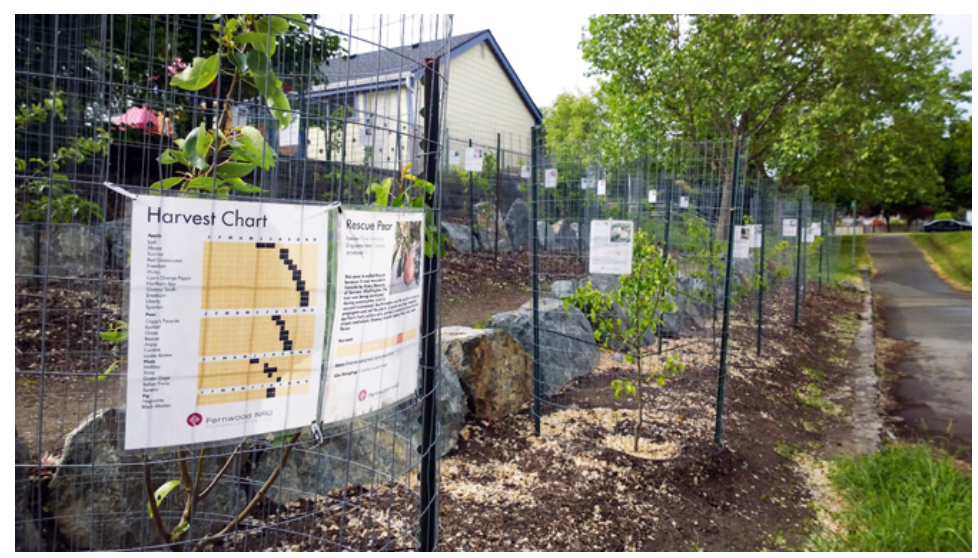

Figure 25: Fernwood Community Orchard.

apples, plums, pears and figs Photo credit: Stephanie Enevoldsen 
overlook the paved play area of William Stevenson Memorial Park, where children participating in the community centre's after-school programs ride skateboards, shoot hoops, and play tag. The orchard was planted in 2013 as part of Fernwood's food security programming, at the behest of local residents interested in growing more local food. It is one of two orchards that comprise the City of Victoria's Community Orchard Pilot Project (the other being Banfield Community Orchard, introduced below). The vision, ultimately, is to use the fruit in the community centre's programs, which include a daycare, a Good Food Box, and their Monday night community dinners.

Each variety of fruit tree in the orchard was carefully selected for its flavour, disease resistance, heritage value, and ability to adapt to climate change. Trees were then planted in Hügelkultur beds, following permaculture principles. ${ }^{86}$ The orchard is tended largely by the centre's staff, with help from occasional volunteers. In reality, this means that the work has fallen largely to Stephanie Enevoldsen, one of the volunteer coordinators hired under the City of Victoria's initiative to support existing community gardens, back in 2015. Stephanie is responsible for both Fernwood and Spring Ridge Commons (just a block away, and also affiliated with the Fernwood NRG, which runs the Community Centre); it is a job much too large for the ten weekly hours she is paid to devote to it. Needless to say, many of Stephanie's hours go unpaid, as she sees the orchard not only as her job but as a labour of love. While not envisioned as a commons, Stephanie feels the

\footnotetext{
${ }^{86}$ Hügelkultur is a method of growing, popular in permaculture, which utilizes dead, rotting wood and other organic matter (e.g., straw, cardboard, leaves, compost, wood chips) as a nutritious substrate into which young trees are planted. The word 'hügelkultur' means hill culture, but beds often begin as trenches which are then filled so full they become mounds. They hold moisture, build fertility, provide aeration, and maximize surface area for growing.
} 
orchard has the potential to become one, and she is actively cultivating a list of willing volunteers who come out for work parties and workshops on pruning, grafting, and processing. As the orchard starts to produce appreciable volumes of fruit, it seems likely that community involvement will increase.

\subsubsection{Banfield Park Community Orchard (Victoria)} http://www.vicwestfoodsecurity.org/

Banfield Park Community Orchard is an initiative of the Vic West Food Security Collective, under the banner of the Victoria West Community Association. ${ }^{87}$ Along with Fernwood Community Orchard, Banfield is part of a municipal community orchard pilot project, sparked by the City of Victoria's Official Community Plan, renewed in 2013, which encouraged increased cultivation of fruit on public lands (Palmer, 2013). Led by energetic local community organizer, Patti Parkhouse, the design and implementation of Banfield's orchard was a highly participatory undertaking. Beginning by inviting locals to indicate on maps how they used Banfield Park, Parkhouse sought both to engage the community and ensure maximum buy-in; by using residents' feedback, she and her codesigners were able to site the orchard in a part of the park that was very underused, but still visible, close to both the tennis courts and the street. Parkhouse also asked community members to suggest fruit tree types; the fifteen varieties ultimately chosen included not only the predictable apple, plum, and pear, but also fig, elderberry, and

\footnotetext{
${ }^{87}$ This same group also planted and currently maintains a commons garden at the corner of Banfield Park, as well as a tea garden, both open to the public to harvest from. The City of Victoria (2016) defines a commons garden as "a communal garden area maintained and managed by community volunteers, where any harvest produced is available to the public."
} 
mulberry, as well as edible chestnuts. The variety ensures that different fruits will be ripening at different times throughout a relatively long harvest season, and there will be a balance between fruits suitable for immediate consumption and those requiring processing into jams, jellies, and baking. Always thinking about the community, Parkhouse also chose dwarf and semi-dwarf varieties so as to make it easy for children to be involved in the harvest.

Constructing the orchard was a very collaborative affair, with the City of Victoria doing some of the work - excavating trenches for Hügelkultur beds, supplying the trees, and putting in the posts for the 8-foot metal fencing (needed to keep out the deer) - and a local landscaping company by the name of Hatchet and Seed directing a few dozen volunteers in filling the trenches and watering the saplings with a mixture of mycorrhizal fungi, activate micro-organisms, and kelp. Meanwhile, other volunteers prepared a corn roast to celebrate the planting. Local artists later designed and constructed three beautiful wooden gates to welcome people in and make the fence seem like less of a

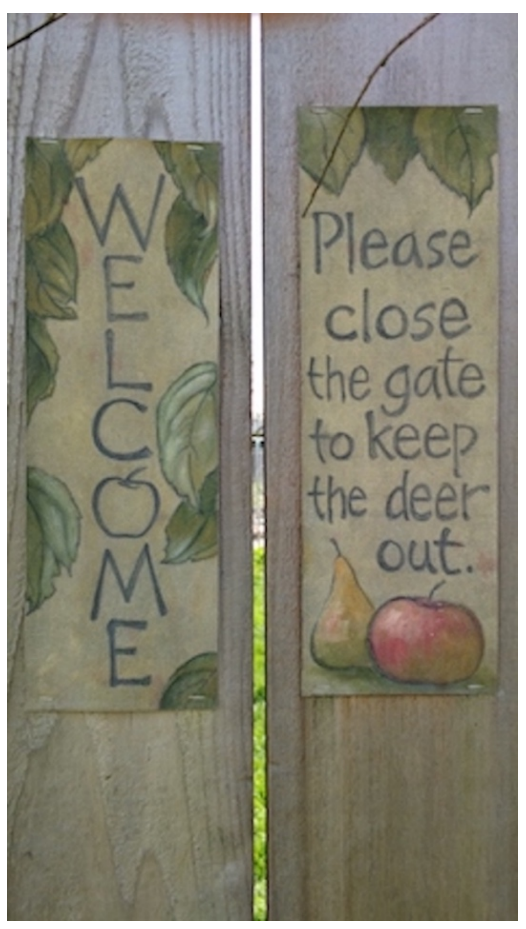

Figure 26: Welcome gate to Banfield Community Orchard. Designed by Jane Baigent. Photo credit: Jennie Barron

barrier. Of course, Patti Parkhouse and her fellow

volunteer organizers put in innumerable hours overseeing it all. 
Parkhouse's vision for the orchard was always that it be about the community as much as the fruit. As a long-time community builder with a strong interest in place-making ${ }^{88}$, she saw the project as a way to strengthen neighbourhood relations and provide a gathering place for community events, including seasonal celebrations. Since its inception, Banfield Community Orchard has hosted school group tours, seasonal egg hunts, and a very popular wassail event each January.

Derived from the olde English words, 'Waes Hael' (meaning 'be of good health') the wassail is a ceremony dating from the $16^{\text {th }}$ century. Its purpose is to awaken the fruit trees from their winter slumber and scare away evil spirits so as to ensure a bountiful harvest. Wassail festivities involve dancing; the sharing of mulled cider, soup and bread; and the crowning of a Wassail king and queen. With Patti's energy driving these wonderful events, future harvests look

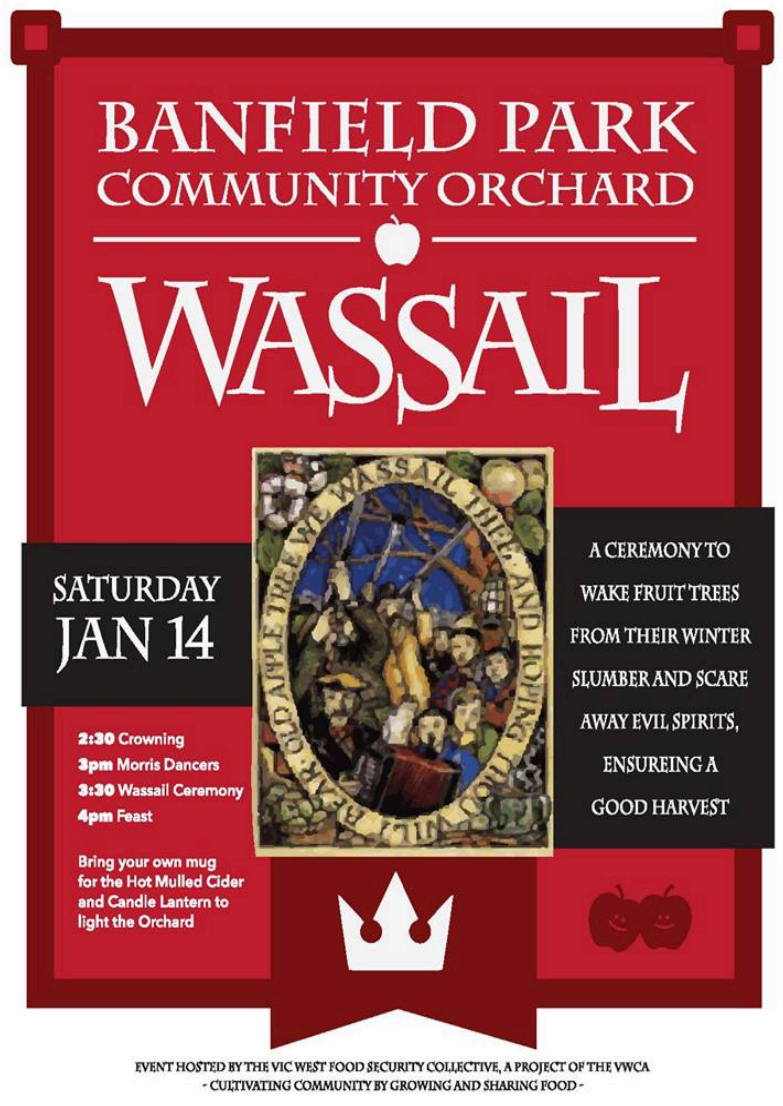

Figure 27: Promotional poster for Banfield's annual wassail celebration very promising indeed.

\footnotetext{
${ }^{88}$ Parkhouse defines place-making as the "process of taking a space and activating it to engage and gather people" (Parkhouse et al., 2013).
} 


\subsection{Conclusion}

This chapter has presented the community orchards to which I will refer throughout the remainder of the thesis. I hope that these short narratives have effectively conveyed the diversity of these sites and the people involved. It is by looking across this broad range of sites that we can gain greater insights into community orcharding, while also tempering any tendencies to over-generalize that might arise from looking only at a select few. In the following chapter, I begin my analysis of what community orcharding is - and isn't all about. 


\title{
Chapter 5 - "It's not really about the fruit!"
}

\author{
“The harvesting is nice, but it's almost incidental." - John (Welland) \\ "It's icing on the cake." - Brian (Welland) \\ "The fruit is totally secondary." - Lisa (Copley) \\ "The fruit might be the purpose for some people, but certainly not for us." \\ - Lynn (Ben Nobleman) \\ "We, the gardeners, are not waiting for that fruit." \\ - Augusta (Jonathan Rogers)
}

\subsection{Introduction}

I wrote in Chapter 2 that my research journey took me in an unexpected direction, in which I had to re-examine the assumptions upon which my initial research questions were based, and which led me to re-assess the role of food in community orchards. In this chapter, I elaborate on that notion to clarify the role of the fruit itself in these projects, before turning, in later chapters, to the issues that are most theoretically central to my analysis.

\subsection{Fruit - Where it all begins}

The most surprising - and consistent - thing that people from all community orchards told me was that neither the orchard, nor their involvement, was really about the fruit. Interviewees sometimes expressed surprise, and even a bit of embarrassment, at this admission, frequently lowering their voices to a whisper as they shared it with me. It was as if there were two things going on - the stated or imputed purpose of the orchard, and the real one - and some confusion about whether this was okay. Consider Deanna's comment: "I don't even consider what I am getting out of it, in terms of the fruit. Like, I don't even want that. Isn't that funny?" While it rocked the foundations of my entire 
COMMUNITY ORCHARDS AS NEW URBAN COMMONS

inquiry, altering the suppositions upon which all my original research questions were based, this revelation became the basis for a whole new way of seeing community orchards. In this chapter, I elaborate on this new way of seeing, and the implications I think it may have for understanding who joins community orchards - who benefits and what motivates them - and how community orcharding relates to food security, food justice, and broader social change. First, though, I describe how harvest and distribution happens now in the community orchards I studied.

At Welland, Coordinator Julia Ford hosts frequent organized harvesting events, at which she makes a strong effort to systematically record the weights of fruits harvested. At Strathcona - where, like at Welland, there are a great number of mature trees distribution of fruit happens mostly at fall work parties, led by the sub-group of gardeners who have made the orchard their pet project. But in between monthly work parties, things are pretty loose and unmanaged - "real haphazard" in the words of one member. Of the two, Strathcona seems more typical of community orchards; at most, harvesting is not managed systematically, mainly because it is so very hard to oversee or control. At most community orchards, the public has access 24 hours a day, 7 days a week, and many people walking through simply help themselves to fruit. Consequently, monitoring and measuring volumes harvested is, in most cases, extremely difficult, if not impossible. ${ }^{89}$

\footnotetext{
${ }^{89}$ At Welland, measuring the harvest is more feasible, because the orchard is in a previously private backyard, in a residential area that doesn't see too much traffic, except from the Galloping Goose bike path. In fact, Julia Ford has had to work hard to draw people in and create public recognition that the park even exists. Mature trees are also harder to pick clean without the aid of a ladder, which mitigates somewhat against casual taking by passers-by.
} 
Given that different fruits ripen at different times, a second challenge (especially in young orchards) is that the long-awaited fruits often get picked before they can accumulate in appreciable (or measurable) volumes. Sometimes, fruit is harvested by the orchardists themselves, as a reward while weeding or pruning (not a problem). At other times, the fruit simply disappears almost the instant it becomes ripe, if not earlier. As Zsuzsa (Ben Nobleman) told me, when asked if she'd eaten the fruits of her labour, "Maybe once we tried a cherry! [laughter] But they were always so small and when it was ripe, it was gone [laughter]. ${ }^{, 90}$ I heard similar comments from orchardists at Spring Ridge Commons, Banfield, and Fernwood, particularly about the most prized fruits - figs and peaches - both of which do not ripen off the tree. The frustration of the labouring orchardists is less that they aren't getting their share, and more that the fruits don't get properly enjoyed when too-eager pickers take them while they are still green. In other words, what most seems to concern orchardists is that the bounty is shared, and appreciated, in a way that matches the organizers' visions.

These visions are still becoming clear, but the outlines are discernible: these are visions of give-and-take, in which those who enjoy also contribute, and in which users demonstrate consideration for each other, by taking only their fair share. What remains unarticulated (and/or the subject of some dispute) is who has rights to appropriate the resource (to use the language of natural resource commons) - i.e., where (or even if) boundaries should be drawn to define the community that holds these rights; what degree of contribution or stewardship earns a person such rights; how the work of stewardship

\footnotetext{
${ }^{90}$ Zsuzsa was a volunteer at Ben Nobleman in the early years and has since moved out to the suburbs. Her experience is therefore also a function of how young the trees were then.
} 
should be valued and monitored (if at all); how "fair share" is determined; and who decides. These questions lie at the heart of the governance of the commons, and as such, will come up again in later chapters. For now, suffice to say it is a significant challenge for community orchardists to identify and agree on those expectations, and then to communicate them to the public.

When Copley began, organizers talked a lot about the eventual division of fruit amongst members, but as Tanya recalls, with some incredulity, "[It was] you had this harvest and you get this...But we had no fruit! There were sticks in the ground, like little tiny twigs, right? We had these plans of grandeur [but] we were in dreamland." Quickly, the vision at Copley shifted from one in which members would care for their own trees, to one in which all tree care, and eventually yields, would be shared. This better suited the collectivist leanings of many initiators, and better suited the reality of an orchard, where entire trees, even groups of trees, can be lost to a single pest (What happens then? Should the member responsible for that tree just pack up and go home?) This means that there is no direct correspondence between how much a member works and how much fruit they get. Asked whether a more tightly regulated system - so many apples for so many hours of work - would be preferable, David (Strathcona) replied, "Nah....that sounds like...I don't know if anybody'd really be too keen on that. It would be like commodification. And who'd want to do it, for one? It wouldn't be a very fun task." Instead, most orchards opt for a more generalized sharing - of the work, the fruits, and the fun. This collectivization, a beehive-type ethos, seems emblematic of the values that guide the community orchard. One way this ethos is manifest is in events at which the fruit is 
COMMUNITY ORCHARDS AS NEW URBAN COMMONS

consumed by all present, together - e.g., an apple-pressing, where participants drink the cider. It is important to have sufficient volumes to make these events a success, but beyond that, it seems that the social dimension of sharing the harvest matters more than the volume anyone takes home.

It is thus deeply disappointing when a group loses the opportunity to share in the harvest together - i.e., when large-scale theft occurs, as happened at Ben Nobleman. Four years into the project, after suffering deadly infestations of disease (including rust, black knot and leaf spot) which forced Susan Poizner and her group to cull some of their cherished trees, the orchard was poised to celebrate the first large and highly anticipated harvest of healthy cherries. But the party was rudely thwarted by a stranger raking all the trees clean the night before the big event (Porter, 2013). It wasn't even an isolated event; the thefts have continued. The community orchardists, however, have resigned themselves to these kinds of losses, and they continue to give their labour and love to the orchard, some even seeing the demand for fruit as proof their venture is needed, and is achieving what it set out to do - offering free fruit to everyone. Given such lofty aims, many even resist labelling such activity as wrong: If this is public land, and not private property, (how) can we even call it theft? they wonder. 


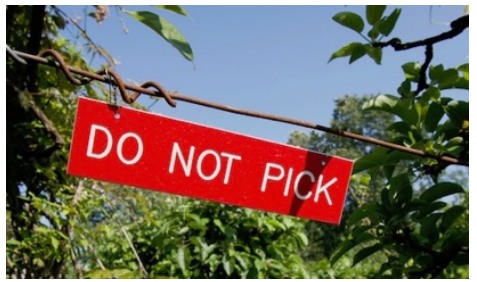

Figure 28: Sign at Strathcona Community Gardens. Photo credit: Jennie Barron

This question - of whether taking fruit grown by others on public land constitutes theft - has become a point of contention in many orchards, among members who would answer it in very different ways. At Strathcona, where the orchard is part of a larger community garden in which people tend private

allotments, the answer for most is "Yes, that is theft!" The garden has signage that makes this very clear - though, judging by the high incidence of reported thefts on the list serve, the signs do not appear to have been very effective. Signs

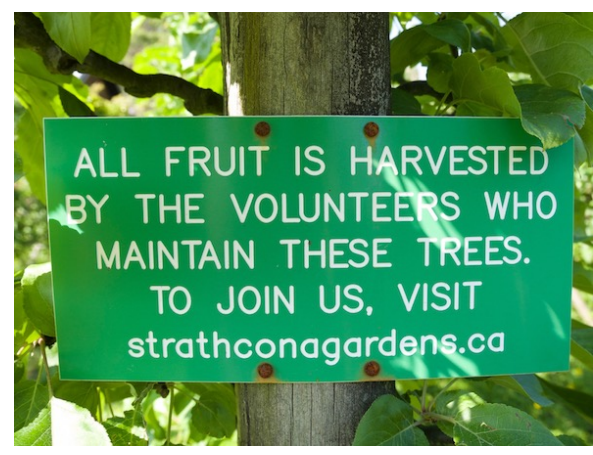

Figure 29: Sign at Strathcona (2). Photo credit: Jennie Barron

prohibiting stealing at Strathcona have also been stolen, destroyed, and tagged, leaving members divided about how to respond. ${ }^{91}$

In other orchards, I saw very little, if any, signage expressly prohibiting harvesting by the public. This is in part due to the difficulty of putting up signage, given the cost and effort to get it made, which involves research, writing, translation (often into multiple languages), graphic design, construction, and installation. On a deeper level, it also reflects a very meaningful confusion and/or disagreement within many groups about what the signs should say. Any message that might go on a sign reflects the group's shared

\footnotetext{
${ }^{91}$ Sylvia explains: "One member...put forth an idea of creating a bigger and a more forcefully worded sign at the entrances, saying 'You're not allowed to take things here. These belong to the gardeners who work hard for them. Do not steal, do not this...' whatever. But other gardeners didn't really want to pursue that at all." The idea of putting in surveillance cameras has also generated strong feelings and debate.
} 
understanding: of its purpose, of public ownership of land, of stewardship, and of community - specifically, whether it should be bounded (through membership) or inclusive of everyone. Moreover, the act of growing free food in public space challenges some of our society's current notions, making expectations even harder to communicate. Says Patti (Banfield), "the perception is that you don't pick in the park, but if it is in the park and it is a commons, then you can pick in the park...but what does picking mean?"

This is the dilemma facing Susan and her friends at Ben Nobleman. Their hard brush with reality has tempered, but not extinguished, the dream. Looking back, Susan reflects,

My vision was, I saw the park animated with people taking care of these beautiful trees with blossoms - and with fruit - and I specifically saw in my vision, young people walking through the orchard, picking an apple as they walked by. So, it's my fault! That was my vision! [But I'm tweaking that] just a little bit to have them just take one piece of fruit and wait until it's ripe, and stuff like that.

Even where a group agrees, in principle, on their position (i.e., fruit only for members or volunteers, or free for the public to sample, or free in any amount), members often struggle to find the exact words to communicate it to the public, not wanting to alienate anyone, while still being clear about the need for some give and take. Patti (Banfield) describes it as striking a balance between "community/sharing, warm and fuzzy, but still somewhat instilling some sort of personal responsibility and...fairness." In the absence of an agreed-upon understanding of all of these things, it becomes very hard for a group to agree on the message, and it becomes easier just to put off, indefinitely, the job of making signs, especially when other tasks seem more pressing. 
At Copley, with the orchard almost ten years old, fruit is now abundant. Tanya observes that where she had once been concerned that volunteers might not get their fair share of fruit, by 2016 she felt that was "almost not a conversation anymore because of the difference in fruit production between this year and last year...there's SO much! Anybody who wants some can take it." Yields are large, not only for apples from the "heritage" trees (those planted by Richard Copley) but also for apples from the newer trees, as well as cherries and berries of various kinds. Some work parties consist entirely of picking fruit, as Lisa describes:

We had wheelbarrows full of [apples] and we were grading them and sorting them. I know we sent some to the Vancouver Food Bank. And I remember when the strawberries were going nuts, I picked a ton of them one week. We literally filled buckets. The kids were helping me and we brought them over to the table where we were having the potluck. And we kind of chowed them down during the course of the lunch, and any leftovers, some of the people took some home.

At Strathcona, when a large tree needs picking, the secretary of the community gardens will send out an email inviting people to come harvest it together, at a set time. People do

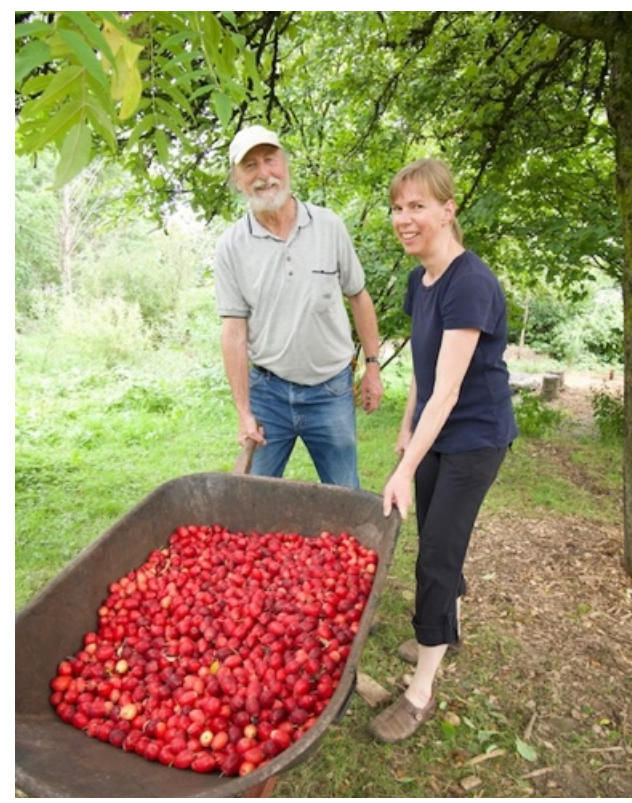

Figure 30: Members harvesting crabapples at Strathcona Community Gardens. Photo credit: Jennie Barron show up to pick and take home fruit, but there is usually fruit left over. What pickers don't take is stored in the toolshed, and the secretary emails the entire membership inviting all members to come help themselves to whatever quantities they might like. Occasionally, the fruit goes bad before it is all claimed (plums, especially, don't tolerate heat and humidity for very long). Nobody likes to see waste, but aside from that, people don't seem too concerned about the particulars of division. It is 
COMMUNITY ORCHARDS AS NEW URBAN COMMONS

understood that orchard members have different preferences (not everyone wants to make crabapple jelly), different-sized households, and varying amounts of time available for preserving.

Maximizing production doesn't seem to rank high on most orchardists' priority lists, owing, in part, to the unresolved challenges of dealing with fruit, and, in larger part, to the fact that no one is relying on the orchard for their livelihood. Says David (Strathcona),

Because we're all volunteer-run, we don't really have the efficiency that a commercial operation would have. So, we will tolerate trees that aren't good performers...we'll put up with all kinds of crap and tend to a tree, even maybe to extremes. And what's the point? Why have a tree that every year doesn't do anything for us when we could replace it with a tree that does? Maybe we should be a little bit more...efficient in our management of it. But for various reasons, we're not.

After years without much fruit, dealing with having lots of fruit requires a shift in thinking. According to Ariel (Copley), distribution is not something the group gave much thought to before now, perhaps because it was not pressing in the early years, before the trees really came into production: "Dealing with a harvest...takes time and could be considered part of the whole picture of maintaining the orchard. But we usually just think in terms of basic maintenance of the trees." Regardless of what orchardists are thinking, fruit tree yields tend to increase from year to year, as the orchards grow (barring infestations and catastrophic weather), and the problem can quickly become one of too much fruit, where the surplus soon litters the ground. So much waste can be upsetting to community orchardists, as Ariel explains: "The question just panicked me, like [spoken with alarm] Food waste! Food waste! Food waste!! Could it go to homeless shelters? Can 
you go door-to-door and offer it to the neighbours?" The problem is one of aesthetics and principle, pragmatism, and neighbourhood politics; fruit that rots on the ground creates conditions favourable to pests - e.g., scab and coddling moth (in the following season), and (more immediately), rats, which in turn attract coyotes. And coyotes are not good for public relations, as members at Copley found out.

The waste problem points to a general lack of systems and capacity (time, energy) for more organized distribution. ${ }^{92}$ As Ariel (Copley) reports,

Dealing with large volumes of perishable fruit is an aspect of the orchard that I don't think we as a group... have thought very much about. [The canning workshop in the first year] was part of Jodi's initial offerings, but since then we have not got beyond picking or picking up the apples (sometimes) and leaving them in bags outside the shed for anyone to take (I don't know if anyone does take them) or letting them rot inside the shed or on the ground.

Orchardists have sometimes invited schoolkids in to pick up the grounders. ${ }^{93}$ Recalls Jodi (Copley), "We would have races to see who could fill up their bucket first." But bringing in school groups also takes organization and time. That's not to say that a better distribution system couldn't be developed; it just hasn't been a priority. The trouble is time, or the lack of it, given that most orchards have no paid staff. "Maybe it would be a good planning exercise, for a student," muses David (Strathcona). Others hint that

\footnotetext{
${ }^{92}$ Even giving away fruit can be harder than one might think. When yields are especially high, the glut of fruit is often city-wide since all fruit trees have benefitted from the same weather conditions. Even organized gleaning programs like the Fruit Tree Project, which are well connected to food banks and other social service agencies, sometimes struggle to find takers for their fruit during the most concentrated weeks in fall. LifeCycles, in Victoria, makes apple cider and apple cider vinegar as a social enterprise, so that may provide Welland with an outlet for some of its fruit.

${ }^{93}$ Grounders can be used, and are used, to make cider, so they don't have to go to waste. But to be safe from E.coli contamination, the cider must be heated to a high temperature before it is consumed.
} 
inattention to distribution is a sign that seeing the fruit all the way through to consumption just isn't a priority. Copley member, Helen, told me that the core group "didn’t want the fruit, they just wanted to build an orchard." And at View Royal, Councilor John Rogers observed that where the harvest ends up isn't much of an issue for the Town: "The only thing that the Town wanted to be sure of is that when people harvest, that there is sufficient liability coverage that if they fall off the ladder, or out of the tree, that the Town is not going to get sued."

Some might expect that community orchardists would want to sell the fruit. But even before considering the practical matters that might be involved in entrepreneurialism, the question of commodification was clearly a non-starter for the people I spoke to. Said Ariel (Copley),

I don't like that idea. I don't see it that way... If the members can sell the fruit, then why can't somebody else take the fruit and sell it? In a way, it just introduces the notion of commodifying property... If the orchard was selling the fruit, then it would be a little bit less of a violation of the spirit of the thing. But maybe not. Because, you know, in the spirit of the thing we communally participate and we communally own...[but] not so much in the commodified sense. We "own" it in that we're responsible to it, but not in that we get to sell it.

Some interviewees did float ideas like selling tree cuttings or value-added fruit products (e.g., jam) to sustain the project, but all seemed to reject the model of producing food for profit, as the following three exchanges illustrate: ${ }^{94}$

Jennie: Is that really important, to have a space where money doesn't belong?

Linda (Spring Ridge Commons): Well, I think that was one of the intents of the space, decommodifying food.

\footnotetext{
${ }^{94}$ The question is hypothetical anyway, since the City of Victoria prohibits the sale of produce from community gardens (which includes community orchards) (City of Victoria, 2016).
} 


\begin{abstract}
$* * *$
Jennie: So, there's really a sense that this is a de-commodified space, where the give and take and the enjoyment of the fruit is completely outside any sort of market or cash economy, right?
\end{abstract}

Brian (Welland): Yeah. It's actually what I enjoy about it.

\begin{abstract}
$* * *$
Jennie: How would it change things, if people were growing the fruit for sale? I'm curious. Just a thought experiment. How would that change things?

Carmen (Strathcona): Hmmmm... That's an interesting point. [pause] You know, there are some things that don't grow in other places and people have found some things that are showing up on Commercial Drive, [for sale] in the produce place, and people say, Wow, I remember seeing that in so-and-so's garden. It's happened once or twice... I think people here would definitely say that's not acceptable and would say to the person, "I'm sorry, but you have to leave."
\end{abstract}

Given all these observations of community orchards - the lack of monitoring or measuring what the trees produce; the low priority given to maximizing production; the absence of systems for ensuring equal allocations of fruit to all members (as there would be in a CSA, for instance); the absence of organized systems for distribution (even an apparent absence of interest in setting up such systems); and the community orchardists' persistence in spite of sizable losses (even in the absence of any tangible gains) - it seems clear that what interviewees told me is indeed true: it's not really about the fruit. In other words, if production were the main focus of the orchard, or if those involved were principally concerned with getting more food for their household to eat, we would expect things to look very different.

So, what is really going on here? And what, exactly, is the relationship of community orchards to food security? Given the large conceptual field onto which we might map 
community orcharding as an activity, it seems important to tease out the differences between and among the concepts that may or may not apply to community orchards, in order to locate and frame them accurately, so that we may draw fair and useful conclusions about them and their role in social change.

\subsection{Roots - The orchard in the field}

Many researchers have conceptualized urban gardening as a form of political expression, as well as social and environmental activism (see, for example, Certomà, 2011; Eizenberg, 2012a; Milbourne, 2012; Nettle, 2014; Pottinger, 2013; Tornaghi \& Van Dyck, 2015; White, 2011a, b); I would say the same of community orchards. Although this assertion is now commonplace among researchers who study community gardening, it is important to be reminded that this is quite the opposite of how gardens have been viewed by the general public - and as commercial or private orchards may be viewed by many people today - i.e., as pastoral places of repose, as tightly cropped, orderly displays of industrial efficiency, or even as florid expressions of apolitical femininity (McKay, 2011b). But just as political expression and activism can express views that range all across the political spectrum, so, too, can community gardens and orchards. ${ }^{95}$ McKay (2011a, b) darkly reminds us that fascists, Nazis, and xenophobes have often practised horticultural politics; Hitler, for example, was a fan of biodynamic agriculture.

Consequently, McKay asserts that "the act of gardening can be ideologically fluid

\footnotetext{
${ }^{95}$ This may sound patronizingly obvious, but I think it is a fact sometimes missed in the academic literature; we are too easily tempted to read about community gardens in New York City and to then, erroneously, transplant those claims and understandings to places like Toronto or Victoria, which, being in a different country, come with different histories, different cultural traditions, and different combinations of political-economic forces, which in turn shape residential patterns, social organization, and inter-group relations - and, consequently, community gardens and orchards.
} 
(though never, I think, blank) and that radical gardening can be dangerous and regressive as well as potentially progressive and liberatory" (2011a, p. 43). The variable flavours of community orchards seem to depend greatly on where they take root, and who is involved. Some sites and groups (e.g., Spring Ridge Commons) have strong anarchist roots, while others (e.g., Welland, with its emphasis on heritage preservation) have a much less radical agenda. Consequently, our understanding of the variety of community gardens and orchards is not well served by over-generalizing, even within a city like Victoria (home to both Spring Ridge Commons and Welland).

Still, there are some commonalities. To the extent that they are producing food, all community orchards can be seen as a model of what Lyson (2004) has termed 'civic agriculture,' offering a more sustainable alternative to the dominant industrialized and globalized food system. Though they don't engage in commercial sales at Welland, as is typical of civic agriculture (by way of a CSA or farmers' market), Julia told me that they have considered implementing something like a Good Food Box program, just not on a cash-transactional basis. ${ }^{96}$ (Details remain to be worked out). Civic agriculture has a dual purpose, being just as much about the 'civic' part as the 'agriculture' part. That second purpose is to foster citizenship, and connection to place, through work. Says DeLind,

To be truly civic, such work, like place itself, needs to be embodied (not abstract) and public (not individual)...It is in literally feeling the "res publica" and in our individual and sweaty sacrifices to it that we begin to inhabit places in any deep and collective way." (2002, p. 221-222)

\footnotetext{
${ }^{96}$ CSA stands for Community Shared/Supported Agriculture, a scheme in which eaters buy shares in a season's harvest and receive a share of the produce each week. By providing financial certainty through guaranteed sales, a CSA helps producers mitigate risk, while also establishing personal relationships that connect "field to fork."
} 
Community orchards nourish what DeLind calls "soil culture" wherein soil is "a medium and marker of sacred places - places that tie us to our past, our present, and our future" (2002, p. 223). The idea of "soil culture" linking us to history recalls the attention paid to heritage at Copley and Welland (both named after biodiversity-promoting conservationists), and the revival of the wassail tradition at Banfield.

Given its alignment with civic agriculture, the association of community orchards with food security might seem to be almost so obvious as to be taken for granted. If food security is "a condition in which all people, at all times, have physical and economic access to sufficient, safe and nutritious food to meet their dietary needs and food preferences for an active and healthy life" (Food and Agriculture Organization, 2008) how could free fruit, grown in public spaces, not contribute to it? ${ }^{97}$ Community gardens, after all, have been lauded for their contributions to food security (see Twiss et al., 2003; Wakefield et al., 2007). Moreover, municipal administrations and food security advocates in Vancouver and Victoria classify community orchards as an extension or variant of community gardens, which are widely assumed to be mainly about food (City of Vancouver, 2013; City of Victoria, 2016). ${ }^{98}$ But given the secondary importance of the

\footnotetext{
${ }^{97}$ This is not the only definition, of course. Ryerson University’s Centre for Studies in Food Security further elaborates on the concept of food security to define it in terms of food availability (supply), accessibility (geographic, economic, and social access), adequacy (nutrition), acceptability (ethics/justice), and the agency of eaters (sovereignty). (Ryerson University, n.d.) ${ }^{98}$ The City of Victoria's Community Gardens Policy (2016) notes that community gardens also promote health and well-being, positive social interaction, neighbourhood building, environmental education, habitat development and connection to nature. But in City policies and other documents, community orchards/gardens are typically listed as food assets, are the purview of the Food Systems Coordinator (Victoria), and are seen as integral to municipal food strategies and related goals - e.g., Vancouver's Healthy City Strategy (City of Vancouver, 2014). This suggests that most people still see them as being primarily as being about the food.
} 
COMMUNITY ORCHARDS AS NEW URBAN COMMONS

fruit to their participants, we might wonder, are community orchards really enhancing food security? And for whom?

Comments from community orchardists suggest that most do not see their projects as an intervention or effort to improve their own household-level food security. ${ }^{99}$ While I did not directly ask interviewees about their economic status, very few interviewees gave any hint that they felt personally food insecure. Freelance artist and animator, Séan (Spring Ridge Commons) was an exception; he told me he felt that food was a big draw, in bringing people to Spring Ridge's food forest:

I mean there's many times when finances are so tight that a little bit of fresh fruit and vegetables from [the Commons] really help out. You know, when the miner's lettuce is in season, that becomes - especially early in the spring - it becomes a really good addition to the diet, right?

Those whose food security would be most enhanced at Spring Ridge Commons are people who are curious and highly motivated - those who care to learn that the orange berries of sea buckthorn are a great source of antioxidants and Vitamin C. But for others, the rarefied superfoods of an urban food forest may not be a satisfying substitute for a missed meal. Other comments suggested that community orchardists believe that their projects $d o$ help alleviate household-level food insecurity for other people, both within and beyond their organizations. Sylvia (Strathcona), remarked, "I think [members] who

\footnotetext{
${ }^{99}$ I often heard the same said of allotment gardening, particularly in public spaces - that it isn't a purely rational endeavour, economically, to grow your own. Carmen (Strathcona) noted that when produce is in season, it is probably cheaper to buy it than grow it yourself, given the cost of seeds and soil additives (e.g., bloodmeal, bonemeal), not to mention the risk that not all that is planted will even come up, and that what does come up might be stolen. Sylvia (Strathcona) estimated, with a laugh, that she spends probably $\$ 300$ each year on seeds, plants and soil, for about $\$ 50$ worth of vegetables. And Sara Orchard, the community garden liaison with the City of Vancouver, acknowledged that community gardens are "a lot more about community interactions than growing a ton of food."
} 
are retired, low-income, single, things like that, those people do count on...that it's nice to get apples, or free fruit, in the fall. It seems to make them very happy to have this available to them at no cost." For others, the orchard seems to promise the possibility of feeding the homeless and destitute, even if only through surreptitious "midnight harvesting”. Said Susan (Ben Nobleman), “That's what we want. We want these trees to be big enough to feed all of us."

Listening to interviewees, I sensed a distance, both geographic and social, between many orchardists and these presumed beneficiaries of the orchard's bounty, if only in the vagueness of their understanding of where the fruit goes. Said one, "The bulk of this fruit goes to the...what do you call them, food kitchens? For the handicapped? Not for the handicapped. For the deprived." That there would be a difference between those who cultivate community orchards and those who most need food NOW, is hardly surprising. Having some knowledge of the circumstances of women living in Vancouver's Downtown Eastside (poverty, stress, ill health, violence, addictions, etc.), Tanya (Copley) explains that "[these women] are not in a place to go and start collecting fruit...It's not where they're at right now. They just need a donation" - a point of view affirmed by Allen (2010, p. 300), who points out that "those with the greatest need often have the least ability to exercise individual choice" precisely because "allocations of choices are shaped by the historical demographics of inequality." Tanya acknowledges the privilege that she and her husband, Mark, have, to choose community orcharding: "We have resources and we have time, so we're doing this." 
The implications of this difference between the orchard's cultivators and (some of) its ultimate consumers suggest that community orchards could possibly be better understood as community-level food security initiatives - as long as the rules of the orchard don't come into conflict with members' desires to share the harvest. ${ }^{100}$ At Strathcona (which, being a community garden, operates on a clear membership basis) the fruit is intended just for members. But one member regularly brings elderly members of his Japanese society to pick apples, and to share them as part of their lunch program, a fact that Community Garden President, Sylvia, wrestles with:

I mean, I come across as an ogre, saying "Sorry, the rules are you can't share." But...I can't shut my eyes to the fact that there are low-income people all over the place who are actually looking forward to those apples. And it wasn't just gardeners. Because it's such a public space, we have to think about this community, not just the members. So, I'm all confused: Who are the apples for?

It's a question that puzzles Tanya, too. She recalls, when Copley was first envisioned,

Some people were like, 'We are growing for food banks.' And other people were like, 'No, we are growing to divide it amongst ourselves.' You know? And these were really kind but heated...not aggressive, but passionate, conversations about where is this food going??

Today she says, laughing almost uproariously, "I don't know who's getting this fruit. I don't know who I'm growing this for! When I volunteer and cut the grass now, I don't know who I'm doing it for. I'm just doing it. Isn't that interesting?!" In short, if we are to understand these orchards as community-level food security initiatives, we must admit that the organizational infrastructure to make them effective as such is not yet in place. But it's not just that; there is more going on here.

\footnotetext{
${ }^{100}$ Community food security puts emphasis on the community rather than the individual level, looking for strategies for collective empowerment and food self-reliance; it stresses prevention with a focus on nutrition and sustainable food production.
} 
Some of the confusion about who the fruit in community orchards is for can be traced to the different meanings of the term 'food in/security'. For some, it refers to in/security at the individual/family or household level, while for others, it refers to our collective insecurity within an unsustainable fossil-fuel based industrial agriculture system in an age of climate change (Barthel et al., 2010; Fraser \& Rimas, 2010; IAASTD, 2009), which makes us all vulnerable (though some much more so than others). ${ }^{101}$ This seems particularly true of those engaged in permaculture, as Matthew explains:

I think some permaculturalists, when they're talking about food security, they're really trying to shake things up at a bigger level - [It's] not so much about how we produce food; it's more about how we design sites. 'Cause if you're just focusing on food, food is nested within its whole social, political, cultural context. You have to understand all those different interrelationships to be able to effect change in the food system. So, I think permaculture is trying to remind us of that.

It seems that it is at this level of systems that we can most meaningfully speak of community orchards and food forests contributing to food security, insofar as they seem to promise a different way of organizing to meet our basic needs - a low-carbon, ecologically aligned, healthy, and socially inclusive system. Nobody I spoke to suggested that community orchards were the solution to food insecurity at this scale, but all seemed to regard them as steps in the right direction, even if they might only ever comprise a small part of a more just and sustainable system, one of many component parts that are still experimental and developing.

\footnotetext{
${ }^{101}$ Doing interviews, I was struck by how many people expressed a sense of collective vulnerability in regards to the food system as a whole, and the potential for food supplies to be disrupted due to natural disasters like floods, fires and droughts, all understood to be increasing in frequency as a result of climate change. Most community orchardists in Victoria and at Welland mentioned living on the island as something that made them feel even more vulnerable. The most vulnerable, of course, are those with the fewest resources and choices.
} 
One way that community orchards move us, collectively, in the direction of food systems change is via food literacy and education. Community orchards promote food literacy by giving children and adults alike a chance to actively engage in the process of growing food, observing when different stages of growth occur, and how hard food producers work to bring us everything we depend on. Lisa recounts taking her students to Copley:

It was Earth Day... and these kids are grade 11, grade 12 - 17-year-olds - and they're going, "Can we pick apples?" And I'm like, "You guys, it's April! Do you know how this works?!" [laughter] And we get there and they're like, "Where's all the fruit?" And I'm going, "Really?? Wow." So, let's have a lesson about where fruit comes from. And seasons. So, we're walking around and I'm going, "This is a flower and that turns into fruit." And honestly, I was blown away by the fact that four or five kids were going, "Wow, cool."

Tanya (Copley) also spoke excitedly about her plans to bring her inner-city elementary school kids from Surrey by Skytrain to see the orchard. Community orchardists, many of whom are educators, know that experiences, particularly sensory ones like tasting, are the most effective teachers, and they thrill at the thought of bringing an "Aha!" moment to others. Said Sherry (Ben Nobleman), "I would love it if the kids saw a cherry, stopped by, picked four or five or six or seven and ate them. I think that would be wonderful!"

Community orchards (and gardens) can also contribute to food literacy at a more complex level. Matthew describes the work of the Environmental Youth Alliance (EYA) at Copley (and other sites) as "a way to connect young people to creative solutions to some of the big social and ecological problems that exist in the world...the environmental impacts of the industrial food system, and also the social impacts of our industrial food system." They do this in a solutions-oriented, experiential way by involving young people in demonstrating food re-localization and inspiring them to use 
COMMUNITY ORCHARDS AS NEW URBAN COMMONS

their new-found knowledge of food systems to bring about larger-scale change down the road. $^{102}$

Community orchards also promote 'food democracy', a term coined by Lang (1999).

Food democracy is promoted when residents feel strong ties of belonging to a place and a community, and when frequent (sometimes daily) negotiations with others are required to live well together in that place. Food democracy is similar to what Baker (2004) and others have called 'food citizenship' - people working to re-shape the food system out of a shared conviction that food is not merely an economic good, but a fundamental right. Making this shift to seeing food as an aspect of citizenship, not just a matter of consumption, is a fundamental pre-requisite to more radical change (Carolan, 2017, p. 5).

Practices that contribute to food citizenship include: participation in community projects grounded in democratic practices (Baker, 2004; Levkoe, 2006; Welsh \& MacRae, 1998); hands-on work with the soil and reverence for nature (DeLind, 2002); learning about food - where, how and by whom it is grown - and the food system (Levkoe, 2006; Travaline \& Hunold, 2010); caring for both the community and the environment (Baker, 2004). DeLind (2002) even specifically mentions the recognition of community gardens as commons as a contributor to food citizenship. Community orchards enable food democracy and citizenship because they provide projects for people to work on together, as well as opportunities to belong and participate, to experience social solidarity and contribute to coordinated action for change, rather than just partaking, individually, in

\footnotetext{
${ }^{102}$ In fact, Kemshaw says, the EYA does not have food security as part of its mandate; instead, it uses growing food as a vehicle to connect kids to nature.
} 
COMMUNITY ORCHARDS AS NEW URBAN COMMONS

"conscious" or "ethical" consumption, a practice that many have criticized for its alignment with neoliberalism (see Dowling, 2010; Goodman, Maye, \& Holloway, 2010; Pottinger, 2013).

I have said that community orchards are not primarily a means of addressing household level food security but are instead a means of advancing system-level food security through the mechanisms of food literacy, food democracy, and food citizenship. What about food justice? Is that an appropriate framing? Originally, I had assumed that community orchards could be understood as an assertion of food justice - i.e., a way of compensating for structural inequalities and putting the needs of the least privileged and most excluded first (Allen, 2010). I now see them in a more nuanced way - that they may contribute to food justice, but not in the ways we might expect, and not yet to their full potential.

Community orchardists $d o$ exhibit concern for social equity, and many are making gestures of reconciliation, by recognizing, through signage, the Indigenous peoples whose traditional (and mostly unceded) territories they occupy, honouring their knowledge in the uses of food-bearing plants for nutrition and medicine. Norquay, especially, has done an admirably thorough job of this. However, I did not hear orchardists making, or foregrounding, explicit connections between disproportionate rates of hunger, food insecurity and diet-related disease among Indigenous people (or other racial minorities) and people of low income, on the one hand, and the systemic racism, colonialism and classism that exists in broader societal structures, on the other (these 
connections being fundamental to food justice, according to Alkon \& Agyeman, 2011; Gottlieb \& Fischer, 1996; Gottlieb \& Joshi, 2010; Heynen, 2012; Holt-Giménez \& Wang, 2011). In other words, community orchards are not really geared to address social disparities at a structural level. Some are making the fruit in the orchards free for the taking, but as Reynolds writes, "there is a distinction between alleviating symptoms of injustice and disrupting structures that underlie them" (2015, p. 240).

Community orchards seem to fit better within the dominant food-movement narrative, which calls for safe, quality food, environmental sustainability, and a communitarian ethos of agrarianism. This is a narrative that is "grounded in the social base of predominantly white, middle-class consumers" (Holt-Giménez \& Wang, 2011, p. 85), and that tends to reflect white, middle-class values in its diagnostic and prescriptive or prognostic frames (Guthman, 2008; Slocum, 2007, 2008). ${ }^{103}$ This is a demographic that fairly accurately describes the majority of those I interviewed, most of whom felt that the ethnic composition of their orchards' membership did not reflect the ethnic composition of the neighbourhoods in which they grew but was instead skewed toward more "whiteness" - though certainly not exclusively.

What is missing, then, if we want to present community orchards as food justice initiatives, is a more explicit engagement with either the food histories and realities of low-income people and people of colour, or the exploitation of labourers in the

\footnotetext{
${ }^{103}$ Diagnostic framing is the "identification of a problem and the attribution of blame or causality" while prescriptive or prognostic framing "serves to "suggest solutions to the problem but also to identify strategies, tactics, and targets"” (Snow \& Benford, 1988, p. 200-201, as cited in Kato, 2014).
} 
mainstream food system (Alkon \& Norgaard, 2009; Gottlieb \& Joshi, 2010; Guthman, 2008; Holt-Giménez \& Wang, 2011) though it should also be said that growing your own is one way that people try to avoid exploiting others.

However, there is a different sense in which community orchards might still be considered a form of food justice. Within food justice movements, we see advocates calling not just for better access to healthy food for all, but for a greater distribution of power within food systems (Alkon \& Agyeman 2011, p. 8). Holt-Giménez and Shattuck write, "No amount of fresh produce will fix urban [North] America's food and health gap unless it is accompanied by changes in the structures of ownership and...a reversal of the diminished political and economic power of the poor and lower working-class" (2011, p. 133). Food justice advocates thus call for redistributive measures to reverse trends of dispossession and concentration of wealth, calling explicitly for the decommodification of land and food (Heynen, 2012; McClintock, 2014; Vivero Pol, 2013, 2015). In the food justice movement, we see claims that food justice "subverts the commodity form itself, by viewing food as a public good, prioritizing its equitable distribution over profit" (McClintock, 2014, p. 148). ${ }^{104}$ Consequently, those community orchardists who are insisting on open access and de-commodification, who are claiming (on behalf of everyone) a right to public space for growing food and trying to make fruit free for the taking - by anybody - are challenging dispossession and concentration of wealth - in a

\footnotetext{
${ }^{104}$ Lang (2003) argues that there is a direct link between commodification and food insecurity, because commodification drives the production of larger volumes of food, for larger markets, and scales up power and control to global institutions and firms. Moreover, commodification de-links food from our sense of self, identity, culture, and social ties (Johnston, 2008), all of which are important to food security in a more holistic sense.
} 
COMMUNITY ORCHARDS AS NEW URBAN COMMONS

radical way. They are delinking food from shopping, reminding people that food, unlike money, does grow on trees (what a miracle that is!), and that growing fruit trees in public space makes the fruit a shared asset.

What is most notable here is that the means through which community orchards are challenging dispossession and seeking redistribution of power have more to do with land and public space than with food per se; they are trying to put the means of production into more people's hands, and not just those who have sufficient wealth to own property. By asserting the commonness of public lands, even reversing enclosure (e.g., Welland), by eschewing market relations and insisting on the primacy of sharing for collective benefit, community orchards are, in fact, challenging dispossession in a profound way, by questioning the hallowed place of private property in the dominant cultures that make up North American society. In this sense, community orchards are at least as much about spatial justice as they are about food justice. If that is the case, it would seem they are best located within a long and continuous expression of (Anglo-European) counterhegemonic politics in which food production has not been the primary goal, but a key plank in the platform (See Biel, 2016; Carlsson, 2008; McKay, 2011a; Miller, 2008; Wilson \& Weinberg, 1999). It is a tradition that includes the $17^{\text {th }}$ century Diggers, the Garden City movement of the late $19^{\text {th }}$ and early $20^{\text {th }}$ century, the "horti-counterculturalists" of the 1960s (McKay, 2011a, b), and the Occupiers, permaculturists, and guerilla gardeners of our own century. I explore this idea in greater depth in Chapter 6. 
To summarize, the lack of emphasis in community orchards on the actual fruit - who harvests it and where it ends up - suggests that framing community orchards in terms of either food security or food justice is not quite right. At the very least, it is incomplete, because community orchards are about so much more than what they produce. Like the trees themselves, community orchards have not only fruit, and roots, but branches that lead us to look out, up, and beyond.

\subsection{Branches - Promoting, Enabling, Inviting}

If community orchardists are confused about what to do with the fruit, they are not confused about the value of the orchards as a whole - what they promote, what they enable, and what they invite in the way of a vision for the future.

\subsubsection{Promoting}

Community orchards promote environmental awareness - not only of human embeddedness in natural cycles and seasons, but of our dependency on ecosystem services, particularly pollination. At all community orchards I visited, there was concern for pollinators, coupled with action to support them by creating more habitat and educating others about their critical role in the food web. This was nowhere clearer than at Welland, where Brian Yeo dedicates nearly all his volunteer time to honouring and continuing Rex Welland's decades of work in this area. Brian offers workshops on mason bees after which everyone gets to take home a mason bee house and some cocoons and become "a mason bee Johnny Appleseed" (as one participant put it). Learning about pollination also promotes an appreciation of agrobiodiversity. The almost overwhelming 
variety at the most established community orchards, particularly Welland and Strathcona, is testament to these projects' direct contributions to increasing agrobiodiversity, which is not limited to the sites of the community orchards; organizers at Welland, SRC, and Fernwood all actively propagate heritage varieties to spread around, and also offer workshops in grafting, to enable ordinary people to join the movement, "crowd sourcing" agricultural biodiversity in much the same way that seed swappers do.

Second, community orchards promote a deeper connection with non-human nature, something many in the city feel is sorely missing in their day-to-day lives, especially for those who live in apartments or row houses and have no private green spaces to retreat to. Said Susan (Ben Nobleman),

Since we planted the trees - there's some neighbouring apartment buildings - and I see a lady come out with her lawn chair and sit under the fruit trees in her lawn chair and just enjoy it like she's on the beach or in her own garden. [It's] a beautiful sight.

Even at Norquay, where organizers have not yet witnessed the hoped-for spontaneous use of the orchard by others, they have found evidence that locals are coming in to enjoy the space: someone has brought in benches and left them there, suggesting at the very least a desire to enjoy just being there, and to return. There is something compellingly "real" about this connection that seems to promise a return to a simpler time. Séan described it this way:

People are more and more sort of mediating the world through a screen of some kind of, like in their cars or their houses and trapped in their own spaces... [At the Commons] it's almost like you can be a kid again.

As Toronto city Councilor Joe Mihevc puts it, "at the end of the day, we are from the earth and of the earth, and [we] want to touch that stuff." There is something especially 
tangible about the human-nature connection that comes from discovering an edible plant in the commons, as Séan explains:

[P]eople come in and are just in wonder: Oh, you mean I can eat this?! ... Then there's just amazing possibilities in that. It's this sort of direct knowing, knowing in your body, something that feels really good.

This connection with the land is deeply therapeutic. Indeed, many interviewees spoke of having had a health or personal crisis of one kind or another and experiencing the healing power of working in the orchard. One orchardist at Ben Nobleman told me,

In 2014 I had treatment for breast cancer. And I still went out to stewardship [days]. I don't think I missed any. Now I maybe didn't do a lot of work but I just felt there was something there that was going to make me feel better.

Others told me that they experience working in the orchard as a tonic, or balm, for the stresses they face in the outside world. Or, in Betsy's words, "the products are for the whole garden and the process is for those of us doing the work." This healing power is partly a function of the meditative nature of tasks that require presence and focus. But it's more than that, too. These experiences - looking at so much greenery, listening to birds, touching bark, smelling blossoms - are both sensory ones (Hayden \& Buck, 2012; Pink, 2007), and relational ones, as Susan demonstrates when she waxes poetic about pruning:

It's the most special time. It's when you create a relationship with your tree... if you're pruning correctly...It's not just hacking limbs off. The tree, with its buds, sort of shows you where it needs to be cut...you watch how the tree works with you. It's a very beautiful time.

Overwhelmingly, I heard people say that they love the work they do in the orchard. Said Yoshi, "it's work that you choose to do and you do with others who make a conscious choice to participate in the same work. It's a pleasure." And Deanna, "I am glad there is a time limit on the day because I feel like I could keep going and going and I would get exhausted. I do lose myself in there. I love it." A large part of the pleasure seems to 
COMMUNITY ORCHARDS AS NEW URBAN COMMONS

derive from the act of nurturing. Betsy: "I think all of us feel that paternal or maternal...we are nurturing these trees. You know we will walk around it and go, 'Oh that poor tree, that is not good'." Susan commented on how gratifying it is to give that kind of care: "It's like having a child... and them growing up to be a beautiful person and knowing that you had a little role in that, by being there for them and supporting them."

We can think of this care work as re-weaving the fabric of community, in all its human and non-human elements. Some interviewees drew explicitly on the Marxian concept of alienation, the rift that arises when people are separated from their natural environment, and from the products of their own labour. ${ }^{105}$ De-alienation, or healing the rift, depends on our being able to re-engage with the "active metabolism of nature through labour" (McClintock, 2010, p. 202). Many scholars have written about urban agriculture's potential to help us do this by co-locating production and consumption (see Jarosz, 2008; Lyson, 2004; Pimbert, 2009; Schiavoni, 2009). This involves working the soil, nurturing seedlings, grafting new trees, protecting young fruit, and interacting with the bees and the blossoms, the sunshine and the rain, even the psyllids and the sawflies. Through such work, community orchardists are able to establish an orientation to their work in which labour is not something done in exchange for goods (fruit), but more to foster relationship. Susan (Ben Nobleman) described "the deal" between the orchard stewards and the trees: "We will care for them and they will give us great fruit, but if we don't care for them, they will give us crappy fruit or none at all." The land and plants the orchardists

\footnotetext{
${ }^{105}$ McClintock (2010) conceptualizes alienation as one of three dimensions of "metabolic rift" the ecological, the social, and the individual - that have come about because of the industrialization of agriculture under capitalism.
} 
COMMUNITY ORCHARDS AS NEW URBAN COMMONS

cultivate are thus neither backdrop nor resource, but elements - actors, even - in their community. Consequently, stewarding the land is not just an economic strategy nor simply a hobby. Caring for the trees fosters something different in community orchardists, something bigger. Says Séan (Spring Ridge Commons), “[There’s] a feeling I get, that this is working. I do feel my alienation taking a little dip." In the words of Jane (Banfield), "it makes us whole."

Still, having this kind of closer, felt connection to the Earth through cultivating food is not something that all city-dwellers want. These differences have come into play at some community orchards in the form of conflicts with neighbours. As outlined in Chapter 4, some neighbours around Copley objected to the development of an orchard on the grounds that intensive food production simply did not belong within city limits. At Strathcona, the feelings ran deeper. Resistance to the community gardens had always been strong from seniors living in the residence built by the Chinese Freemasons. One interviewee recounted to me that at one point, someone had decided to interview them to find out what exactly they found so objectionable about the gardens, which their apartments overlooked. She learned that the gardens reminded them of poverty. Indeed, it's a mark of privilege to be able to want to "get your hands dirty" - the privilege of never having been ostracized or thought of as "dirty", of not having internalized the stigma and shame of being seen as inferior to people who can buy their food at a store. ${ }^{106}$

\footnotetext{
${ }^{106}$ And an example of the kind of White, sub/urban, middle-class sensibility that informs the alternative food movement but does not resonate universally.
} 


\subsubsection{Enabling}

Community orchards typically serve as demonstration projects, usually offering educational workshops that enable members and local residents to acquire and practice new skills, which they can then apply in their own yards (for those who own property). Welland, for example, has a Fruit Tree Apprentice program, where participants learn skills like pruning and grafting, and how to deal with pests, like the coddling moth. Many who come to Welland get turned on to growing their own fruit trees by the realization that maintaining them can be less work than gardening annuals. They are moved by Rex's legacy and generosity, and excited to learn that "exotic" species like paw-paw and persimmon can be grown on Vancouver Island. Community orchards thus inspire people to grow their own food and give them tools to do so, thus helping to overcome what Brewster Kneen called 'distancing' - "the disempowering and deskilling of people from producing their own food and being able to eat well” (as cited in Levkoe, 2006, p. 90).

Community orchards are enabling in another, very important sense; they enable community building. Said David (Strathcona), "Social interactions are probably worth as much or more to people, I think (even if they don't know it or don't say it) than the actual produce - you know, how much I get for the energy I put into it." Connecting people who live close together seems so easy but it is, in fact, so infrequently done that the Vancouver Foundation has created a grant stream to incentivize community-building events: residents can apply to the City for up to $\$ 500$ to host a block party or similar event that has the sole purpose of bringing neighbours together to strengthen the social fabric of the community (Vancouver Foundation, n.d.). At community orchards, this 
coming together is achieved mainly through work parties (which always include a potluck) and harvest festivals. At most orchards, these are casual affairs, but at some e.g., Copley, in the first couple of years - there were so many people that such events required a high degree of management and skill. Organizers made a concerted effort to help people get to know each other, and to provide activities for all ages, as Tanya describes: "People signed in and I welcomed them - they got a name tag, because names are important. We had [a] little table and we always had crayons and paper for [kids] to draw, and so there was a real community feel." Work parties and harvest festivals are different from block parties, of course, because they bring together people who not only live in the same vicinity, but who have committed to a shared project and worked sideby-side to realize a common vision. It is this shared commitment and shared labour that is ultimately most socially bonding and fulfilling. Martin (Strathcona) told me:

There used to be people who came just to work parties (they didn't have plots; they didn't want them) 'cause the work parties are fun! Maybe not on a crappy day, but on a regular day, they're really fun. You're next to someone, you're talking, you're having a good time. That's really important to me, that we make that bonding experience really positive.

Other interviewees shared with me the excitement they felt at building something big together, for the common good. Noted Tanya, "There was a sense of Hey, we're doing something, and it's awesome. Look what we're building!" In these words of interviewees, there is a clear sense that dedication, sacrifice, and sweat are socially powerful forces. Said Lisa: "[There's something] really re-affirming to me about a collection of people that devote part of their life, even when the weather's really crappy, contributing to something bigger than themselves." Yoshi (Copley) was another who made an explicit connection between work and community building. He talked about seeing work as a 
positive force, and the orchard as a rare place to "cultivate the culture of enjoying work," the sort of place and community he looks for but doesn't often find.

[I]t is difficult for me to find those kinds of opportunities in the city. People will come to events for pleasure or entertainment...If there's a sporting event, you can gather thousands of people...But when it comes to the other things, it's not that easy to come by.

Some would say that community building is in fact the orchards' most important function. Likening the Ben Nobleman orchard to Toronto's many community gardens, Councilor Joe Mihevc told me, "Many folks [like to] see things grow, to take pride in what is grown and what comes from the earth. But really, it's about the connections that are made." These connections are both among residents in the community, and between them and their local government, says Mihevc:

For many city residents, especially new immigrants, City Hall can be a scary place. There's 50,000 employees, there's cops, there's...Emergency Services, there's Planning, there's Public Health, there's Parks, there's Rec, it goes on and on. So, City Hall can feel very far away. [And] a project like this, that allows the community to phone City Hall, know who the local Parks person is, ask for a dumpload of either compost or wood chips or something like that, it really gives the community the sense that those civic employees are working for them.

Community orchardists generally seem to appreciate the importance of the social dimension of their undertakings. At Copley the motto is, Caring for community, land, and each other. Similarly, the email signature tag from Banfield Community Orchard is Cultivating community by growing and sharing food. But this appreciation - or finding a balance between the (social) process and the (tangible, edible) outcome - isn't always easy for organizers, particularly for those who had initially imagined that the orchards' prime directive was to produce a significant volume of fruit. (Many orchards didn't even have social gathering spaces in their initial designs, although benches and tables have since been added at almost all sites.) Patti Parkhouse (Banfield) described having to rein 
in a desire to just plant trees and instead acknowledge the value of volunteers' desire to socialize: "If we have a work party and people are standing around talking and I am really focused on getting some work done, I have to put my agenda aside and go, 'You know, Betty and Sally are really getting to know each other, and that's great!'” For others, like George and Helen (Copley), the simultaneous pursuit of social objectives and significant fruit production signals confusion - that people don't really know why they're doing it, or that they haven't been able to identify clear objectives and organize themselves effectively to meet them. It may be a matter of finding the right balance among the elements or accepting that there will always be a tension between them and choosing to embrace rather than resolve it.

It is interesting to ponder the relationship between food production and community building. Councilor Joe Mihevc calls food security "a good handle" for the community development piece:

Really, whether it's art and culture, or basketball for kids, or childcare, it's about the community that you build, that then spins off into other areas. The community relationships get strengthened and those community relationships end up in everything from love affairs to child care to...I'm a senior and I need someone to do this... fix my pipes. All that stuff. Why is food a particularly good one? It's because we're so alienated from the food that we produce. So, it's better this than another basketball program. Way better. Way better.

Clearly, food is a hook - it brings people together. (And no community orchard would dream of having a work party without a potluck!) But food is more than just a handy means to an end, a hook for which any other hook might be substituted, with equal effect. As Hannah (Banfield) perceptively noted, "[The orchard] is really focused on community building... but the thing that draws [people] is definitely still the food, right? It's not 
necessarily, I want to come out so I can build community." The idea of food - of growing trees that just keep giving fruit, year after year - is critical for those who join community orchards. As David (Strathcona) observed, "I know the food's the main draw... even if we never get a single fruit off those things...If the food wasn't there, even as an idea, if it were flowers, the whole thing wouldn't happen."

In sum, there is value in the orchard that goes way beyond the fruit; and there is value in the experience that goes beyond any measurable outcomes, as Martin (Strathcona) suggests:

So, like, these apples for instance, you know we have a hard time keeping them disease-free - we don't use any pesticides. We have a hard time not having them stolen - a huge portion of them get stolen every year. And yet, we still get something out of it. There's a day where we divvy them up at the end of a work party and people get to take them home and often you have to cut off the bad parts...[But] there's a real communion there that's beyond the efficiency of what this could be as a commercial orchard.

These findings accord with those of other researchers. In 2014, Nathan McClintock and Mike Simpson, of Portland State University, published a survey of urban agriculture organizations and businesses in North America which found that the UA landscape in the US and Canada is very diverse; and that participants frame their engagement with UA in diverse ways. Foremost among motivations for participants is community-building, followed by education and sustainability, with food security, food justice and food sovereignty coming further down the list (McClintock \& Simpson, 2014, p. 16). They, too, found that few urban agriculture organizations appear to even keep track of the volumes of food they produce. While their report did not go into depth about the reasons, I would suspect that they are similar to those I have found. 
So far, I have asserted that beyond a concern for food security (including food literacy, democracy, and citizenship), people who engage in community orchards are motivated by what such projects promote (environmental awareness, a closer connection to non-human nature; healing and de-alienation), and what they enable (skill acquisition and practice; community building, including connections among residents and between residents and City Hall). But I believe that there is still one more layer to the question of what community orchards are all about; and it is to be found in what they invite.

\subsubsection{Inviting}

Consistently, interviewees shared a view of what they were doing, through their volunteering and their learning, that spoke of its importance and deep meaning to them. This sense of significance is indicative of the prominence of food in the social-change landscape in recent decades. Growing (as well as hunting, fishing, and gathering) food can be seen as a universal and timeless experience - a matter of everyday survival, the central act of social reproduction, and/or a vehicle for the continuance of culture through tradition (among other things). But food-growing in large North American cities has also, in recent years, taken on additional significance due to the socio-political and ecological context we now find ourselves in: that of a world that is rushing headlong into ecological disaster, while the rich get richer and the poor continue to lose ground, and while millions suffer from loneliness, alienation, and despair about the future (Klinenberg, 2018). Not surprisingly, many interviewees explicitly linked their orcharding work to the need to prepare for a very uncertain and anxiety-provoking future. Séan (SRC) spoke of "precarious" world conditions due to global warming and loss of habitat, and "sketchy" 
political situations; saying he felt these concerns were now being felt "almost instinctively at every level of society." Stephanie (Fernwood and SRC) also referred to the pressing need to adapt to climate change, by figuring out which varieties of foodbearing trees will survive under different climatic conditions. Augusta (Jonathan Rogers) spoke of the urgent need for people to re-learn the skills of growing our own food, in anticipation of a time when we may again need to rely on them. Deanna (Welland) talked about the need to preserve and maximize agricultural biodiversity, in light of corporate control of seeds and genetic engineering. And Jodi (Copley) spoke of how the orchard could be a model, or incubation site, for developing the capacity to live together in the future, when we are going to need more and better interpersonal skills, in order to interact beneficially with people beyond our nuclear family, people who hold different opinions, cultures, and values than us, but who are our neighbours. While none is an avowed survivalist, Séan, Stephanie, Augusta, Deanna, and Jodi all anticipate a future characterized by constraints, uncertainty, and change, and a need to develop greater collective resilience, a need that is well recognized in the literature on sustainable urban governance (Barthel et al., 2015).

In this context, and because of the potential many people believe it has to relieve us of these pressing problems, growing food now presents itself as not just a core element of sustainable urban development (Barthel et al., 2015; Field, 2009) but a potential solution to nothing less than an existential crisis. For those without access to the levers of power, growing food is an accessible and very pragmatic way to actively help our society radically change course. The influence of The 100-Mile Diet (published over 10 years 
ago) is still keenly evident in the words of interviewees, especially in Victoria and Vancouver. In fact, the book was specifically cited by several orchardists as the reason they became involved - to help increase food production in the city and thereby reduce "food miles" and the carbon emissions associated with the transport of our food from far away. Transition Victoria, a group dedicated to reducing the community's reliance on fossil fuels and enhancing community resilience, took on Spring Ridge Commons as their food project; that's how stalwart super-volunteer Linda Chan got involved. The City of Victoria community orchard pilot project, of which Fernwood and Banfield are a part, is understood by the City as a way of reaching its sustainability goals (Holmen, 2012). ${ }^{107}$

While some scholars have criticized the alternative food movement for its enthusiastically uncritical conflation of localism with justice (e.g., Allen, 2010; Born \& Purcell, 2006; DuPuis \& Goodman, 2005), others have argued that there is still value in this equivalence. Says Pottinger, "framing global food system problems as local concerns galvanises support, and organising ethical consumption at city-scale enables its reimagination as a collective rather than individualistic practice" (2013, p. 666). Most people engaged in community orchards continue to place a lot of faith in re-localization. Consequently, learning to care for fruit trees takes on great import for many participants. Being so much more than a horticultural hobby, community orcharding represents, for many, a solutions-oriented way to join in social solidarity and coordinated action with

\footnotetext{
${ }^{107}$ One might reasonably ask how well such goals are met - i.e., whether the volume of fruits consumed from community orchards makes even a dent in reducing the city's carbon footprint, but of course, directly measurable impacts do not tell the whole story. When people are surrounded with the messages and living examples of sustainability, organizers trust that it will permeate their thinking and the other choices they make, not just around food, but also transportation and other aspects of lifestyle.
} 
others who fear, and worry, and care about the future as they do. This lends a profound sense of purpose and meaning to these otherwise quotidian acts of caring for trees, as Deanna (Welland) relates:

[Julia] took me on as a fruit tree apprentice and it's funny how excited I was. My kids thought it was hilarious. I applied for this position and they were like, $O h$, how cool is that! and when I got it I am like, Oh my god, I got it!! and they were like, Mom... you got a volunteer position. But I do feel honoured to be a part of it.

Like Deanna, most people I interviewed expressed a desire to be part of a large cultural shift - a revolution, even - toward a saner, healthier, more sustainable way of inhabiting the earth; and toward ways of designing cities that ensure that public land is used for public benefit. They see, inherent in it all, the possibility of more harmonious and humane ways we might relate to each other. That is not to say that those who cultivate community orchards think of their actions as 'political' per se; most don't. ${ }^{108}$ In fact, many interviewees told me of their disillusionment with more "political" (contentious) activities and how they sought relief from their earlier commitments through community orcharding, through which they could take a constructive approach to social change, rather than an obstructive one (an experience that resonated with my own). In so doing, they are part of a larger shift, in the past two decades or so, away from protesting the status quo, and toward building the alternatives in the here and now, instead of only dreaming or talking about them (Nettle, 2014, p. 9). Other examples of this shift include independent media, renewable energy cooperatives, community housing associations and

\footnotetext{
${ }^{108}$ This is hardly surprising. Gardening and political action have long been seen as incongruous, gardening being understood largely as an activity undertaken in the private sphere, and/or for leisure purposes, and political action being seen by most to involve demonstrations, marches, petitions, strikes, or other confrontational actions typically targeted at the state, or at corporations - hence the apparently oxymoronic title of McKay's Radical Gardening.
} 
the like. Gandhi called this strategy 'constructive programme.' In his later years, it came to be even more important to him than ahimsa (nonviolence), though he tends to be remembered more for the latter. ${ }^{109}$ The phrase, "We must be the change we wish to see" (oft-attributed to Gandhi) has great resonance among those who join community orchards. ${ }^{110}$ Says Peter Lamborn Wilson, "Growing a garden has become - at least potentially - an act of resistance. But it's not simply a gesture of refusal. It's a positive act. It's praxis" (Wilson \& Weinberg, 1999, p.10).

By localizing food production, engaging directly in the process with their own physical labour, eschewing machinery and synthetic chemicals, and operating outside of the cash economy, community orchardists are embodying their politics. By putting on harvest festivals and food-related cultural events, they are also providing others with a "lived experience of doing and creating instead of the current norm of buying and following" (Nettle, 2014, p. 156; emphasis added). "Being the change" in community orchards, then, is not about undermining or replacing "the system" or "destroying capital" (surely not the only metric of whether a social-change practice is worth doing); it is not even so much about meeting real material needs at present. Rather, it's about making a public statement that people can be producers (not just consumers) and can be (at least to some degree)

\footnotetext{
${ }^{109}$ That said, Gandhi did not believe in choosing constructive program over obstruction. He made it clear that would-be agents of change should be constructive wherever possible, and obstructive wherever necessary. Constructive programme does not invite an apolitical or apathetic condition of non-engagement in struggle, but very often suggests the need to do both, a position also advocated more recently by Naomi Klein (2014) in her book, This Changes Everything: Capitalism vs. The Climate.

${ }^{110}$ These exact words cannot be found in Gandhi's collected writings but are sometimes attributed to his grandson, Arun Gandhi.
} 
independent of the corporate industrial food system. This makes the community orchard a "didactic display," a prefigurative ${ }^{111}$ direct action strategy for social change (Nettle, 2014, p. 16). Consequently, advocates of cultural repertoires - or prefigurative politics refute the criticism that they are naïve simply because the alternatives they construct are not sufficient to provide a viable wholescale alternative to dominant practices at this time. Instead, their value lies in inviting visions of collective transformation (as opposed to individual resistance via consumer politics). As Galt et al. write, "people coming together for something greater than the 'day-to-day struggle' produces hope about their communities and future, particularly when the transformations, both material and ideological, are visible and meaningful” (2014, p. 135). In the end, while some will argue that gardening (and other cultural strategies) may detract from the necessarily more conflictual work of making demands of the state, and may even mute or divert energies that should be channelled in that direction, others believe such acts are indispensable.

Because community orchards aim to cultivate more collective and less individualized subjectivities (an essential part of a post-capitalist politics, according to Gibson-Graham, 2006), they are what Galt et al. call "subversive and interstitial food spaces (SIFS)" "spaces of production driven by rationalities that diverge from capitalist rationality" (2014, p. 137). This suggests that the role of community orchards is not so much to change the food system as it is to plant the seeds of new ways of seeing ourselves in relation to others. They suggest that community orchards are more akin to experiments in

\footnotetext{
${ }^{111}$ Prefiguration is the idea that means and ends must be consistent, and that strategies must lay the groundwork for the future in the present. It is a concept that is prevalent in anarchist strategic thought, and that has been adopted by feminists, peace activists and the autonomist movement (Nettle, 2014, p. 179).
} 
communal living - belonging more to the utopian tradition than to any strand of food politics. I elaborate on this in Chapter 6.

The constructive, transformative and hope-inducing nature of community orchards (in idea, at least) explains much of their appeal. But there may be an even deeper motivation, too. As projects that promise so much, community orchards also provide a source of meaning, as part of participants' quests for greater purpose in their personal lives. Observing a similar phenomenon - an intentional community forged around community supported agriculture in East Sussex, UK in the 1990s - Ravenstock, Moore, Welch and Hanney (2013) identify the endeavour as a form of 'liquid leisure', a term coined by Blackshaw (2010) to denote a new form of leisure that entails engagement in civil labour - that is, work done in the service of others. ${ }^{112}$ According to Ravenstock et al., this kind of leisure is less about the activities people engage in, and more about " "the display of credibility, relevance, and competence in our 'voluntarily' chosen 'free' time activities [that] speaks to others about who we are, what we hold to be valuable and how we can make a difference"” (2013, citing Rojek, 2010, p. 3). Tom (Welland) exemplified this trend when he said, "I think it's become very culturally acceptable to say, 'You know what? I'm all about going out and working volunteer time in a park.' Twenty-five years ago, that was kind of pooh-poohed...Now, I'm finding that there's a little bit of cachet in that."

\footnotetext{
${ }^{112}$ The term 'liquid leisure' is in turn derived from Bauman's (2000) work on 'liquid modernity' which deals with changing notions of time and how it is deployed in Western societies in the early $21^{\text {st }}$ century (as cited in Ravenscroft et al., 2013, p. 630).
} 
As seen in the East Sussex example that Ravenstock et al. write about - and in community orchards - 'liquid leisure' is characterized by a collapse of the traditional work-leisure boundary. While civic agriculture, particularly in cities, does invite a certain degree of “"playin' farmer”" (Ravenstock et al., 2013, p. 631), the work itself $i s$ hard, much harder than many realize when they first sign on. What makes it a form of leisure is the devotional quality of participants' engagement with it - the impressive enthusiasm, love, and loyalty these projects seem to generate in their adherents. This devotional quality derives from participants' belief in the transformative potential of their activities, a faith that may even be sustained well beyond the point when orchardists begin to question how consequential their labours really are.

According to Ravenscroft et al., such devotion is driven not only by participants' commitment to counter-hegemonic ideals, but by a driving need for greater meaning in their lives, and for the expression of a new and more satisfying sense of self. In this view, what food, as the nominal raison d'être of the projects, really offers is a sense of higher purpose for participants to align themselves with. More than just producing fruit, participants are giving expression to deeply personal values, and positioning themselves as co-creators of their preferred vision of the future. In the words of George McKay, they are engaging in the "tender tending of a fertile future" (2011a, p. 135) - not only ecologically, but spiritually, too. Consider the words of this anonymous interviewee, speaking about her motivations for becoming involved:

I imagined that it would be a good space for a kid. So, I thought, this is part of my identity that wants to be a mother and wants to nurture and wants to have community and wants that to be visibly...physicalized in this orchard. 
In sum, community orchards invite people to express their social and moral aspirations and commitments. They appeal to those who seek greater meaning in their lives, and who have sufficient leisure time, energy and resources with which to pursue it. They appeal to those who want to nurture and be healed, and who share a common narrative about what is wrong with the world and what can fix it, which leads them to find the healing and meaning they seek in practical food projects. They appeal to those who excite at creating novel and enticing spaces, which promise (or at least symbolize) a future of sustainability, connection, and collective wellbeing. Unfortunately, say Ravenscroft et al. (2013), the devotion required to sustain such difficult projects, and the sense of community that attends them, may be present only as long as participants also see them as a means of furthering their own self-realization. This may explain why both this sense of vocation and the feeling of community that orchardists work so hard to co-create also appear to be somewhat fragile, as we shall see in later chapters.

\subsection{Conclusion}

Community orchards are politically complex spaces. They both are and are not about the fruit. We can't write off the food aspect altogether; something edible is being contributed by community orchards, even if the volumes at some orchards are still small and/or hard to quantify. Even if we look only at volumes of fruit produced - or, more accurately, consumed - community orchards can be seen as providing a contribution to urban gleaning or gathering - an additional, sustainable, but often overlooked, means by which anyone in the city may secure food and augment their diet (McLain, Poe, Hurley, Lecompte-Mastenbrook \& Emery, 2014; Wilson, 2013). Of course, we do not know who is taking the fruit that "disappears" from community orchards. We don't know who they 
are, how diverse they are, how much fruit they take, how important that fruit is to them, and whether the taking is need-driven, opportunistic, or prompted by curiosity. At best, however, community orchards are only a complement to a more comprehensive food system; no one seems to see them as having the potential to subvert or take the place of markets, whether at the local or corporate scale. ${ }^{113}$ Nor do participants indicate that they see community orchards as having the capacity to address the large social problems to which the food justice movement typically addresses itself - namely, racism, colonialism, and "the diminished political and economic power of the poor and lower working class" (Holt-Giménez \& Shattuck, 2011, p. 133).

Of course, community orchards, as demonstration and education sites, still do good things. They promote (agro)biodiversity, foster food literacy, and enable skill-building (or what the Transition Movement calls "re-skilling") in food production; they provide experiential learning opportunities that instill in city-dwellers an appreciation of the labour required to produce food, and revive the cultural practices associated with it (everything from supporting pollinators to making cider and celebrating the wassail). One cannot understate the importance of geographically accessible urban growing spaces for

\footnotetext{
${ }^{113}$ One implication of my assertion that "it's not about the fruit" is that it may undercut some of the critiques often made of community gardens (insofar as they may also extend to community orchards). In the scholarly literature, there are those who believe that food activists who engage in organized gardening projects are conflating civic charitable food security activities with resistance or political action and that they are initiating projects at scales incommensurable with much larger scale of the problems they seek to address (Born \& Purcell, 2006; Dupuis \& Goodman, 2005; Guthman, 2008). But if large-scale food insecurity and hunger is not the problem community gardens and orchards exist to address, then the conflation and incommensurability charges don't stick. Besides, if the goal is not to feed everybody, but to change culture and consciousness, then the local can be a site of extra-local change (Nettle, 2014, p. 176).
} 
accomplishing these vital tasks (Barthel et al., 2015, p. 1322). Community orchards also advance food democracy by asserting (if only implicitly) that food should be a right of citizenship, and that the fulfillment of this right is a critical component of a more democratic and just society. In these many and important ways, they may well contribute to our long-term collective food security at the systems level.

Going beyond food, community orchards promote healing and de-alienation; they enable community-building through an earned sense of place that derives from experiences of dwelling and stewarding a little patch of urban land; and they invite us, as a society, to imagine (and manifest) hopeful visions of a viable future. The fact that an orchard can contribute to so many goals is precisely what some find so compelling. Wekerle (2004, p. 385 ) asks, "How do everyday acts of resistance, involving the social construction of place and the reconstruction of urban landscapes for food production, relate to social movements focused on policy and societal change?" In the case of community orchards, my answer would be that community orchardists are using food, on a small scale (in the form of a practical project), as a vehicle to build community, knowledge, motivation, and capacity to change society on a larger scale. ${ }^{114}$

Community orchards meet the needs of those who participate in them - needs for vocation (deeply purposeful work) and connectedness in socially fragmented,

\footnotetext{
${ }^{114}$ An analogy might be to the way the Black Panthers used their Breakfast Program for Children as a tool to cultivate a militant movement to "dismantle the capitalist structures of racism" (HoltGiménez \& Wang, 2011, p. 89; see also Heynen, 2009). The Panthers' ultimate goal went beyond feeding hungry Black children; but food was also more than a means to an end; it was a key plank in their platform.
} 
ecologically alienated, and technologically mediated world. They provide a community to belong to, largely constituted by a significant shared vision; a canvas (public green space) on which to act and demonstrate individual and collective efficacy; and a set of norms and practices that stand in fundamental contrast to the dominant norms and practices of the alienated, consumerist society from which community orchardists seek relief - thus making possible more viable alternatives. Yet, while community orchards meet many needs, those who participate in them seem to think less about what they are getting from the orchards, and more in terms of what they are creating: an accessible community green space that is shaped and maintained by the free gift of the orchardists' labour, care, and time. This generative space is that of the commons - regardless of how much, or how little fruit is produced. This commons is produced via the four main tasks I identified in Chapter 2 and have alluded to here - resisting enclosure; appropriating community space; decommodifying exchange; and claiming power to shape the city. The next four chapters explore how each of these tasks is being accomplished in community orchards, the challenges experienced by community orchardists in doing so, and the ways these activities intersect with ongoing wider debates about commons, community, urban space and governance. 


\section{Chapter 6 - Resisting Enclosure \\ "Call it whatever you want; just don't develop it!" 115}

Take note that England is not a Free people, till the Poor that have no Land, have a free allowance to dig and labour the Commons, and so live as Comfortably as the Landlords that live in their Inclosures. (Pamphlet of the Diggers) (Everard et al., 1649)

What we call land is an element of nature inextricably interwoven with man's institutions. To isolate it and form a market for it was perhaps the weirdest of all the undertakings of our ancestors. (Polanyi, 1944, p. 187)

\subsection{Introduction}

It came as a pleasant surprise to me to learn that the vocabulary of 'the commons' and ‘enclosure' were familiar to many of my interviewees - not only at Spring Ridge Commons, but also at other sites. Hartley Rosen, one of the founders of Copley Community Orchard. told me that commoning had been part of the project's foundation from the beginning and that everyone was comfortable talking about it in this way - a fact borne out by the comments of interviewees. This chapter discusses the explicit and implicit resistance to enclosure that is evident in community orchards, relating it to similar projects and developments, both historical and contemporary, which collectively suggest a framing of community orchards that has at least as much to do with challenging land ownership and property rights as it does with pollinators and fruit. It also explores the enclosure-related challenges that orchardists face as they struggle to be both inclusive and sustainable.

\footnotetext{
${ }^{115}$ In this chapter and the three that follow, I have taken actual quotes from interviewees to serve as sub-titles because I believe they sum up in a very pithy way the sentiments of many of those with whom I spoke. This quote came from Sylvia (Strathcona).
} 
The words of my interviewees make it very clear that they were deliberately and selfconsciously engaging in projects of reclaiming the commons as an alternative to enclosure. Augusta (Jonathan Rogers) talked about community orcharding as a way of introducing alternative ideas to private ownership, "rather than everybody having their own backyard"; similarly, Ariel (Copley) told me, unprompted, that she would "like it to be an unenclosed space... a space where it's not about capitalism." Stephanie (Fernwood, Spring Ridge Commons) articulated a well-informed summary of the history of the commons, making a comparison to local historical Indigenous practices:

Traditionally in this territory, people who managed the land, First Nations people, would have had somewhat common areas that they managed collectively. There would have been more family entitlement to certain areas - say, camas patches but a common sharing of the land goes back to older, tribal, traditional food systems. And then as civilization has shaped society and the landscape, I think commons still survived. But as land ownership and privatization started becoming favoured, by capitalism, the commons got taken over and sort of taken away.

Betsy (Strathcona) mused about the commons of her childhood in England, where there were paths and open meadow bits - and "white and red toadstools and fairies [that] lived underneath!" John and his fellow orchardists from Welland stressed the significance of the covenant on the land that brought the formerly private property into the public domain and that prevents Welland Park from being sub-divided and sold by the Town of View Royal any time in the future. John (Welland) voiced appreciation for the commons of Welland Legacy Park when he said,

The one thing about Welland Park is that it's communal. Everyone is coming there for the common good. And not only that, it's the greater good. It's not just because we get the benefit of fruit trees, but we also get the common good of the environment and the pollinators.

At Strathcona, Sylvia, heartily agreed with the characterization of the gardens as commons: 
Yes, certainly, commons. They're commons that have to be protected over the long-term. They're in such a precarious state, community gardens, or any of these designated green spaces... We could lose so many aspects of the commons, as we've seen already with neoliberalism. I think this might be just another frontier that neoliberals would just love to get hold of and develop on.

Hearing such comments from interviewees affirmed for me that analyzing community orchards as commons was still appropriate, whether it is the fruit that they are commoning around, or the space itself. They seem to see their orchards as a space apart, a counter-force to the hegemonic institution of private property. In this sense, community orchards can be seen as heirs to a long counter-cultural tradition of actively working the land to produce food as a way of resisting enclosure. It is in this frame or lineage that I consider them in this chapter.

\subsection{Historical influences}

The most obvious exemplar of this tradition of resisting enclosure is, of course, allotment gardening on public land, which was a direct response to the great historical enclosures that began in the UK over 400 years ago. The enclosures dissolved the commons - where ordinary people used shared land to produce and procure food, gather fuel, and graze their livestock (Barthel et al., 2010, p. 1323) - and turned them into the exclusive private holdings of the wealthy. The hunger and suffering that resulted from mass migrations from the countryside to cities led people to demand space for growing food. Concerned landowners, major industrial employers and local governments were alert to the plight of those who had lost their traditional rights to the commons and sought a way to quell the turmoil such enclosures induced. They granted use-rights to the poor to grow food on both private and public land, and what began as an informal concession eventually became institutionalized with successive articles of legislation, including the Allotments 
Act (1887) which was later strengthened in successive articles of legislation, including in 1950, when municipal governments (councils) became obliged to provide allotment gardens any time residents expressed a demand for them ("Allotment History" n.d.; Crouch and Ward, 1988). This legislation is still in force today across the UK. And while it might seem that the allotment represents a kind of pseudo-private property, insofar as gardeners are free to express their creative and horticultural personalities by cultivating individual plots, theirs is still a collective right to space that does not include the right to alienate (sell) or to exclude others from joining or using the larger space.

Community orchards share other historical antecedents that revolve around resistance to the institution of private property. George McKay traces the history of some of these forms of "radical gardening" in his book of the same name (2011a). He recalls that the revolutionary promoters of the English Commonwealth of the $17^{\text {th }}$ century called for fruit trees to be planted in hedgerows as part of an agenda for publicly accessible food:

Samuel Hartlib's A Designe for Plenie called for 'a generall and universall Plantation of such wholesome fruit (according to proportion) as might be for the relief of the poor, the benefit of the rich, and the delight of all... The light of nature will teach us that a common, and publike good is to be preferred to all private profit.' (McKay 2011a, p. 155)

Around that same time, there were the Diggers, who called for fundamental reform of land ownership (Plant, n.d.). ${ }^{116}$ They saw the "overthrow of the monarchy and the declaration of a free Commonwealth... as a first step towards the abolition of private property rights in favour of the communal ownership of land" (Plant, n.d.). In 1649, they

\footnotetext{
${ }^{116}$ The Diggers were a subgroup of the Levellers, who levelled fences or dug up hedges that privatized property; they became a political party under Charles I, advocating a levelling of differences in rank and status (Linebaugh, 2009).
} 
squatted and cultivated land - planting parsnips, carrots and beans - on St George's Hill, Surrey to protest the enclosure of land that made some into tyrants and most into downtrodden labourers (Linebaugh, 2009, p. 89). ${ }^{117}$ After only one year, the Diggers were "burned off the Commons" (ibid) when authorities set fire to their shelters and destroyed their crops (Plant, n.d.). Still, the performative aspect of growing food to protest greed and profiteering was so significant that it set a model for centuries to come: "the symbolism of taking back as common land that which had been enclosed...overshadowed the negligible material value of planting corn in barren soil" (Duncombe, 2002b, as cited in Nettle, 2014).

The land-grabbing tactics of the Diggers have been retained in collective cultural memory, revived in various times and places. One of these historical echoes was the infamous claiming of "People's Park" in Berkeley, California in the spring of 1969, when thousands of students, hippies, professors, musicians, Black Panthers, members of the newly established "Women's Liberation Movement" and the underground media - what McKay (2011a, p. 119) calls "the widest swirl of the counterculture"- occupied a rubblestrewn block of vacant land owned by UC Berkeley with the goal of transforming it into an outdoor concert venue and a people's garden, the basis of a new culture protesting the "unjust imposition of an urban order" (Allen, 2007, as cited in McKay 2011a, p. 121). ${ }^{118}$ The response was shockingly brutal: Ronald Reagan, then-governor of California, was reported in the San Francisco Chronicle as saying, "If there has to be a bloodbath, then

\footnotetext{
${ }^{117}$ The St George's Hill squat was not the Diggers' only land occupation, but it may be the best known. According to Plant (n.d.), there were at least 34 other sites across many counties where Digger communities and sympathizers carried out similar actions.
} 
let's get it over with" (McKay 2011a, p. 120). Local police fired shotguns into the crowd, killing one and seriously injuring over 100 others. This led to days of rioting to which the National Guard responded by spraying teargas from helicopters. Looking back, Nettle reflects that we can see People's Park as a key moment in the story of origin of community gardens in North America (2014, p. 36) - at least for those gardens that have sprouted on re-claimed vacant city lots. ${ }^{119}$

Another important historical development in this (admittedly very English) lineage is the early $20^{\text {th }}$-century Garden City movement, started by Ebenezer Howard. Though it was later associated with much more moderate influences and outcomes, Howard's Garden City movement began as a radical combination of social idealism and landscape design a "'new commonwealth' less dedicated to the dictates of capitalist competition and more to cooperative socialism" (McKay 2011a, p. 33). In a draft of one of the diagrams for his Garden Cities of Tomorrow, Ebenezer Howard wrote the instruction, "GO UP AND POSESS THE LAND!” Appealing to socialists and utopians alike, the Garden City model entailed combining what Howard saw as the best features of town (social opportunity, high wages, cooperation) and country (rural beauty, pure air and water, and freedom) in such a way as to overcome the limitations of each (lack of society and work in the country; and crowds, high rents, and slums in the city). A crucial piece of the

\footnotetext{
${ }^{119}$ Many people date the community gardens movement back to its beginnings in New York City, with the first garden established by visionary artist Liz Christy and her Green Guerillas in 1973, making it now roughly 45 years old (McKay, 2011a). But others have pointed out that this may be a particularly White telling of a larger story. Hern (2016) quotes an African-American community leader in Portland as saying "We always gardened. We always shared our gardens and our food. We didn't need 'community gardens', that's a white invention" (as cited in McClintock, Miewald, \& McCann, 2018, p. 368).
} 
vision was that the Garden City's land - both its gardens and its parks - would be commonly held: "under the ownership of the citizens themselves, financially managed on their behalf by a board of trustees" (McKay 2011a, p. 31). Boundary markers such as hedging were discouraged, in the interests of encouraging more social interaction and community. Raymond Unwin, one of the project's architect-proponents, expressed the project's vision for social change through design in these words:

In the squares and quadrangles of our Garden City dwellings the spirit of cooperation will find congenial ground from which to spring, for there association in the enjoyment of open spaces or large gardens will replace the exclusiveness of the individual possession of backyards or petty garden-plots. (Coates, 2001, as cited in McKay, 2011a, p. 32)

In the first actual Garden City, Letchworth, gardens abounded; there was also a food reform restaurant and a health food store. Yet, as with community orchards, the Garden City movement wasn't really about the food per se. Rather, gardening (including the planting of fruit trees) was but one element of a larger social experiment that sought to reduce urban deprivation and engage residents in collective self-governance. In McKay's words, the model, at its best, "offered routes out of an atomized urban experience and into the social city" (2011a, p. 41).

More recently, beginning in 2011, the Occupy movement used food-growing to assert a claim to the commons. In Berkeley, California (echoes of People's Park!) 200 urban farmers occupied the research farm at the University of California (Berkeley) and planted two acres of crops in an effort to prevent the land from being sold off for condominium development (see Brooks, 2012; Conant, 2012). ${ }^{120}$ Not only was this a protest against

\footnotetext{
${ }^{120}$ This story was recently made into a movie. See http://occupythefarmfilm.com/ for the official trailer.
} 
COMMUNITY ORCHARDS AS NEW URBAN COMMONS

private development; it was also a fully embodied critique of the role of private (corporate) interests in shaping knowledge and research at publicly funded universities. Of course, growing food wasn't incidental to the strategy; it was heralded as the best alternative use of land and one that represented values counter to those of privatization like cooperation, and sustainability, and putting human need before profit. Occupy isn't the only movement for social change to have employed the growing (or at least planting) of food as a tactic to claim or re-claim land; The Land is Ours, Reclaim the Streets, Critical Mass and protests against the World Trade Organization (WTO) have all done so at one time or another (Nettle, 2014; McKay, 2011a).

\subsection{Resisting Enclosure}

Considering all these examples, historical and contemporary, I believe that what is going on in this resistance to enclosure has the following significant features, which are shared by community orchards:

1) Challenging the ordering of space into the exclusive binary categories of private and public and asserting the existence of a liminal space between the two;

2) Recognizing and promoting non-ownership interests in land, thereby breaking down the absolutism of private property and furthering the true "sharing economy"; and,

3) Asserting the rights of collectivities - and the benefits.

I will discuss each of these in turn, along with the challenges they pose and how community orchards are meeting them. 


\subsubsection{Challenging the public/private binary}

Blomley asserts that "One of the most consequential of categorical boundaries relating to the spatial order of property is that which separates the realm of private ownership from the sphere of public ownership" (2005, p. 283). According to Elshtain (1999, p. 24) it is a fundamental (not incidental or tangential) ordering principle through which the sociospatial world is rendered intelligible (as cited in Blomley, 2004, p. 284).

$[\mathrm{P}]$ rivate and state ownership are assumed to exhaust all viable options for property. Thus, there may be many owners of land, but, for practical purposes, ... only two classes of ownership (Geisler, 2000, p. 65). While private ownership is clearly the expected norm, forms of collective ownership are acknowledged. However, these are carefully hedged: either ownership is vested in private parties or it resides with organized governments. Thus, in the conventional lore, markets are based on private rights, or, when markets fail, property may be governmentally managed (Rose, 1994, p. 110). (Blomley, 2004, p. 283)

Consequently, challenges to this spatial ordering are of real consequence. This explains why community orchards sometimes encounter resistance as they declare and begin to inhabit a liminal realm between the public and the private. This liminality is both in terms of ownership - government vs. individual - and activity - those things we do out in public vs. those things we tend to do more in domestic settings, like grow and prepare food. By bringing food cultivation out of the domestic space of the home or backyard and into a publicly owned and publicly accessible space, orchardists are blurring the distinctions between private and public, creating what Blomley (2005, p. 281) calls an "interstitial activity" and upsetting the "normal" ordering of urban space (Wekerle, 2005; Wekerle \& Classens, 2015, p. 1178). This assertion of a liminal space can lead some (e.g., uninvolved neighbours) to object to the existence of an orchard within city boundaries, seeing agriculture as something that belongs more to the countryside (as described in Chapter 4). Liminal space can also confuse people, particularly when it 
comes to harvesting - Can I really pick and eat these berries?? And if so, how many? It may also bring to the fore cultural and linguistic differences among users of the space. To this end, Martin (Strathcona) gives the example of an older Asian community gardener who was regularly bringing night soil down from her house to use as fertilizer: ${ }^{121}$

[T] hat's what she would have done, where she came from, but you can't do it here; there's a restriction against it. So, there's been a need to get translators in at various times...And you probably wouldn't want to put that on a sign...maybe just keep that between gardeners. We have to think of this as a public space.

Inhabiting the liminal realm is particularly challenging for organizers, as Sylvia (Strathcona) explains: "Part of our lease agreement stipulates that it has to be open to the public, but because we're leasing the land, we're responsible for everything." As a leaseholder on Parks land, Strathcona community gardeners can erect buildings, hold weddings, and allow members to spread the ashes of loved ones in the space. But they must also take care of any garbage the public leaves behind and fix costly breaks in the water lines of their underground irrigation systems, which seem to occur multiple times a year. As Sylvia further explains:

Legally, it's not public space, but conceptually, it is. We lease this property, and we develop the rules for what happens on that property, but with caveats. It's a really weird thing. We're kind of stuck in the middle. We can't have an event there without getting a liquor license, let's say...We straddle the public and private; there's no clear distinction. And every week I look over more paperwork and try to figure out, How does that work? What are our obligations?"

The line between acceptable and unacceptable uses of garden/orchard space is particularly hard to draw and maintain. Recent legislation in both Vancouver and Victoria allows those experiencing homelessness to camp in parks (Sinoski, 2015), but it does not

\footnotetext{
${ }^{121}$ Night soil may be defined as "human excrement collected at night from cesspools, privies, etc., and sometimes used as a fertilizer" (Collins English Dictionary, 2018).
} 
apply to community gardens. This puts the gardeners and orchardists in the bizarre and ironic position of governing, what Betsy (Strathcona) called their "non-private private space”. Both Strathcona and Spring Ridge Commons have had to tear out large tangles of wild Himalayan blackberry because they were so overgrown that people had created little cave-like spaces inside, which they were using to conceal bicycle chop shops (where stolen bicycles get dismantled and built into new ones). Strathcona and SRC have also had to decide for themselves as a matter of internal governance (and debate) whether and under what conditions to allow people who are tenting to stay. Evicting people from a community orchard would seem to contradict orchardists' espoused values of inclusiveness and their clear distaste for enclosure. Moreover, members of these organizations tend to feel great empathy for the homeless, many of whom struggle with untreated mental illness and/or addictions. Says Martin (Strathcona), "You know, I'm not one of those Not In My Backyard (NIMBY) people. People on drugs don't bother me half as much as you know, some person that lives next door, with their Mercedes, that is uppity." At the same time, organizers also have to ensure that activities taking place in the space don't impinge on others' safety. Tents are one thing, but used condoms, discarded needles, and human feces are not welcome.

Consequently, both groups' practice has generally been to tolerate what they can, but then eventually ask campers to move on, calling in City staff assistance where necessary to help. It's never easy. Says Séan (Spring Ridge Commons),

We want it to be a refuge for people who need it and that means the homeless folks, right? So, it's a question of keeping the balance between the people who are in desperate need and the needs of the neighbours who want to live in a safe neighbourhood. 
On the positive side, the emergence of community-maintained liminal spaces like orchards tends to pique an interest, on the part of neighbours and passersby, in what is going on in their local green spaces, and often a greater respect for it. Said Tanya (Copley), "I know that once I tell people that I'm a volunteer cutting the grass, there's often more empathy to the situation than [if] I'm a City worker cutting the grass." Some interviewees also felt that this heightened respect for community members who are volunteering their time for the greater good translated into more respect for the land itself. Said Augusta (Jonathan Rodgers): "I think the more that it looks like [volunteers] are caring for the trees, the less likely they are to be vandalized, and the less likely someone is going to think, 'Oh, this is just the Parks Board' or something." These reactions underscore the novelty of caretaking arrangements in a commons, where users of shared space are accountable to each other, not to a higher or distant authority. But these are early days and most of the public has yet to recognize or appreciate the difference. Vandalism still occurs - people knock over beehives, write graffiti on sheds, dump old tires and appliances, even take axes to picnic tables, destroying them. Fortunately, these events, as disheartening as they may be, occur infrequently.

In the end, we might ask, of what value is it that such liminal spaces even exist? I believe the answer is that as the commons are neither private nor public, their viability and workability requires a space in between. Advocates of the commons have pointed out that "the concept of the modern city builds itself in the systematic negation of the notion of commons" (Bandyopadhyay, 2011, p. 36). This is largely due to the ways that neoliberalism has shaped urban form with its preference for the revenue-generating 
spaces of entrepreneurialism, private ownership, and capital (Blomley, 2004; Harvey, 2008; Lefebvre, 1991). Commoning, therefore, strives to reverse this trend by removing enclosed land and space from the private realm and returning it to the public, though not in the form of the local state; rather, into the realm of ordinary people (commoners) who control it democratically (at least in theory). Given the usual bifurcation of property into only private and public, this third realm is necessary if commoners are to have any agency in shaping urban space. (This will be the subject of Chapter 9.)

Perhaps the greatest value of liminal spaces lies in their capacity to bring the realm of social reproduction into conversations about politics, following the long-standing feminist tradition of making the personal political. Food - including all the ways it is produced, procured, prepared, and shared - is both essential to social reproduction and at the same time, contested, as it raises important questions of power having to do with who does it, for whose benefit, at whose expense, where, how, and with what impacts on the Earth. Making food activities more public is a way of repositioning the domestic sphere as the centre of collective life, and about providing a foundation for re-appropriating and re-collectivizing social reproduction as a way to break from the social isolation and ecological unsustainability of a system predicated on the single, nuclear-family home and the gendered division of labour that tends to prevail within (Federici, 2011; Tornaghi, 2016). Doing so in liminal spaces also draws public attention to the potential to re-embed economics in nature, culture, ethics, and spirituality through communal effort, ritual, celebration, socialization, and reciprocity with the Earth (Mies \& Bennholdt-Thomsen 2001, Quilligan 2012). Ultimately, it helps provide us with a roadmap of where we need 
to go if we wish to grow a food system that is "able to supersede market-driven, unsustainable, unequal and individualized approaches" (Tornaghi, 2016, p. 797) and an economy that is embedded in, and subordinate to, social and cultural life in general.

\subsubsection{Recognizing non-ownership interests in land}

The idea of usufruct - the right to use and harvest from the land in the absence of property ownership - is hundreds, if not thousands of years old (Goldie, 1985; Pierce, 2010; Wekerle \& Classens, 2015, p. 1176). Usufruct is borne out in laws and customary practices governing the sharing of water, and in age-old practices such as gleaning, which was one means through which peasants resisted enclosure in the early $17^{\text {th }}$ century (Linebaugh, 2009, p. 76). It is also testament to the idea that property in practice (notwithstanding our binary mental construct of it) is dynamic, often blurring the private/public boundary. Blomley (2004) asserts, in fact, that property is not even really a thing but a socially enacted relation between 'owners' and 'non-owners' (see also Wekerle \& Classens, 2015). Community orchards' implicit assertion that the fruit they produce is for sharing (whether just with members or with the public at large) is an affirmation of usufruct and a way of challenging the institution of property by breaking it into its constituent elements or rights.

While we typically think of property in terms of private, fee-simple ownership of a piece of land, this is not the only way to think of it. Elinor Ostrom argued that what we normally call 'property' in fact refers to bundles of rights, separate and combinable in different configurations. They include rights of access (the right to enter a property); management (the right to transform the resource and regulate internal use patterns); 
withdrawal (or usufruct) (the right to harvest specific products from a resource); exclusion (the right to decide who will have access, withdrawal or management rights); and alienation (the right to lease or sell any of the other four rights) (Ostrom 2009, p. 419-420). Common property may confer rights of access, management, withdrawal, and exclusion without conferring any rights of alienation. Furthermore, it is possible to make moral claims to property in which one does not even have a stake of ownership. Blomley (2008), for example, argues for the property rights of the urban poor who use and inhabit the public urban space they do not own. Seeing property as bundles of rights, and disentangling rights of access, use, and management from ownership, frees us to imagine a wider variety of spatial forms and more diverse ways that community groups might be entitled to use it. Again, this unsettling of hegemonic spatial notions is a necessary building block to the development of commons, especially food commons. In an era in which there is such a disparity between the outrageously high costs of land on which to produce food and the untenably low profit margins for food producers, we need diverse and creative land use strategies now more than ever.

We can see the revival of usufruct and this unbundling of the rights that constitute property occurring in other sites beyond community orchards and gardens too. These include organized gleaning programs such as LifeCycles' Fruit Tree Project (Victoria), the Vancouver Fruit Tree Project, Not Far from the Tree (Toronto), Hidden Harvest (Ottawa) and many others. ${ }^{122}$ In these programs, volunteers harvest excess fruit from trees belonging to private landowners who agree to share the harvest with the volunteers

\footnotetext{
${ }^{122}$ See Poitevin-DesRivières (2018) for a detailed case study of Ottawa's Hidden Harvest.
} 
and/or a local food bank. Another similar development is that of sharing backyards, in which property owners with space but without the ability or inclination to use it productively share their yards with urban farmers who wish to produce food intensively but haven't the land to grow it on. Wekerle \& Classens (2015) write about one such initiative run by the AfriCan Food Basket (AFB) in Toronto. Vancouver's City Farmer does something similar with its Edible Garden Project (Salomone, 2013). A third example is the growing popularity of urban foraging, a practice in which "city residents interact with diverse urban landscapes and vegetation, often finding edible, medicinal, and craft-related species in formally and informally managed spaces where ownership may be less than clear" (McLain et al., 2014, p. 235). This practice, which some would label subversive, takes place in alleyways, along railroad tracks, and other interstitial spaces, as well as in public parks - notwithstanding the fact that rules prohibiting foraging in public parks are commonplace (McLain et al., 2012) ${ }^{123}$ Foraging can therefore be understood as another liminal activity - neither private, because it takes place in public space, nor public, because it is not sanctioned or provided by any level of government. Foraging is also liminal because of the unconventional relationships with urban nature it encourages. While parks have been historically viewed as pleasant backdrops within which to rest and recreate, the harvesting of nuts and fruits in parks brings park users into a material interchange more similar to a "working forest" approach (McLain et al., 2014, p. 235). This makes foraging "neither entirely urban nor rural" (ibid, p. 237).

\footnotetext{
${ }^{123}$ McLain et al. note resistance by municipal park managers to foraging: "park managers in New York City consistently describe foraging as an inappropriate and incompatible use." (2014, p. 235). This is not the case in Victoria, where the City now encourages commons gardens (defined as open-access, specifically for the public to glean from) and boulevard gardening.
} 
To summarize, community orcharding, gleaning, sharing backyards and foraging are noncapitalist practices (Gibson-Graham 2008) that articulate rights of access, use (usufruct), and harvesting not to ownership but to stewardship based on an ethic of care for both the land and other people (Certomà \& Tornaghi, 2015, p. 1128; Wekerle \& Classens, 2015). While each on its own may not seem terribly significant, when seen in the context of each of the other alternative forms of tenure and land use that have recently arisen, the potential cumulative impact starts to seem impressive. To this list we may also add other novel arrangements - for example, the growing of food on the grounds of schools and churches and hospitals - which seem to be growing in popularity and legitimacy (McLain et al., 2014). Collectively, these undertakings promote what we might call the true "sharing economy" (not to be confused with the unregulated renting economy) which is not only more social, but also more environmentally sustainable. ${ }^{124}$

\subsubsection{Asserting the rights of collectivities}

The third aspect of resisting enclosure has to do not with the object of property (the land) but with the subject (who has rights to it). While private property is associated with individuals or corporations (which are treated as persons under the law), and public property is said to be "owned" by the vast and impersonal entity that is the state (or the "Crown" in Canada), the metaphorical space allotted for collective property by groups of

\footnotetext{
${ }^{124}$ It is not only community orchardists, gleaners and foragers that are driving at this. McClintock \& Simpson report with interest that more than 40 percent of the (small-scale alternative) food businesses they surveyed in Cascadia (Vancouver, Portland and Seattle) also identified "reclamation of the commons" and "alternative economy/non- or anti-capitalist exchange" as primary motivations $(2016$, p. 71$)$.
} 
people in North American society is relatively small, at least for most non-Indigenous people. ${ }^{125}$ Of course, we have models of collective ownership - both those that are associated with exclusive and elitist institutions (e.g., private yacht clubs, ski clubs, golf clubs, gated communities, etc.) and those associated with more progressive politics (e.g., cooperative housing, credit unions, workers' coops, and community land trusts, which are growing in popularity) (Huron, 2015; Wekerle \& Classens, 2015). For those who resist privatization, new and more institutions of collective ownership are vitally necessary; the rejection of enclosure demands workable alternatives. Some advocates of the commons would go further to say that the commons are not about common property (a term some see as conceptual slippage), but about erasing the whole notion of property: "An agenda for commons is a project to undo property and to unlearn the pedagogy of modern law. This might be an impossible project. But, it is impossibility that constitutes the very philosophy of activism" (Bandyopadhyay, 2011, p. 41). For that reason, and because community orchardists are not in a state of legal ownership of the lands they work (they lease them), it is more correct to speak of collective trusteeship. Hence, one of the goals expressed by community orchardists is to open up the space of possibility for more collective trusteeship in the public imagination. Matthew spoke directly to this point, when he described Copley Community Orchard:

It's a new kind of public space...I think the way we conceive of public space in our society is that public space is kind of everyone's and no one's and then private space is someone's, and there isn't really space for collective ownership. And what we're doing at Copley is we're creating space for that collective identity again, to have a sense of owning something together.

\footnotetext{
125 Of course, Indigenous communities are more familiar with concepts of collective rights and title, and the nuances of their relationship to concepts of property. These offer a useful model for the commoning movement. Moreover, I believe that that non-Indigenous proponents of the commons may, in turn, be able to support Indigenous resurgence by reinforcing the legitimacy of collective ownership/trusteeship.
} 
As novel kinds of arrangements that many community members have limited experience with, community orchards, as organizations, must grow into these ideas - and do so together. Susan (Ben Nobleman) talked about how different communal norms are from those that prevail where she lives:

You know, in the old days an area like this was called the commons, and everybody knew it belonged to all of us, not one of us... [but] kids that grow up in this neighbourhood don't even understand that concept... And it's not that they're not good kids, it's not that they're not from good families. They just have been brought up in huge one-family homes where your stuff is your stuff and nobody should touch your stuff and you don't share your stuff. You know?

Tanya (Copley) spoke to the same issue when she described her group's learning in this way:

[At the beginning] people were like, "You will have your own tree and then you can decorate your own tree and make little circles around it..." And then, finally, I just said, "So when my tree doesn't have any apples on it and yours does, I'm going to pick apples from your tree! Right? [laughter] And I remember making that joke, and people laughed and then they went, [more soberly] "Oh, right. So, the garden model doesn't work for this orchard." See, I'd never been part of a community garden, so I didn't have this sense of my plot. But a lot of the people had, and so they had this sense of ownership of the plot. So then once that broke and people started going, "Okay, this is a community project," then that was the first breakthrough.

The lack of experience means that groups have to figure out for themselves what is appropriate and proper in the use of collectively held space. They come to see the need for some authority and some regulation, but, as described in Chapter 5, they often struggle to arrive at internal consensus on these points and then to communicate their understandings to the public. It's a long and steady learning curve, to say the least. That said, collective trusteeship is already working sufficiently well at most sites that many interviewees could express a clear appreciation of its benefits. David compared Strathcona to other community gardens that are more allotment-based: 
[Strathcona] is actually run by everyone together; everyone has a stake in how it operates. It's not just me going to my individual plot. It's me going to my individual plot in this context of a shared space that we all take care of together, which is what Strathcona is. And we say, given a preference, this one's way better. Because you're getting more than just your food.

Séan (Spring Ridge Commons) indicated that the collective use of space was a primary motivator for him:

One of the essential things for me is this overcoming of...this emphasis on private property and on my own little space and my car, my house, my fence around it, and my life...or the project of my life which is just somehow this little bubble that exists in and of itself or itself. And sort of coming out of that a little bit, gradually, by just finding these spaces where it's possible to meet your neighbours and do something together that is in everyone's interest: growing food, food that is shared, you know?

In each of the above quotes, we hear the overtones of a desire for a true sharing economy. We get the sense that those involved are engaged in expanding their circle of care and ethical concern beyond the usual bounds in a society that treats private property ownership and nuclear families as the norm. However, as clear as the benefits of collectively held space are, there are also challenges.

\subsubsection{Boundedness, without enclosure}

The kind of sustainable natural resource commons that Elinor Ostrom studied were managed or stewarded by a self-identified community of interdependent users that was associated with that piece of land, and each other. In fact, Ostrom found that the boundedness - the clarity of boundaries demarcating both the community and the resource - was perhaps the most important feature of successful, sustainable commons 
(Cox \& Arnold 2009; Ostrom, 1990; Ostrom 2009). ${ }^{126}$ The reasons are rather selfevident: communities of users equally dependent on a shared resource will share a mutual vulnerability and a need to be accountable to each other. Knowing where the resource begins and ends is important for monitoring resource use and for communicating the bounds of the commons to others; likewise, knowing who is part of the community, and therefore responsible for its maintenance, helps to ensure that no one is free-riding or shirking responsibility. Those who succumb to these temptations can be sanctioned by their fellow resource users and pressured to pull their weight going forward. Because the commons are not just resources or the land, but the whole system governing them, the community and the land together is a socio-ecological whole that must have some definition if it is to remain in balance.

In a community orchard, clear boundaries around both the orchard itself and the community (i.e., by limiting access to members) would, on the one hand, help ensure equitable sharing of both the fruit and the labour; all those who helped themselves to fruit would also take on their fair share of maintenance responsibilities. However, most community orchards are required by the terms of their leases (and their location in public

\footnotetext{
${ }^{126}$ The other principles or best practices are less germane to community orchards, given their lack of emphasis on the distribution of the fruit, and their lack of rules. However, as an interesting aside, they include congruence (between appropriation and provisioning rules and local social and environmental conditions; as well as proportionality between the benefits obtained by users and the inputs required - i.e., labour, material and money); collective choice (most of those affected by the rules can participate in modifying them); monitoring (of users and the resource itself by monitors who are accountable to the users); graduated sanctions for non-compliance; conflict-resolution mechanisms that ensure rapid access to low-cost local arenas for resolution of conflicts; ability to self-organize without challenge by external government authorities; and nested enterprises (the organization of all the above in multiple layers, nested by scale) (Cox \& Arnold, 2009; Ostrom, 2009).
} 
parks) to be fully open to the public at all times. Moreover, many community orchards are philosophically committed to an ideal of the commons that is not bounded at all. ${ }^{127}$ Unfortunately, this ideal of boundlessness seems to derive from a misunderstanding of commons as places to which anyone can have access but toward which no one need feel any responsibility. I believe this misunderstanding can be attributed to Hardin's very widely accepted "tragedy of the commons" thesis. Under these conditions, I would agree that tragedy (the despoliation of the commons) is indeed a possible, even likely, outcome. The problem is that Hardin did not distinguish between open-access resources and common property. Open-access resources are defined by the absence of any rights to exclude, and therefore by an incapacity for management or regulation; whereas 'common property' is associated with collectively held rights to exclude others (Poteete et al., 2010). This simply means that common property is managed or governed by a group; and groups, by definition, must have boundaries if it is to be at all clear who comprises the group that is doing the managing or governing and is agreeing to be bound by it. Said Jane (Banfield), "I can see how it would be a lot easier to have a commons if there were an acknowledged boundary, rather than a kind of leaky boundary." To be clear, this does not mean that anyone should be excluded who wants to join, just that joining should mean something. In the interests of sustainability, rights of access and usufruct must be balanced by responsibilities. Moreover, people are better able to accept and fulfill responsibilities when they elect to join a group, and both rights and responsibilities of membership are clear. (Those who haven't joined or made a commitment can also be clear that neither the rights nor the responsibilities pertain to them.)

\footnotetext{
${ }^{127}$ Strathcona, as a well-established membership-based organization, is the exception here.
} 
Sometimes, however, the idea of boundedness gets mixed up with orchardists' legitimate concerns about exclusion - the fact that they do not want there to be any barriers to participation nor any limits to giving. In the words of another interviewee, the very idea of in-groups or out-groups "makes us feel racist":

Especially if you were raised on the multicultural theory of acceptance and tolerance - which are really positive values - it's hard to find a place for that boundary without feeling guilty about it. But...it exists whether you acknowledge it or not, and when you're building a group, if you don't have it, you're going to run into huge problems - mostly problems of just expending so many resources and so much of your time and then having it just get dissipated into this vast, unquenchable network of strangers.

As long as boundedness is seen as tantamount to enclosure, orchardists' commitment to radical inclusion (absolute open-access) comes into a seemingly irresolvable tension with the need for responsibility to be shared by all users. Often, the consequence is that a few people end up acting as the primary stewards and a much larger number of people walk through the orchard, many of them just helping themselves to fruit, but not feeling like they are part of something or that they need to give anything back. These passers-by are not members of the orchard and they may not even want to be. (It seems unlikely that non-members are going to come through the orchard and spontaneously put down some mulch or do an hour of weeding, yet some organizers did express to me that they hoped this might happen.) Furthermore, those few who carry a disproportionate share of the weight of keeping things going are often personally torn between the ideal they have set for themselves (to share unreservedly with anyone and everyone) and the reality of their own limitations, in terms of time, energy and motivation. While some interviewees expressed an acceptance of this imbalance, at least for now, others suggested that they were beginning to feel it couldn't last. One interviewee commented that "the way it 
appears it's happening is a free-for-all, right? Like, we're working the land and people are eating it."

It is, however, possible to see the boundedness question as being unrelated to inclusion or exclusion and related instead to the presence or absence of conditions for access or participation. In other words, anybody can join, if they are willing to comply with the rules or norms or just the basic concept of give-and-take. As Wayne (Copley) put it, "We're willing to take anybody who wants to be part of it, to help out with any aspect of it. So, it's open to anybody. It's not bounded." Membership, in this view, is not about inclusion or exclusion, but about having a sense of belonging that includes a commitment to contributing.

On a more material plane, there is the question of fencing. This is a delicate subject. To some community orchardists, erecting a fence around the orchard would be tantamount to enclosure (a very weighty word in this movement) - and, as George McKay points out, likely summons a visceral rejection of the most elevated and anti-social form of private property prevalent today, the gated community (2011a, p. 192). In Vancouver, the Parks Board even prohibits fencing on their properties. For others, however, a fence simply offers much-needed protection for the fragile young trees. In fact, as Kurtz (2001, p. 660) notes, the origin of the word 'garden' is the Indo-European root gher, to enclose. Protecting the orchard is also a matter of equity, as one can easily argue (as Karl Linn did) that the labour and loving creations of those who volunteer for the public good deserve as much protection as does the private property of individual landowners (2007, 
p. 21). At Banfield Community Orchard in Victoria, it was clear that the orchard would require a fence around it to protect it from deer (of which there are many in the city). The City initially resisted, out of concern that fencing would convey the sense of a private space within a public park. The group countered by comparing the orchard to the adjacent tennis courts, which also require fencing to keep balls contained, but are nonetheless open to all. They then proposed a re-design of the fencing to make it as open-weave as possible with artist-designed gates that would serve as welcoming portals, making it very clear that everyone was permitted and encouraged to enter. In the end, the City agreed and the fence and gates appear to be performing both of their intended functions.

\subsection{Conclusion}

Commoning is first and foremost a resistance to enclosure and the institution of private property. Community orchards, like other commons, offer a model that challenges the hegemonic ordering of property into only two categories (public and private) and carves out a liminal space in between. They do this in part by dis-articulating the various rights that are bundled together in the concept of property and asserting a moral-political (if not legal) claim to space that is based not on ownership (rights of alienation) but on rights of access, withdrawal (usufruct), and management, built on an ethic of care. In doing so, community orchards fundamentally challenge dominant conceptions of property in which atomistic individuals (or the state, or corporations, acting as legal persons) own alienable bits of nature, and replace it with a more ecologically oriented model of trusteeship. Community orchardists do struggle somewhat with rights of exclusion, which form part of the bundle we call property (even common property); while some orchardists might 
like to be able to establish boundaries around the resource for the sake of sustainability, they are generally quite reluctant to do anything that might communicate a message of exclusion. Instead, they focus on the rights of collectivities (loosely defined) and on the benefits - the joys that come from working together on a shared project that is at once tangible (in the form of the orchard itself) and intangible (in the sense of manifesting and inhabiting new political spaces that model more communal ways of being in the world). The establishment of orchards exemplifies Blomley's (2004) claim that property is “a crucial basis for political claim-making and creative opposition" (Wekerle \& Classens, 2015, p. 1177). In the following chapter, I explore more deeply the nature of the spaces community orchardists are claiming for community, and the requirements and challenges that attend the construction of community space. 


\section{Chapter 7 - Appropriating Space for Community \\ "And we became a park!",128}

\subsection{Introduction}

To a casual observer coming across the 14 fruit trees that constitute Ben Nobleman's community orchard - trees that are, more often than not, devoid of fruit and therefore look much like any other trees one might find in a park - it may be hard to appreciate the significance of their existence and to understand the feelings they evoke in those who have worked so hard to establish them there. But the transformations of public space that have come about with community orchards are highly significant, if not always dramatic or showy. In Chapter 6, I looked at community orchardists' efforts to resist enclosure or the privatization of land through the disarticulation of the various rights that are bundled in conventional notions of property and the valorization of a different kind of property rights - ones that accrue not based on individualistic legal ownership but rather on collective stewardship and care. In this chapter, I turn my attention to public land and explore what it means to claim or appropriate public space for community in a way that distinguishes it from public space that is provided and maintained by governments. Again, I describe how community orchardists make such claims, what challenges they encounter along the way, and what ethical, political, and intellectual issues are raised by these developments.

${ }^{128}$ This quote comes from Lynn (Ben Nobleman). 
COMMUNITY ORCHARDS AS NEW URBAN COMMONS

I situate this analysis within the emergent conceptualization of urban agriculture as an alternative social production of space, a discourse currently articulated by urban theorists and critical geographers interested in relations between community groups and local governments. Certomà and Tornaghi call this "the new urban land question" by which they mean the "emerging urge for access to, and direct control of, urban space" (2015, p. 1126). We can plainly see this urge expressed in the transformations of all sites I studied.

\subsection{Spatial transformations}

It is evident from talking to community orchardists that the spaces to which they have dedicated countless hours, weeks, and even years of their time, have all undergone deeply meaningful transformations as a result. Interviewees commented on the dramatic increases in usage of those spaces by the public - people setting up lawn chairs amidst the blossoming trees, bringing their children to play and explore, eating lunch at the picnic tables, hanging out, playing guitars. In some cases, this increased usage of the space can be directly attributed to the establishment of the community orchards. In other cases, the community orchard instigated an engagement with the space by local residents which then snowballed into other initiatives that built on that initial excitement. Having described each of the sites in Chapter 4, for my purposes here, I will just recall those descriptions to refresh the picture in the reader's mind.

\subsubsection{Copley (Vancouver)}

What was once a large field of tall grass, crisscrossed with footpaths and mowed a few times a year, now features numerous varieties of flowering fruit trees, vines, shrubs, 
strawberry patches, raspberry canes, even perennial beds of rhubarb and asparagus. A tidy little red-and-white painted toolshed sits partway along a comfortably wide peagravel path lined with food-bearing trees that get more impressive with each passing year. Signage welcomes visitors and picnic tables entice them to stay. Volunteers have cleaned up the underbrush around the older "heritage" trees, and they make a point of collecting fallen fruit before it rots. While the immediate neighbourhood had previously been a site of muggings, drug activity, and even a murder (some years ago), interviewees associated with Copley noted that they felt the space was now much safer. Co-founder Jodi Peters described the transformation as "taking a space that was really run-down and ugly...and creating a model of functionality and use that people benefit from. That transition that the community can see, right in their neighbourhood, is pretty big." Said Wayne, "it's just like night and day, [compared to] four years ago."

\subsubsection{Strathcona (Vancouver)}

If any of my sites could be described as 'formerly blighted', this would be the one. Strathcona's orchard, however, is just one part of a larger community garden, within an even larger park, and needs to be understood in that context. In Chapter 4, I recounted the long history of Strathcona's development, so here I will simply reiterate that it was due to the unrelenting persistence and resilience of community members that the site was transformed at all. The City, of course, played a role, but the instigation and pressure came from local residents, who, over many decades, took it from a mud flats-cum-hobo camp-industrial wasteland - with no plantings, no seating, no drainage - to a highly valued and well-used neighbourhood amenity that now includes a soccer field, a 
skateboard park, a climbing wall, a gazebo, pathways, water fountain and, of course, Strathcona Community Gardens (including the orchard) and its sister site, Cottonwood Gardens. Strathcona features an eco-pavilion with solar panels, a composting toilet, and a greywater recycling system that uses irises to purify the water. Two large recent grants and a generous donation of native plants have allowed gardeners/orchardists to begin planning a pollinator meadow, with boardwalk and pond, where they envision local experts initiating "citizen science" projects with schoolkids. Martin reflects on the dramatic transformation:

This park looked like hell when it was first...it was just a mud pit! It SUCKED. It was the worst park in the city. Now, it's always active and it's way less undesirable. People even walk dogs at night now...There's been a HUGE labour of love to make this place.

\subsubsection{Spring Ridge Commons (Victoria)}

As outlined in Chapter 4, the transformation of a school bus parking lot into a food forest has been ongoing since the late 1990s, with periods of disuse and overgrowth interspersed with periods when stewards lavished great care on the space. That care is in evidence today in the form of a thriving multi-story permaculture system, with wellmulched pathways that wind in aesthetically pleasing arcs through the greenery, leading to a central gathering space made of whimsically painted benches where stewards, neighbours and all manner of free spirits come together for herbal tea under the shade of a large damson plum tree. To the east, there is a beautiful mural painted on the side of a neighbour's garage. And throughout the space, the creative spirits of artists are in evidence, whether in the signage, the toolshed, the herb spiral or the painted pole. Linda Chan, one of SRC's primary stewards over the past few years, describes Spring Ridge 
COMMUNITY ORCHARDS AS NEW URBAN COMMONS

Commons today as "a sanctuary... a space where [people] can be in nature and be away from the hubbub of life."

My two other main community orchards - Welland and Ben Nobleman - are located in parks, so their transformation was perhaps less visually dramatic; still, the shift from being under-utilized and minimally maintained to being spaces of ecological vitality and conviviality is a deeply felt transformative change for those who now call that space their own.

\subsubsection{Welland (View Royal - Greater Victoria)}

The site that is now Welland Legacy Park was meticulously maintained by Rex Welland for many years. In fact, it is his legacy of care that so inspires volunteers there today. After Rex's family donated it to View Royal, the Town did basic maintenance, cutting the grass and so on, but such a dense and horticulturally diverse orchard was well beyond the capacity of the Town to maintain. According to my interviewees, it was only when LifeCycles took over as custodian of the property that things came alive again. Said Tom, "The park is in much greater shape now than it was three or four years ago." Still, the main difference relates to the way community members have been grafted onto that space, slowly but surely, to the point that there is now a solid cadre of regular volunteers displaying a real emotional investment in what the space is becoming. City employees still come in to cut grass, but the more specialized and skilled horticultural work is done either by Julia (as LifeCycles' staff person) or by the volunteers she has trained through her Tree Care Apprentice program, begun in 2017, which is proving to be very 
COMMUNITY ORCHARDS AS NEW URBAN COMMONS

successful. Most volunteers are motivated by what they can learn - i.e., about fruit tree propagation, pollinator care and support, grafting, pruning, pest control, etc. - but Julia has also fostered an emotional attachment to the space that comes through in the words of volunteers like Deanna: "When I go into the orchard and I see that the caterpillars have got to them, it's funny; I am deeply affected, like Did I let that tree down?"

\subsubsection{Ben Nobleman (Toronto)}

In the words of Joe Mihevc, City Councilor for the ward in which Ben Nobleman is located, the little parkette was "a dead zone" before the community got involved. Orchard instigator Susan Poizner's term for it was "a dog-poop park"; and Lynn, hearing those words, added, "I'm sure some of the dogs probably thought, What are we doing here?!" In Lynn's words, the space has been transformed 'a thousand percent". Ben Nobleman's transformation owes itself not just to the addition of fruit trees, edible bushes, herbs, and the volunteer-initiated pollinator garden (which replaced diseased junipers and other lowmaintenance shrubs with colourful flowers that bloom all season long) but to the installation, a year or so later, of a new playground by the City of Toronto, and, of course, the 20-foot-long harvest table that Susan Poizner and her orcharding friends found funding for. It seems that once one group starts caring about a space and trying to make it better, it inspires others to join in. Now the orthodox Jewish community from the nearby synagogue regularly picnics in the park, enlivening the space even further. Mihevc couldn't be happier: "The planting of new trees, the attention, people cleaning up the park. The place is fully animated now. That park is whole. It's whole and it's good." 


\subsection{Animating Community Space}

This idea of "animating” is critical for understanding community space. As Karl Linn (2007, p. 206) points out, the Latin root word 'anima' refers to the soul, the vital principle. And it suggests this fusion of the social and the spatial that is at the heart of appropriating space for community. Appropriating, in this sense, is not just about staking a claim to something. Rather, it is about fostering a relationship in which the social (the community) and the spatial (the orchard) co-constitute and shape each other. My observations of community orchards suggest that there are four ways that this sociospatial relationship develops, each of which also acts to differentiate community space from merely public space (i.e., that provided and maintained by the state). These four mechanisms are participatory design; active labour; higher purpose; and psychological ownership.

\subsubsection{Participatory design}

Eizenberg notes that a community must do more than occupy a space and operate within it; to be a community, members must participate in the production of their own material environment according to a shared culture, history, desire and vision (2012a, p. 776). This observation echoes Lefebvre's view that space is essential to meeting a community's needs and realizing its rights: "groups... cannot constitute themselves, or recognize one another, as 'subjects' unless they generate (or produce) a space” (1991, p. 416). Consequently, it is in the creative and generative acts of design and building that landscapes become participatory (Saldivar-Tanaka \& Krasny, 2004, p. 409) and thereby rendered deeply meaningful to their inhabitants. 
At several of the orchards, interviewees described the various ways they sought to include neighbours and other community members in the planning and development of the orchards. Organizers at Banfield, who were actively engaged in other place-making initiatives in Vic West, sought community input as to the location of the orchard. They asked people to show them on a map of potential locations how they used those spaces; they hoped to identify a piece of the park that was accessible but underutilized and therefore not likely to create conflict - and they were successful. Organizers at Copley held an Open House, followed by a design charrette facilitated by an external party. Although they did not invite "blue sky" thinking (they had already committed to the idea of perennials and collective stewardship) they took existing usage of the space and other concerns shared by participants into consideration as they drew up precise plans for the space. Even once plans were approved, they sometimes changed, because of community input. At Ben Nobleman, the brouhaha that erupted was resolved in part by organizers drastically scaling back their plans to plant many fewer trees than they had originally hoped. It took four or five community meetings and a lot of skill and patience on the part of their City Councilor, but in Mihevc's words, "the community found its middle ground." Having now the benefit of hindsight, organizers who spoke to me stressed very strongly the need for more extensive community consultation, which may have prevented the misunderstandings that caused such hard feelings.

Maintenance and upkeep is also shaped by community consideration, for better or for worse. Typically, it has to do with the presence of weeds or the length of the grass. At Strathcona, Martin described a growing need for attention to what the neighbours may 
think. With the gentrification of the Strathcona neighbourhood, many of the things the old "lefty" or laissez-faire gardeners of the 1990s tolerated now have the potential to create conflict, as Martin explains:

We're in an area that's now changing - that road's going to go through, that area's going to be developed - this neighbourhood's getting full of a lot of mouthy, rich people. We'd better be more proactive. We can't, for instance, leave that corner filled with drug paraphernalia and blackberries.

Similarly, Matthew (Copley) described the influence of certain neighbours, who objected to the orchard from its inception:

There is still resistance, especially from neighbours on the west side of the orchard, and that resistance has definitely shaped the way we maintain the orchard and has pushed us toward having more of what I consider a Victorian garden aesthetic - really tidy, mowed lawn - rather than putting energy into really trying to maintain tree health or diversify the plant populations that live at the orchard to make it more of a forest-style garden.

Appeasement has a cost, in terms of energies diverted, but not appeasing the neighbours can often be worse. Spring Ridge Commons is a case in point. In Chapter 5, I described the friction between the creators of the Commons and those who live adjacent to it on all sides, a friction that erupted in vigilante maintenance in the summer of 2014. Tensions were high between Commons stewards and neighbours, the latter group having the Fernwood Neighbourhood Resource Group (NRG) on their side (the NRG offered to pay for the removal of debris from the site). Many people expressed their candid views on Spring Ridge Commons' Facebook page. Said one, who had volunteered as a steward for over 10 years, 'I'm still pissed off about it. It's my garden more than it is Fernwood NRG's". Today the friction with the neighbours is more quotidian, having to do with young people using "bongs" to smoke pot and/or making noise. 
Says Séan,

We are on pretty good terms with the neighbours; we do our best to keep a lid on some of the things that might be deemed obnoxious, like loud music way into the night and stuff like that. There is usually a little party in here, but for the most part it stays pretty reasonable, I think. At least that's my impression.

At other sites, conflicts with neighbours have been less overt, more subterranean.

Orchardists don't always fully understand the reasons for the neighbours' disapproval, but on occasion, the conflict itself has led to greater understanding across social divides. Martin described the situation at Strathcona some years ago when one of the garden's most charismatic and efficacious leaders, Mugs, decided to investigate why so many residents from the Asian seniors' home seemed to object to the gardens, or at least resisted becoming engaged. With the help of a translator, she discovered that they saw the gardens as being "like their old country, where they came from. They saw it as being about poverty, about the times that they wanted to leave behind." Mugs' investigation brought about the realization that perhaps the "garden chic" aesthetic cultivated by middle-class North American "foodies" is not universally admired.

At sites where community involvement has been limited, there is a noticeable lack of community psychological ownership of the space, and consequently, volunteer labour. At Fernwood, organizers chose to engage landscape professionals to design and maintain the orchard. This was a function of their priorities (a greater emphasis on fruit production), but the resulting orchard design - all trees, in rows, with nowhere for people to sit doesn't do a lot to foster community attachment to the space. At Norquay, despite many attempts to engage the community, organizers have struggled to foster a neighbourly attachment to the space, a desire to see it as their own. A staff member of the Renfrew- 
Collingwood Neighbourhood House Food Security Institute explained that while the commons model sounded "ideal...we're definitely not there yet...Right now it's taking much more shepherding than that." My engagement with Norquay was insufficient to offer a fully informed analysis of why this is the case, but all interviewees who spoke of Norquay seemed to convey a sense of frustration and disappointment about the lack of community engagement with the site. It is worth noting that community orchards (or other community spaces) that begin as projects of non-profit organizations face a peculiar challenge: they know that it is an important principle of community development to let projects develop and evolve according to participants' interests, and yet as grant-seeking non-profits, they must articulate an a priori vision for the space to potential funders. Said one interviewee,

Funders want to know exactly what you're planning to do before you do it. And unless you have the funds to support that kind of thorough consultation process, it's hard to say what the neighbourhood wants. Very few funders will give seed money for consultation.

The effect of participatory design is to make the orchard a lived space, reflecting the needs and possibilities of a group that modifies it to make it their own (Lefebvre, 1991, p. $366,165)$. Lived space tends to have a less managed aesthetic, compared to public parks. In describing their orchards, interviewees used words like 'untamed', 'organic', 'more like going to the country'. As Yoshi reflects:

When I go there with my kids and my kids' friends, it's nice that it has a little bit of a sense of wildness in the city. They have to come up with their own way to play with that space, without the structure or without certain toys. They have a path and trees and rocks and grass and they just figure out how to have fun. 
Said Sylvia (Strathcona),

You don't feel that it's too structured, or ...that you're being led to use the space in a particular way...it feels like anything goes. And that's a different feeling than in, let's say, a public park that has been designed by a landscape architect...At the same time, it also feels a little bit sketchy sometimes [laughter] because you don't know what's happening...

Lived space stands in contrast to the abstract conceived space of real estate investment and to the public spaces produced by planners and other professionals - whom Lefebvre called "elite corporate and state oligarchs" (as cited in Purcell \& Tyman, 2015, p. 1135). It is not that these professionals don't have great design sense and smart, practicable ideas; it is simply that there is a difference between spaces we experience passively - that are designed for us to consume - and those we have a hand in shaping. As Purcell and Tyman note, "[U]rban space should be familiar to users because they inhabit it every day. But in fact, it has been alienated, 'made strange' to them because it is produced not by them but for them by others" (2015, p. 1135; see also Neo \& Chua, 2017). Community involvement in design attempts to lessen this alienation and make community space feel different (comfortable, familiar) to users. When the process of shaping the space makes room for participants' imaginations and design sense, more people tend to join in.

As Karl Linn said, "people sense the dynamic energy inherent in the creative process and want to be part of it" (2007, p. 70). Linn learned this by trial and error. The early commons he helped communities design had little vegetation, and without the need for people to visit regularly to care for the plants, they were not well maintained. At same time, many community gardens were "devoid of sociability settings" (ibid, p.12). Combining the two became the most successful strategy for building lasting, cared-for neighbourhood commons. 


\subsubsection{Active Labour}

The second way that community space comes into being in community orchards is through the shared active labour of care-taking. The pride and sense of community identity that interviewees expressed in relation to their orchards didn't come about because somebody gave them that space, or even because somebody let them make choices about how it would look; the community had to work for it, together. As Sherry (Ben Nobleman) insightfully observed, "You can’t just call a meeting and say, 'We're a community'. You have to get people involved in doing." They need to experience their membership in community (Everts, 2015). In community orchards, that work, or doing, takes many forms: weeding, watering, collecting windfall, spreading mulch, grafting, pruning, mowing, repairing machinery, cleaning up tools, cleaning out pollinator "condos", managing pests, thinning fruit, not to mention all the planning and organizing that necessarily precede these more physical activities. In the process, communities shape their spaces, rendering them "zones of transformative care" (Tsing, 2012, p. 45).

Simultaneously, the act of shaping and caring for the space also creates the community. And the community consists not only of the people involved, but also of the plants and wildlife. Results of an internal survey conducted by members of Copley Community Orchard indicated that the model of collective caretaking is well-liked; respondents used phrases like, "One garden, tended by all" and "Like a community garden, only better." This aligns with De Angelis' (2003) view that communities are not constituted simply on the basis of common characteristics, such as living environments, beliefs, or professions. 
Rather, they are constituted through cooperation, collaboration and communication on the usage, production, and maintenance of a common resource (Hardt \& Negri, 2004). Indeed, while orchardists express pride in the results of their hard work, what I heard far more often about the work had to do with the feelings of togetherness that shared work generated. Lynn (Ben Nobleman) commented,

It's like having six good girlfriends, you know? And then if you get somebody who just comes every once in a while, she's brought into the loop as well. And it's like girls you would go out for a drink with or go and have coffee with.

The work of food growing provides a necessary social glue at a time when many people's existence is becoming increasingly atomized. Jane (Banfield) talked about the way things used to be when she was a kid:

The front porch and the front yard was where it happened; that's where we played, and that's where we met everybody coming and going, and where we'd take off with our friends and our parents would sit on the porch in the evening... [But then] everybody started making a back deck, and families started looking backward and inward, at all those gizmos and television... But we need that community interaction. And if it's not happening so much on our streets...then having something like [the orchard] really helps.

This dynamic goes a long way to explaining why "the current resurgence of food growing is generally celebrated as a rediscovery of the 'community' (Holland, 2004; Glover et al., 2005; Firth et al., 2011)” (Tornaghi \& Van Dyck, 2015, p. 1250). Said Yoshi: "I probably wouldn't ever have met [my neighbours] if there wasn't an orchard. So those encounters are valuable."

Some community orchards have found, however, that after the initial push to bring the vision of the orchard into being - an effort that brought many in the community together 
- it was hard to sustain that kind of energy when the projects moved more into the maintenance phase. One respondent to Copley's internal survey wrote:

The first year was very exciting as we were planting trees and converting a field into a community orchard. Now we are asked to arrive at 10 on a Saturday or Sunday to do work in someone else's garden. This is not as compelling to many people as what we did in the first year.

Particularly when the work gets hard, it needs to be balanced with celebration. Both build community, in different but complementary ways. Everyone loves harvest festivals and movie nights in the park but the role of work is to bond people in a shared venture or journey towards a vision. Celebrations then act to renew and invigorate the energy required to do the hard work by appreciating everyone's contribution and taking time to appreciate accomplishments and work well done. That's why orchard and gardening work is almost always accompanied by food.

Shared physical work also has a unique ability to bridge social difference, bringing into contact people who might otherwise never have interacted, let alone learned about each other's skills and worldviews. Carmen commented on the diversity of people at Strathcona, saying,

It is very nice, very, very nice, particularly as I grow older. You know, my husband and I decided that we were not going to be in this 55-year-and-older building - nooooooo! Not for us! [laughter] We like to see kids around, and adolescents, and young people. So here is sort of a little replica of that...different nationalities, different foods, people...

Deanna (Welland) described a different aspect of the social diversity she has encountered in the orchard:

I have been in more of a corporate environment, [but] the other people that I am meeting are not coming from that kind of life at all. They have tree planting experiences or... different ways of life... it's fascinating and interesting. 
Ariel, too, commented on her realization, following a conversation in the orchard about a high-profile current issue (the BC teachers' strike of 2014), that "it made me think that there might be more diversity in political views in the orchard that I realized, or expected."

That said, I do not want to overstate the diversity that exists in community orchards, particularly when it comes to orchardists' ethnic and cultural backgrounds. Most interviewees observed that the diversity of orchard membership isn't as great as in the general population in their neighbourhood, and that as a group, community orchardists do tend toward more European (white) ethnicities, though there are a fair number of people of Chinese and Japanese backgrounds involved too, particularly in Vancouver, where over $31 \%$ of the city's population identifies as East Asian. ${ }^{129}$ Though it falls beyond the scope of this research to prove, I think it likely that the appeal of community orchards may be greater for populations whose cultural and political histories feature orchards more prominently. Orchards have been described as profoundly, even "quintessentially" English (King \& Clifford, 2011, p. 3) though they also proliferate in the temperate zones of Europe, Asia and, of course, North America (Rupp, 2014). In East Asia, apples have been grown for thousands of years; in fact, the wild apple ancestor of modern apples hails from the Tien Shan mountains in Kazahkstan, on the Chinese border (Pollan, 1998). By contrast, one of my interviewees, who hails from the Philippines, told me that there is no translatable word for 'orchard' in her language, Tagalog. She speculated that this might

\footnotetext{
${ }^{129}$ This includes people of Chinese, Japanese, and Korean descent. An additional 16.2\% identify as South Asian, Southeast Asian, West Asian, or Filipino (World Population Review, 2018).
} 
account in some small way for the lack of interest in the orchard idea at Norquay, where many neighbours hail from the Philippines. My point here is just that there may be some cultural specificity to the orchard idea and that we ought to all have the humility to accept that an idea that may sound appealing to one ethnic group, especially the dominant group, may not resonate universally, and may lead to the inadvertent creation of spaces that feel exclusionary to other groups. This is especially germane to the issue of decolonization, which I discuss in Chapter 7.

To summarize, community orcharding (like gardening) brings people together in ways that actually change their experience of community and of urban space (Eizenberg, 2012a). Through meaningful work, they come to see themselves as a constituent part of that space, and the space as a constituent part of themselves as community members. Perhaps Lynn said it best: "Sherry and Susan saw a need, and with the help of Joe, we became a park. Because it wasn't a park before, even though it was called Ben Nobleman Park. There was nothing there."

\subsubsection{Higher purpose}

A third way that community-appropriated space is different from government-maintained public space has to do with its purpose, or the functions it performs. In Chapter 2, I asserted that space can function as a resource for the expression of dissent. In community orchards, what we see is not overt dissent per se, but an implied critique of the status quo turned into a constructive expression of alterity. The space of a community orchard or garden expresses intrinsically normative statements: that good, heathy, sustainably produced food is under-valued in our society and needs to be more prominent and 
appreciated; and that public space that is maintained by the public purse ought to grow something more useful than huge expanses of lawn, ringed with ornamentals. This is the statement that Occupy Toronto's offshoot, "Occupy Gardens", was making in the spring of 2012 when they planted a free community food garden on the lawn of Queen's Park (Bonnar, 2012). ${ }^{130}$

The demonstration - or performance - of growing food also motivates many community orchardists. Accepting that the volume of fruit produced in Spring Ridge Gardens is somewhat limited, Linda explained to me that the real purpose of the site is to show... ... what's possible to grow in your neighbourhood. You see all the variety of plants in here. You see buckthorn, you see goumi berries, you see goji berries, you see kale, you see different varieties of plants...You could [grow it]...in your backyard, or some sort of parkland in your own neighbourhood.

In using land to express the potentialities of a sustainable vision of the future, community orchardists (and gardeners) mobilize public space for socio-political ends, just as governments have been doing for centuries (Lawson, 2005). McKay (2011a) writes about the dual history of (government-run) parks, in terms of their uses to both foment and deter public protest. Parks provided an important venue for the encouragement of democracy; they were places to hold public meetings and exercise both freedom of speech and freedom of assembly. This was a cherished right in Britain (particularly among the Irish in England) and one that was strenuously pursued and protected by the working-class public in particular (ibid, p. 16-17). Speakers' Corner in London's Hyde Park is probably the most famous of such spaces dedicated to public dialogue and debate

\footnotetext{
${ }^{130}$ The garden flourished until late September when, just before a big harvest and without any notice being given to the gardeners, City workers tore out all the plants and replaced them with sod (Bonnar, 2012).
} 
(ibid, p. 23). Interestingly, its development was closely related to the practice of public executions, before which a condemned criminal was permitted to address the assembled crowd. Says McKay, "as capitalism and the legal system developed, criminal offences and their most drastic punishment increasingly revolved around crimes of theft by the impoverished" (2011a, p. 24). Consequently, Hyde Park became the site of a developing critical discourse around "diminishing customary rights against the growing imposition of capitalist social relations and the rule of private property"' (Roberts, 2008, as cited in McKay, 2011a, p. 24).

Since at least the Industrial Revolution, parks have been designed to quell urban unrest. Perkins (2010) describes how the move to create parks - known as 'positive environmentalism' was used to appease the working classes, when many people worked up to 16 hours a day in factories and lived in squalid dark little quarters; authorities apparently found acculturation through nature more effective than using brute force to quash riots (2010, p. 255). From a pamphlet by an anonymous writer in 1854, Hoyles quotes the following very telling paragraph:

The more people have of new plants, and the more they delight in them, the happier and the better they will be; we will let them into Kew Gardens unwatched, and yet not a leaf is rifled; we build, or they build for themselves, Crystal Palaces, and we make for them parks and gardens, where they may walk unrestrained and roll upon the grass even, and bask in the sunshine, and revel in pure air. And what is the consequence of this? We must condense the reply into one sentence - We have had no Revolution. (Hoyles, 1991, as cited in McKay 2011a, p. 12)

In the early $20^{\text {th }}$ century, public parks also served to "assimilate the restive working masses to middle class virtues" (Perkins, 2010, p. 255). The "moral geography" of parks was communicated through landscape design elements such as bandstands, drinking 
fountains, and statues on plinths, urging reverence for figures of the government and monarchy, entrepreneurs, benefactors, and triumphant military figures (Conway, 2000, as cited in McKay, 2011, p.14). Parks with amenities like ball fields were built by municipal governments - and even some factory owners - as sober alternatives to socializing at the local tavern or beir garten (Rosenzweig, 1983, as cited in Perkins, 2010, p. 256). (The reader may recall that this was exactly the case in Strathcona, even before it came into existence as a public park.) The temperance movement thus became one of the driving ideologies behind the provision of public green space (Cranz, 1989, as cited in Perkins, 2010, p. 256).

The same was true of public gardening. During the period of mass urbanization consequent to the Industrial Revolution, while the working classes made demands for land from the state, which the state fulfilled (by providing allotments), the state also brought its own agenda to bear. According to Wilson (2010, p. 42), gardens served both to "alleviate the grind of poverty and to diffuse the growing support of socialist parties." Again, gardening was encouraged as "part of a moral crusade" (Hoyles, 1994, as cited in McKay, 2011, p. 166) with garden policies banning not only liquor, but also betting, gambling and bad language (Wilson, 2010, p. 45). In these ways, we can see demonstrated the utility of public park spaces for creating proper urban citizenship (McKay, 2011a, p. 256). Chiara Certomà summarizes it thus:

Well-organised urban green areas represent the government's ability to control space and society at large. Thus, the planned disorder of the romantic garden or the organised symbolism of geometrical gardens was not merely innocent arrangements of green space, but the very representation of the dominant cultural ideology (2011, p. 978). 
The point here is that community orchards (and gardens) have a moral geography of their own, one that subtly, or sometimes overtly, resists the messages of social control that have been historically built into parks, gardens, and other public spaces. The moral geography of the community orchard communicates an expression of disapproval that public spaces designed by professionals and under the care of the state so often have little practical utility, at a time when there is great public need for a more sustainable food system. Other messages conveyed by the design of some community orchards (and gardens) concern the importance of sharing and social inclusion. Spring Ridge Commons (SRC), for example, seeks to be a refuge for at-risk youth, and others living on the margins. Organizers encourage the youth to make the space their own, if not to garden in (most aren't into that) then just to play music and hang out together. As Séan pointed out, a lot of these kids feel they don't have many places they can go and not experience disapproval. Linda (SRC) also expressed her desire that the space be a "sanctuary" for homeless people. ${ }^{131}$ This often leads to a level of tolerance exceeding that of most public parks, though community orchardists and gardeners often find that their own inclusive ideals are hard to square with the realities of marginalized populations. Says Betsy (Strathcona),

I remember we had a plot that was the mental health plot, and who would ever want to say no to mental health? [But] it was hugely problematic because there were people who were psychotic... When someone is really hallucinating and delusional, it can be pretty frightening for people around them. [One gardener's] garden was destroyed, and another gardener gave up because the guy [with mental illness] ...he was planting rocks. He would dig up the green stuff, then plant the rocks, then put the grass down... So you know, you can be inclusive, but sometimes, if you are really wanting the food part, you have to draw the line.

\footnotetext{
${ }^{131}$ Linda did, however, acknowledge that the homeless cannot stay there long-term because of the inevitable sanitation problems that come from sleeping and camping where there are no toilets.
} 
COMMUNITY ORCHARDS AS NEW URBAN COMMONS

Consequently, questions about maintaining the openness of the space to everyone continue to be openly debated among members.

By asserting and enacting what they see as a higher purpose or more inclusive use of public space, community orchardists confront and redefine conventional enactments of public property. ${ }^{132}$ The apparently innocent act of growing fruit is in fact an act of insurgent urbanism (Hou, 2010) - defined as the "re-appropriation of the right of people to shape their own living environment...through direct acts on the materiality of space" (as cited in Tornaghi \& Van Dyck, 2015, p. 1251). It must be said, however, that the appropriation of space for community is not always a politically radical or progressive act; rather, it will reflect the unique character and political flavour of whatever particular community is doing the appropriating. The appropriation of space for community can just as easily be conservative as anarcho-libertarian. ${ }^{133}$ As an example, Certomà and Notteboom (2017, p. 66) investigated three case study gardens in Belgium and found them all to be very different - "one more middle-class and informed by the bourgeoisbohemian ("bo-bo") sensibility; one more oriented to increasing the social welfare of marginalized groups through food security; and one characterized by the "extreme leftanarchist urban counterculture", more of an "autonomous reappropriation of city space". I trust that the descriptions of my study sites in Chapter 4 have made clear that this diversity also exists in community orchards.

\footnotetext{
${ }^{132}$ I have borrowed, with gratitude, this notion of confronting and redefining conventional enactments of public property from Wekerle \& Classens (2015, p. 1176) who use it in reference to private property - specifically, the actions of those who share backyards for the purposes of growing food. ${ }^{133}$ I was reminded of this fact when one interviewee at Welland expressed his enthusiasm for volunteer maintenance of the park as a way to help out the City and reduce the load on taxpayers.
} 


\subsubsection{Psychological ownership}

A fourth way that community-appropriated space is different from public space concerns the strong sense of 'psychological ownership' community members feel in relation to it. The concept of psychological ownership may be defined as a "feeling of possession in the absence of any formal or legal claims of ownership" (Mayhew et al., 2007, p. 477) and "a sense of jurisdiction over a space" (Hester, 1975, p. 57-61) (both as cited in Nettle, 2014, 40). According to Parker et al. (1997), psychological ownership derives from feelings of responsibility and care towards the object of possession (as cited in ibid). A sense of psychological ownership exists when the object "is perceived to be part of the extended self”' (Eizenberg, 2012b, p. 107). I would add that each of the three preceding factors I have discussed above seems to act to augment the sense of psychological ownership. That is, the more people participate in designing and shaping a space, the more they actually physically labour to produce and maintain it, and the more the intended purpose of the space resonates with them as meaningful and in need of asserting (or performing), the greater the sense of psychological ownership they will feel for that space.

Psychological ownership is strongly in evidence at community orchards. Ariel (Copley) admitted,

I like saying that it's "my" orchard and I like walking by it and thinking, I helped plant those trees and I watered those trees; I weeded that. I like the feeling of connection, which is much more than if it was a City park.

Several interviewees suggested other terms that they preferred to 'ownership' - like 'attachment', 'responsibility', 'protectiveness' and 'pride' at contributing to the community. Said Séan (Spring Ridge Commons), "You feel responsible for this space 
that you're living in, that you're occupying and you want to see it developed in the richest and most abundant way possible." Said Lynn (Ben Nobleman), in reference to the pollinator garden, "I'm very protective of it. It's like my baby." Sometimes, psychological ownership can create tension within the group, as Sylvia (Strathcona) noted:

A number of people, especially people who've been there for a while - 20 years, 30 years - they become very animated when someone suggests change of some sort because I think they worry about something getting lost, you know? Losing something they're very attached to.

At other times, or for other people, the experience of psychological ownership is one of expansiveness and connection. Matthew (Copley) articulated it beautifully when he said:

For those of us who have put in the sweat equity to make this place what it is, it feels different when you go there. It feels a bit like a homecoming. But it's not like owning a car. When you buy a new car, it's yours, and there's this excitement of it being yours. It's this individual thing that's very specific to you. At Copley, there's a sense of ownership, but it's an ownership that opens your heart to other people too, and you feel a closeness not just in the space, in the trees, but also to all the other people who have cared for that space with you. So, the idea of public space becomes more than just freedom to move around in open space; it's also about having a heart connection to other people in your community.

Psychological ownership depends critically on the locus of control over the space or the project remaining within the group. This has been noted by many scholars in relation to community gardens and commons (see Becker, 2015; Drake, 2014; Eizenberg, 2012a, b; Linn, 2007). Writing about a grassroots-initiated community orchard in Portland, Oregon, Becker (2015) recounts the shifts that took place when a non-profit organization was invited to assist and expand the orchard, and consequently brought in a new management style, new people from outside the neighbourhood, and new ideas about how the orchard should work. This "assistance" dramatically changed the community of the orchard and the way it made decisions. Within a year, there was no longer any discernible participation by the neighbours who had started the project, as the locus of control had 
shifted to the non-profit. Similarly, Eizenberg (2012b) narrates the story of the 126 community gardens in New York City that were "saved" from the City's bulldozers thanks to the interventions of either the Trust for Public Land (TPL) or the New York Restoration Project (NYRP) - both non-profits. The TPL model involved transferring actual legal ownership of the gardens to the community gardeners in the form of land trusts, while the NYRP model involved getting private sponsors or foundations to invest in (and put their names on) individual gardens. NYRP's model also involved getting professional landscape designers to re-develop the gardens, and installing much-wanted amenities like water tanks, electricity and toilets. Unfortunately, these "improvements" were made without consulting gardeners, who ended up feeling alienated from their own gardens. Eizenberg's analysis echoes Becker's findings in terms of highlighting the importance of keeping the locus of control within the community of gardeners/orchardists.

Among the community orchards I studied, at least two - Copley and Welland - have experienced a shifting locus of control, though in different ways. As the reader will recall, Copley began as a project of the Environmental Youth Alliance (EYA). However, from the beginning the space was divided into two separate areas: one for the EYA to use in their work with youth; and one for the community, which was expected to develop its own design and assume ownership for its part. While this distinction made sense on paper, there was some conceptual muddiness on the ground, in part because the EYA offered leadership, expertise, and services that the community group leaned on quite heavily, and in part because the EYA staff also considered themselves part of the community. Consequently, they wore different hats at different times, often volunteering 
COMMUNITY ORCHARDS AS NEW URBAN COMMONS

well beyond their paid hours, and becoming de facto leaders of the community group. When EYA Coordinator, Jodi Peters, left the project and moved away, the community group had to re-organize and try to discover a gravitational centre that it had not developed from the beginning. While those who spoke with me were generally quite circumspect in talking about the group's challenges, I gleaned that there had sometimes been friction with the EYA, and at times a bit of a leadership vacuum, followed by personality clashes and/or power struggles over things like project direction and group processes. In 2017, the community group, now much smaller, organized itself into an independent non-profit society. While many of those previously involved have now left the organization, the group has been re-invigorated; members I spoke to in the summer of 2018 indicated that they have re-found their enthusiasm and that the orchard is once again thriving. 134

Welland is also a unique case insofar as its genesis was not in a community group. Welland began as a private undertaking of a landowner, whose horticultural collection was then transferred to public ownership, with a non-profit (LifeCycles) contracted to act as caretaker of the property. Although the project did not originate in a grassroots community group, it seems to have "grafted" quite well, as evidenced by the enthusiasm and sense of psychological ownership expressed by the volunteer stewards of Welland Community Orchard. That said, its success also appears to be largely a function of the capable leadership being provided by LifeCycle's Julia Ford. It is an open question as to whether those who volunteer there have a sense of group identity that could withstand her

\footnotetext{
${ }^{134}$ Of the seven who left, three moved away and two left primarily for health reasons.
} 
departure or that could allow the group to govern itself going forward, if LifeCycles were no longer involved and paying a wage to an (albeit very part-time) coordinator. Julia sees this as a desirable eventuality, that her own role could be "super minimal" in five years' time:

I think it would be really nice to evolve to that point that there's at least a core group of people who feel comfortable taking care of the space and feel like it's theirs and feel like it's something that they're engaged in stewarding. [But] I think that is part of the challenge, in that they are stepping into something that is not theirs.

To summarize, I have said that there are four ways in which community orchardists appropriate space for community: through participatory design, active labour, a sense of higher purpose, and psychological ownership. These four mechanisms work in concert to create a sense of community space that is different from merely public space. That is, it is not just the participatory design or shared experience of work, but the shared experience of shaping space and working together in the service of a higher aim that produces psychological ownership and attachment to space. As many others have argued, community space is constituted relationally - between and among members, and between the members and the space itself: "[C]ommunity space does not pre-exist or determine social relations within that space; rather, relationships are what produce community space (Massey, 2005; Murdoch, 2006)" (Drake, 2014, p. 180). Just as importantly, the production of these spaces serves to create a sense of community when these four mechanisms are activated. The more that each of these mechanisms can be continually kept in motion within a group with consistency of membership, the clearer the group's collective identity will become and the stronger their ties to their shared space will be. 
The idea that community is constituted relationally (Rose, 1997) helps explain why not all community orchards are yet functioning as fully animated community spaces: Fernwood, for example, was designed by professional landscape contractors and is maintained by the part-time community gardens coordinator affiliated with the Fernwood Community Centre. Opportunities for community members to get involved on a one-off basis do exist, but these are not sufficient for the community to feel like it's their "baby". Likewise, at Norquay: Hard-working community orchard promoter Jo Tobias hopes that with more plants and interpretive signage that the community will "embrace [the space] a little bit more". But because the space's development does not depend on community participation in decision-making and management, it is hard to see how this could achieve the necessary shift of the locus of responsibility to the community - a shift that a community group must really want to make happen.

\subsection{Limits \& Challenges}

Appropriating space for community is not without its challenges. I have identified three that I think merit discussion here: 1) the question of who constitutes the community that is appropriating the space; 2) the impermanence of community; and 3) the tendency to romanticize community and thus to be unprepared to deal with the conflict that invariably accompanies it.

\subsubsection{Who constitutes the community?}

As I said in Chapter 2, 'community' as a concept can be mobilized to legitimize an undertaking by denoting participation, collective action, collaboration, and agreement 
(Williams, 1995, p. 140, as cited in Nettle, 2014, p. 120). As a term, 'community' connotes greater authenticity than 'public,' as well as a sense of collaboration and agreement. Set in opposition to 'society', the term 'community' seems to promise dealienation and a return to simpler times, as well as a sense of security (Biel, 2016). But who, exactly, are we talking about when we refer to "the community"? This is rarely clear, and it is a problem that extends far beyond community orchards and into just about any discussion in which the term 'community' is invoked. Tony Blackshaw claims that 'community' has become "one of the most vague and imprecisely drawn concepts in the social sciences; it seems to mean everything and nothing” (2010, p. 2). While at one time, 'community' could be assumed to be co-terminus with spatial proximity (i.e., neighbourhood, or small town), Kingsley and Townsend (2006) suggest that community is now better defined by a perception of personal connectedness. Connectedness can develop on the basis of shared interests or shared identity; on the basis of shared practice - for example, professional “communities of practice" (Lave \& Wenger, 1991) or shared fate, such as occurs when a population experiences a catastrophic weather event or epidemic (Everts, 2015).

In the realm of alternative food projects, 'community building' is often a stated goal, though clear definition of the community may still be lacking (Firth et al., 2011). It is important to acknowledge that "multiple social networks and groups can overlap in one place without forming a community (Kato, 2014; Massey, 1994)” (Becker, 2015, p. 9). These may be networks of neighbours (bound by geography, though often not really bound at all), networks of activists (bound by ideology) or networks of recreationalists 
(bound by their shared uses of the space). Our understanding of community also varies depending on whether we are thinking of the community who is involved in taking responsibility for the space, or the community of beneficiaries; these may or may not overlap, depending on how benefits are defined.

At my study sites, it was clear that there was a mix of people involved; propinquity did definitely bring in some neighbours who might never have joined such a project otherwise. Some - like Tanya (Copley) - who had no previous involvement in the "foodie" movement in fact became strong leaders. But there were often just as many orchardists (often including those in leadership roles) who did not live nearby. Wayne described the membership of Copley Community Orchard this way: "I would guess about a third of the people in the membership live within two or three blocks; another third live within five miles; and the other third comes from all over the place." Wayne makes a distinction between 'members' and 'neighbours', noting that the members, who have invested a lot of sweat equity into the orchard, feel a strong sense of psychological ownership, but "the people who live around there are pretty quiet about [the orchard]" (except when the grass needs cutting!) The distribution of members at Strathcona and Welland seems similarly mixed. At Banfield, organizers have really tried to make the project a neighbourhood-based one, using the frame of placemaking to build up community identity in Vic West. In Toronto, Susan (Ben Nobleman) assured me that membership was not limited to the neighbourhood: "It's not about geographically where you live. It's Do you care about fruit trees? Do you want to come and join us? Do you want to build community? Then you're part of it." Nonetheless, nearly all of Ben 
COMMUNITY ORCHARDS AS NEW URBAN COMMONS

Nobleman's volunteer stewards reside in the neighbourhood. At Norquay, the opposite seems to be true. Said Jo Tobias: "There are not a whole lot of people coming from around the orchard itself, even though [the Renfrew-Collingwood Neighbourhood House Food Security Institute] distributed the flyers, they advertised on social media. [There] just wasn't enough interest."

To generalize, it seems that at most sites, the driving inspiration comes at least as much from ideological community as from geographical community. This isn't inherently problematic; despite initial differences, it is possible that those who are implicated in a project by accident of geography will come to accept, and even welcome, the values and vision that are driving project proponents who may have come from outside the neighbourhood. Developing shared analyses and values is one way a more inclusive community can constitute itself (Nettle, 2014, p. 125). But having the drive behind a project come from outside the neighbourhood does have potential consequences for the sustainability of said projects. Tornaghi \& Van Dyck explain their very similar experience in relation to a community garden in Leeds, UK:

Local residents remained a minority in the composition of the group, and despite consistent manifestations of interest and curiosity on the part of new individuals, passers-by and locals, the group never really grew substantially and new members did not take ownership of the project - or take on a proactive role - and once the key players moved on to other projects, the group vanished (2015, p. 1257).

Determining who constitutes "the community" in relation to an appropriated space raises all sorts of questions that I will return to in Chapter 9. These questions concern whose priorities get favoured by municipal governments, who gets included or excluded from public space (and whose responsibility it is to exclude or accommodate them), who 
COMMUNITY ORCHARDS AS NEW URBAN COMMONS

governs the space and what happens when the appropriation of space for community brings unintended but powerful consequences - for example, (eco)gentrification.

\subsubsection{The Impermanence of Community}

This dynamic I have just described, in which local residents do not assume psychological ownership for a space that was appropriated by a non-geographical community, brings us to the second challenge: the transitory nature of communities in this era that Bauman (1999) has dubbed 'liquid modernity'. Unlike in traditional commons of centuries past, when people stayed in one place (where their land was, or their family's land was), today's economy makes employment more precarious and people much more mobile. We are much less likely than our parents' or grandparents' generations to settle in one place and stay put for decades. Said Helen (Copley), "Jobs are typically contract jobs... once you deliver the final report you move on to the next one." George (Copley) added,

I think ideally...you would have people who live right near it, who walk by it every day and say "This is my neighbourhood." But that's difficult in a place like Vancouver because people are moving around so much they don't really get a sense of what it means to be their neighbourhood.

George and Helen's observations seem to be confirmed by the fact that among those community orchardists I interviewed, at least six have ceased to be involved because their jobs have changed, which in some cases also brought about a geographical move.

Also, unlike commoners of the past, people who are collectively appropriating space for new urban commons today are generally doing so entirely by choice, not because they share a dependency on the resource. This lack of shared dependency on a resource makes participation in maintenance much more optional and increases the incidence of what 
Elinor Ostrom called collective-action problems. These include shirking and free-riding, not just by passers-by who have no connection to the orchard but feel enjoined to take some fruit, but also by orchard or garden members who commit to contributing a certain amount of labour but then don't follow through. This severely limits the potential of community orchards as natural resource commons (i.e., commons in which the fruit is the main purpose) because a lack of dependency means that members do not feel the same sort of accountability to one another that they would if they felt vulnerable to losing their access rights. Monitoring, and sanctioning rule-breakers, is also next to impossible in entirely optional systems - especially those set up to be open-access, as most community orchards are. As George put it, "It does come back to [the question]: Are people doing something with a piece of land on which they depend? And in the globalized food system, we actually depend on the stuff in Chile." Consequently, this lack of dependency on the resource makes membership in the orchard much less constant and reliable from one season to the next.

Community can also be transitory to the extent that it forms around what Blackshaw (2010) called 'devotional leisure', in which people may engage in community orchards as part of a quest to further their self-development (see Chapter 5). Blackshaw (2010, p. 17) explains:

Men and women today use community as Foucault [1984] suggested we use art in order to fashion an authentic existence. Like art, community offers us new ideas about how to live, as well as inspiration, moral lessons, comfort and tales of the lives of others and how these might inform how we might live ourselves. It is through this 'care of the self' that community becomes manifest, where we perceive we can become somebody, can find an authentic existence through selfdiscovery and self-fashioning. 
COMMUNITY ORCHARDS AS NEW URBAN COMMONS

Devotional leisure is typically episodic in nature: people "come together at key moments, such as harvest, to work together and to experience intense moments of bonding that are understood individually and collectively as experiences of community" (Ravenscroft, 2013, p. 637).

Unfortunately, the sense of community that we derive in this way may be only as secure or long-lasting as the need that brought us to it. One of Ravenscroft's interviewees expressed it this way: "Community is a contingent thing-people come into relation with others; this becomes intense, then they pull away ... it's a merry-go-round - people get on and off; some want a long ride and others have enough very quickly" (quoted in Ravenscroft, 2013, p. 636). Community orchards illustrate this point well; in the time I was studying them, a significant number of those I interviewed, who were at one time deeply involved and committed, have moved on. While I didn't always press them for an explanation, I suspect that the individual reasons they might give could be understood in the larger context of Bauman's ideas about "liquid modernity", as elaborated here by Blackshaw:

In liquid modernity, we are always leaving places we have grown to love, and we spend the rest of our lives trying to regain the feeling of them again. This is why communities today are best understood as cleave communities - cleave meaning both to slice into episodes and to cling to - which reflect the pointillist and romantic sensibilities that are the basis of contemporary community life [pointillist referring to a tendency to have no expectations of the future, and to look fondly on the past, while being intent on living in the here and now]...We are thoroughly comfortable with community as somewhere we can visit and leave after awhile (Blackshaw, 2010, p. 16).

In contrast, Blackshaw says that more enduring communities require "some degree of self-sacrifice, if not the total abnegation of individual freedom" (2010, p.16). Self- 
COMMUNITY ORCHARDS AS NEW URBAN COMMONS

sacrifice, especially to the point of giving up one's freedom, is hardly a prevalent ethos in today's world, at least not in the dominant society in Canada. Only time will tell how much self-sacrifice orchardists can put up with, and how long these elective communities formed around community orchards will endure.

\subsubsection{Romanticizing community}

The third challenge or limitation that comes up when groups appropriate public space for community is that the concept of 'community' is very easy to fall in love with, but invariably, the romance eventually gives way to the long, hard work of maintaining relationships. In this sense, 'community' is very much like 'family' - warm and fuzzy ideas in our hearts, and fraught with messiness on the ground. Consequently, in activist and popular discourse, we tend to attribute to 'community' all manner of powers - e.g., to reduce isolation and enhance wellbeing; to increase trust and social capital; to unify disparate elements of society; to increase feelings of belonging; to develop civic virtue; to permit an escape from politics - or, conversely, to activate democratic participation. Blackshaw (2010, p. 6) notes that 'community' is "another word for utopia" - a concept that "everybody ostensibly admires, and is very often keen to celebrate, but hardly ever calls into question, or seems capable of discussing in any critical way" (2010, p. 20). Instead, "the goodness of community becomes self-referential and self-evident" (Neo \& Chua, 2017, p. 668). In reality, of course, communities are a site of contestation and power politics, meaning that conflict is inevitable (Blackshaw, 2010, p. 165). Sometimes the conflicts are between orchard proponents and nearby residents; and sometimes they are within the orcharding groups themselves. I will discuss each of these in turn. 
At Copley, Ben Nobleman, and Spring Ridge Commons, opposition from neighbours has created rift, at times. At Copley the conflicts have been relatively minor - having to do with safety and aesthetic concerns, which were, for the most part, worked out once they came to light. At Ben Nobleman, when the orchard was first proposed, a few angry neighbours mounted an all-out campaign to vilify orchard proponents. Believing, mistakenly, that they wanted to take over the entire park and turn it into a messy "fruit farm", they started a petition and circulated what organizers claim were rumours and lies. Things got pretty tense. Organizer Susan Poizner recalls, "I kind of just hid because there was so much hate coming at me!" Finding a middle ground so that all park user groups could be happy took some time, and the skilled diplomacy of City Councilor Joe Mihevc, but Ben Nobleman's orchardists now feel that the rifts that once existed have almost all mended. Susan reported to me that when the trees were all established, one of the orchard's fiercest opponents came along on an orchard tour: "She looked totally grumpy all the way around the tour [but] at the end of the tour she said, 'Susan?' And I said 'What?' And she said, 'I want to thank you because this is very nice.'”

At Spring Ridge Commons, Linda Chan was one of several who commented to me that notwithstanding the odd exception (one little old lady), the neighbours around SRC have "never really bought into it." This is no doubt a function of many factors, the first being differences in values when it comes to the vision for, and aesthetics of, the space; even flourishing forest gardens can appear untidy and unkempt to those of us with a markedly more ordered expectation of how gardens should look. Second, there are marked differences in impacts when the space is poorly maintained. For those who come from 
outside the neighbourhood to work on the commons by choice, the impact of not coming, or of others shirking their responsibilities, is not as deeply felt as it is for those who must live there, day in and out, and who must contend with the hazards, the noise, smells, and mess in their immediate view. These neighbours can come to feel especially resentful if the project was not something they supported in the first place. It is no doubt therefore significant that Spring Ridge Commons began as guerilla gardening. As wonderful as the improvements are that come of transforming a rubble-strewn lot into a forest garden, we would do well to remember that it can also be problematic when anyone, no matter how well intentioned, appropriates space without notification, consultation, or involvement of existing users or nearby residents, a point that Adams, Hardman \& Larkham (2015) make clear.

In most cases, conflicts with neighbours have led to greater mutual understanding and workable solutions. They have also engendered a lot of learning, typically about how carefully groups need to consult, listen, and work with local residents when proposing a change to neighbourhood space. Then, after thorough consultation, groups need to be prepared to accept a certain degree of enduring disagreement, usually from a very small number of people. Said Susan (Ben Nobleman):

You'll never have $100 \%$ agreement. I've been told by people in Parks and Recreation that no matter what you want to do in a public space, $5 \%$ of the population will absolutely hate the idea. And when they attack you and when they get all mean, don't get all worried. Just say, "Oh, they're part of the 5\%." So, for the rest of the people, [you just have to] communicate as well as possible, what it is you're looking for, what are the advantages.

Internally, within community orcharding groups, conflict is also an unavoidable reality, and often the harder kind to deal with. All communities contain within them multiple 
dimensions and degrees of difference. For those engaged in contesting the status quo, the differences can be extreme. Certomà and Tornaghi note that "the complex political universe of urban gardeners includes different groups whose aims (taking power, contesting power, abolishing powers, etc.) and means (pacific protest, direct action, guerrilla, uprising, riots, cultural opposition, DIY practices, etc.) are definitely heterogeneous" (2015, p. 1124). Consequently, Feenstra (2002, p. 102) notes that "building relationships of trust in a participatory food system is not always easy; in fact, sometimes it can be frustrating. I am beginning to learn to expect some friction...If there is not any, I am suspicious."

Then, too, there is the fact that prefigurative politics, especially with an anarchist inflection, involves a lot of experimentation. People know what they don't like about the status quo, but they haven't necessarily worked out new shared, agreed-upon systems of working together, nor skills for dealing with interpersonal conflict. Tanya (Copley) recalled:

We had a hard time at the beginning, figuring out how we were going to make decisions - i.e., if we were going to vote. But then if we vote, then someone's out and in. And making sure everyone's voice was heard. It was a little bit new for me, in terms of really trying to think about how this power structure should look [and] what does that really mean when we have conflict?

Wayne (Copley) described the ensuing process and decisions the group came to:

We didn't want an autocratic, dictatorial type of governance so we went to a kind of consent [sic]-based way of doing things... We have an attitude of, If we can't figure out how something is really going to screw things up, we're going to try it... If it works, great; if it doesn't work, we'll fix it. So, whenever we make a decision, we always put a time to re-visit that decision.

An interviewee at Strathcona talked openly about sources of tension in her group: 
Our meetings are fairly raucous. Not raucous, but there's a lot of anger. People have visions for the garden. They have frustrated expectations about what the garden should be about. It's almost four acres but it's totally run by volunteers... The little money we get, we have to write proposals for. And it's a lot of volunteer labour involved. There are 100-120 gardeners, I believe, and there are maybe 15 who do the work ${ }^{135}$... So you can imagine how much resentment there is. And that's been happening for almost 10 years now...

Ensuring some sense of equity in the distribution of tasks is important at virtually all sites, but it is clear that members also have very different capacities to contribute, owing to their different stages in life, job commitments, and family responsibilities. Most often it seems that there is a core group of people (whom Martin dubs the "super-volunteers") who take on leadership roles and assume the responsibility for planning and other preparatory work in advance of work parties, and/or completing the tasks that are still left done after everyone else goes home. Says Martin: "The rest of the people aren't going to take those hard choices on." Most just want to be 'foot soldiers', as one person said. They want to show up, be directed, put in their time, and leave unburdened by any sense of ongoing responsibility until the next work party rolls around. Working out who does what, and how much, is a perennial source of tension in many groups. In addition to the super-volunteers, orchards also need leaders with the capacity to inspire and hold a group together through thick and thin. Where leadership is weak or contested, conflict frequently erupts. And conflict, as one person said, is something we as a society still do poorly. Developing the skills to do conflict well - to communicate clearly, assertively, and with compassion to see that group members' needs are met or their concerns are at least heard - takes time and patience and fortitude.

\footnotetext{
${ }^{135}$ This interviewee later clarified that she meant doing the work outside of the regularly scheduled work parties, and that typically, they will have about 50 people show up at a work party to maintain the common areas, including the orchard, the paths, the compost and other shared facilities.
} 
In spite of the challenges of being and working "in community" - to appropriate space, develop it or maintain it - community orchardists also expressed to me their appreciation of the process and the learning that comes with it. Said Sylvia (Strathcona), "I find it a very interesting social experiment about how people get together and create something of meaning, through sheer will and volunteerism. I mean, it's amazing how much we do get done.” And Jodi (Copley),

It really taught me the value of diversity and built that trust that people in the neighbourhood - un-professionalized community groups - can really accomplish things, that people are willing to put in volunteer time to create things that benefit their community, and things that don't immediately benefit themselves.

\subsection{Social appropriation and decolonization}

Underlying the struggle to appropriate space for community are deeper questions about whose space it really is to shape: Is it the City's? The public's? The neighbourhood's? What if it's unceded Indigenous territory? (And it is, at least in Vancouver and Victoria). I cannot leave this discussion of social appropriation of space without addressing the fundamental question of decolonization: If the act of colonization was the theft of others' commons, how many among us are in a position to "reclaim" them? Is the discourse of commoning consistent with decolonization or just another manifestation of a colonizing impulse by a dominant group in society? These are big questions, which go well beyond the scope of my research. However, they need to be noted for the important questions they are. In this last section of the chapter, I will put forward an argument for commoning as a means of moving toward decolonization. 
If we begin with the assertion that Indigenous peoples are Earth's original commoners (Linebaugh, 2009, p. 5) it is easy to see how colonialism and imperialism were constituted as not only the theft of First People's lands and earthly riches, but as the negation of commons, or collective ownership, as a construct. In his (2009) book, The Magna Carta Manifesto: Liberties and Commons for All, Linebaugh, a historian, shows that the Magna Carta, which originated as a demand to give lords and other elites more rights vis-à-vis the king of England (and which centuries later became an instrument of imperialist rhetoric and elite domination) in fact also originally served to advance the interests of the common people by spelling out the nature of their entitlements to the gifts of the forest (e.g., fuel, wood for building houses and carts, wild honey, fruits, vegetables, flowers, and grazing for cattle and other livestock). For centuries following its adoption, the Magna Carta was at the centre of ideological battles between those championing private property and those seeking to defend tribal and collective rights - as well as to level the Hindu caste system (ibid, p. 118), and abolish slavery. The abolition bill of 1807 was called a "Magna Carta for Africa in Britain" and a "Magna Carta of Negro rights" (ibid, p. 140). Going beyond the Magna Carta, Linebaugh makes the links between commoning traditions in places as diverse as Basque country, ${ }^{136}$ Russia, and New Mexico. He presents examples of the many ways that commoners around the world have resisted enclosure and demanded a return to communal systems of tenure and stewardship. These examples include peasant resistance to the theft of common lands which was an important basis of the French revolution (ibid, p. 274); the 1921 manifesto

\footnotetext{
${ }^{136}$ As a fascinating aside, Linebaugh traces the adoption and movement of the Basque symbol of social equality - the seamless woolen beret - through France (via Basque refugees), then to the Resistance, to the beatniks, to Che Guevara and to the Black Panthers!
} 
of the Pan-African Congress ${ }^{137}$ which demanded, among other things, "the ancient common ownership of the Land and its natural fruits and defense against the unrestrained greed of invested capital" (ibid, p. 265); and the struggles of the Zapatistas and other Indigenous peoples of the Americas to defend their common lands from colonial theft. Consequently, he says, it is really to Indigenous peoples that we owe the return of the issue of the commons, of the drive to re-commoning: "The sacred hoop surrounds the open commons" (ibid, p. 249).

The point here is that commoning fits with decolonization because the commons speak to a relationship with land and territory that precedes both private and public property (Chan \& Sharma, 2007). In fact, public parks and gardens were early institutions of the colonial state (Nettle, 2014, p. 104). Commoning, like decolonization, is about asserting rights to land and space that are neither private nor public, given that public, in usual usage, refers to the state ("the Crown" in Canada). This is because commons aren't really about property, but about a fundamentally different relationship with the land that is not only collective, but also non-proprietary. As Menzies writes, "notions of land occupancy as a trust rather than a commercial arrangement...go to the heart of what might be called the ethos of the commons" (2014, p. 26). I would argue that such notions also go right to the heart of decolonization. Still, making the two impulses of commoning and decolonization consonant with one another isn't necessarily going to be easy. As with any social movement, questions of power and the potential for exclusions and/or co-optation are omnipresent. Food production and agrarianism are a very powerful way of

\footnotetext{
${ }^{137}$ The Pan-African Congress refers to a series of seven meetings that have been held through the past century (1919-2014) to address the issues facing Africa as consequence of European colonization.
} 
appropriating land and claiming rights to space, but when we look around the globe, we can see examples that span the political spectrum, from Brazil's Landless Workers Movement to Israel's illegal settlements in the Palestinian West Bank. A lot, then, depends on who is claiming to be a "commoner" and how the discourse of commoning is mobilized.

I find it encouraging that several community orchards are acknowledging the Indigenous territories, peoples, languages and knowledge on which they are built. Norquay has produced attractive interpretive signage to teach visitors about traditional uses of plants like kinnick-kinnick, salal, wild strawberry, and Oregon grape; while Spring Ridge Commons has a little reserve set aside for growing camas. ${ }^{138}$ Thoughtfully, Séan observes that "we have to do it in very respectful ways. It's gotta be something that's sort of orchestrated by First Nations people. So hopefully that will be something that happens in the future." Séan's words demonstrate an awareness that decolonization requires much more than a colonial politics of recognition (Coulthard, 2014). According to Coulthard, it requires the renewal of Indigenous practices and values, and a politics of resurgence that is not only anti-colonial, but also non-patriarchal, anti-capitalist, and rooted in a healthy and spiritual relationship with the natural world. Most importantly, a politics of resurgence must de-centre the putative authority of the Canadian state to "grant" rights or “allow” Indigenous jurisdiction over lands.

\footnotetext{
${ }^{138}$ Camas (Camassia quamash) is a native lily that is characteristic of Garry-oak ecosystems, which were once common on southern Vancouver Island but are now endangered. Camas bulbs were at one time a very important food source for First Nations throughout the Pacific Northwest (Huff \& Johansson, 2012).
} 
Given the general orientations of community orchardists as I have described them up to this point, there is seemingly great potential for a form of solidarity politics that articulates these kinds of Indigenous value positions to those of community orchardists. In other words, I believe that commoning has a chance of working well in concert with decolonization initiatives, and that there is good reason to appreciate its potential in this optimistic light. However, the fact that most community orchards are currently being initiated, developed and maintained by non-Indigenous people could well pose a significant challenge when it comes to communicating and realizing this potential consonance. If Indigenous peoples in Vancouver, Victoria, and Toronto perceive that the spaces of community orchards are less open, less inclusive, or less diverse than ordinary public spaces, on account of having been appropriated for community by non-Indigenous peoples, or being culturally coded "White", there is a chance that they might see commoning as yet another form of colonization and reject any involvement in it, especially if they do not identify with that community geographically, ideologically or culturally. Given also the "Englishness" of orcharding and the associations of the word 'commons' with England (one of the main colonial powers that have oppressed Indigenous peoples in Canada), such an outcome would not surprise me. But it would also be very unfortunate, given that the commoning impulse is clearly more sympathetic to decolonization than to its opposite. Much, I think, will depend on the ability of community orchardists to forge direct and trusting personal connections with Indigenous individuals and organizations and on orchardists' ability to articulate (or modify) their vision in a way that not only recognizes Indigenous rights to land and self-determination 
COMMUNITY ORCHARDS AS NEW URBAN COMMONS

in principle but also accedes to Indigenous cultural and political resurgence on the ground.

\subsection{Conclusion}

It has been said that community gardens are "the 'fulfillment' of the idea that citizens can and should take control of public land (Carr, 1992, p. 68, as cited in Nettle, 2014, p. 99). In fact, none less than Henri Lefebvre himself pointed specifically to gardens as effectively appropriated space (1991, p. 366). I am making the same claims for community orchards (with the caveat that some are more effectively appropriated than others). I have also said that the appropriation of space for community at the five main community orchards I studied has involved spatial and social transformations that have altered participants' perceptions of public space, and sometimes also the perception of those viewing those transformations from the outside. Instead of being seen as spaces that "nobody" owns (the government often being reduced to "nobody"), community orchards are being recognized as spaces "owned" by communities, not in the possessive sense, but in the sense of being the objects of a community's responsibility and loving care. Through orchardists' participation in designing and shaping them, and through their shared labour in actively maintaining them, in the interests of serving a higher purpose, those spaces have been not just appropriated, but animated; they have soul.

Unlike in some community gardens we may read of in the scholarly literature, where gardeners seek to overcome a personal sense of disenfranchisement, these community orchardists (most of whom would not identify as marginalized) are asserting a popular 
right to land in principle; that is, to the idea of the commons. There are limits, challenges, and important questions that come into play along the way, having to do with who is doing the appropriating, the impermanence of community, and the messy realities of working in community when the bloom comes off the rose. Finally, there are opportunities presented by the social appropriation of space for community to think about how such acts of commoning might be articulated to the more overtly political movement for decolonization. I believe that the potential for congruence is there, though far from guaranteed.

In the previous chapter, I looked at commoning in community orchards as resistance to enclosure. In this chapter, I considered commoning as the appropriation of community space. In the next chapter, I explore a third aspect of commoning in community orchards - decommodifying exchange. 


\section{Chapter 8 - Decommodifying Exchange: The Gift Ethos in the Orchard "It's just the abundance that we share.",139}

\subsection{Introduction}

Food scholars have long been calling for the decommodification of food, seeing commodification as one of the fundamental injustices of our dominant, industrial food systems, and a major driver of price volatility and hunger (Alkon and Mares, 2012; Hassanein, 2003; Johnston, 2008; Welsh \& MacRae, 1998). Because decommodification stands in direct opposition to the notion of food as a human right (Rosset, 2006; Magdoff, 2012), both food scholars and food activists have advocated for basic life-goods like food to be met through non-commodity channels, "insulated from the values and ethics of the conventional food system" (Vivero Pol, 2013; Wilson, 2013, p. 730-731). At the same time, many authors (e.g., Eizenberg, 2012a; Follmann \& Viehoff, 2015; Johnston, 2008; Linn, 2007; Tornaghi, 2014) have identified the potential of community gardens to function as de-commodified spaces or commons, due to the qualities that make them inherently subversive of the commodity form - namely, the way they view food as a public good and prioritize its equitable distribution over profit (McClintock, 2014, p. 148). Few scholars, however, have explored the decommodified nature of community gardens in great depth, to elaborate on what the alternatives to commodification may look

\footnotetext{
139 This quote comes from Séan (Spring Ridge Commons).
} 
like, or to articulate what a decommodified space is, rather than just what it is not (but see Eizenberg, 2012a; Vivero Pol, 2013, 2015). ${ }^{140}$

In this chapter, I explore what it means for a community orchard (or garden) to be a decommodified space - that is, what it means when neither the fruit nor the labour required to maintain it is exchanged for money. ${ }^{141}$ I build on Crouch and Ward's much-quoted (1988) observation about the centrality of the gift relationship in community gardens by turning to the source of their observation, Lewis Hyde's theory of the gift. Using Hyde's theory, I illustrate the ways in which community orchards are instantiating a gift economy in regards not only to the fruit of the orchard, but also to the labour the community orchardists contribute to maintaining the orchard for everyone's benefit.

\subsection{A Culture of Giving}

In their work on allotment gardens in the UK, Crouch and Ward (1988) assert that interactions in the garden are predicated on a social and economic practice they term 'the gift relationship". This relationship owes itself in part to the legislative fact that "by and large, produce grown by allotmenteers cannot be sold commercially for profit. [Instead], the standard treatment of a surplus or seasonal glut is to give it away" (McKay, 2011b).

\footnotetext{
${ }^{140}$ José Luis Vivero Pol has written extensively about the need to de-commodify and "recommonify" food by valorizing its non-monetary dimensions (as an essential resource, human right, cultural item and tradable asset) $(2013$, p. 20; 2015). He envisions a time when global and local food production and distribution systems will no longer be governed exclusively by market rules, but by "institutional arrangements based on collective actions, appropriate legal collective entitlements, adequate funding and political support...[with] due consideration by politicians and academics" (2013, p. 20). In what he calls a "food commons regime" self-regulated collective actions for food ("crowd-feeding") will represent the third pillar of governance, complementary to market and state $(2015$, p. 12$)$.

${ }^{141}$ These are not the only decommodified elements in community gardens. Access to these spaces is also decommodified insofar as no fees are charged; knowledge is also shared freely within.
} 
This same ethos of the gift seems to prevail in community orchards in Canada, and it animates relationships among orchardists and the trees/fruit/land/Nature they care for. This ethos is visible in many ways, most obviously in a generalized culture of sharing. As in the allotments that Crouch and Ward describe, where gardeners generously share their produce, seeds, tools, and knowledge with each other, people in community orchards regularly share materials, tasks, and expertise - and the fruit, of course. As Jane (Banfield) explains, "We all planted it. We all work in it. We all harvest it, and it's not always the same people, the same time. And we share. Sharing is the big thing." One can also see the gift ethos in the enthusiasm orchardists express for sharing the orchard's abundance with others. As Séan (Spring Ridge Commons) articulates,

When you grow food here it's with the understanding that you may not be harvesting it, somebody else might. So, it's sort of gift giving, in that it's like Christmas or a potlatch or something like that, where the emphasis is on the giving, and so much abundance is generated out of that.

It is hard to overstate the importance of decommodification in maintaining and promoting a culture of giving. As Michael Carolan reports, the introduction of money, often as an enticement to people to give more, is well known to deter and reduce giving. Economists call it the "crowding-out effect" whereby intrinsic motivations are crowded out by external rewards $\left(2017\right.$, p. 111). ${ }^{142}$ This suggests that the absence of money or cash equivalencies is part and parcel of what brings people together in mutual aid, in a spirit of generosity, and with feelings of commonality. One lesson we might take from this is that

\footnotetext{
${ }^{142}$ As far back as the 1970 s, researchers looking at the phenomenon of blood donation were reporting that programs that paid people a nominal sum to donate actually had lower rates of participation (Carolan, 2017, p. 111). This changed the meaning of the donation from being a selfless act to one motivated by self-interest; their donation was no longer a gift. The mere suggestion of the idea of money - in research studies using piles of Monopoly money or a screensaver depicting floating cash has been shown to reduce research participants' willingness to help others and to see themselves as having less in common with other participants, as compared to controls (Carolan, 2017, p.113).
} 
the fruit in community orchards should not be exchanged as an enticement to get people to join, or do the work. For one thing, there may not always be enough of sufficient quality that it could constitute fair compensation for the work those members will doubtless put in. But much more importantly, it is because it frames the fruit as the real reward, thereby crowding out the intrinsic rewards that people seek and do find, in the experience and in giving freely of themselves as they do.

\subsubsection{Fruit as gift}

As exemplified by Séan's quote, community orchardists tend to hold a view of nature as gift, not commodity. The apples and cherries and quinces are gifts of nature; so are the bees, and the pollination services they perform. Martin (Strathcona) spoke to this point exactly:

I got interviewed a while ago. A camera crew from one of the news shows came down here and... And [the interviewer] kept wanting me to say that I'm saving money by growing food. And... I'm like Obviously you've never gardened before because that's not how it works. Nobody gardens that much for those reasons because it's expensive when you think about your labour... There's a different rationale. It's really to get out of the cycle of food being [something] that comes through commerce. Disconnecting with it as a commodity, being in touch with seasonal cycles and natural spirit is a huge part of it.

Matthew (Copley) was even more explicit in describing his intentions around community orcharding and gardening - these having to do with "removing it from this commoditybased economic system and putting it into more of a social, community-based context." He added,

It has a different meaning. It has a different feeling to it, too. It's nourishing both for you individually, and your health, but it also nourishes the spiritual and social side of us that commodity agriculture-industrial food system doesn't nourish in the same way. 
When orchardists see the fruit this way - a view most evident in the way Copley community orchardists regard the "heritage trees," - they are expounding a relationship to nature in which the gifts of fruit come through their labours, but not from them directly. This is a view that Hyde says, "makes evident the true structure of our relationship to the sources of our wealth" $(2007$, p. 191). That the fruit is a gift, and not a commodity, is also evident in the way community orchardists tend to speak about the trees, using the language of nurturance, as shown in Chapter 5. In caring for the trees, community orchardists are deliberately engaging in relationship with them, rather than just producing products. (Recall Susan's quote about pruning being “the most special time" for just this reason.) It's a relationship not just to one or more living things, but to natural cycles, a relationship that acts to heal the alienation that so many refer to. As Hyde writes,

[T] he circle of gifts enters the cycles of nature and, in so doing, manages not to interrupt them and not to put man [sic] on the outside... When we see that we are actors in natural cycles, we understand that what nature gives to us is influenced by what we give to nature (2007, p. 23-24).

\subsubsection{Labour as gift}

"Labor should not be sold like merchandise but offered as a gift to the community"

- Che Guevara (as cited in Hyde, 2007, p. 87)

Community orchardists devote countless hours to their projects and make the orchards a very significant focus of their lives, sometimes for years on end. In this way, spearheading a significant transformation of a public space is like giving a gift to the whole community. Orchardists labour to give the gift of knowledge - particularly to neighbourhood children, who will benefit from seeing how food grows and tasting it right off the tree - and the gift of enjoyment that others will get out of being in an improved 
space where they interact in beautiful ways. Orchardists also gift their labour to planning, organizing, tending, and problem-solving when things go sideways - as when irrigation lines or standpipes break and it is up to the orchardists to fix them. Carmen (Strathcona) commented on the spirit of service that community orchardists (gardeners) exemplify:

We are 95 people. So there's always somebody willing to do something. We wanted to order soil and somebody said, Well, we need to find out the best cost, and the best soil and so somebody says, Oh, I'll research that. So there's always someone willing to do a little something: Oh, I'll take care of the website or Why don't I open a Facebook page for us members?

Tom (Welland) modelled this same spirit when he said, "Ask not what the orchard can do for me; ask what I can do for the orchard."

\subsection{Hyde's Theory of the Gift}

In Chapter 2, I introduced Hyde's theory of the gift. In this section, I reiterate its main precepts and show how they are illustrated in the community orchard.

\subsubsection{The difference between commodities and gifts}

The difference between a gift and a commodity is profound. The gift is offered freely, with no expectation of return to the giver; it functions to establish a feeling-bond between people. In large groups, gifts act not so much to consolidate bonds of affection between individuals as to constitute and affirm group membership - to make one body out of many (Hyde, 2007, p. 97). In community orchard and community garden circles, this is illustrated nowhere so obviously as in the long-established ritual of the potluck (de rigeur after a work party) where labourers come together and share the edible gifts each has brought to the community table. The commodity, on the other hand, is exchanged either 
for money or for an equivalently valued trade item; the exchange leaves no lasting connection between the individuals involved. Writes Hyde,

Because of the bonding power of gifts and the detached nature of commodity exchange, gifts have become associated with community and with being obliged to others, while commodities are associated with alienation and freedom. (2007, p. 85-86)

The freedom of commodity exchange has to do with the lack of any lasting obligations between people that are created as a result. With gifts, there are obligations. The first is to accept the gift, and the second is to keep the gift in motion, to keep on giving.

\subsubsection{The value of the gift lies in its being consumed}

The fact that the gift must be accepted - used, consumed - presents a paradox: Hyde writes, "Gifts are a class of property whose value lies only in their use and which literally cease to exist as gifts if they are not constantly consumed" $(2007, \mathrm{p}$. 26). This idea - that a gift is only a gift when accepted and enjoyed as intended - sheds light on the way many interviewees reported feeling about people taking fruit from the orchards. When they imagine that people have eaten the fruit, especially if they were hungry, then orchardists feel gratified because the fruit has at least served as a gift. When they see that people have taken only one or two bites from a fruit (often unripe) and then thrown it on the ground, they feel frustrated - in part, because they dislike waste, but more so, I believe, because their ability to give has been thwarted. If only that person had waited until the fig was ripe, they would have discovered how incredible a ripe fig tastes! And when they imagine that someone might be taking the fruit to sell, the disappointment is profound because it represents a violation of this understanding of the fruit as a gift - an understanding they had hoped would be shared. Turning the fruit into a commodity thus 
profoundly alters the meaning of their labour and the phenomenon with which they are engaged - or wish to be.

\subsubsection{The paradox of gift exchange: the gift, in being used, is not used up}

Paradoxically, too, it is the use of gifts that ensures their plenty. Hyde uses the example of creative gifts, noting that we frequently speak of talent as a gift. In the creative context, his point is made most clear: in being used, the gift is not used up. To the contrary,

To have painted a painting does not empty the vessel out of which the paintings come. On the contrary, it is the talent which is not in use that is lost or atrophies, and to bestow one of our creations is the surest way to invoke the next. (2007, p. 189)

As Hyde says, "what is given away feeds again and again, while what is kept feeds only once and leaves us hungry" (2007, p. 26). This echoes Séan's words when he observed that so much abundance is generated out of giving. It further echoes eons of wisdom encoded in Indigenous practices of ritually sacrificing the object of a hunt to ensure the future fertility of nature. Indigenous "first fruits" stories ${ }^{143}$ that teach this practice convey the understanding that 'the forest's abundance is in fact a consequence of man's [sic] treating its wealth as a gift" $(2007$, p. 24). Orchardists, in generously joining their labour to nature, are in fact illustrating this lesson too - that treating nature's bounty as a gift is the best way to ensure abundance for the future. 


\subsubsection{The gift must be kept in motion}

A gift economy entails three obligations: to give, to accept, and to reciprocate. Unlike commodity exchange, which is concerned with paying to balance the scale, gift exchange creates an obligation, not necessarily to return the gift directly, but more often to pay it forward, producing a sense of momentum, of weight shifting from body to body. Community orchardists give of themselves in response to the gifts they have received from those who came before, from each other, from the land itself. At Welland, orchardists frequently refer to the altruistic efforts of the orchard's namesake, Rex Welland, whose generosity and public spiritedness continue to inspire others to give of themselves for the community. Julia reflects on Rex's contribution with awe, "Somebody, not that different from you and me, did this, in their retirement, in their spare time, and look at how it's transforming this community!"

The labour of co-workers is also a gift in that it contributes to realizing the vision community orchardists share. And at Ben Nobleman, in Toronto, there is evidence that the voluntary labours of the orchardists and their enthusiasm for improving their park has influenced City workers, who, in response, have gone above and beyond, giving gifts of their own to support the orchardists' efforts to improve the park. Susan outlines this dynamic as she experienced it:

Parks and Rec, when they know how much we care about our park, I think they spend more time there. And if I have a problem, I can call the Head Gardener of our area, and he's so happy to come out and help us out, and just spend a couple of hours in our park, because he knows that we care. 
This anecdote illustrates the infectiousness of the gift - the way it inspires others to give in kind, producing that sense of momentum or weight-shift from body to body that keeps the gift in motion.

\subsubsection{The autonomy of the giver}

As outlined in Chapter 2, a gift economy is governed by the ethical directives that each participant should determine their own contribution (within vaguely specified expectations) and that the equivalence of two persons' contributions is not to be discussed. The equivalence of the counter-gift is left to the giver and cannot be enforced by any kind of coercion. Consistent with this ethos, community orchardists I spoke with described their work (gifts) as wholly voluntary, and frequently expressed how much they enjoy freely giving of their time. Séan (Spring Ridge Commons) commented,

You're working in a way that isn't bound in the same way that other work is. In volunteering your work it's like you still own your labour, right? It's the difference between work that is done for remuneration or that becomes a kind of slave labour, 'cause that's labour that's being taken from you. This is labour that you give but you're getting so much in return. It gives it a certain power when you give your labour freely... labour is the only thing that you actually possess as a poor person.

Successful community orchard leaders and initiators understand the importance of allowing volunteers the freedom to choose to labour in the orchard or not, and they respect it. As Zsuzsa (Ben Nobleman) explained,

It's never like, You didn't come last time. I was looking for you! When you give people a choice - you can come or not - people choose to go. But if they tell you to go, you'll be like, I'm not going! It takes away your freedom. 
The autonomy of community orchardists to be able to determine the nature and extent of their own contribution is also very important to them. Said Brian (Welland), of his extensive work championing and supporting native pollinators,

I'm 80 years old and I want to do my thing when I want to do it. And this fits in perfectly...I enjoy doing this. I enjoy seeing the success from doing it, but nobody puts any pressure on me. If I didn't want to do it this month, then they just leave me alone to do my thing. I don't come to many of their Sunday pruning gatherings, etc. I may come to one of their big gatherings, if then. But they just leave me alone to do my thing, because they know I'm doing it.

Interviewees also indicated that when the giving is free and not at all coerced or imposed, people often do much more than they need to. Carmen (Strathcona) gave a good example:

Before, we assigned tasks to people who were not able to come to work party. But in January we had a whole list of things that needed to be done and we said to people, "Sign your name beside whatever you'd like to do. And here's the person that you will email or contact once the work is done." So, this way people chose what really interested them more, and I think they put more hours into it than if they were assigned. We have a gardener who goes to church every Sunday so he doesn't come to work parties but he's here at least three times a week and he does all the mowing of the grass and cuts stuff. And he paints tables and uses his own money.

\subsubsection{The gift is to the giver}

"The gift is to the giver, and comes back most to him - it cannot fail..." - Walt Whitman

The final key aspect to understand about gift theory in relation to community orchards is that the gift gives back to the giver. Hyde describes gifts as "an emanation of Eros" (2007, p. 357), which he seems to understand in the Jungian sense (as opposed to the classical Greek, Platonic, or Freudian sense) of a desire for connection and wholeness, in contrast with 'logos', which he associates with objectivity and rational calculation. This sense of connection and wholeness is deeply satisfying, such that there may be no other return necessary for the giver. The act of giving is self-reciprocating. Again, the theory 
fits what I observed. When asked about what motivates them to contribute to community orchards, interviewees sometimes mentioned therapeutic benefits such as relaxation and enhanced mental health, and a sense of connection with others. But more often they talked about the rewards of giving itself - i.e., finding personal fulfillment through activities that have meaning and purpose and that enable them to "give back" or "contribute to the community." 144 Said Deanna (Welland), "It's so fulfilling, absolutely so fulfilling. I look forward to it. I had to miss one day and it was... It didn't feel right!” As Deanna's fellow orchardist, John, observed,

It's almost like when you work. If you just work for a pay cheque, the extrinsic rewards, then the job isn't that important. But with the intrinsic rewards and selffulfillment and community contribution, then it becomes a lot more valuable. That's what Welland Park is providing for us. It's a really great place to be.

Perhaps no quote better exemplifies Hyde's principle that the gift is to the giver than this one from Séan (Spring Ridge Commons):

It's not necessarily me giving, I am being given to at the same time...I am not thinking, Oh, I am giving this to this person. It's like I am receiving. I always feel that it's a privilege.

\subsection{Applying gift theory to understand complex dynamics in the orchard}

Gift theory helps us understand some of the complex dynamics community orchardists experience, both with outsiders and internally, amongst themselves.

\footnotetext{
${ }^{144}$ I am expressing the majority view. It also needs to be said that when systems break down, or interpersonal conflicts arise that aren't dealt with effectively, or when a command-and-control structure takes root, the intrinsic rewards can be occluded by tension. At one orchard which has been experiencing difficulties of late, a member who has taken a step back commented of other orchardists that "they are continuing to put in their time but increasingly with the sense that they are doing it for the sake of somebody else rather than real personal satisfaction." For various reasons, the community is struggling. Whether cause or consequence of the breakdown, I can't say, but the spirit of the gift has been lost.
} 


\subsubsection{Theft}

As noted in Chapter 5, the concept of theft from the community orchard is complicated.

On one level this is because orchardists recognize that they do not own the land, nor control access to it - community orchards are public in both senses of the word.

Therefore, the orchardists feel that they cannot claim exclusive rights to the fruits produced within the orchard, either legally or morally. Even in those orchards that operate on a clear membership basis (e.g., Strathcona), and where fruit should, by rights, accrue just to members, many members express a desire not to be insular or exclusive, like a club. Says David (Strathcona), "We're not hardline. We are a community resource, for community members, we support community. If people are really hungry and they want food, we're more likely to give to them as not." In other orchards, the long-term vision has always been an enlarged circle of abundance and sharing. Says Yoshi (Copley), "The intention really is to make it a community resource, [even if] we haven't done a very good job advertising or selling it in that way." "145 Consequently, most community orchardists express resignation at the frequent losses of fruit. They accept that the produce isn't really their own and that a certain amount of it can be expected to "walk" each season. Augusta (Jonathan Rogers) explains, "For me, there was an understanding that you wouldn't be able to protect it from harvest. It would just have to be, whoever's there, picks it, takes it." But as Sylvia (Strathcona), notes, not everyone in the orchard shares this view:

\footnotetext{
${ }^{145}$ Here again, I am presenting what seems to be the majority view. But it is important to acknowledge that some orchardists would likely dissent and not support my interpretation. Two people at Copley indicated to me that they felt that orchardists did secretly want their share of the fruit, as the fulfillment of their rights as members, but that they weren't expressing or acting on that and so were experiencing cognitive conflict.
} 
I always thought of the theft in the garden and the orchard as fleas with the dog. We're an inner-city garden. People love to wander through. You can't expect impoverished people not to grab something. To me, it's not a big issue. But for many gardeners it is. They're up in arms about it, to the point of wanting to take photographs of perpetrators and post them.

This anger Sylvia refers to is understandable. To those who regard their garden plots or the orchard as a form of (pseudo) private property, it must feel like an unambiguous case of theft. But for those who might see themselves to be engaging in more of a gift economy, I believe uninvited taking creates distress because it violates the spirit of the gift, in at least three distinct ways.

Earlier in the chapter, I described how orchardists can become frustrated with people who take fruit before it is ripe, and/or who take a bite and then throw it on the ground. Such acts thwart the givers' intentions, depriving them of the fulfillment of giving a fullyformed gift that will offer pleasure to its recipient. In the scenario in which people take too much fruit, the autonomy of the givers is undermined in a different way. Ideally, when one gives, one does so knowingly and deliberately; giving is a choice made by the giver, even if the recipients of one's gift remain largely unknown. Having all the cherries raked from your trees the night before a planned harvest celebration is different. It is not just the fruit but the givers' agency that has been stolen.

Second, more than the loss of the fruit, what community orchardists seem most disappointed about is the lack of consideration such acts show for others, who may be denied the opportunity to enjoy their share of fruit as a result. Linda (Spring Ridge 
Commons) sees this less as a case of theft and more as a lack of knowledge about appropriate ways to act in the commons:

There are people that will come in and take out bags of stuff. And that's not necessarily right when they do that. So, it's how do we prevent that from happening? How do we get people to consider other people when they harvest? There's a lot of education needed around that.

Community orchardists want everyone to share their vision of participating in a way that is fair to all; theft is wrong because it denies others their gifts, effectively excluding them from the circle.

The third problem is that people who take but don't work to maintain the orchard aren't contributing gifts of their own. Observed Tanya (Copley), "It appears it's a free-for-all, right? Like, we're working the land and people are eating it." This is a third kind of violation of the spirit of the gift - a failure to reciprocate and help keep the gift in motion. This may be the hardest problem to solve, especially for community orchards located within public parks, because a space characterized by a gift economy, if it is to function as a managed and sustainable commons, needs clear boundaries to establish where and for whom its norms apply. Yet a public park is, by definition, open-access; not bounded at all, but contiguous with the social and economic space that makes up the rest of the city, in which decidedly different norms prevail.

The frustration community orchardists feel in response to these problems all makes sense if we think of them as violations of the rules, or the spirit, of the gift economy. But how is the public to know that these rules even exist? One could blame community orchardists for not communicating their vision clearly enough. As noted in Chapter 4, signage 
COMMUNITY ORCHARDS AS NEW URBAN COMMONS

conveying the community orchardists' understanding of what they are offering or proposing to the public is decidedly rare. But many have questioned the efficacy of signs. Says Lynn (Ben Nobleman), "I think sometimes signs [might work but]...you know, if somebody's going to take it, it doesn't matter if there's a sign or not. So there's no sense barking about it. It is what it is." Moreover, it seems that community orchardists haven't all worked this out yet for themselves. In fact, most probably haven't consciously thought of what they are doing in these terms. But if it is a gift economy they want to create and invite others to join, that is a profoundly different model than most in our individualistic, consumerist, private-property oriented society are accustomed to. To get the public "on board" with this ethos and vision is bound to take time.

\subsubsection{Confusion}

In Chapter 5, I explained that some orchardists have expressed confusion about why they're doing what they're doing, and for whom. I interpret this not to mean that they need to know who exactly is getting the fruit (people often give without a clear vision of the recipients as an act of social faith) but that they don't know what sort of model they are creating or becoming part of. Is it more like an allotment garden or even a club, in which membership is clearly bounded and members have rights that non-members don't have? Or are they virtuously and selflessly cultivating edible landscaping, open to any and all, with nothing expected in return? Some orchards have a clear conception of which model they are following in theory - e.g., Strathcona is a community garden, membership-based, and clearly bounded - but have difficulty asserting and defending the rights of members given their location and the permeability of their boundaries. Other 
orchards - e.g., Ben Nobleman or Spring Ridge Commons - seem to be opting for more of an edible landscape model, while a third group of orchards seem to reflect some internal diversity of viewpoints as to which of these two models they are aspiring to follow. These two models correspond to two different conceptions of commons - on one hand, the type of material and managed commons that the Ostrom school has theorized extensively in relation to natural resource management; and on the other, the more popular (mis)conception of commons as completely open-access spaces unencumbered by any sort of rules or management. To my mind, a gift economy would seem to fit best with a managed commons insofar as it does have rules (ethics, expectations).

\subsubsection{Structure and Fairness}

No one denies that to enjoy the fruits of the harvest, members need to contribute to the upkeep of the orchard. And most people - especially those in leadership positions - find that some degree of structure and organization is desirable and necessary to see that this happens. Most people appreciate it when expectations about attendance at work parties are clear, as this helps ensure a degree of equity and gives members the assurance that they are fulfilling their commitments to each other. A membership structure is one tool some orchards use to communicate expectations and privileges. Says Matthew (Copley),

I think [membership] gives people that sense of identity and belonging to the community... And it's transparent and open and fair: everybody is signing up for the same deal. It's formalized and it creates a sense of equity. If there is no membership then everybody is making up their own idea about what their role is at the orchard.

However, beyond membership, figuring out how to organize bodies and energy - how much structure is enough and not too much - takes a fair bit of experimentation. Some orchards initially set out to keep records of each member's contribution (premised, 
presumably, on the idea that fruit was to be "paid for" with labour). This is understandable. Commodity exchange is what most of us are used to, so it makes sense. Moreover, the relationship ties in a newly formed affinity-based community may not be strong, making it easier for logos to prevail over eros. However, these orchards experienced difficulties operationalizing these systems, not least because there was, at least initially, no appreciable volume of fruit to offer in exchange for members' labour. And if there wasn't much fruit, then for what, exactly, were members exchanging their labour (and/or their membership fee)? One thought was that it was for access to knowledge, in the form of invited experts giving talks or workshops at, or outside of, work parties. At Copley, initially, there were so many people involved that limiting numbers at workshops was necessary. But as initial enthusiasms waned, as seems typical of all new initiatives, excess numbers were no longer a problem, so this conceptualization collapsed.

Other problems arose, it seems, because members did not respond well to hierarchically structured committees with their "flow charts of power" (as one interviewee put it).

Tanya recalled, with a good dose of humility, what this looked like at Copley:

Our first meeting a lot of the original people were business people, and kind of like paper professionals. And so we built our orchard on this ridiculous business model. To be fair, it's a ridiculous business model, right?!? But we didn't hold tight to it.

George (also from Copley) spoke to how it worked out: "And so they had all these rules in place, which turned out to not really match what was going on... In essence, nobody paid any attention to the rules." In addition to the systems breaking down, some people 
experienced interpersonal conflict, and some even became so frustrated they left the organization.

It seems that it is not obligation per se that people chafe at, but imposition. In a gift economy, the obligation to give, and to reciprocate, is understood and accepted. When people feel an obligation to the orchard and to each other that arises from within, it compels them to give in ways they typically feel good about. But when the shape, form, timing, quantity, or value of the gift is externally dictated, or seems to come from "above", people will tend to resist. Lisa (Copley) conveyed insight into this dynamic when she compared the community orchard to another commoning initiative she is involved in - a "little free library" that she and her husband erected in front of their house.

When we built that lending library in front of our house, someone said to me, "If I could give you one piece of advice, it would be, don't put up any signs. Because we had a community lending library that was great, for years, and for some reason, somebody put up a sign that said, 'If you take a book, you have to leave a book' and the whole thing just fell apart." So, from the start we've never put up anything that was [like], 'Hey, this is sharing and you have to leave something.'

And Copley is the same. Even with the membership thing, it's not...I remember the first time I saw anything about it, it was like, We ask that people attend four work parties a year - or something like that. And I'm a busy person, so I'm going, What if I can't make it to four work parties? So, any way that people can contribute to it is beneficial. So again, to not put rules, to not say there's a maximum or a minimum, I think it's cool.

Community orchardists seemed especially reticent to link the amount of work done to the workers' entitlement to a particular quantity of fruits, or proportion of the harvest. Recall from Chapter 5 David's view on correlating orchardists' hours worked to numbers of apples or other fruit, "I don't know if anybody'd really be too keen on that. It would be like commodification." The reasons for de-linking inputs and outputs are many and 
include, admittedly, the difficulty of quantifying, measuring and monitoring members' labour, and the acknowledgement that each member brings different abilities to contribute. Some who are older or physically less fit may not be able to contribute in ways that require heavy lifting or bending over or sustained vigorous activity, while some who have young children might be time-strapped and unable to consistently show up as planned. But I think the avoidance of equivalences can also be traced to the effects this might have on relationships within the orchard. Specifically, the lack of trust suggested by some members' felt need to measure and monitor others works actively against the establishment or nurturance of social bonds. It is just as Hyde says, that "emotional connection tends to preclude quantitative evaluation" (Hyde, 2007, p. 85). And for those who understand themselves to be engaging in a gift economy, and who see their labour as a gift, the very idea of measurement is alienating and de-motivating. In short, quantifying the value of each person's contribution dissuades participation (giving) and thus risks undermining the development of the community the orchardists wish to foster (exactly as gift theory would suggest). Community orchardists understand intuitively what Hyde meant when he wrote that "[W]ealth ceases to move freely when all things are counted and priced." (Hyde, 2007, p. 28). Instead, the ethos in the community orchard tends more towards Marx's oft-quoted maxim, from each according to ability and to each according to need. In other words, the volunteer labour of the orchardists is decommodified not only in the sense that it is non-remunerated, but also in the sense that orchardists generally refrain from calculating equivalencies between effort or hours put in and produce received. 
To summarize, community orchardists do not regard their work in the orchards as something they do in exchange for produce; as we saw in Chapter 5, the fruit is not at all the main reward or motivation for those who take part. While volunteer orchardists do often feel rewarded by more intangible benefits, the relationship between their labour and what they get out of working cannot be understood as a calculated exchange of one for the other. Seeing their labours instead as gifts helps us to appreciate what it is that keeps people giving, and why some kinds of internal organizational conflicts around fairness and structure are bound to arise.

This way of seeing also suggests some practical implications for managing community orchards. Most community orchards put something in writing about how many hours per month they expect members to contribute and/or how many work parties they need to attend per year. As Linda (Spring Ridge) says, "This is a shared space but it needs supporters too". But these are meant as guidelines, and there is little scrutiny or monitoring of members' actual behaviour. Most of the time, members are entrusted to be self-monitoring and to do their part with little, if any, external verification. That is not to say that it always works, just that it works for the majority of people most of the time; autonomy and self-direction with loose oversight seems to bring out the greatest commitment and initiative in members.

There is an art to motivating and sustaining the continued involvement of free actors in voluntary initiatives. Organizers must never forget that members are, above all, participating voluntarily. And as Karl Linn (2007, p. 30) learned through his commoning 
experiments in the 1970s and 1980s, "Unlike regular employment situations, in which workers may be forced to swallow their pride and tolerate humiliation and indignities to avoid jeopardizing their paychecks, the participation of community gardeners requires that their involvement be enjoyable." Sometimes, when there are large numbers involved, as Copley had in its first two years, a high degree of organization and structure will be required, even if only on occasion. But within that system, volunteer choice must still be paramount. Tom described what he appreciated about Julia's leadership at work parties at Welland:

It was very easygoing, it was kind of, Put your foot in the water, see if you like being involved, and then however much time you can dedicate to it...It's very much in the feel and tone of working with volunteers: Are you okay with this? How are you feeling about...? Or, is anyone really interested in this for today? It's that kind of thing, rather than saying, You and you, this is what you're going to do for the next two hours.

The results in these orchards suggest that too much structure is, at best, simply wasted effort and, at worst, smothers the spirit of giving and the spontaneity that comes with it, leading to disengagement. But a lack of structure has obvious problems too. To make things even harder, the ideal degree of structure will vary from person to person. Some, like Séan and Linda Chan, prefer a more anarchist approach. In Séan's words, “This is much more free-form and I think that is what keeps it going, to a large extent. There is a huge amount of spontaneity involved in it." Of course, for every person who has stayed and who credits the loosey-gooseyness of the arrangements for keeping things going, there may be another (or several others) who have left for the opposite reason - because things were too loose and unstructured. Ideal structures will also vary through time, as well as from group to group. What works well at Spring Ridge Commons may not work 
so well at Welland or Ben Nobleman. Consequently, it can take a while for groups to arrive at an agreed-upon system for managing labour and seeing that tasks get done.

\subsubsection{Burnout}

As noted above, gift exchange is often circular, meaning that givers give to someone from whom they will not receive, though they will in turn receive from someone else; Hyde writes, "When the gift passes out of sight and then returns, we are enlivened...each gift is an act of social faith" (2007, p. 20). This is very much true in the community orchard, where the faith is that others will continue to give, to show up, to stay with you, to follow through on what they said they'd do. And it is a faith that is regularly tested, as Jane (Banfield) candidly observes:

It's exhausting. And we've both gone through these things where we're like To hell with it. I just can't do it. I'm tired of asking and being the only one. And then something amazing happens, like 10 people turn up, absolutely bizarrely, and you're just filled with this energy that takes you a little bit further...

My hunch is that it is not just the labour itself, but the reciprocity (or lack thereof) that makes the difference between continuing and burning out. When orchardists feel that others are keeping the gift in motion, they are motivated to continue, even when the work is hard, as it often is.

That said, it seems fair to ask if perhaps some community orchardists are giving too much. Recent scholarship looking at unpaid internships on urban farms (and rural ones) has raised this question and flagged its gendered implications, given that so many interns are young women. Mincyte and Dobernig write, 
Even if [interns] justify their work in terms of spirituality and liberation, it is clear that they often stretch the limits of their schedules to squeeze in activities that benefit not only the wider community, but also developers, municipalities, and owners of commercial enterprises (such as commercial farms). (2016, p. 1781)

In this way, the authors write, "free and creative labor in alternative economies presents itself as a site both for self-reinvention as well as self-exploitation" (Mincyte \& Dobernig 2016, p. 1781). Interestingly, what I found in my research is that interviewees who labour for free in community orchards do not report feeling exploited in the least. They feel that they are working by choice, giving their labour to a project of their choosing, exerting significant agency and feeling gratified in doing so. Even when explicitly asked whether they might be doing the City's work for them, they denied feeling that way.

However, the situation was different for those whose engagements in community orchards occurred at least partially through paid employment - as in the EYA staffers working at Copley in Vancouver, the volunteer coordinators hired part-time (10 hours/week) in Victoria, and the part-time coordinator hired by Lifecycles to manage the Welland Legacy Park community orchard. The challenge for paid staff is that they are simultaneously working in the market economy, in which their labour is being exchanged for cash, but also giving of themselves as volunteers. And the line between the two is blurred, both in their own minds, and in terms of others' normative expectations of what they should be able to do, and how much time they should be able to contribute. This blurring has the potential to create internal conflict as well as a sense that because they have more responsibility than others for the upkeep and success of the orchard, and because they are being paid for far fewer hours than they work, that their volunteering is less than voluntary, and/or that they are being taken advantage of - not by the community 
orchard members or volunteers, but by whatever body is funding their 10- or 15-hours-aweek job. Said Stephanie (Fernwood, SRC),

I will both put in volunteer time, where I'm not charging for everything I do, because I just love pruning trees and I love teaching people how to graft and I want to share skills. But at the same time...trying to develop something consistent and economically to support things going on here, it does take a lot of time.

My interpretation of this dynamic is that gift-givers (i.e., volunteers) are happy because they do not expect monetary compensation; they have other sources of financial support, which liberates them to use their free time to engage in a gift economy. But non-profit staff or contractors who work in community orchards have a reasonable expectation of compensation. Unfortunately, workers in the non-profit sector tend not to be handsomely paid nor do they have great job security. Moreover, they tend to operate in both worlds at once - the world of market exchange, in which their labour is a commodity, and the world of the gift, in which they aspire to give freely. The boundary here is blurred, and the time they give to the gift economy is time that might otherwise be going to earning a better living. Moreover, that time is given in amounts often exceeding what they might want, owing to the strong sense of responsibility and emotional attachment they feel to the projects. Consequently, it is these givers who are more apt to feel frustration and fatigue at the endless pulling in opposing directions (across this boundary) that they feel in their roles. It is remarkable that they continue to express the level of enthusiasm they do for community orchards.

This observation points to another point we must not overlook, which is that those who participate without remuneration in community orchards are those who can afford to make gifts of their time and labour. That is not to say that they are wealthy; in fact, it was 
observed by more than one interviewee that wealthier people, in general, tend not to participate in urban agriculture initiatives. My point is, rather, that we should take care not to criticize community orchards for some putative failure to include more low-income people, given that the requirements of participation might well represent an added burden on those for whom resources such as time and energy are already scarce. This point is consistent with a growing literature documenting the very low rates of engagement with community (i.e., allotment) gardens, community kitchens, and good food box programs by low-income families - see, for example, Loopstra and Tarasuk (2009). These are schemes that are designed to directly benefit low-income people experiencing household food insecurity, yet those low-income families who are interviewed indicate that the programs do not match their needs and interests. How much truer this must be of community orchards, where the rewards are more indirect or intangible.

\subsection{Conclusion}

Interactions in community orchards are predicated on the gift relationship. This includes interactions between orchardists and the trees (land, soil, pollinators, Nature...) as well as interactions among orchardists and between them and the public. The gift relationship shapes and informs the way community orchardists feel about the space, the fruit, and the ways they give of themselves to make both available to others. This gift orientation is evidenced not so much in their words (it is not language that was used in interviews at all), but in the resistance they express to commodification, in the nature of the joys and disappointments they report, and in the conditions under which they offer their labour. 
COMMUNITY ORCHARDS AS NEW URBAN COMMONS

Hyde's theory of the gift enriches and expands our understanding of what it means for the community orchard (or community garden) to be a "de-commodified space." It is not just a space marked by an absence of monetary transactions, but one in which even the notion of equivalence in exchange is challenged. A de-commodified space is one that evinces a sense of obligation to give or reciprocate that arises from within rather than being imposed from without. A de-commodified space is one in which volunteering is so much more than doing unpaid work; the voluntariness of it is paramount - i.e., the autonomy, the agency, the gift. This understanding is especially important when we consider that many community orchardists are driven to heal a sense of alienation they feel from the land; labour can only be thought of as de-alienating to the extent to which it is freely given.

Hyde quotes the anthropologist Marshall Sahlins, who famously claimed that hunters and gatherers "have affluent economies, their absolute poverty notwithstanding". This is because they do not arrange production and distribution through the behaviour of prices, nor allow an "insufficiency of material means [to] become the explicit, calculable starting point of all economic activity" (Hyde, 2007, p. 28). Following both Sahlins and Hyde, we can see that the gift economy is in fact a rebellion against scarcity, or its centrality as an organizing principle in modern economies: "In the world of gift...you not only can have your cake and eat it too, you can't have your cake unless you eat it.” (Hyde, 2007, p. 27). Where use assures plenty, and to possess is to give, new ways of seeing and sharing open up to ensure the continuation of "this abundance that we share". 
Does this mean that all food provision can be organized this way - produced by volunteers and given away for free? We all know that there are realms of human need that are not well supported in a market-centred economy. And as a society, we do sometimes find non-market ways to organize around the provision of things we value - if we value them enough. I see in the efforts of community orchardists a recognition that food may fall in this category, and a desire to organize in non-market ways around its provision. However, there are limits of scale when it comes to gift economies, as Hyde acknowledges:

When we speak of communities developed and maintained through an emotional commerce like that of gifts, we are therefore speaking of something of limited size. It remains an unsolved dilemma of the modern world, one to which anarchists have repeatedly addressed themselves, as to how we are to preserve true community in a mass society, one whose dominant value is exchange value and whose morality has been codified into law. (2007, p. 116)

Moreover, it is plainly evident that those who produce food have expenses that must be paid in cash (many of them!) and they need to make a living. Even voluntary organizations need financial support. Consequently, some degree of gift and commodity co-existence must be expected in even the most progressive food systems. Still, I take the existence of community orchards as a sign that some among us, at least, are starting to point us in the direction of food as a commons more generally, even if the eventual shape of such a thing might only exist in embryonic form today. Markets are still ubiquitous in our lives and will undoubtedly be for some time to come, but non-commodified spaces like community orchards, where the gift relationship predominates, do signal a hopeful resistance to market triumphalism. 
The preceding three chapters have outlined three dimensions of commoning as it is occurring in community orchards - resisting enclosure, appropriating space for community, and decommodifying exchange. In Chapter 9, I introduce the fourth dimension or task of commoning - the expression and realization of popular rights to shape the city - and consider what community orchards can tell us about new possibilities for the shared governance of public land: specifically, what roles are appropriate, just, and feasible for community groups, or commoners, to play, relative to and in combination with the state. 


\section{Chapter 9 - Claiming power to shape the city \\ "The first answer was always 'no'. And always, the community somehow got it done anyway." "146}

\subsection{Introduction}

Building on what I have written so far about community orchards resisting enclosure and appropriating public space for community, it should be clear that community orchards are

above all, exemplars of political gardening - described by Certomà \& Tornaghi as "forms of political agency that contest, transform and re-signify 'the urban"” $(2015, \mathrm{p}$. 1123). In this chapter, I explore the fourth aspect of commoning - claiming power to shape the city (i.e., contest, transform and re-signify 'the urban'). This claiming of power is a mechanism of commoning that synthesizes the previous three already discussed resisting enclosure (Chapter 6), appropriating space for community (Chapter 7), and decommodifying exchange (Chapter 8). I locate this activity in the current scholarly discourses and debates around the right to the city, and neoliberal governmentality. I argue that each of these framings adds some understanding of how community orchardists claim power to shape the city, and that a view of community-City partnerships as transactive governmentality (Certomà \& Notteboom, 2017, p. 52) seems particularly germane to community orchards as new urban commons.

\subsection{The right to the city}

The right to the city (RTTC) concept was first put forth by Henri Lefebvre 50 years ago when he published a little tract titled Le droit à la ville on the 100th anniversary of the

\footnotetext{
${ }^{146}$ This quote comes from David Tracey (Strathcona).
} 
publication of Das Kapital and just before the student and worker uprising of May 1968 in Paris. The right to the city takes as a minimum condition the liberal notion of redistributive justice - that the city should be structured toward meeting the needs of all its citizens for products and material goods - and, Lefebvre would add, for "creative activity...information, symbolism, the imaginary and play" (Lefebvre, 1968, as cited in Mitchell, 2003, p. 18). The right to the city, however, goes beyond distributive concerns to include a democratic right to participate politically in shaping the city. For Lefebvre, this right was not so much to be claimed but reclaimed, given that citizenship, by definition, originated as rights to the city ('citadin' being the term for an urban dweller)(Purcell, 2002, p. 102). ${ }^{147}$ In Purcell's words: "Whereas conventional enfranchisement empowers national citizens, the right to the city empowers urban inhabitants" (ibid).

The right to participate politically in shaping the city has many layers. At its most basic, it is a right to physically access, occupy, and use urban space; above that, is the right to participate in decisions concerning the production of such space (Purcell, 2012) - to actively and creatively partake in the city, not just to possess or "consume it as an experience" (Zukin, 2010, p. 6). At a third level, the RTTC is about urban dwellers having the capacity and authority to govern urban space, a right that Passidomo says they [we] "have been structurally and systematically denied" (2016, p. 273). Through all

\footnotetext{
${ }^{147}$ According to Pocock (1998, as cited in Purcell, 2002), until the 17th century, rights of citizenship - indeed all political struggles of citizens - were focused at the city level. Later, these struggles shifted in focus to the state, and eventually the modern nation-state. I should note, though, that not all urban dwellers were granted the status of citizen. Women and slaves, for instance, were not considered citizens. Property ownership, city of birth, and age were also considered criteria for citizenship in different times and places.
} 
layers, the realization of these rights involves the identification, assertion, and negotiation of values. Harvey writes,

[T] he question of what kind of city we want cannot be divorced from the question of what kind of people we want to be, what kinds of social relations we seek, what relations to nature we cherish, what style of life we desire, what aesthetic values we hold. The right to the city is, therefore, far more than a right of individual or group access to the resources that the city embodies: it is a right to change and reinvent the city more after our hearts' desire (2012, p. 4).

Any effort to change and reinvent the city invariably involves struggle; for Lefebvre and his followers, the right-to-the-city is inherently a struggle against capitalism. Lefebvre argued that capitalism and urbanization were intimately and necessarily connected. Put simply, capitalism's main drive is to generate profit and reproduce itself. Capitalists perpetually produce a surplus that must be absorbed if it is to produce a profit. That surplus can be in the form of labour or capital or both. Urbanization (along with such phenomena as military expenditures) provides a way to deploy and absorb this surplus (Harvey, 2008, p. 24). Cities are thus both the result of the geographical and social concentration of this surplus product and the place where the dominating powers of capitalism are most intensely at work (Dikeç 2001, p. 74). As the capitalist mode of production has come to dominate all areas of social life, cities have become the site and source of social stratification, hegemonic power, and inequality (ibid). Consequently, for Lefebvre, the focus of political and class struggle had to be urbanization precisely because urbanization was so important to the survival of capitalism (Harvey, 2008, p. 28). A right to the city is a right to resist urban capitalism's internal logic. Says Harvey, The right to the city has to be construed not as a right to that which already exists, but as a right to rebuild and re-create the city as a socialist body politic in a completely different image - one that eradicates poverty and social inequality, and one that heals the wounds of disastrous environmental degradation. For this to 
happen, the production of the destructive forms of urbanization that facilitate perpetual capital accumulation has to be stopped (2012, p. 136).

Many scholars have asserted that urban agriculture offers one means of realizing the right to the city (see Certomà \& Tornaghi, 2015; Eizenberg, 2012a; McClintock, 2014; Purcell \& Tyman, 2015). Much writing about the contestations involving community gardens in places like New York City has also located them in terms of this sort of anti-capitalist class struggle - a bid by marginalized groups to assert an entitlement to land, space, and/or resources that has been denied them (Ferris et al., 2001; Schmelzkopf 1995, 2002). These struggles have been highly contentious and ideologically polarized affair, pitting capitalist developers and pro-development politicians - with their emphasis on the exchange value of space - against poor residents, new immigrants, environmentalists, anarchists, and others more concerned with the use value of space (Schmelzkopf, 1995, 2002).

This framing does not entirely seem to fit the community orchards I have studied. At these sites, it would seem that community orchardists are not, by and large, emerging from, or representative of, marginalized populations; nor has the emergence of their orchards in Vancouver, Victoria, or Toronto been accompanied by the sort of loud and nasty political confrontations that cities like New York witnessed in the 1990s (see Schmelzkopf 1995, 2002). We don't see in community orchards an overt "taking back" of neoliberal-dominated urban space for social use; of my five main sites, two are within city parks, one is within a community garden, and two were developed on land that was not considered developable, for one reason or another. That is not to deny that the potential for future contest and conflict with developers, or a pro-business, development- 
minded City administration - or even community association - exists. ${ }^{148}$ Nor is it to refute the history of sites like Strathcona Gardens, which illustrates the relatively low priority accorded by successive municipal administrations to open, green space in a neighbourhood that badly needed it and the degree of persistence that was required on the part of the community to claim and defend that space against more lucrative uses. It is just to say that the gardeners-vs-developers construct that has existed in other times and places does not appear to be the prevailing dynamic in these community orchards at this time. This lack of overt conflict is also a function of political circumstance insofar as all three cities have had municipal administrations or champions very friendly to the ideas of local food, community gardening, and sustainability (discussed below).

That said, as explored in the preceding chapters, we do still see a quieter (more Canadian?) assertion of counter-hegemonic values and priorities, as well as a desire by community orchardists to actively shape urban space to reflect these values and priorities - not just by voting, or writing letters, or giving input into a top-down consultation process led by the City, but also by seizing the reins and doing it themselves. This is the activity Lefebvre called autogestion (French for 'self-management'). For Lefebvre, autogestion was about workers re-appropriating control of the means of production and thus "strik[ing] directly at the system of property rights on which the capitalist economy

\footnotetext{
${ }^{148}$ In light of the maintenance difficulties that Spring Ridge Commons has faced, interviewees indicated that some voices with the Fernwood Neighbourhood Resource Group (NRG) have floated ideas about more entrepreneurial uses of the space. Copley, too, seems to be under some pressure. One interviewee recounted that a developer had been visiting homes in the area, offering to buy, on condition that owners sign a non-disclosure agreement, a condition that this interviewee described as "being picked off like flies." It seems very possible that the value of real estate in Vancouver has now climbed so high that the City could be reconsidering the developability of that site.
} 
rests" (Purcell \& Tyman, 2015, p. 1134). Autogestion, however, is not limited to workers or to relations with employers; nor does it have to do with seizing control of the state. Purcell and Tyman argue that autogestion goes beyond both market and state; that it is generalizable to the whole urban population and that it lies at the core of the right to the city:

We argue that the right to the city is, in its most fully developed form, a declaration by people that they intend to struggle for a radically democratised city beyond both capitalism and the state, a city where inhabitants produce and directly manage urban space for themselves, through free activity $(2015$, p. 1133).

Sounds a lot like the commons. Moreover, say Purcell and Tyman, it is through autogestion around urban agriculture that urban residents can counter and overcome their own alienation "from their labour, from other people, from food, from ecological processes, and from urban space" (2015: 1138). It is in autogestion that Purcell and Tyman believe the true radical potential of urban food cultivation resides. Certomà and Tornaghi appear to agree when they write, “A new Lefebvrian 'contract of citizenship' signals the beginning of a struggle for a generalised political awakening among citizens against the alienation of people, and towards the re-appropriation of food production and the collective production of urban space" (2015, p. 1127).

\subsection{Autogestion in community orchards}

I see autogestion happening in community orchards, in three ways: 1) initiation community members are driving the development of community orchards; 2) management - community members are managing the orchards, with significant authority and autonomy granted to them by the City; and 3) governance - the community 
orcharding groups are figuring out for themselves how to operate as self-governing entities.

\subsubsection{Initiation}

To begin, it is clearly at the grassroots level that most community orchards are initiated. In Vancouver, interest in local and urban food production has been demonstrably high for well over a decade. The grassroots Vancouver Public Space Network (VPSN) released a "manifesto" in 2008 reporting long waiting lists for community gardens. They pointed out that the City and community groups were "unable to work fast enough in developing new gardens to meet this demand" and requested that the City "get serious about community gardens" (VPSN 2008, p. 5). ${ }^{149}$ (This was before community orchards were recognized as a possibility.) The impulse to start community orchards came from grassroots organizations - the Environmental Youth Alliance (Copley); the RenfrewCollingwood Food Security Institute (Norquay); and community gardeners (Strathcona, Jonathan Rodgers).

In Victoria, interviewees described a groundswell of interest in local food that had been communicated to City officials by way of the democratic consultation process to renew the Official Community Plan. Said Jane, "Our [OCP] made it very clear to the City [that] there was a LOT of people - it wasn't just a few rabble rousers - who said, 'Yes, there should be more food grown on public land.'" Virginie Lavallée-Picard, Food Systems

\footnotetext{
${ }^{149}$ The City did get serious about community gardens. In anticipation of Vancouver hosting the Winter Olympics, Councilor Peter Ladner put together a proposal to build 2010 community garden spots in the city by 2010. In fact, the City built many more and still there are wait lists.
} 
Coordinator with the City of Victoria, agrees that the interest is coming primarily from the community and the City is responding: "[W]hat the City has practically done is make the space for more of that conversation to happen."

In Toronto, the initiation of Ben Nobleman Community Orchard was even more grassroots, in the sense that originators had no organizational basis or affiliation when they began. Susan Poizner just reached out to the Parks and Recreation supervisor for her area and said, "I want to fix up this park." She remembers,

He was so excited! He said, "What would you like to do?" We've got a little funding. Do you want a little annual bed?" He was excited. He was an awesome person...And I said, "Actually, what we want, you might think is a bit funny, but we want fruit trees.' And he was over the moon...He happens to grow fruit trees in his own backyard and he loves them. And he said, "Sure I'll help you. Let's do this!"

The very fact that citizens feel the need to fix up their local parks could be indicative of neoliberal disinvestment in public spaces. The point here is not to deny the existence of neoliberalism in the contemporary city, but to say that whatever the context, residents are initiating change in ways consistent with the notion of autogestion. I do not find in community orcharding any evidence that it is "growth coalitions" that are "mobiliz[ing] non-profits and local citizens to participate in projects that generate economic value from deprived locations" (Perkins, 2009, p. 258). The impetus is coming from earnest citizens themselves.

\subsubsection{Management}

Second, autogestion involves the actual day-to-day management of the orchards. Userbased management can look very different from one orchard to the next and also very 
different from public spaces managed by the City, as Séan (Spring Ridge Commons) explains:

It's the people that come into the park that recognize its possibilities and want to maintain it that way and so they do what needs to be done in order to ensure that it does. We have people that are sort of marginal people that do check and make sure that there aren't any needles left here and there, people that are here at odd times of the day or early in the morning or late at night, just sort of keeping watch on things.

Orchardists appear to be managing their spaces with a high degree of autonomy from the City (or other landowner/leaseholders). Says Councilor Mihevc,

They have tons of autonomy. They call us when it's Harvest Day because they want me there. They call the Parks people when something really big needs to be fixed, or when they need the compost or the wood chips. That's basically it. And then they kind of go nuts.

Wayne (Copley) says the same of Vancouver: "The City is pretty much hands-off. We're free to do what we do as long as we don't bug the neighbours too much." While Copley's orchardists do not have license to build any permanent structures, they do have the autonomy to "alter the landscape pretty freely" as Matthew put it. Sara Orchard, who at the time of my interviews was working with the Vancouver Parks Board as the main point of contact for community orchardists and gardeners said,

We try to make them as independent as possible. Ongoing issues might be the water connection... If there is a leak or something like that, I would help out. Or if there are really extreme gardener disputes, then I might get involved. But we really want them to be managing it themselves.

Municipal administrations in Victoria and Vancouver have placed a few stipulations on what community orchardists and gardeners can do. The sites must be open to the public and maintained organically. They must be developed so as to become a community asset. Naturally, they must comply with building codes, fire regulations, and municipal bylaws. And when groups propose a new orchard or garden, they must notify nearby residents by 
leafletting the neighbourhood and putting signage on the site, giving neighbours an opportunity to provide feedback. After that, it is up to the community groups to ensure that they are managing the sites adequately; there is no supervision or oversight provided by the City. Sara Orchard made the point that this is not child's play: "Ultimately, from a legal prospective, it is a license agreement so the group has insurance and we are transferring over responsibility and liability to the group." Community groups also know very well that if they want more opportunities for food-growing in public places, then they need to do a good job. Jane (Banfield) explained:

After the Official Community Plan, the City was basically forced to do something to have food in public places. So, they very carefully offered it to two fairly active food communities. And we knew, when we were given that, that we had to make sure it worked. Because if it had failed, then there's all the [reason] for saying, Well, it's just not going to work in public places. So, we knew that it was very, very important that this orchard succeed.

Community orchardists have, on the whole, demonstrated a high degree of success to date in managing their spaces. Strathcona gardeners and orchardists have been granted a 25-year lease (instead of a 5-year lease). And at Copley, when neighbours have called the City to complain, the City of Vancouver has deferred to the group. Tanya explained, I think they have looked up when the next work party is and told the people to come and talk to us. But the City has not said anything to us about grass-cutting. Which is amazing. And this year it's been pretty high! It's been a pretty lack-ofcutting year! [laughter]

While this deferral could be seen as off-loading by the City onto civil society, it could also be seen as the City respecting and strengthening the authority and legitimacy of the community group as managers of the space. In fact, two of the eight best practices for commoning that Elinor Ostrom elucidated have to do with the ability of commoners to self-organize and create their own institutions in a way that is respected as legitimate by 
external government authorities; and the organization of activities into nested enterprises (Ostrom, 1990). This means that the smaller entity of the commons is nested within the larger entity of the City (Cox, Arnold \& Tomás, 2010). If we understand community orchards (and gardens) as commons, this nesting can be seen not as off-loading but more positively as autogestion.

\subsubsection{Self-governance - "We're making it up as we go along..."}

The third way I see autogestion happening in community orchards lies in the emergence of self-governance by the orcharding groups. For community groups, developing this capacity to govern themselves seems to be the hardest piece. Self-governance requires a wholly different subjectivity from that of the volunteer. Heather Menzies, a scholar of the commons, calls this subjectivity 'implicated participation'. The difference, she says, is that people have to get used to responsibility and power. Writing about Gabriola Commons, on Gabriola Island, BC, Menzies explains,

People who become involved in the Commons are often deeply steeped in hierarchy, representative authority and delegated power. They're used to either being in charge or being told what to do... Not so on the Commons where everything is decided by teams, and the teams are run through direct, participatory democracy. All this takes time and patience, and the habits of attentive listening, humility, and negotiating differences respectfully (2014, p. 72).

Jodi said much the same thing about Copley: "People are still so used to having stuff be made for them and then having the terms of their participation in it [dictated], as opposed to creating those terms themselves, or negotiating that." Several community orchardists spoke about what a steep learning curve the shift to self-governance represents. Ariel (Copley) admitted, 
[At the beginning] somebody was making sure that it was going along. And then it was like, Okay, community, make it go! But I, at the beginning, had no sense that it was my responsibility to make it go. I was like, Okay, let me know when to show up and weed. That was my attitude. And so... I think that was the transition. Now we're going, Oh, we're responsible. Better take responsibility!

Martin (Strathcona) recounted similar difficulties in his group.

I'm finding that more and more that I'm having to kinda, at meetings, say to people, "We're all volunteers. We're all on equal status here. Don't make these huge demands." And more than once lately someone has gotten really red in the face and said, "Well, who's in charge? Who's getting paid to do this?" And they accuse Frankie - he is our plot coordinator, and it's just a volunteer job - and they say, "No, he's being paid to do that." No, he isn't; he's just a volunteer, like everyone else.

The self-governance piece - the need for it - isn't even visible to most people when they initiate or join a community orchard, as Wayne (Copley) pointed out:

You know, everybody joins because it's an orchard. Very few people join to say, "Well, I want to run membership. Or, I want to figure out about governance." So there seems to be this gap that needs to be fixed... Or else the organization runs into trouble.

At Copley, a few years into the project, discontent was rising and cracks in the group began to emerge. A couple of newer members decided to investigate by surveying the membership to see what they liked about the orchard and their involvement and what they were not so happy with. The resulting report indicated that the problems had mostly to do with inattention to governance - i.e., a need for greater transparency and clarity about how the organization works (“Who's making decisions anyway?”). At the same time, lots of people indicated that they didn't care too much about having a voice in decision-making; most, like Ariel, just wanted to be "foot soldiers" - i.e., to arrive at work parties and be told what to do. I found this at other orchards, too. Betsy (Strathcona) told me, "I made a pact with myself when I joined that I wasn't going to be involved other 
COMMUNITY ORCHARDS AS NEW URBAN COMMONS

than being a gardener and a member of the community work parties and gradually I got sucked in to being treasurer."

Members at Copley also indicated that internal communications were often difficult or lacking, and that it was very important that group process be reflective of a collective model (i.e., consensus-based) and also important that certain individuals did not dominate or unilaterally make decisions. Disagreements around decision-making are hard to avoid in a loosely structured organization that has not yet developed their own governance structures and processes. Lisa (Copley) observed, "It's very open, and it's also very susceptible to particularly strong personalities kind of running the show, whether that's good or bad." On the good side, those who like to "run the show" are often appreciated for getting things done. Even projects that are dedicated to consensus and horizontalism need people to call and facilitate meetings, work out complex design details and logistics of materials delivery, coordinate drop-offs and pick-ups, write grant applications, figure out what tasks need to be done at work parties and what instructions volunteers will need to do those tasks, and stay until after the last volunteer is gone, wrapping up loose ends. (These tasks can, of course, be done by different people, and in the interests of horizontalism, the leadership can be rotated.) On the bad side, those with strong personalities often clash, especially when it comes to decision-making and policy development. For example, Copley's orchardists argued about who should get to decide whether to accept a donation of persimmon trees for the orchard (which some felt were not suitable for the site) and whether to create and abide by policy or continue making decisions on an ad hoc basis. 
At some orchards, the anarchist leanings of many members mean that even the question of whether to have decision-making structures at all is debated. One interviewee described her group as having ridden a pendulum swing from one extreme of too little structure to the other extreme of too much. At one point, governance in the community garden/orchard seemed to be under the sway of people who wanted no structure, no rules (not even any squares or rectangles in the garden design!) Later, membership shifted and someone with a preference for task assignments and scheduling took charge. In this interviewee's view, neither extreme was quite right, as the first felt too chaotic and the second felt too regimented, which turned some members off. At Spring Ridge Commons, those who seem most attached and committed appear to be the ones who favour going with the flow and letting the always-changing mix of personalities shape both the space and the social dimensions of the commons more organically. Séan spoke positively of that approach:

Everyone is coming [to the Commons] with a different history and different ideas and we sort of exchange ideas and allow the garden in a way to evolve just by virtue of all the different people that are coming into it and changing it. Every time a different person comes in they bring something different into it. So that's really fun. You could say it's a game in a sense... and it's a place where we can collectively envisage how we would like to see our life on the planet.

For others, the variety of colourful personalities that often populate community orchards and gardens can be a source of frustration, as one person explained,

So how do you consult the membership? There are people who don't have phones; there are people that don't have email...I tried to start a Facebook group [and there was] a HUGE amount of friction, like, I don't want to go on Facebook. I tried to start a Google group...People flatly refused to join that... anti-corporate sentiment. And fear. There's people that think that Facebook is somehow going to pour out of their phone at night and kill them. [laughter] So it's been very difficult to even have a way of getting ideas out. 
Some members want to have a say in decisions but aren't as keen to attend meetings or read the minutes. Documentation is also challenging for informal community groups. Martin (Strathcona) gave a good example:

Recently, we had a problem with some drainage backing up, and when we dug it up...we found no one had ever finished the installation of the drainage pipe! So, for 30 years the drainage didn't go the proper place and nobody knew that because no records had been kept!...So we're trying to figure out how to keep records. We used to keep records on paper... Do you use a computer? Whose? And then the format changes?!

Unsurprisingly, another of Elinor Ostrom's best practices for governing the commons deals with conflict resolution. The most successful - that is, the most equitable and sustainable - commons around the world all involve low-barrier, easy access to means of conflict resolution (Ostrom, 1990). Unfortunately, none of the community orchards I studied had anything in the way of established processes for conflict resolution. It seems to be the "elephant in the room" that everybody sees and no one wishes to name. Said one interviewee, "The products, I think, are pretty easy; we know how to make sustainable orchards. What we don't know is how to keep a group of people together and organized in a sustainable way." Another under-recognized need is for long-range planning. Said Wayne (Copley),

If you don't train people or sort of groom them or show them that they belong to the organization not just in the moment but for the future, you end up with things that put the organization in jeopardy all the time if somebody gets sick or leaves. We don't think of that very much. We just keep thinking, if the bugs show up and we don't have enough people, the trees will die.

In sum, community orcharding groups demonstrate autogestion insofar as community members initiate these orchards, manage them with a large degree of autonomy, and learn self-governance, as challenging as that may be. In this sense, the right-to-the-city discourse provides a useful framework for understanding community orchards. 
COMMUNITY ORCHARDS AS NEW URBAN COMMONS

However, there is another, more critical way that some scholars have framed the work of community gardeners (and orchardists, by extension) which we need to consider here: neoliberal governmentality.

\subsection{Neoliberal governmentality}

For those dedicated to countering neoliberalism and capitalism, there is a concern that community initiatives may inadvertently play into that which they oppose. Cutbacks to state-provided social services under neoliberalism have led governments to offload responsibilities to underfunded non-profits and volunteer groups in civil society, which try to compensate by delivering services and entitlements formerly provided by the government at lower cost (Allen \& Guthman, 2006; Castree, 2010; Guthman, 2008; Poppendieck, 1999). This deployment of civil society as a "flanking, compensatory mechanism" (Jessop, 2002, p. 455) serves not only to compensate for cutbacks to statesponsored services, but to conceal and even justify them. As Biel (2016, p. 111-112) writes, such dynamics allow the neoliberal state to "conserve the energies it might otherwise be forced (under Keynesianism, for example) to devote to running society... and thus allow it to offset the entropy of capitalism." Biel also makes the point that governments that harness community's "free energy of self-organization" $(2012, p$. 111-112) also exert control through the constraints they place on what civil society can (and cannot) do. Ghose and Pettygrove agree: "Although formally independent of the state, voluntary organizations that rely on or compete for state funding may become "arms" of the state, serving to translate state policies to non-state practices (Swyngedouw, 2005; Trudeau, 2008; Wolch, 1990)" (2014, p. 1093). 
COMMUNITY ORCHARDS AS NEW URBAN COMMONS

Consequently, some scholars have argued that far from resisting neoliberalism, community gardens have become instruments of neoliberal governmentality (see Alkon \& Mares, 2012; Guthman, 2008; Harris, 2009; Holt-Giménez \& Wang, 2011; Pudup, 2008). Pudup (2008) and Guthman (2008) are particularly critical of the emphasis on self-sufficiency and personal responsibility they perceive in the alternative food movement, seeing these as markers of neoliberal discourse. Rose (1996) sees the same danger in the creation and maintenance of open public spaces by communities, in that they bring about a new technology of governing. What Rose (1996) calls "governing through community" combines "the political rationalities of a neoliberal ethos of selfresponsibilization of the individual and the neo-communitarian ideal of active citizenship" giving rise to a new form of social control (as cited in Rosol, 2011, p. 251).

A related dimension of this problem lies in the suggestion that citizenship is no longer given but must be earned through participation in volunteer, community-building activities (Lepofsky \& Fraser, 2003; Perkins, 2010, p. 258). Rosol cites one case in which a local government in Germany, faced with massive budget cuts, not only offered residents the "opportunity" to maintain existing parks for free but actually "presented volunteering as the only alternative to an unwanted selling off of public green spaces or the introduction of entrance fees for parks" (2011, p. 244). This example, while not representative, illustrates the end-point of the slippery slope of governing through community. It makes citizenship conditional, available "solely to individuals who claim it through formal participation or community-based organizing" (Ghose \& Pettygrove, 2014, p. 1103). This is inherently unjust, given that not all residents have the means - i.e., 
financial freedom, knowledge, physical ability, health, and time - to participate, and that in marginalized communities especially, "volunteerism requires extracting material and labor resources from already resource-poor citizens, who struggle to fulfill basic survival needs" (ibid). Moreover, by promoting and even conscripting, citizen participation, neoliberal governments may "discipline citizens to accommodate rather than confront the state (Elwood, 2004; Ghose, 2005; McCann, 2001; Perkins, 2010; Pudup, 2008)” (Ghose $\&$ Pettygrove, 2014, p. 1107). Perhaps the most pernicious aspect of this purported dynamic concerns the allegation that community gardeners and other volunteers do not understand how the government is using them, and instead come to believe "that it is in their self-interest to take on such work in place of the state (e.g. Agrawal, 2005; Taylor, 2007)" (Drake, 2014, p. 179). It follows that any invocation of 'community' or volunteerism in the context of the shared management of urban resources must be accompanied by some wariness of the risks, since the line that separates community empowerment and cooptation by the state may be fine indeed (Perkins, 2009, 2010; Rosol, 2010). However, not all scholars of community gardens agree with this analysis.

The counter-point to the neoliberal governmentality argument is represented by those who have framed community gardens as "spaces of contestation, reactions to the social and environmental injustices of neoliberalization" (Eizenberg, 2012a, p. 767;

Schmelzkopf, 1995, 2002; Smith \& Kurtz, 2003; Staeheli et al., 2002); and by those who take a more positive view of active citizenship. For example, Staeheli $(2008$, p. 16) writes that "gardens are indicative of the potential for a reimagining of citizenship that can be developed through community... where new political imaginations and moral values 
[are] cultivated, along with flowers, vegetables, and greenery." Some even call into question the basis on which scholars have positioned community gardens as neoliberal or anti-neoliberal. Galt, Gray \& Hurley cite Ward (1998, p.12):

I often wonder how we reached the situation when honourable words like 'enterprise,' 'initiative' and 'self-help' are automatically associated with the political right and the defense of capitalism, while it is assumed that the political left stands for a big brother state with a responsibility to provide a pauper's income for all and an inflation-proof income for its own functionaries. (2014, p. 141)

They go on to say, "Increases in community and individual initiative, self-sufficiency, and self-help cannot be solely read as something that more easily allows for the abandonment of the liberal vision of the state, but rather need to be seen as a positive development" (ibid). White (2011a, b) writing about African-American farmers in Detroit, would likely agree.

I say the same, especially of the care - "for land, community, and each other" ${ }^{150}$ - that I see in community orchards. I worry when I read critiques that suggest that community gardening organizations that practice an ethic of care are accepting the relocation of responsibility for social welfare away from the state and onto the community (see, for example, Knigge, 2009). This alarms me because it seems to overlook an important distinction - between social services and welfare entitlements (which the state has a responsibility to provide) and care. Care is not just labour; it's all about relationship. I have not met one person who would rather receive "care" from the state than from a community to which they felt they belonged and toward which they felt some mutual affection. Do we not want to live in communities where we take care of each other,

${ }^{150}$ Recall that this is Copley Community Orchard's motto. 
COMMUNITY ORCHARDS AS NEW URBAN COMMONS

instead of having the state do it? We must not make the mistake of assuming that the state should perform all the functions that people are performing when they come together in community orchards and gardens.

Then there are those who take a more ambivalent or nuanced position. Nathan McClintock has argued that urban agriculture is neither wholly radical nor neoliberal, but "may exemplify both a form of actually existing neo-liberalism and a simultaneous radical counter-movement arising in dialectical tension" (2014, p. 148). This suggests a need to apply more focused lenses, and direct attention to the fertile ground of this dialectical tension, and the contradictions, hybridities and new possibilities it may generate. I believe that community orchards (like community gardens) illustrate McClintock's argument well.

\subsubsection{Neoliberal governmentality in community orchards?}

I will admit to feeling alarmed when I heard a volunteer at Welland suggesting that he would be willing to take a trimmer and tidy up the property edges after municipal staff have mowed the grass, to save them the work; and also, when I heard that at one time the Town was considering getting Julia and her volunteers to add mowing the grass (using the Town's riding tractors) to their responsibilities. (Recall that View Royal is a nonunion town, so there would have been little to stop them from offloading that work, if they had determined it was feasible.) For me, this raised big red flags and questions about everything from workplace safety and liability to the very evident possibility that residents were indeed being conscripted into doing the Town's work for free, just as the 
COMMUNITY ORCHARDS AS NEW URBAN COMMONS

proponents of the neoliberal governmentality argument have predicted. In the end, the Town and Life Cycles together determined that this was not an appropriate assignment for volunteers. I was similarly concerned about offloading by the neoliberal City onto the shoulders of all-too-willing volunteers when I heard several interviewees muse that what they were doing did amount to creating a public park for the City, without compensation. However, I also heard strong evidence to suggest that this dynamic is not as simple, or as foreboding, as I initially believed.

I have come to the conclusion that there are at least four good reasons to believe that the most pessimistic predictions regarding government off-loading or citizen conscription into neoliberal governance will not come to pass. These have to do with 1) the lack of evidence that municipalities are supporting community orchards in a bid to save money;

2) the amount of work required to sustain these spaces over the long-term; 3) the unwillingness of (most) community orchardists to take on what they feel falls properly under the City's jurisdiction; and, 4) the strong need for community groups to retain the sense that they are gifting their labour and time, and not being coerced into it.

\subsubsection{Municipalities not saving money}

The first reason it is unlikely that community orcharding represents the "thin edge of the wedge" of citizen incorporation into neoliberal schemes of governance is that I do not find any evidence that municipalities are saving money by having volunteer residents green vacant lots or add fruit trees to existing parks. In fact, it seems to cost the City to do so, especially where they have created positions such as that of a Food Systems 
Coordinator, and/or granting streams to support existing community gardens and orchards, as they have in Victoria (other municipal supports will be discussed below). In fact, as Toronto Councilor Joe Mihevc explained, even when municipal governments sponsor volunteer participation events, like ravine clean-up or tree-planting, they do not save money.

It takes more time for staff to basically organize the volunteers and bring all the shovels and pay for all these shovels and clean up after for people who don't plant right, and so on. But you do it for different reasons, right? It's about community engagement, and all those other things.

John Rogers, town councilor in View Royal and active volunteer at Welland, also confirmed that the Town pays a lot more there than they would at an equivalent-sized park without an orchard. He adds,

But on the other hand...the number of people going to this park, for the size, is proportionate to the investment. The amount of time spent in Welland Park is far, far more. So, we recognize that this investment is because the community wants to spend time in that park.

The fact that Welland Legacy Park is managed by a non-profit does mean that people like Julia can prevail upon the goodwill of private business owners or contractors in the community to donate a trellis or donate the design of interpretive signs or come dig post holes for free in a way that they wouldn't do if it was the City or Town government asking. As a non-profit, LifeCycles is also eligible for grants that the Town could not apply for. Still, it would be hard to argue that the Town of View Royal is motivated to engage with Welland as a way to trim its budget. If they wanted just to save money, they could maintain it to the same standard as they do other parks (grass-cutting etc.) and let the fruit trees grow wild. Thankfully, this is not an option they are considering. In Vancouver, the spaces that groups have appropriated for community orchards are ones 
COMMUNITY ORCHARDS AS NEW URBAN COMMONS

where the City was previously doing very little maintenance. Norquay was a vacant lot; Strathcona, a mud flats; and Copley, a field, with tall grass that was mowed infrequently. The savings for the City of Vancouver at these sites is no doubt more than eaten up by what the City is investing in staff time to pay for positions like Sara Orchard's.

\subsubsection{Too much work - "You know, volunteering isn't cheap!"}

A second reason I think residents are not being co-opted into promoting a neoliberal agenda is that community orcharding involves a lot of hard work - work that I believe volunteers will only be motivated to do when they are advancing their own agendas. Even when they are feeling quite in control of their projects, the work can be overwhelming. Copley's "Delta Force” investigation revealed that many members thought the labour contribution requirements (monthly half-day work parties) were difficult or impossible to meet. In Séan's words, “It never ceases to astonish me how much work a small piece of land can be." Others spoke of volunteer burnout in the group, exhaustion bordering on resentment, and a need for more work to get done than is actually getting done. The start-up phase is full of novelty and anticipation and brings many enthusiasts on board, but the "honeymoon period" eventually passes. Tanya (Copley) put it succinctly: "Planting trees was sexy. Cutting grass now is not." Weeding, too, has limited popularity, though doing it with friends helps make it more palatable. Often, orchardists have great intentions to expand the orchard and make the project even greater, but these, too, fall by the wayside when all of life's other demands vie for attention. Said one, 
I think I signed up for Grant Writing and I even had a meeting at my house, but I never followed up. I didn't really have the energy to be on the grant-writing team - my job distracts me. I like the idea, but it just didn't happen.

In addition to the physical labour, there are the endless meetings, where it's not uncommon for a few people to dominate the discussion or hold to seemingly irresolvable differences over matters of trivial importance. Many people find meetings very offputting. Even the celebrations that were so fun in the first couple of years eventually become yet another thing to organize, and when the core volunteers begin to tire, the celebrations often go dormant. Said one,

I don't know if I'm jaded, but I just feel that people in this community are superkeen to receive, but not so keen to give...They love the Harvest Festival; they really enjoy all the work we put into it. But nobody's lining up to help us.

People are still joining, but not at the rate they were when the orchard idea was new. As Helen (Copley) put it, "half a dozen newcomers are still sort of a thin broth for a rich soup." Work is not just labour; it's mental energy, social capital, physical presence and emotional investment. ${ }^{151}$ It sometimes also requires volunteers' own money, or a great deal of time and effort trying to come up with money. In addition to appealing for donations and applying for grants, orchardists sometimes organize Go Fund Me campaigns, or they find things to sell to raise money. Linda (Spring Ridge Commons) said it best:

You know, volunteering isn't cheap. There's your time that you put into this versus something else. There's also gas...and other things that come into play when you're volunteering as well.

Given how much work it is to keep a community orchard alive, it is easy to see how things can break down. We may wonder instead, What makes orchardists stick with it? I

${ }^{151}$ I thank Charles Levkoe for this insight. 
believe the answer has to do with the sense of psychological ownership that those actively involved in creating community orchards feel for "their" spaces, and in the intrinsic pleasures they experience in giving. As discussed in Chapter 7, community orcharding groups feel a strong sense of psychological ownership over community spaces when they participate in designing them; when they actively and voluntarily contribute their labour to developing them; and when they believe that the spaces are serving a higher purpose that aligns with what is meaningful and valuable in their worldviews. If (or when) community orchardists feel they are not engaged in these ways because the City, or an outside agency, has imposed a design, or a requirement to labour, or tried to align volunteers more with their own agendas, then their sense of psychological ownership will suffer, and with it their willingness to do the hard work necessary to help community orchards thrive; there will be no inspiration to carry volunteers through the perspiration.

Other scholars have made similar findings. In Chapter 7, I mentioned Eizenberg's (2012b) analysis of what happened when the New York Restoration Project (NYRP) took over dozens of that city's community gardens. When the NYRP introduced private/corporate sponsorship and professional landscape design, gardeners became alienated and disengaged. As another example, Drake explores two major approaches to community gardening - "one where the essence of authentic community gardening is based in grassroots management (Mees \& Stone, 2012), and one where planners and organizers seek to transform and mold individuals (Lawson, 2004)" (2014, p. 180). She finds that "externally organized gardens, seemingly the ones most oriented toward 
neoliberal mantras of community self-reliance, never really took shape, and indeed produced passive resistance by neighbourhood residents" (2014, p. 193). Without active participation in design and a self-initiated will to labour in the service of their own visions, residents will not "buy in", especially when it seems that others are trying to change them.

\subsubsection{City's jurisdiction}

Third, residents resist incorporation into neoliberal governance because most have a sense that as residents, they are entitled to a minimum level of services which the City has a duty to provide. In community orchards, there are few things that irk orchardists more than being assumed to be an unpaid City clean-up crew for members of the public who leave garbage behind. Even as they recognize that most members of the public simply don't understand the novel caretaking arrangements in a community orchard, most would like to see the City pick up the garbage. It's not a question of labour as much as of jurisdiction. Said Augusta (Jonathan Rodgers):

I think [community orcharding] has to be married with having public employees. I wouldn't want [just] volunteerism - it's the City's and the government's responsibility to provide and maintain those spaces. But I think it's good to have people's input and involvement in taking care of them.

Other interviewees indicated resistance to the thought of having to take over municipal responsibilities. ${ }^{152}$ Tanya described a discussion the Copley group had,

At the very beginning - this was nixed pretty fast - people were talking about playgrounds for kids. And I'm like, Noooooo. There's insurance involved with

\footnotetext{
${ }^{152}$ Notably, these are not things that the City asked community orchardists to do, but things that the community orchardists were, themselves, considering. This is exactly the dynamic Perkins has in mind; he critiques Wolch's (1990) shadow state thesis as incomplete because it sees power as flowing unidirectionally from the state outward and does not consider how groups and individuals co-produce dominant society's social and political agendas $(2009$, p. 396).
} 
playgrounds. And maintenance. And we are not a park. But that's what we've become.

Community orchardists display mixed feelings about becoming a park. On the one hand, they love what they have created; but on the other, they do not wish to accept all the responsibilities that might come with it, especially responsibilities without capacity. Neighbourhood groups maintaining green space that is not officially a park have no ability to regulate things like hours of use, camping, or smoking because bylaws governing parks don’t apply.

I concur with other scholars: that if and when volunteers perceive that the work they are doing is not supplemental to normal City operations, but an effort by the City to offload its proper duties onto citizens, they will reject that role. Herbert (2005) investigates the devolution of responsibility in the exercise of community policing in Seattle and finds that even residents who were initially enthusiastic about the idea of volunteering to make their communities safer quickly became disillusioned. He writes that while the state may try to frame the move as strengthening local control, residents "recognize state offloading when they see it and thereby resist, albeit largely passively, the assumption of increased responsibility" (ibid, p. 854). Herbert argues that this is because they believe that the state "possesses some enduring duties to its citizenry" (ibid, p. 859) which include the provision of police services [and we may conjecture, the maintenance of parks]. Consequently, Herbert concludes that 'community' is like a trapdoor; it "can give way under the expectations that neoliberalism wishes to place upon it; it often cannot fulfill the obligation the state seeks to off-load" (ibid, p. 852-853). In part, this is because residents, at least in Herbert's study, do not view community as "a crucible for self- 
determination" but instead just "a hoped-for source of minimal, yet predictable, connection" (ibid, p. 855). Consequently, Herbert concludes:

Community can ostensibly perform two functions in projects of neoliberal governance; it can stand as a recipient for devolved authority, and it can legitimate that very devolution...[But] community in neoliberalism does not work to perform well either of [these] two tasks" (ibid, p. 852)

In Rosol's example from Berlin (outlined above):

The administration, faced with massive financial cuts, [had] an interest in reducing its own workload particularly by outsourcing unskilled, repetitive, nonqualified work. The community gardeners, however, [sought] a self-determined use and organization, which necessarily also includes decision-making power (2011, p. 248).

As a result of these incommensurable interests, she writes, "the neoliberal state strategy [failed] in establishing a shared conviction regarding the necessity of volunteering in the green sector." (Rosol, 2011, p. 240). In other words, helping the state is not a motivation for most people. Rather, residents are motivated by being part of a group and gardening for enjoyment; in fact, Rosol writes that if it does not bring fun, they do not engage in it (ibid, p. 247).

In short, we may predict that any attempt to pass ordinary responsibilities for public green space maintenance to residents will fail because residents still view park maintenance as a job for the local state. Maintaining community orchards is different because those who initiate them see them as projects that go "above and beyond" what residents expect the City to provide. While community orchardists' initial enthusiasms might on occasion lead them to volunteer too much, I believe they will ultimately want this dividing line to be clear, and will resist, if and when the City tries to blur it. 


\subsubsection{Labour as gift}

The fourth reason I believe that citizen enrollment in neoliberal governance is not the correct framing in the case of community orchards is because of the centrality of the gift dynamic. As explained in Chapter 8, community orchardists tend to view their volunteering as a gift that they offer, to their communities, Nature, fellow members, and themselves. They do not generally conceive of their labours as a gift they make to the administrative entity of the City. Orchardists will not feel this way if they sense that their "volunteer" labour has become mandatory, or that they are doing it because someone else (i.e., the City) has required them to. This dynamic was developing at Copley in part because of the way the space was being shared between the Environmental Youth Alliance (EYA) and the all-volunteer community group. The community group was reliant on the non-profit EYA, which held the lease, and which had funding from various partners and a contract with the City of Vancouver. However, the funding from the City was not sufficient to pay for coordination of work on the community side. This put the EYA in the unenviable position of having legal responsibility for the entire space but no financial capacity to maintain the community side. Under such conditions, not only is the locus of control unclear, but so too are roles. When low-paid staff of non-profits have to work "off the side of their desks" (as so many do), they are not acting as volunteers. Said one EYA staffer, "To have it be something that's sort of considered as part of my job, even though I don't have any time or resources to do it - it feels VERY exploitative." Given that the work of the EYA is also work that benefits the City, the potential for resentment is huge, as this anonymous interviewee expressed:

The EYA maintains five public spaces right now, in a very creative and I think really exceptional way. All of those spaces are public access, and resources for 
the community and for the services we're providing, we don't get a lot of public support from government to do that work. Yeah, so personally, I've been really frustrated, actually, with that.

Said another staff person of a supporting non-profit,

From my perspective, straight up as an employee, what this relationship means is that I get a contract where I'm not actually paid for all of my hours and I don't have security and I don't have benefits. Right? So it's a nice relationship for the [municipality] and for [the non-profit]. Is it the best relationship for me as an employee and as a person trying to make a living in the city? It is a really tricky thing. I don't have a good answer. But... it would be really nice if [they] just valued hiring someone full-time to manage the orchard.

It is important to distinguish that the relationship here is not one between the City and volunteers, who are clear about their freedom to engage in community orcharding (or not), but between the City and a non-profit, which had to lay off several staff one year when the City drastically cut its funding. It is well-known that non-profits bear the brunt of much governmental offloading, and this instance involving the EYA seems to speak to that dynamic. As a non-profit, the EYA is trying to provide not only socially worthwhile programming but also jobs. As such, it is dependent on the City's cooperation (and sometimes, funding, although usually very modest); consequently, there is a significant power imbalance between the parties. With volunteers, the power dynamics are different. When volunteers don't like the conditions of their engagement, they will often simply disengage. Governments wanting to entice residents to do work that serves the City's interests therefore have to offer something more significant in return - not wages, but opportunities to pursue their own interests, as they see fit, on their own terms. The power of the volunteer lies in his or her ability to choose when to give and when to walk away. 
Having suggested four reasons why community orcharding should not be seen as an instance of citizen co-optation into neoliberal governmentality, I also acknowledge that there is at least one sense in which it can be argued that community orchards may yet foster neoliberalism. McClintock (2017) has advanced the argument that community gardens provide cities with "symbolic cultural capital" that can be mobilized by developers to extract higher rent, and by boosters and financiers "to competitively promote a city's reputation as a hotbed of sustainability and livability in hopes of attracting new investment, skilled labor, and green consumers" (McClintock 2017, p. 4). Community gardens supply cultural capital because as Sharon Zukin has pointed out, over the last 30 years, 'Food has emerged as the new 'art' in the urban cultural experience" (2010, p. 29). Community gardens therefore signal transformations from low-wage neighbourhoods to middle-class ones. Gardens in residential yards are implicated, too - especially those in front yards (McClintock et al., 2016). Food gardens in front yards signal an "ecohabitus" that is associated with "hip" eco-friendly millennials - the prime movers of gentrification. McClintock (2017, p.4) explains ecohabitus as a 're-articulation of the field of highclass consumption, fostered by a more general social valorization of environmental consciousness' (Carfagna et al., 2014, p. 3) [which] also fuses concern for environmental sustainability with the 'valorization of the local' and 'revalorization of manual labor' (ibid, p. 15) that undergird foodie emphases on 'quality, rarity, organic, hand-made, creativity, and simplicity’ (Johnston \& Baumann, 2014, p.3).

Consequently, instead of the predominant dynamic in community orchards (gardens) being one of use value versus exchange value, McClintock $(2017,4)$ notes that we now have a commensurability with market logics (citing Walker, 2016), insofar as volunteer 
orchardists and gardeners are providing "free gifts of culture" (citing Stehlin, 2016)

which are then exchanged for economic capital at different scales. ${ }^{153}$

This is particularly true in progressive urban centres such as Vancouver and Victoria. In Vancouver, it is very clear that community orchards and gardens help advance the City's sustainability goals, as Wayne (Copley) points out:

What we do for them in return is we provide a lot of publicity in that we've got [an orchard], we've been successful, we produce fruit. The City is really promoting this Go Green thing. You know, Vancouver's trying to be the "greenest" city on the planet. So, we allow them to have some evidence that that's true.

Nor is it lost on community orchardists that their projects help attract both tourists and people to move to the neighbourhood. Stephanie (Fernwood and SRC) told me, "There are people I know who have moved to Fernwood because there's great stuff going on with local food production. So, [there are] people wanting to invest and stay." Likewise, Patti (Banfield) commented, "I think we're giving the City a good reputation, I think they are being looked upon favourably. That's what the Parks Director wanted: “Let's put Victoria on the map."

As positive as these interviewees make it sound, the down side is that community orchards and gardens can also contribute to rising property values and urban gentrification - "the production of space for progressively more affluent users" (Hackworth, 2002, p. 815). This observation has been made by many scholars (see Gottlieb \& Joshi, 2010; Linn, 1999; McClintock, 2017; Quastel, 2009; Rosol, 2011,

\footnotetext{
${ }^{153}$ McClintock points out that production need not be commodity-based to be part of a capitalist mode of production $(2017$, p. 3$)$.
} 
COMMUNITY ORCHARDS AS NEW URBAN COMMONS

Voicu \& Been, 2008). Interviewees at Ben Nobleman and Copley made this same observation spontaneously. Jodi commented, "We really improved the site for people. And we probably actually raised the property values of some of the [surrounding homes].” Dooling's (2009) more specific concept of ecogentrification expresses the idea that seemingly positive environmental improvements can lead to undesirable social outcomes, including the displacement of homeless people (2009, p. 622). Clearly, even open-access parks and green space are not universally beneficial.

As McClintock, Miewald \& McCann (2018) note, the dynamics linking urban agriculture and ecogentrification need further clarification. What we do know is that gardens (and orchards) that develop on vacant land can eventually be lost to development when formerly undesirable properties become valuable. Strathcona Community Gardens is a case in point. It used to be that the land Strathcona sits on was not really all that desirable. But, said David,

The land is REALLY valuable now. And I was always worried that we're going to get along fine, they're going to use us as a showcase, and then as soon as it comes down to a crunch they'll say, "You know, that land you're growing some quince on... I can get 8 million dollars for that spot [under] the drip line of that tree." And we'd be out of there in a song. And that's actually still always a prospect.

Alternatively, gardens (and orchards) can become incorporated into the marketing of neighbourhoods in ways that add value to new construction (Quastel, 2009). In these ways, community gardens and orchards are undoubtedly implicated - if only unintentionally - in the production and governance of the neoliberal city. 
And so we return to McClintock's (2014) idea that community orchards and gardens stand in a complex and sometimes contradictory relationship to neoliberalism. Consequently, Galt et al. argue that "a single explanation of expanding the neoliberal project is too tidy of a theorization" (2014, p. 1137); they instead call on scholars to "subvert binary thinking and embrace paradoxical thinking" (ibid). Paradoxical thinking is, in the words of renowned educator Parker J. Palmer (2007, p. 69),

[...] a view of the world in which opposites are joined, so that we can see the world clearly and see it whole. Such a view is characterized by neither flintyeyed realism nor dewy-eyed romanticism but rather by a creative synthesis of the two.

Thinking paradoxically, we can be neither dismissive of community orchards as cooptation to the neoliberal agenda nor complacent in the certainty that they always resist it (Certomà \&Tornaghi, 2015; McClintock, 2014). As Tornaghi \& VanDyck remind us, there is a need "to remain vigilant about the risk of serving the [state's] interest in outsourcing responsibilities to the community in the name of a neoliberal agenda, rather than one of empowerment and justice" (2015, p. 1259-60). At the same time, we should look for the cracks, where the light gets in. ${ }^{154}$ As Rosol (2011, p. 250) argues, neoliberalism “changes opportunity structures. Well-organized groups do have, and actually take on the opportunity to insert, their own interests and promote a different agenda." This politics aligns nicely with Gibson-Graham's (2006) and Harris' (2009) calls to "read for difference" (rather than domination) in accounts of local food activism.

\footnotetext{
${ }^{154}$ This is, of course, a reference to Leonard Cohen's famous song, "Anthem", the chorus of which goes, "Ring the bells (ring the bells) that still can ring; Forget your perfect offering; There is a crack in everything (there is a crack in everything); That's how the light gets in."
} 
COMMUNITY ORCHARDS AS NEW URBAN COMMONS

This position refuses to lend neoliberalism the power to script all resistance in its own terms - a view I take with respect to community orchards.

My research indicates that community orchardists both feel and exert more agency than governmentality theory presupposes, and that they actually want to govern themselves, their spaces, and their resources while at the same time still holding municipal governments responsible for providing services and supports that make autogestion possible. The City - and developers - can certainly take advantage of the community gardening and orcharding phenomenon, but they can't make happen what citizens are unwilling and unmotivated to do themselves. Making lasting and equitable commons requires a form of public-popular partnership that allows power to be shared and benefits to accrue to both.

\subsection{Commoning as a Public-Popular Partnership}

I see this form of partnership already emerging with community orchards and gardens. The most effective partnerships entail high levels of political support, practical assistance, mutual benefits and collaboration through informal planning. When these are present, we have the makings of sustainable new urban commons.

\subsubsection{Political support}

Orchardists in Vancouver and Victoria have been fortunate to enjoy a high degree of political support from municipal administrations. In Vancouver, Gregor Robertson, of the centre-left Vision party, has been mayor for over a decade (since 2008). His administration ushered in a friendly climate for foodies by inaugurating his tenure by 
planting a vegetable garden on the front lawn of City Hall (Ross, 2010). Around the same time, recalls Copley co-founder Hartley Rosen, there were individuals in the Social Planning department who were really keen on the orchard concept "because it was new and exciting". Rosen credits the City's Social Infrastructure Planner, Dr Wendy Mendes, with "stickhandling" the proposal behind the scenes and finding significant funding to help see the vision realized (funding that the EYA was then able to leverage). Then there was Vancouver's Greenest City initiative - a bid to become the world's most environmentally friendly city - which set targets for increasing urban tree canopy. Community orchards fit well into that scheme too. The alignment of the City's social and environmental orientation with community orchards has helped not just with securing the use of city land but also with managing community opposition when the orchards were first proposed. According to one interviewee, residents around Copley who disliked the orchard idea didn't really have a say in whether it was going to happen - it was "already a done deal" because it was a choice that the City had made.

In Victoria, Dean Fortin - another "green" progressive - held the mayoral seat from 2008-2014. Fortin prioritized sustainable development and a green transportation strategy, along with his main priority, affordable housing. Since 2014, Lisa Helps has served as mayor. Helps is a former activist and community organizer who was very involved with the Fernwood Community Association prior to her election. Helps and her council are extremely supportive of community orchards and urban agriculture generally. Since 2015, Victoria has put considerable resources into their Growing in the City initiative, in an effort to become a leader in urban food systems. They employ a Food 
Systems Coordinator and give out modest grants to support half a dozen neighbourhood community associations that have created food spaces to ensure they can maintain them. The City actively promotes small-scale commercial urban agriculture in private yards, rooftops, and vacant lots. The City also supports the growing of vegetables, fruit, flowers, and nuts on public land through community orchards, community allotment gardens, commons gardens, and boulevard gardening. They have an Urban Tree Stewards program that allows individual residents to plant up to six fruit or nut trees in a public park and take care of them themselves. Finally, Victoria is one of the most permissive jurisdictions in North America when it comes to allowing urban residents to keep poultry and bees. All this support notwithstanding, it is still true that the drive for community orchards has come from urban residents. And this is probably as it should be in a democratic system. As Jane (Banfield) said, “I don’t know how well a Council can lead, really. I think Council has to be pushed. That's my experience."

In the town of View Royal, Julia Ford lauds the town council, staff, and Parks and Engineering Department for being "super on-board":

I think, to their credit, the View Royal Council really does see that they're investing in something that is a regional resource, and... that's been one of our selling points: that we have a resource that it essentially unique in Canada. And they really have an opportunity to kind of take a leadership role and be lauded for it.

In Toronto, too, community orchardists have benefitted from political support, though not necessarily that of the mayor. While 2003-2010 saw the progressive and environmentally minded David Miller in office as mayor, in 2010, Rob Ford was elected to a four-year term. Ford was socially and fiscally conservative, outspoken, controversial and no friend 
of the environment - not a likely ally for Susan Poizner and her friends. But Toronto has a system of governance by wards, and the ward where Ben Nobleman Park is located has been represented by Councilor Joe Mihevc for over 20 years. Mihevc has a reputation for promoting social justice, diversity, sustainability, and public health, and for fostering strong civic engagement. With Mihevc (who also successfully championed the cause of backyard chickens) it seems that Ben Nobleman Community Orchard had the support they needed, regardless of who was in the mayor's seat. Mihevc explains his philosophy this way:

I'm always one of the top spenders of my own office budget. The Toronto Sun [a tabloid], they go after me for being one of the top spenders, but I spend it all on community stuff. Like, when you go [to Ben Nobleman] tomorrow, you'll see a load of compost. That came out of my office budget. So that cost me $\$ 250$. But what a great expenditure! For 250 bucks you keep the community happy and they do good things with it. And they're the ones who then use that compost and put it all over the place in the park. That's a brilliant investment. And guess how many calls I get, complaining about my spending habits? Zero.

It seems fair to say that the relationship of municipal politicians to urban agriculture has been evolving steadily over the past decade, even the past five years. It wasn't always this way, as David (Strathcona) recalls:

Apparently, there was for a long time at the Park Board, a culture of "No"...If the community asked for something - especially if a bunch of lefties in Strathcona asked for something - the automatic answer was "No." And always, the community somehow got it done anyway. Now, the Park Board has kind of shifted...There's more of a community-oriented culture...They're really into it! There's an urban agriculture push on in the City; we're seen more like allies. They're often trying to help us...The first answer is not automatically "No" anymore.

In Victoria, when some residents starting gardening in boulevards, the City opposed it. Then they tolerated it, and now they have a policy promoting it. Hannah (Banfield) cheered the City's growing willingness to support commons: 
There's been a lot of battling for so long and then now, it's like Whoa! It feels like there's so much opportunity for these commons spaces. There are conversations around a community bake oven, in public parks. Things like that are happening.

Sometimes, support depends on the proclivities of individual City staffers. Says Susan (Ben Nobleman), "If you happen to get lucky and have a wonderful gardener/supervisor, then it's magic. They'll find a way to do things. If you have a person in charge who's a bit of a hardline person, then you'll get nothing." Sometimes the official answer and the actual response are different. Said Lynn, "When we asked for compost, they said they didn't have any, and yet two bales were delivered to the park. So, somebody went out...We just say thank-you." Political support isn't, however, something that community orchardists can always take for granted. As David (Strathcona) knows from years of experience, "Sometimes a party gets in and they're green, and community-friendly and all that, and then the developer party gets in and it's more, Eight million dollars is eight million dollars." Wise community orchardists and gardeners work during the politically friendly years to get as much support as possible institutionalized within City infrastructure and policy.

\subsubsection{Practical assistance}

All community orchardists I spoke with indicated that the municipal administrations had been very helpful in practical ways, especially in the start-up phase. The levels of support provided, however, vary from one jurisdiction to the next. In Vancouver, some interviewees suggested that they felt the City was almost "an absentee landlord"; one said that their main contribution is "letting us squat on the land" or, in the words of another, “just leaving us alone." However, the City does supply orchards and gardens with wood 
chips and amended soil each fall. At start-up they helped Copley with some free compost and in-kind donations, as well as small grants to purchase other needed supplies. At Strathcona, the City's main presence is in the form of visits by park rangers, who are called if someone needs to be asked to leave. Sylvia had kind words for the rangers: "They're very good about it, they're very, very kind. And they will store [the homeless person's] belongings if they need them to, and redirect them to shelters, that sort of thing." Tasks the orchardists/gardeners at Strathcona must do themselves include installing and repairing irrigation works, maintaining the buildings and the compost toilet, and collecting garbage. (For some reason, the City will pick up garbage at Strathcona but they have refused to do so at Copley.) At Strathcona, which is officially classified as an urban farm, gardeners had to put in a proper lane to allow fire truck access.

The City of Vancouver also pays for water, though this was only thanks to the efforts of Vancouver community gardeners who pushed for it. In 2007, the Vancouver Community Agriculture Network (VCAN) was formed to be a voice for urban agriculturalists in the City. David Tracey (Strathcona) explained:

At the time, the City was getting really interested in food security and so they held a symposium to find out what they could do to support city gardeners. VCAN, being organized, had determined that their top priority was to get the City of Vancouver to pay for water (Strathcona was paying something in the order of $\$ 2,500 /$ year). Their argument was, We're actually improving a public space on the City's behalf. We're not asking you for pay. (But if you want to talk about that, we could.) Meanwhile, don't charge us for water in this public area. And we got it!

Getting the City to pay for water in community gardens was a huge policy win for VCAN, one that orchardists and gardeners hope will provide them with security in the 
future, if and when a less orchard-and-garden-friendly administration is voted in. As David explains, un-doing something like that, once it's in policy, is hard: "There's a lot of wheels you have to put in motion. It's more difficult for them. The status quo has a pretty strong force in how municipalities run."

In Victoria, the City bought the trees for their two pilot projects at Banfield and Fernwood. They also installed the water connection, which they service twice annually, and as of 2016, they pay for water. The City will also supply minimal fencing (e.g., split rail, not deer-proof); removal of debris and pick-up of invasive plants for safe disposal; and staff time in helping community groups refine their vision and carry out consultations. They used to provide gardens and orchards with leaf mulch and wood chips, though this was discontinued in 2016, much to the chagrin of community orchard members. Perhaps the most important form of support the City of Victoria offers is the grant for volunteer coordinators. As Jane (Banfield) remarked, organizers are often "trying to do crisis management - you just do the most important things first before it all falls down. And so sometimes you just never get to organizing so that it will run well..” That's why the grant providing for just 10 hours of paid staff time per week can make a huge difference to the sustainability of these projects.

At Welland, LifeCycles' contract with the Town of View Royal included deliverables having to do with infrastructure - a toolshed, a pathway, a composting toilet - so as to make it a usable public park. But the Town now plays more of a support role to LifeCycles, supplying staff and equipment to cut the grass (as they would do in any 
park), and taking away cuttings from the trees, which they mulch and then return in the fall, covering the bases of the trees and making sure that the ground is prepared properly for the winter. The Town pays the full cost of water and is also available for any heavyduty work that LifeCycles, Julia and/or the volunteers can't manage on their own.

For Ben Nobleman, the City of Toronto provides compost, wood mulch, water, and soil, when needed. The City also purchased the toolshed (which the volunteers painted), and regularly bring bags for the tree cuttings, which they also take away. If a tree dies, the volunteers ask the City for a new one. At all sites, it seems that there is an understanding that City crews should continue to provide the level of maintenance and care that the spaces received before the community groups initiated their orchards (or gardens) and/or the same level of maintenance and care that other parks receive - e.g., basic grass-cutting, edging and trimming.

Occasionally still, conflicts arise, communication breaks down, and mistakes are made. One very significant example involved City workers coming to Copley Community Orchard, without notice, and cutting all the irrigation lines to the trees, apparently to "standardize" operations across sites (leaving each with only a standpipe). It was very costly for the EYA to fix - and frustrating. Said one interviewee,

Working with the City and (especially) the Parks Board is like communicating with the Wizard of $\mathrm{Oz}$ - it's really hard to know what's going on behind the curtain. When you ask them what their role is they often laugh and then give very confusing, convoluted answers that require a lot of if/and/but statements.

Sometimes, support must be negotiated. At Banfield, the City of Victoria wanted the trees to be surrounded with grass (i.e., no under-plantings) but the community group thought 
that was anti-ecological, preferring a more permaculture-oriented design. The parties were able to compromise, agreeing on a cover crop of clover and hügelkultur beds. The City then brought in an excavator and donated the waste wood to fill the trenches. Patti Parkhouse also insisted on deer fencing and the City agreed to it, offering to install the fence posts. The community group added the wire fence and custom-designed gates. There was clearly a desire on both sides to cooperate as much as possible. Said Jane (Banfield), "You try to make your proposal attractive to the City...You want to celebrate the olive branch."

\subsubsection{Mutual benefits}

For a public-popular partnership to succeed, both parties must feel they are benefitting from the arrangement. In general, City governments benefit when residents improve Cityowned spaces, making them both more attractive and better used, which keeps them from being sites of unwanted activity. Says Joe Mihevc,

I LOVE supporting...When groups of people get together and find a way to animate a public space, that's gold. That is gold! They become the stewards of the park, they become the animators of life in the park, they develop programs; it becomes a way of being. And that's good civic government; that's good community engagement; and it's a great project.

Cities also get positive recognition for their support of urban agriculture; Welland Legacy Orchard is definitely a point of pride for the town of View Royal. Cities also get help in achieving their own goals - i.e., those laid out in their strategic plans and Official Community Plans (OCPs). Victoria's Food Systems Coordinator, Virginie LavalléPicard, explains that in the City's Strategic Plan, for example:

Objective \# 8 is to enhance and steward public spaces, green spaces and food systems...But then you look at Objective 7, and it has to do with facilitating social inclusion and community wellness. So, even though community gardens or 
our food system may not be explicitly included in Objective 7, I would certainly see community gardens playing a role in that objective as well.

And, to the extent that urban agriculture promotes gentrification, we may also add that municipal administrations probably benefit, financially, albeit indirectly, in the form of an enriched tax base and an influx of tourist dollars.

Community orchardists feel that they, too, are benefitting and that their give and take with the City is a fair exchange. Said David (Strathcona),

You know, this is something that citizens are really clamouring for...I think the general reaction on the gardeners' side is, Great! We get this space. We don't have this space at home, and we get to use it here, and that's a great thing. The City's being kind to us.

Jodi (Copley) said,

Having an amenity like a park...that they don't actually maintain, is kind of beneficial. But I never felt that the City was pawning it off so much. The City got really good face time, in terms of turning this vacant lot into a productive community project. And we got a huge space in the middle of Vancouver to do urban agriculture on - which is kind of mind-blowing!

Likewise, Julia (Welland) commented, "I think we do get a fair shake out of this town in that it's their park, and they're giving Lifecycles access to it, and that's huge."

Partnerships can also offer the potential for win-win solutions to both parties' problems.

For example, Stephanie explained that stewards at Spring Ridge Commons were looking at the possibility of rain gardens, which would benefit the orchardists/gardeners by supplying irrigation and diversifying how the site is hydrated, and would benefit the City by channelling storm water away from storm drains, lessening the impacts (of flooding events) on municipal infrastructure. Likewise, Julia notes that at Welland, "Lifecycles gives the Town the ability to enliven that space with more flexibility than they would 
have [alone]...and [LifeCycles] does get more stability than [we] would have if the Town wasn't there, in terms of funding."

\subsubsection{Collaboration through informal planning}

A partnership is about collaboration, and collaboration involves negotiation of interests and power relations. The City's power is most clearly expressed in terms of the security (or insecurity) of tenure they are willing to provide to community orchards and gardens. Jodi (Copley) remembers:

We had to pull tooth and nail to get a five-year agreement from the City...We're like, We're planting trees here. We're not going to do it with a two-year agreement! I do remember that it was a fight and we were frustrated often with the City's kind of lack of ability to understand that we can't invest this kind of energy and money into something that we don't get long-term tenure of. ${ }^{155}$

Typical leases also give the City the ultimate trump card. As David (Strathcona) said, "We sign what they write...We don't bring our own lawyers and say, 'No, we refuse to do this until we have this out of there' because then they'd say, 'Well, screw you then. Don't take it."”

However, there are also ways in which community orchardists (and gardeners) have gained important concessions from the City. I have described how Patti Parkfield and others in Vic West negotiated a modified design for Banfield that incorporated some permaculture design elements and a deer fence, and how the City cooperated and contributed significantly. I have also described how the Vancouver Community

\footnotetext{
${ }^{155}$ Interestingly, not all orchardists believe that long-term tenure should be a given. Wayne (Copley) commented, "A lot of people say, Well, we're doing an orchard, so it should just be permanent. But I think we have to prove it to the City, show them that it's something worthwhile or show the City that the community wants it...To me, just because we're doing this stuff [doesn't mean] that it should stay forever."
} 
Agriculture Network (VCAN) negotiated free water for community gardens \& orchards from the City of Vancouver. In both instances, the City had an interest in what the community gardeners were doing or providing for them, so the interactions were more collaborative than antagonistic. In general, this seems to be the case for community orchards, in their relationships with municipalities. They seem to fit a model that Certomà and Notteboom (2017) call 'informal planning'. ${ }^{156}$

The concept of informal planning emerges from "a critical reading on the relationships between top-down and bottom-up processes" and "suggest[s] the existence of a more collaborative relationship (though entailing a certain degree of antagonism) between institutional, private and community actors" (ibid, p. 52). In place of the idea that urban form is the product of oppositional and "ongoing struggles over who gets to shape the qualities of daily urban life" (Harvey 2012, p. xii), informal planning "activates rolemixing between different social actors (people, administration, associations, business, individuals...) all requiring listening to others' positions and negotiating their own" (Certomà \& Notteboom, 2017, p. 65). The authors continue,

For instance, despite owing a lot to the alternative urban culture, urban gardening initiatives often became an integral part of the institutional planning strategy, not because they are flattered by it, but because they transform it through continuous, non-linear and networked relationships (including cooperation, antagonism, opposition...). (ibid)

\footnotetext{
${ }^{156}$ Informal planning may be contrasted to 'counterplanning' (Shatkin, 2004) which refers to bottom-up actions to claim and shape public space, but without as much give-and-take, negotiation, or collaboration with City officials. Counterplanning seems like a good descriptor of guerrilla gardening, but not of most community orchards.
} 
Informal planning helps explain how far the City of Victoria has come in its orientation toward food growing in public space in the past five years; pressure from residents has pushed Council ahead while still maintaining and building good working relationships. By using an approach that is more interest-based than power-based, urban residents are compelling the state to provide support for their initiatives, in the form of space, labour, money, water, enabling policy and at times, significant institutional support. This recalls Arjun Appadurai's claim that given the right "conditions of possibility" - including "leadership, morale, flexibility and material enablement" citizens can "appropriate significant parts of the means of governance" (2001, p. 26). It is thus not hard to agree with Certomà and Notteboom when they write that "by reversing the arrow of traditional participatory processes, [actors] are changing neoliberal planning itself”' $(2017$, p. 66).

As a frame, informal planning is much more complimentary to citizens who are acting as change agents than is the concept of neoliberal governmentality. The latter suggests that citizens are not thinking for themselves, not generating ideas, not truly empowered, unaware that they are acting as unpaid agents of the state's political agenda. The concept of informal planning gives citizens credit and honours their "willingness to take the lead or at least add their voice to decisions on urban space destination and planning" (ibid, 2017, p. 55). Certomà and Notteboom write, "the concept of informal planning leads us to reconsider the post-Lefebvrian critique of planning as a tool of domination and it suggests that planning per se can be a co-creative process, empowering citizens in selfproducing public space” (ibid, p. 66). Informal planning, as a construct, is also more sympathetic to those in local government who genuinely believe in community-based 
(food) projects, and who see a place for community members as active, creative agents, not just passive recipients of programs and services. The City representatives I interviewed (Virginie, Joe, Sara, and John) all fit this description, as each is also personally active in the community orchards and/or elsewhere in the food movement.

The more nuanced perspective on City-community relations that the concept of informal planning represents seems to be gaining traction among scholars of urban agriculture (UA). Thornton (2017, p. 971) asserts that this "re-imaging [of] UA, as a form of social production, can potentially bridge the 'antagonistic relationship' (Brenner, 2012, p. 19) that exists between socially just spaces and neo-liberal policy spaces."

Research in some Western cities has revealed examples of effective citycommunity partnerships and with respect to community gardens more specifically (McCarthy, 1997; Agustina \& Beilin, 2012), where workable relationships between state, corporate and community interests are both possible and socially, economically and environmentally beneficial.” (ibid., 973)

Thornton also points out that "Lefebvre's theorising does not exclude the possibility of city-community partnerships" (2017, p. 970). These are partnerships in which neither the community sector nor the institutional sector dominates or succeeds in transforming the other in its image. As Certomà and Notteboom put it,

[I]nformal planning does not represent the climax of the liberatory power of alternative urban culture, neither the consequence of a progressive inclusion of alternative practices in neoliberal, institutional urban planning; rather, it is the expression of an emerging and transactive governmentality (2017, p. 52).

This idea of transactive governmentality fits the community orchard context very well. Perhaps I should say contexts, in the plural, for it seems important also to acknowledge that community orchards, as outcomes of informal planning, vary widely across the different sites, owing to the diversity in communities' political orientations. Some 
communities' engagement looks a lot like neo-communitarianism ${ }^{157}$; their philosophy is a pragmatic, We'll help the City maintain our parks so we can make them better. Others more closely resemble Pickerill and Chatterton's idea of "autonomous geographies" "spaces where people desire to constitute non-capitalist, egalitarian and solidaristic forms of political, social and economic organization through a combination of resistance and creation" (2006, p. 730). Their philosophy is more utopian - We'll do it all ourselves just so we can have this space to shape as we like. In other words, as McClintock (2014) contends, the cultivation of an active and engaged citizenry can be seen as the engagement of neoliberal subjects or as the activation of radical democracy and an activist sensibility; indeed, both may be happening at the same time. What you see depends on where you look.

\subsection{Supporting commons within the City - limitations and concerns}

I have said that there is a type of public-popular partnership I see around community orchards, which, in its best expression, entails high levels of political support and practical assistance coming from municipalities, benefits for both the orcharding community and the City, and a collaborative ethos that is achieved through informal

\footnotetext{
${ }^{157}$ Neocommunitarianism is a political position concerning the role of community vis-à-vis the state that aligns with neoliberalism. It tends to be apolitical and focuses on the activation and building of moral community (in a socially conservative sense) as a solution to social problems. DeFilippis, Fisher, and Schragge write, "To their credit, these new communitarian theories, with new nomenclatures of social capital, community capacity, assets building, consensus organizing and so forth, seek to move right-wing discourse away from the deficits and failings of individuals and families to more collective ones at the community level. They respond to a clear decline of collective behavior since the mid-1970s and seek to counter the extreme individualism and privatism of the past generation with work that emphasizes the value of greater public engagement" (2006, p. 675).
} 
planning - in other words, an emerging transactive governmentality. I believe this is the kind of governance necessary to support commons within cities. But the fact that many community orchards are struggling to continue suggests that this may not be enough. Some interviewees expressed the view that their projects, as currently organized, are simply unsustainable. Said one, in reference to a group she has stepped away from, "I think what's missing in... [the community orchard] is any sense of enabling authority. They are just a bunch of rag-tag kids after the nuclear war, who are trying to pull together a project. It's just not enough.” More enabling authority might help, but I don't think alone, it is the answer. Eizenberg (2012b) describes how the Trust for Public Land (TPL) in New York City bought up dozens of community gardens that were otherwise destined for demolition. But when they transferred legal ownership to local groups, the ensuing responsibilities (i.e., having a board of directors, and having to be involved in the administrative management of these properties) ultimately discouraged many residents from being involved.

In some cases, this kind of involvement impedes rather than encourages the ongoing participation in the production of community space. The spontaneous collective action of residents over space is placed within a rigid structure of management and responsibilities that diminishes the grassroots essence of community gardens and its dynamic and organically developing production (Eizenberg, 2012b, p. 111).

If we think of the commons as a "public trust", then it makes sense to imagine them remaining the responsibility of the state and local government providing the institutional capacity that can enable community members to be meaningfully involved, without offloading too many bureaucratic responsibilities on them. Some community orchardists think this can happen. Said Helen (Copley), "That is what democracy is about, is shaping policy and saying 'Now listen, politicians, we don't want any more ornamentals, what we 
COMMUNITY ORCHARDS AS NEW URBAN COMMONS

want is fruit!' And they say OK and then they enable.” However, other orchardists are not so sure.

The prospect of communities assuming greater control for shaping their own spaces as commons also raises some important ethical questions. Given existing differences in capacity and resources between and among communities even in the same city, there is a high probability that leaving communities to instigate, develop, maintain, and sustain their own commons (in the form of an orchard, a garden, or a park) could result in "uneven greening" (Heynen \& Perkins, 2005) unless local governments actively compensate for these differences. Leaving too much in the hands of community can leave more vulnerable communities responsible for overcoming systemic disinvestments on their own. And Perkins (2010, p. 263) argues that a critical look back through the history of urban green space provision shows that no arrangement has achieved equity in the distribution and/or quality of environmental amenities - the state has not generally been a good partner to poor or working-class communities (Zukin, 2010, p. 245). The history of Strathcona is but one immediate example. One could argue that the City of Victoria giving $\$ 6000$ to those community garden or orchard sites that were already active with food projects might just be privileging better-off neighbourhoods that had already shown capacity to organize.

A different concern is raised by Rosol (2011, p. 250) - that more self-determination could allow community groups to promote exclusionary or even "revanchist" (Smith, 1996) spaces. It is, of course, possible that community orchards and gardens are already 
exclusionary, in the sense that they reflect the values and priorities of a largely middleclass, often white, constituency - "bodies wealthy in time, money, and knowledge who are able to consume fresh, local food" (Slocum, Cadieux \& Bloomberg, 2016, n.p.). Should these "bourgeois utopians"158 (Harvey 2012, p. 7) be the only ones shaping public space? As Harvey points out, "the right to the city is an empty signifier. Everything depends on who gets to fill it with meaning... (2012, p. xv). David (Strathcona) articulated this very concern when he said:

I wouldn't really approve of a system where a group of citizens could come in and take over the land and do whatever. Because what if a group of citizens came into our space and said, Okay now WE are the citizens here...And we don't like all these vegetables and we're going to get rid of these and plant petunias, which everyone agrees are beautiful. You know? We wouldn't want that either. I don't know how they make those rules and decide what makes your group more legitimate than another group.

That's why the City typically has a thorough consultation and engagement process.

Victoria's Food Systems Coordinator, Virginie Lavallée-Picard, explains:

We need to have a system where we can keep options open and be responsive to the needs of the community as a whole not just the community gardeners. That's also the role of the city - to balance that out and accommodate the people that might also be interested in activities other than gardening.

As Staeheli et al. write, "The resolution of one conflict may become the basis for the next struggle. The struggle for the right to public space - and the city - is always on-going, and conflict over and between different rights to, and in, the city never ceases" (2002, p. 204).

\footnotetext{
${ }^{158}$ This is a term that no doubt also includes a good many of us who seek to practice communityengaged scholarship in the name of social change...
} 


\subsection{Conclusion}

This chapter has explored how community orchardists are claiming power to shape the city - a mechanism of commoning that builds on the previous three already discussed resisting enclosure (Chapter 6), appropriating space for community (Chapter 7), and decommodifying exchange (Chapter 8). I have situated this discussion in the context of the right-to-the-city discourse, and debates around neoliberal governmentality. I have argued that Lefebvre's concept of autogestion (which is constitutive of the right to the city) is key to understanding what community orchardists, as commoners, are doing spatially as they initiate, manage, and govern themselves around community orchards. I have also presented arguments supporting McClintock's (2014) assertion that community gardens (and orchards) supply both resistance to neoliberalism and a means of furthering it, albeit often unintentionally. I have argued that the kind of public-popular partnerships we see in community orchards are a form of transactive governmentality, which seems conducive to supporting community orchards as new urban commons. Finally, I have reflected on the limitations and ethical concerns that come into play when community orchards - and commoners generally - claim power to shape the city. 


\section{Chapter 10 - Conclusion \\ "As I sometimes say about urban gardens, [whispering] 'It's never about the food.' The food is just a small piece of it." ${ }^{159}$}

Michel Foucault wrote, "The garden is the smallest parcel of the world and then it is the totality of the world" (1986, p. 26). I have felt much the same way, thinking and writing about community orchards, for they touch on so many critical questions: questions having to do with land ownership and access, food production and consumption, commodification, sustainability, governance, democratic power, conflict resolution, labour, community, and the production of urban space. As we come to terms with the unsustainability and multiple inequities of our present lives, and look for ways to do better, many of us actively search for new models and ways of being that promise to enhance the common good and meet our "deep craving for community" (Linn, 2007, p. 206). The commons presents itself as one such way, and community orchards as one "actually existing," albeit emergent, realization of the commons ideal. ${ }^{160}$

I was motivated to explore the phenomenon of community orchards as new urban commons because commons are not just about resource allocation and governance but also about profoundly re-ordering relationships within communities, including all their human and non-human elements. As Linebaugh writes, "To speak of the commons as if it

\footnotetext{
${ }^{159}$ The interviewee quoted here is Toronto city councilor and urban agriculture promoter, Joe Miheve.

${ }^{160}$ The short phrase 'actually existing' is in reference to Guthman (2008, p. 1180) who writes about "actually existing neoliberalizations in the food system" and before that, to Brenner and Theodore's (2002) article about the geographies of "actually existing neoliberalism".
} 
were a natural resource is misleading at best and dangerous at worst - the commons is an activity and, if anything, it expresses relationships in society that are inseparable from relations to nature" (2009, p. 279). The activity of commoning embodies the idea that land is not something we can own, but something to be held and stewarded, in trust and through an ethic of care. The activity of commoning also embodies the idea that community is not a static grouping of people (already in existence but dormant, just waiting for more people to start knocking on each other's doors) but an enactmentsomething we create together (Butler, 2010; Drake, 2014) through our labour, gifts, conflicts, and celebrations. Séan (Spring Ridge Commons) described his involvement this way:

I saw it as an opportunity to have this very creative interaction with the land and with the people coming into it in a really interesting way that could be perhaps a model for how we can go forward, changing some of the perceptions and outlooks, especially having to do with how work gets done, the nature of private property, [and] how we establish a connection with the land especially as immigrant people, which essentially most of us are, apart from the Indigenous folks.

This makes commons such as community orchards and gardens not just a tangible resource but also "an organizing concept for new ideas about quality of life and urban sustainability" (Hou et al., 2009, as cited in Milbourne, 2012, p. 946). As an organizing concept, the commons make visible a realm that is beyond both market and state (but not without them); that is, a third way of meeting our needs and shaping the city that depends on a partnership with the local state but privileges community control. As such, the commons illustrate a profound and ongoing redefinition of urban space and the public sphere as it relates to neoliberal interests, community membership, citizenship, and the state. 
COMMUNITY ORCHARDS AS NEW URBAN COMMONS

In the past five years or so, a growing number of scholars have begun articulating this ongoing redefinition of relationships to urban space and the public sphere with urban food growing and, even more specifically, food commons (see, for example, Certomà \& Tornaghi, 2015; Follmann \& Viehoff, 2014; McClintock, 2014; Purcell \& Tyman, 2014; Tornaghi \& Van Dyck, 2015; Wekerle \& Classens, 2015). Some, such as Tornaghi and Van Dyck, have noted that much more substantial engagement with the concepts of urban food production and food commons are needed (2015, p. 1251). This was exactly my aim in undertaking this research: to deepen my own understanding not just of community orchards, but also of what commoning means in the context of food systems or projects, what commoning entails or requires, and what we can make of its potential and limitations.

In general terms, my contribution to theorizing new urban commons lies in the way I have considered both their exogenous and their endogenous dimensions by, on the one hand, contextualizing them with respect to the forces of neoliberalism and urban governance and framing them in relation to capitalism, enclosure and commodification; and, on the other, considering their emergence and sustainability in terms of participants' needs and desires, as well as the relational dynamics that operate within orchards as decommodified spaces. Appreciating both exogenous and endogenous dimensions is essential for an understanding of commoning as process (as opposed to commons as merely resources). It also addresses a gap in the literature that has been identified by leading scholars of the commons, including Huron (2015) and Tornaghi (2016). 
In specific terms, this research has shed significant light on the following questions:

1. What is motivating participants in community orchards? (How do they see the meaning, value, and significance of what they are doing?)

2. In what way(s) might community orchards still be commons? (What are participants producing and sharing? What are they self-governing around, if not the fruit?)

\section{What can community orchards teach us about the challenges and potential of producing and sustaining new urban commons?}

I will briefly summarize my answers to each, beginning with the motivations of participants in community orchards. From my interviewees, I learned that community orchards both are, and are not, about the fruit. That is, orchardists get excited about the idea of fruit and they do enjoy eating it - particularly while together. And while growing fruit in a community orchard does not dramatically change most people's eating habits or purchasing practices, it does provide a valued complement to their diets, particularly for those who are on a tight budget or are highly motivated to try unfamiliar foodstuffs, like medlar, haskaps, sour cherry, or shipova. Many community orchardists are also highly motivated to learn food-related skills and gain knowledge that can help them become more self-reliant. Many of them expressed delight at how much they've learned. Said Tanya,

I know for me, on a personal note, that I've connected to the land. Because before this project I knew NOTHING. Look, I knew the seasons. I had some awareness of the cycle of plants. But I'd never planted anything. I grew up in a home that didn't have gardens. And I stood there and gave a lecture about asparagus, you know!?

However, the relative lack of attention to maximizing production or optimizing

distribution in community orchards, and the fact that fruit sometimes even goes to waste, 
suggest that it is not really the outputs from the community orchards that motivate orchardists to provide the inputs they are supplying.

Rather, I believe that it's the idea of the community orchard that appeals to those who join, more than the tangible reality - that idea being one associated with systems-level sustainability, community-level resilience, interpersonal cooperation, and a shift to a lowcarbon, ecologically aligned, healthy, and socially inclusive food system. Contained within this idea is the assertion that food is not just an economic good, but also a fundamental right; community orchardists are clearly very interested in decommodifying food and making land access for food-growing open to everyone. (While most might not consider their work 'political' per se, one cannot deny that making food free is radical!) So even if community orcharding doesn't change the dominant food system that its participants still depend on, it does show the dominant system for what it is: not the only way to do things. Community orcharding, then, is one of many ongoing experiments in feeding society differently, and "prioritizing citizenship over consumption" (Carolan, 2017, p. 146). In this sense, community orchards still are about the food. I remind the reader of the words of David Tracey (Strathcona): "I know the food's the main draw... even if we never get a single fruit off those things...If the food wasn't there, even as an idea, if it were flowers, the whole thing wouldn't happen."

Going beyond food, community orchardists are motivated to enhance their own and others' environmental awareness, and foster a deeper connection to Nature; they are motivated to find personal healing, de-alienation and social connections to others through the orchard; and they are motivated by the act of nurturing and a view of labour as 
relationship (not just exchange). Community orchardists are motivated to join with fellow community members who share their vision and desire to build something worthwhile that goes beyond a narrowly defined self-interest. They are motivated by the opportunity to believe in a more hopeful future and to engage in prefigurative practices that make means consonant with ends - to start building the future they want right now (Gandhi's idea of 'constructive programme'). Finally, they are motivated to engage in a form of devotional leisure that can provide greater meaning in their lives and enable the expression of a new and more satisfying sense of self. Recall the words of Jane Baigent (Banfield), speaking about why she volunteers as an artist, a food producer, and an active member of her community - as she said, "it makes us whole." In short, I believe that the role of community orchards is not so much to change the food system right now as it is to plant the seeds of new ways of seeing ourselves in relation to the Earth and each other.

In response to my second research question - In what way(s) might community orchards still be commons? - it seems clear to me now that community orchards are not the type of commons studied by those in the Elinor Ostrom tradition. That is, they are not economic institutions for the allocation of scarce resources. However, they are still very much commons insofar as they fit well within most or all of the other narratives of commoning outlined in Chapter 2. Specifically, as I have shown, they are spaces of sociability and community empowerment, a means of creating wealth outside the market, a moral claim, and a public good. As community orchardists through their interactions with municipal administrations demonstrate, commons are still the responsibility of the state, insofar as community orchards demand and require the state's enabling authority, political support, 
material assistance and cooperation in order to create and maintain them. As commons, community orchards also suggest a proto-political philosophy that is fundamentally democratic, egalitarian, and participatory, even if actual operations on the ground sometimes fall short of these high ideals. I expect that much learning will need to take place if we are to transition to a profoundly different way of organizing ourselves more collectively and less hierarchically. For some community orchardists, commoning is an activist phenomenon, and a discourse they actively invoke, explicitly or implicitly, to resist neoliberalism. Said Sylvia (Strathcona), "I don't care if it's a community garden or an allotment plot or an orchard or whatever, as long as it is put aside for something green that isn't landscaped." When asked how she felt about the work and responsibilities she shoulders for maintaining the orchard and gardens for the benefit of all, Sylvia replied, "I see it as the cost of protecting this land from development." Finally, community orchards are commons insofar as they are aligned with the commons' shift toward sharing and collaboration. As Séan (Spring Ridge Commons) put it, “Anyone coming into [the Commons] actually shares ownership in this space for however long they are here. It exists when you come through the gates. This is your place, right? And hopefully [everyone] will get that sense."

Community orchards are also commons because they are predicated on what I see as the four main tasks of commoning: resisting enclosure, appropriating space for community, decommodifying exchange, and claiming power to shape the city. Resisting enclosure (Chapter 6) involves challenging the public/private binary around space; recognizing non-ownership interests in land (unbundling the rights that are often bound together in 
COMMUNITY ORCHARDS AS NEW URBAN COMMONS

dominant conceptions of property); and asserting the rights of civil society collectivities (not just individuals, governments, and corporations). Appropriating space for community involves engaging other commoners through participatory design and active labour towards a shared goal that they feel has great meaning and is socially and environmentally worthwhile. It also involves developing a sense of psychological ownership on the part of the community and a qualitatively different relationship to space than commoners (community orchardists) feel towards merely public space.

Decommodifying exchange pertains not only to the fruit in the orchard, but also to knowledge and labour, in the sense that work is de-coupled from tangible rewards and from rights of access. It also involves fostering a sense of obligation to each other - to give and to reciprocate in order to keep the gift moving - rather than an obligation to fulfill requirements set by a higher authority. Finally, claiming power to shape the city involves practicing what Lefebvre called autogestion, which we see happening in community gardens by way of their grassroots initiation, management, and community self-governance. It also involves the development of a kind of collaborative publicpopular partnership that Certomà and Notteboom (2017) have called transactive governmentality. Sustaining this partnership depends on the community groups receiving adequate political support, practical assistance, and benefits from the City, and the City seeing that their own needs and interests are being served through their support of community orcharding/gardening groups. 
My third research question asked, What can community orchards teach us about the challenges and potential of producing and sustaining new urban commons? Clearly, commoning in community orchards has some limitations and challenges of which we must be well aware. Community orchardists indicated some limitations in their ability to communicate their visions to the general public, and in their ability to stop theft from occurring - theft being an ambiguous concept in an open-access space, especially where sharing the fruit with anyone and everyone is part of the orchardists' own vision. Other limitations relate to energy and time: community orcharding is a lot of work, all on the backs of volunteers; burnout is almost unavoidable. Challenges in community orcharding include working within the intriguing liminality of both community space and the activities that may take place in community orchards; figuring out how to resist enclosure and exclusion while still preserving or creating the boundedness necessary for sustainability (i.e., avoiding collective-action problems); and keeping the locus of control within the community, while also dealing with the impermanence and (sometimes) lack of internal stability in commoning groups. Other challenges include the learning curve involved in coming to group self-governance; and need to reflect critically in an ongoing way on the ethical dimension of appropriating space for community by asking, Who is doing the appropriating and in whose interests? Who is being excluded? Challenges also include facing up to the reality of community - that it is messy and invariably involves disagreement and the negotiation of difference - a reality that simply tells us that community orchards, like all commoning groups, and much of society at large, need to find better ways to deal with conflict. 
In terms of the potential that community orchards possess which may yet be untapped, first, I see a clear alignment with decolonization imperatives; it will require skilled articulation of the conceptual connections and some patient relationship-building between non-Indigenous and Indigenous peoples (for whom the word 'commoning' might even suggest colonization) to realize this potential, but I believe that it is there, and can be realized, eventually. Second, proponents of community orchards have the potential to develop the "alternative subjectivities - more communal and less individualized" - that Galt et al. (2014, p. 137) argue form an essential part of a "post-capitalist politics" (Gibson-Graham, 2006). If so, the first task would be to build stronger social connections between and among community members. In that sense, community orchards are doing important work, first by questioning well-established notions - about what is "ours", about who has rights to shape public space, and about whom it is for - and second, by shifting our focus away from the state as provider of solutions and towards each other, while still holding the state accountable for supporting citizen-driven solutions. Third, proponents of community orchards strive for new ways of meeting basic human needs, whether for food, or for sociability, or for urban spaces that connect and ground us in our natural home. I don't mean to say that community orchards will fundamentally change the way most city-dwellers in Vancouver, Victoria or Toronto eat, recreate, or relate to each other. Community orchardists themselves don't believe they are the sole solution to these problems; they are only one part of some possible solutions, and maybe just one step pointing in the direction of new habits, practices, and norms that have not yet been imagined. But I do see community orchards as necessary, wonderful experiments - "part 
COMMUNITY ORCHARDS AS NEW URBAN COMMONS

of a collective effort of providing the air needed for other experiments to breath [sic]" (Tornaghi \& Van Dyck, 2015, p. 1261).

As more such experiments take root, I hope that their proponents and supporters in municipal administrations will be able to learn some practical lessons from the experience of the community orchards I have studied. These include the importance of allowing community orchardists maximum autonomy, and resisting efforts to standardize orchards in the name of efficiency (or any similar perceived imperative). It is vitally important that community orchards be allowed to express their uniqueness and reflect the communities from which they emerge, for this is what ensures the sense of psychological "ownership" or attachment that fuels community orchardists and sustains them through the inevitable challenges of growing and maintaining these spaces as a generous gift to their communities. A second pragmatic lesson I hope others may take away is that there are a great many ways that municipalities can support community orchards materially that can make a huge difference to their sustainability - e.g., with the provision of water, wood chips and leaf mulch; with support in reaching out to neighbours and facilitating agreement (and compromise, where necessary) as well as with financial support for parttime coordinators who can help ensure a desirable level of maintenance and good relations with nearby residents. The more these material supports can be institutionalized into local government policy and practice, the better chance community orchards will have of being able to carry on if - or, more likely, when - municipal administrations change and the political climate for local food efforts becomes less favourable. Third, I hope that the story of community orchards will illustrate and affirm the potential for 
productive working relationships between community groups and municipalities that are not always the product of oppositional struggle but that develop through negotiation, listening and cooperation, where each party sees the other as helping advance their own interests. Community groups clearly have the capacity to influence change at the City level. Indeed, it is the job of the grassroots to lead, and nudge the City forward; and it is the job of the City to respond, not by taking over the governance of local initiatives but by helping build the capacity of community groups to enrich urban life and animate urban space through projects such as these. Finally, I hope that my examination of the workings of the gift ethos in community orchards will offer a lesson in what makes a gift economy work - i.e., self-direction, loose oversight, sufficient (but not excessive) structure, as well as a willingness to refrain from measuring, comparing, and quantifying participants' labour and capacities to contribute, embracing instead the variety of ways people contribute to community projects, and honouring Eros over Logos in the spirit of the gift.

For future research in this area, I would like to explore some newer community orchards I have been learning about - for example, one started with Susan Poizner's assistance in a low-income, high-density housing complex in the Jane-Finch area of Toronto, where most residents are recent immigrants to Canada. I would also like to study other food commons beyond orchards, particularly urban community land trusts that include land for food production, such as the Parkdale Neighbourhood Land Trust in Toronto. ${ }^{161}$ I am interested in learning whether in these more multi-cultural environments the idea of a community orchard, or more generally a food commons, still has cultural resonance - and

\footnotetext{
${ }^{161}$ For more on the Parkdale Neighbourhood Land Trust, see http://www.pnlt.ca/about/
} 
for whom; as well as how residents in those communities understand, frame, and explain their motivations and the significance of what they are doing. I'd like to see how these understandings and framings may differ from those of the community orchardists I have come to know, and whether, for instance, either household food security or food justice figure larger in these communities' priorities. I would also like to see if learning about different manifestations of community orcharding or food commoning might change my thinking about their relationship to community, urban space, decommodification, neoliberalism or transactive governmentality. Finally, I am interested in relating these food commons to the emergent literature on urban agroecology and urban food sovereignty, which go beyond community food security to embrace a range of empowerment objectives in the areas of skill-building, knowledge, and re-skilling, as well as control over land.

As experiments, community orchards may be part of a larger historical trend. George McKay describes the enclosures as "one of the most radical political shifts in the UK in the last four hundred years: from communal to private land" (2011a, p. 157). Considering all of the necessary and wonderful experiments in commoning and collaboration going on around the world, and all the demands for decolonization and decommodification, I am optimistic enough to believe that we are currently witnessing, and experiencing, the beginnings of another radical shift, if not back to the past, then at least away from excessive privatization to more communalism, new forms of commoning, and a deeper sense of community. Perhaps it is only happening in limited ways, only in the ideological fringes far from the political mainstream, or the rarefied corners of a counter-cultural 
bourgeoisie. But I hope that it still counts. After all, as Harvey points out, Lefebvre's theory of revolution is not one of grandness and unity, but rather of modesty and spontaneity - moments of "irruption" when "disparate heterotopic groups suddenly see, if only for a fleeting moment, the possibilities of collective action to create something radically different" (2012, p. xvii). ${ }^{162}$ Similarly, both Gibson-Graham and Harris call for a recognition of "modest beginnings and small achievements", and an opening up to a "politics of the possible" (Gibson-Graham, 2006; Harris, 2009). Community orchards are modest, and many are small. But they are possible because they already exist. Of course, we cannot know everything that is possible nor if that which is possible will ever be achieved, but this not knowing should be reason for hope, not despair. We don't know what the future holds, but surely some of it is good. As Pickerill and Chatterton point out, with reference to Rebecca Solnit's inspirational writings, "while our actions' effects are difficult to calculate, 'causes and effects assume history marches forward, but history is not an army. It is a crab scuttling sideways, a drip of soft water wearing away stone' (Solnit, 2004, p. 4)” (2006, p. 738-739).

In the end, I have come to believe that community orchards are indeed our "giving trees" - just not in the way I first imagined them. That is, community orchards are less about what people get from them (free gifts of fruit) and more about what people give to them and through them - to themselves, to each other, to their communities, and to the Earth. Sustaining community orchards is about keeping these gifts in motion. I hope that my work serves as a contribution to that end.

\footnotetext{
${ }^{162}$ Harvey contrasts heterotopia with isotopy, defined as "the accomplished and rationalized spatial order of capitalism and the state" (2012: xvii-xviii).
} 
COMMUNITY ORCHARDS AS NEW URBAN COMMONS

\section{References}

Acharya, K.P. (2005). Private, Collective and Centralized Institutional Arrangements for Managing Forest “Commons” in Nepal. International Forestry Review, 25(3), 269-277. Retrieved from httsp://journals-scholarsportalinfo.proxy.library.carleton.ca/pdf/02764741/v25i0003/269_pcaciafmfin.xml

Adams, D., Hardman, M., \& Larkham, P. (2015). Exploring guerrilla gardening: gauging public views on the grassroots activity. Local Environment: The International Journal of Justice and Sustainability, 20(10), 1231-1246. doi: 10.1080/13549839

Allen, E. (2010). Growing community food systems. In R. Heinberg \& D. Lerch (Eds.). The post carbon reader: Managing the $21^{\text {st }}$ century's sustainability. Post Carbon Institute. Retrieved from http://library.uniteddiversity.coop/Cooperatives/Food /Growing_Community_Food_Systems-Post_Carbon_Reader.pdf

Allen, P. \& Guthman, J. (2006). From "old school" to "farm-to-school": neoliberalization from the ground up. Agriculture and Human Values, 23(4), 401415. doi: 10.1007/s10460-006-9019-Z

Alkon, A. \& Agyeman, J. (Eds.) (2011). Cultivating food justice: Race, class, and sustainability. Cambridge, USA and London: MIT Press.

Alkon, A.H. \& Mares, T. (2012). Food sovereignty in US food movements: Radical visions and neo-liberal constraints. Agriculture and Human Values, 29(3), 347359. doi: 10.1007/s10460-012-9356-Z

Allotment history - A brief history of allotments in the UK. (n.d.). Retrieved from http://www.allotment-garden.org/allotment-information/allotment-history/ 
COMMUNITY ORCHARDS AS NEW URBAN COMMONS

Ames, G.K. (2013). Community orchards. National Sustainable Agriculture Information Service (ATTRA). Retrieved from http://www.attra.ncat.org

Amin, A. (2005). Local community on trial. Economy and Society, 34(4), 612-633. doi: $10.1080 / 03085140500277211$

Andersson, E., Barthel, S. \& Ahrné, K. (2007). Measuring social - ecological dynamics behind the generation of ecosystem services. Ecological applications, 17(5), 1267-1278. Retrieved from http://www.jstor.org/stable/40062032

Appadurai, A. (2001). Deep democracy: Urban governmentality and the horizon of politics. Environment and Urbanization, 13(2), 23-43. Retrieved from http://journals.sagepub.com.proxy.library.carleton.ca/doi/pdf/10.1177/095624780 101300203

Bailey, K., Lobenstine, L., \& Nagel, K. (n.d.) Spatial JuSticE: a frame for reclaiming our rights to be, thrive, express and connect. Design studio for social intervention. Retrieved from http://ds4si.org/storage/SpatialJustice_ds4si.pdf

Bailey, C., White, C. \& Pain, R. (1999). Evaluating qualitative research: Dealing with the tension between 'science' and 'creativity'. Area, 31,169-179. doi: $10.2307 / 20003972$

Baker, L. (2004). Tending cultural landscapes and food citizenship in Toronto’s community gardens. Geographical Review, 94(3), 305-325. doi: $10.2307 / 30034276$

Bakker, K. (2007). The "commons" versus the "commodity": Alter-globalization, anti-privatization and the human right to water in the global South. Antipode, 39(3), 430-455. doi: 10.1111/j/1467-8330.2007.00534.x 


\section{COMMUNITY ORCHARDS AS NEW URBAN COMMONS}

Balivé T. (2011, Feb 19). The Production of Space [Blog post]. Retrieved from http://territorialmasquerades.net/the-production-of-space

Ballamingie, P. \& Johnson, S. (2011). The vulnerable researcher: Some unanticipated challenges of doctoral fieldwork. The Qualitative Report 16(3), 711-729. Retrieved from http://www.nova.edu/ssss/QR/QR16-3/ballamingie.pdf

Bandyopadhyay, R. (2011). Primitive accumulation of capital and de-commoning: Three moments in the history of capital. In Vocabulary of Commons (pp. 27-42). Anand, Gujarat, India: Foundation for Ecological Security. Retrieved from https://www.slideshare.net/OpenSpace/vocabulary-of-commons?qid=e9fb9c553e11-4275-89fa-aee175dd2417\&v=\&b=\&from_search $=1$

Barnes, P. (2006). Capitalism 3.0: A guide to reclaiming the commons. San Francisco: Berrett-Koehler Publishers.

Barron. J. (1993). The Greening of St Patrick's. Pathways: The Ontario Journal of Outdoor Education, 5(4), 5-7.

Barron, J. (2000). In the Name of Solidarity: The Politics of Representation and Articulation in Support of the Labrador Innu. Capitalism, Nature, Socialism, 11(3), 87-11. doi: 10.1080/10455750009358934

Barron, J. (2002). Romancing the Other in Aboriginal Support Work. In J. Bird, L. Land, and M. MacAdam (Eds.), Nation to Nation: Aboriginal Sovereignty and the Future of Canada (2nd ed.), (pp. 227-238). Toronto: Irwin.

Barthel, S., Folke, C. \& Colding, J. (2010). Social-ecological memory in urban gardens: retaining the capacity for management of ecosystem services. Global Environmental Change, 20(2), 255-265. doi: 10.1016/j.gloenvcha.2010.01.001 
COMMUNITY ORCHARDS AS NEW URBAN COMMONS

Barthel, S., Parker, J. \& Ernston, H. (2015). Food and green space in cities: A resilience lens on gardens and urban environmental movements. Urban Studies, 52(7), 1321-1338. doi: 10.1177/0042098012472744

Baxter, J. (2010). Case studies in qualitative research. In I. Hay (Ed.), Qualitative research methods in human geography ( $3^{\text {rd }}$ ed.) (pp. 81-97). Oxford University Press: Don Mills.

Becker, E.J. (2015). Beyond fruit: Examining community in a community orchard (Masters thesis). Retrieved from Dissertations and Theses http://www.pdxscholar@pdx.edu (Paper 2628)

Bertussi, M. L. (2012). The faxinal: A Brazilian experience with the commons and its relationship with the state. In D. Bollier \& S. Helfrich (Eds.), The Wealth of the Commons: A World Beyond Market and State (254-257). Amherst, MA (USA): Levellers Press.

Betz, M. (2014). Governance of community orchards: A case study (Unpublished graduate paper written for Y673 Seminar, The Vincent and Elinor Ostrom Workshop in Political Theory and Policy Analysis). Indiana University, Bloomington, IN.

Biel, R. (2016). Sustainable food systems: The role of the city. London: UCL Press. Retrieved from http://www.igescanada.com/wpcontent/uploads/2017/08/Sustainable-Food-Systems.pdf

Blomley, N. (2004). Un-real real estate: Proprietary space and public gardening. Antipode, 36(4), 614-641. doi: 10.1111/j.1467-8330.2004.00440.x 
COMMUNITY ORCHARDS AS NEW URBAN COMMONS

Blomley, N. (2005). Flowers in the bathtub: boundary crossings at the public-private divide. Geoforum, 36(3), 281-296. doi: 10.1016/j.geoforum.2004.08.005

Blomley, N. (2008). Enclosure, common right and the property of the poor. Social and Legal Studies, 17(3), 311-331. doi: 10.1177/0964663908093966

Bollier, D. (2012, June 5). The commons emerges as a theme at the People's Summit in Rio [Blog post]. Retrieved from http://bollier.org/blog/commons-emerges-themepeople $\%$ E2\%80\%99s-summit-rio

Bollier D. \& Helfrich, S., (Eds.) (2012). The wealth of the commons: A world beyond market and state. Amherst, MA (USA): Levellers Press.

Born, B. \& Purcell, M. (2006). Avoiding the local trap: Scale and food systems in planning research. Journal of Planning Education and Research, 26(2), 195-207. doi: $10.1177 / 0739456 \times 06291389$

Bradshaw, T. K. (2008). The post-place community: contributions to the debate about the definition of community. Community Development, 39(1), 5-16.

doi: $10.1080 / 15575330809489738$

Brenner, N. \& Theodore, N. (2002). Cities and the geographies of "actually existing neoliberalism.” Antipode, 34, 349-379. doi: 10.1111/1467-8330.00246

Bresnihan, P. \& Byrne, M. (2015). Escape into the city: Everyday practices of commoning and the production of urban space in Dublin. Antipode 47(1), 36-54. doi: $10.1111 /$ anti.12105

Brooks, J. (2012, May 8). On UC's Gill Tract, occupying farmers say they're not going anywhere yet [Blog post]. Retrieved from https://www.kqed.org/news/64739/occupy-the-farm-gill-tract 


\section{COMMUNITY ORCHARDS AS NEW URBAN COMMONS}

Brown, J. (2004). Ejidos and comunidades in Oaxaca, Mexico: Impact of the 1992 reforms (report on Foreign Aid and Development \#120). Retrieved from http://www.rdiland.org.

Burnett, G. (2008). Permaculture: A beginner's guide (extract). Spiralseed. Retrieved from http://www.rivendellvillage.org/beginners-guide-to-permaculture.pdf

Butler, J. (2010). Performative agency. Journal of Cultural Economy, 3(2), 147-161.

Caffentzis, G. (2004). A tale of two conferences: Globalization, the crisis of neoliberalism and question of the commons. The Commoner. Retrieved from http://www.commoner.org.uk/?p=96

Carlsson, C. (2008). Nowtopia: How Pirate Programmers, Outlaw Bicyclists, and Vacant-Lot Gardeners Are Inventing the Future Today! Edinburgh, Oakland \& West Virginia: AK Press.

Carolan, M. (2017). No one eats alone: Food as a social enterprise. Washington: Island Press.

Castree, N. (2010). Neoliberalism and the biophysical environment 1: what "neoliberalism" is, and what difference nature makes to it. Geography Compass, 4(12), 1725-1733. Retrieved from https://doi.org/10.1111/j.17498198.2010.00405.x

Certomà, C. (2011). Critical urban gardening as a post-environmentalist practice. Local Environment: The International Journal of Justice and Sustainability, 16(10), 977-987. Retrieved from http://dx.doi.org/10.1080/13549839.2011.592181 


\section{COMMUNITY ORCHARDS AS NEW URBAN COMMONS}

Certomà, C. \& Notteboom, B. (2017). Informal planning in a transactive governmentality. Re-reading planning practices through Ghent's community gardens. Planning Theory, 16(1), 51-73. doi: 10.1177/1473095215598177

Certomà, C. \& Tornaghi, C. (2015). Political gardening. Transforming cities and political agency. Local Environment: The International Journal of Justice and Sustainability, 20(10), 1123-1131. doi:10.1080/13549839.2015.1053724

Chaker, A. M. (2012, June 12). The shared backyard: Homeowners exchange a bit of privacy for more garden and socializing. The Wall Street Journal. Retrieved from https://www.wsj.com/articles/SB100014240527023037681045774606915239130 90

Charmaz, K. (2006). Constructing grounded theory: A practical guide through qualitative analysis. Los Angeles, CA: Sage.

Cheria, A. \& Edwin. (2011). Towards a vocabulary of commons. In Vocabulary of Commons (pp. 1-26). Retrieved from http://www.slideshare.net/OpenSpace/ vocabulary-of-commons

City of Vancouver. (2013). Vancouver Food Strategy. Retrieved from http://vancouver.ca/files/cov/vancouver-food-strategy-final.PDF

City of Vancouver. (2014). A Healthy City for All: Healthy City Strategy - Four-year Action Plan (2015-2018 Phase 2). Retrieved from http://vancouver.ca/files/cov/Healthy-City-Strategy-Phase-2-Action-Plan-20152018.pdf

City of Victoria. (2014). Interim Boulevard Gardening Guidelines [Pamphlet]. Retrieved from http://www.victoria.ca/assets/Departments/Parks $\sim$ Rec $\sim$ Culture/Parks/Do 
COMMUNITY ORCHARDS AS NEW URBAN COMMONS

cuments/Interim\%20Boulevard\%20Gardening\%20Guidelines\%20City\%20o f\%20Victoria.pdf

City of Victoria. (2015). Growing in the City: Part 1-Urban food production on Cityowned lands Appendix A: Engagement Summary Report (Phase 1). Retrieved from https://pubvictoria.escribemeetings.com/filestream.ashx?documentid=14594

City of Victoria. (2016). Community Gardens Policy. Retrieved from http://www.victoria.ca/assets/Community/Growing in $\sim$ the $\sim$ City/Community\%20 Gardens\%20Policy_Revised\%202016.pdf

Clark, K.H. \& Nicholas, K.A. (2013). Introducing urban food forestry: A multifunctional approach to increase food security and provide ecosystem services. Landscape Ecology, 28 (9), 1649-1669. doi: 10.1007/s10980-013-9903-z

Conant, J. (2012, May 15). Back to the land for the Occupy movement: Commons at the heart of the issue in occupation of agricultural land in the Bay Area. On the Commons. Retrieved from http://onthecommons.org/magazine/back-land-occupymovement

Coombes, B. (2007). Defending community? Indigeneity, self-determination and institutional ambivalence in the restoration of Lake Whakaki. Geoforum, 38(1), 60-72. doi: 10.1016/j.geoforum.2006.05.006

Coombs, M. (2011). Lobstering and common-pool resource management in Maine. Grassroots Economic Organizing (GEO) Newsletter, 2(9). Retrieved from http://geo.coop/node/654 


\section{COMMUNITY ORCHARDS AS NEW URBAN COMMONS}

Cosgrove, S. (1998). Community gardening in major Canadian cities: Toronto, Montreal, and Vancouver compared. Urban Agriculture Notes. Retrieved from http://www.cityfarmer.org/canadaCC.html

Cox, M., Arnold, G., \& Villamayor, T.S. (2010). A review of design principles for community-based natural resource management. Ecology and Society, 15(4), 38. Retrieved from http://www.ecologyandsociety.org/vol15/art38/

Creswell, J. (2007). Qualitative inquiry and research design: Choosing among five approaches. Thousand Oaks, CA: Sage.

Creswell, J.W. (2009). The selection of a research design in J.W. Creswell (Ed.), Research design, qualitative, quantitative and mixed methods research (pp. 3-21). Los Angeles: Sage.

CR-FAIR. (2016, May 3). Deepening roots: Neighbourhoods as fertile grounds for growing food literacy and access [Powerpoint presentation]. Retrieved from https://static1.squarespace.com/static/56e5a1d4e321404618f47dc7/t/574d1bcb2ee b81625a013de4/1464671181459/FoodHubsRoundtable.pdf

Crouch, D. \& Ward, C. (1988). The allotment: Its landscape and culture. London: Faber and Faber.

De Angelis, M. (2003). Reflections on alternatives, commons and communities, or building a new world from the bottom up. The Commoner, 6. Retrieved from http://commoner.org.uk/deangeli06.pdf

DeFilippis, J., Fisher, R., and Shragge, E. (2006). Neither romance nor regulation: Reevaluating community. International Journal of Urban and Regional Research, 30(3), 673-689. doi:10.1111/j.1468-2427.2006.00680.x 


\section{COMMUNITY ORCHARDS AS NEW URBAN COMMONS}

DeLind, L. (2002). Place, work and civic agriculture: Common fields for cultivation. Agriculture and Human Values, 19, 217-224. Retrieved from https://journalsscholarsportal-info.proxy.library.carleton.ca/pdf/0889048x/v19i0003/217 pwacacffc.xml

Department for Communities and Local Government, UK (2011). Community orchards case studies. Retrieved from https:/www.gov.uk/government/publications/casestudies-community-orchards

Diacon, D., Clarke, R. \& Guimarães, S. (Eds.). (2005). Redefining the commons: Locking in value through community land trusts. Building and Social Housing Foundation. Retrieved from http://www.bshf.org/publishedinformation/publication.cfm? thePubID $=111$

Dikeç, M. (2001). Justice and the spatial imagination. Environment and Planning A, 33(10), 1785-1805. doi:10.1068/a3467

Diver, S.W., \& Higgins, M.N. (2014). Giving back through collaborative research: Towards a practice of dynamic reciprocity. Journal of Research Practice, 10(2), M9. Retrieved from http://jrp.icaap.org/index.php/jrp/article/view/415/354

Domene, E. \& Sauri, D. (2007). Urbanization and class-produced natures: Vegetable gardens in the Barcelona Metropolitan Region. Geoforum, 38(2), 287-298.

Dooling, S. (2009). Ecological gentrification: A research agenda exploring justice in the city. International Journal of Urban and Regional Research, 33(3), 621-639. doi:10.1111/j.1468-2427.2009.00860.x

Dowling, R. (2010). Geographies of identity: climate change, governmentality and activism. Progress in Human Geography, 34(4), 488-495. 
COMMUNITY ORCHARDS AS NEW URBAN COMMONS

doi: $10.1177 / 0309132509348427$

Drake, L. (2014). Governmentality in urban food production? Following "community" from intentions to outcomes. Urban Geography, 35(2), 177-196. doi:10.1080/02723638.2013.871812

Drugmand, D. (2014, Sept 5). Beyond the CSA: Four ways communities support everything from books to beer. YES! Magazine. Retrieved from http://www.yesmagazine.org/happiness/beyond-the-csa-four-ways- communitiessupport-everything-from-health-care-to-beer

DuPuis, M. \& Goodman, D. (2005). Should we go "home" to eat? Toward a reflexive politics of localism. Journal of Rural Studies, 21, 359-371. doi: 10.1016/j.jrurstud.2005.05.011

Eizenberg, E. (2012a). Actually existing commons: Three moments of space of community gardens in New York City. Antipode, 44(3), 764-782. doi: 10.1111/j.1467-8330.2011.00892.x

Eizenberg, E. (2012b). The changing meaning of community space: Two models of NGO management of community gardens in New York City. International Journal of Urban and Regional Research, 36(1), 106-20. doi: 10.1111/j.14682427.2011 .01065

Everard, W., Winstanley, J., Goodgroome, R., Palmer, J., Starre, T., South, J. \& Taylor, J. (1649). The True Levellers' Standard Advanced. Retrieved from https://www.bilderberg.org/land/diggers.htm\#True

Everts, J. (2015). Invasive life, communities of practice, and communities of fate. Geografiska Annaler: Series B, Human Geography, 97(2), 195-208. 
COMMUNITY ORCHARDS AS NEW URBAN COMMONS

doi: $10.1111 /$ geob. 12074

Fairlie, S. (n.d.). A Short History of Enclosure in Britain. The Land: An occasional magazine about land rights. Retrieved from http://www.thelandmagazine.org.uk/articles/short-history-enclosure-britain

Federici, S. (2011, January 24). Feminism and the politics of the commons. The Commoner: A Web Journal for Other Values. Retrieved from https://www.thecommoner.org

Feenstra, G. (2002). Creating space for sustainable food systems: Lessons from the field. Agriculture and Human Values, 19, 99-106. Retrieved from https://journalsscholarsportal-info.proxy.library.carleton.ca/pdf/0889048x/v19i0002/99_ csfsfslftf.xml

Fernwood NRG. (2014, Feb 7). Our Principles and Values. Retrieved from http://fernwoodnrg.ca/fernwood-nrg-about-us/our-principles/

Ferris, J., Norman, C., \& Sempik, J. (2001). People, land and sustainability: Community gardens and the social dimension of sustainable development. Social Policy and Administration, 35(5), 559-568. Retrieved from https://doi-org.proxy.library. carleton.ca/10.1111/1467-9515.t01-1-00253

Field, D. (2009). The crisis of food security: Building a public food system. Esurio: Journal of Hunger and Poverty, 1(2), 1-8. Retrieved from https://foodshare.net/custom/uploads/2015/11/Esurio_002.pdf

Firth, C., Maye, D., \& Pearson, D. (2011). Developing “community” in community gardens. Local Environment: The International Journal of Justice and Sustainability, 16(6): 555-568. doi: 10.1080/13549839.2011.586025 
COMMUNITY ORCHARDS AS NEW URBAN COMMONS

Flyvbjerg, B. (2006). Five misunderstandings about case-study research. Qualitative Inquiry, 12(2), 219-245. doi: 10.1177/1077800405284363

Follmann, A. \& Viehoff, V. (2015). A green garden on red clay: Creating a new urban common as a form of political gardening in Cologne, Germany. Local Environment: The International Journal of Justice and Sustainability, 20(10), 1148-1174. doi: 10.1080/13549839.2014.894966.

Food and Agriculture Organization (FAO). (2008). An introduction to the basic concepts of food security. Retrieved from http://www.fao.org/docrep/013 /a1936e/a1936e00.pdf

Foster, S.R. \& Iaione, C. (2016) The city as commons. Yale Law and Policy Review, 34, $1-53$.

Foucault, M. (1986). Of other spaces. diacritics 6(1), 22-27. Retrieved from https://wwwjstor-org.proxy.library.carleton.ca/stable/464648

Fraser, E., \& Rimas, A. (2010). Empires of food: Feast, famine and the rise and fall of civilizations. New York: Random House.

Galt, R., Gray, L.C. \& Hurley, P. (2014). Editorial: Subversive and interstitial food spaces: Transforming selves, societies, and society-environment relations through urban agriculture and foraging. Local Environment: The International Journal of Justice and Sustainability, 19(2),133-146. doi: 10.1080/13549839.2013.832554

George, S. (1998). Preface. In M. Goldman (Ed.), Privatizing nature: Political struggles for the global commons (pp. ix-iiv). London: Pluto Press/Transnational Institute. Ghose, R. \& Pettygrove, M. (2014). Urban community gardens as spaces of citizenship. Antipode, 46(4),1092-1112. doi: 10.1111/anti.12077 


\section{COMMUNITY ORCHARDS AS NEW URBAN COMMONS}

Gibson-Graham, J.K. (2006). A postcapitalist politics. Minneapolis: University of Minnesota Press.

Goldman, M. (1998). Introduction: The political resurgence of the commons. In M. Goldman (Ed.), Privatizing nature: Political Struggles for the global commons (pp. 1-19). London: Pluto Press/Transnational Institute.

Goldsmith, E., Hildyard, N., Bunyard, P. \& McCully, P. (Eds.). (1992). The Ecologist: Whose Common Future? 22(4). Retrieved from https://reader.exacteditions.com/issues/5345/page/3

Goodman, M.K., Maye, D. \& Holloway, P. (2010). Guest editorial: Ethical foodscapes? Premises, promises, and possibilities. Environment and Planning A, 42(8), 17821796. doi: $10.1068 / 143290$

Gottlieb, R. \& Fisher, A. (1996). Community food security and environmental justice: Searching for a common discourse. Agriculture and Human Values, 3(3), 23-31. doi: 10.1007/BF01538224

Gottlieb, R. \& Joshi, A. (2010). Food justice. Cambridge, MA: MIT Press.

Guthman, J. (2008). Neoliberalism and the making of food politics in California. Geoforum, 39(3), 1171-1183. doi: 10.1016/j.geoforum.2006.09.002

Hackworth, J. (2002). Post-recession gentrification in New York City. Urban Affairs Review, 37(6), 815-43. doi: 10.1177/107874037006003

Haraway, D.J. (1991). Simians, cyborgs and women: the reinvention of nature. London: Free Association Books.

Hardin, G. (1968). The tragedy of the commons. Science, 162(3859), 1243-1248. doi: $10.2307 / 1724745$ 
COMMUNITY ORCHARDS AS NEW URBAN COMMONS

Hardt, M. \& Negri, A. (2004). Multitude. New York: Penguin.

Harris, E. (2009). Neoliberal subjectivities or a politics of the possible? Reading for difference in alternative food networks. Area, 41(1), 55-63.

doi: $10.1111 / \mathrm{j} .1475-4762.2008 .00848 . \mathrm{x}$

Harvey, D. (2008). The right to the city. New Left Review, 53, 23-40. Retrieved from https://newleftreview.org/II/53/david-harvey-the-right-to-the-city

Harvey, D. (2012). Rebel cities. New York: Verso.

Hassanein, N. (2003). Practicing food democracy: A pragmatic politics of transformation. Journal of Rural Studies, 19(1), 77-86. doi: 10.1016/S0743-0167(02)00041-4

Hayden, J. \& Buck, D. (2012). Doing community supported agriculture: Tactile space, affect and effects of membership. Geoforum, 43(2), 332-341.

doi: 10.1016/j.geoforum.2011.08.003

Herbert, S. (2005). The trapdoor of community. Annals of the Association of American Geographers, 95(4), 850-865.

Heynen, N. (2009). Bending the bars of empire from every ghetto for survival: The Black Panther Party's radical antihunger politics of social reproduction and scale. Annals of the Association of American Geographers, 99(2), 406-422.

doi: $10.1080 / 00045600802683767$

Heynen, N. (2012). Food justice, hunger and the city. Geography Compass, 6(5), 304311. doi: 10.1111/j.1749-8198.2012.00486.x

Heynen, N. \& Perkins, H. (2005). Scalar dialectics in green: Urban private property and the contradictions of the neoliberalization of nature. Capitalism Nature Socialism, 16(1),99-113. doi: 10.1080/1045575052000335393 


\section{COMMUNITY ORCHARDS AS NEW URBAN COMMONS}

Holland, L., (2004). Diversity and connections in community gardens: a contribution to local sustainability. Local Environment: The International Journal of Justice and Sustainability, 9(3), 285-305. doi: 10.1080/1354983042000219388

Holmen, R. (2012, November 30). City of Victoria supports pair of community orchards. Victoria News, A4. Retrieved from https://www.vicnews.com/eeditions/?iid=i20121130071037705\&\&headline $=$ VmljdG9yaWEgTmV3cy9JbiB Nb3Rpb24sIE5vdmVtYmVyIDMwLCAyMDEy\&\&doc_id=12113015110179f381dd2bf8435894e5315cb5df8b0b

Holt-Giménez, E. \& Shattuck, A. (2011). Food crises, food regimes and food movements: rumblings of reform or tides of transformation? Journal of Peasant Studies, 38(1), 109-144. doi: 10.1080/03066150.2010.53878

Holt-Giménez, E. \& Wang, Y. (2011). Reform or transformation? The pivotal role of food justice in the U.S. food movement. Race/Ethnicity: Multidisciplinary Global Context 5(1), 83-102. doi: 10.2979/racethmulglocon.5.1.83

Horst, M., McClintock, N. \& Hoey, L. (2017). The intersection of planning, urban agriculture, and food justice: A review of the literature. Journal of the American Planning Association, 83(3), 277-295. doi: 10.1080/01944363.2017.1322914

Howard, B. (Producer). (2014). The Spring Ridge Commons public meeting 2014 [Video file]. Retrieved from https://www.youtube.com/watch?v=EdkbkmeNyCI

Huff, V. \& Johansson, E. (2012). Camas at the confluence: Where ecology and culture meet at Kp'itl'els. Menziesia, Summer/Fall, 3-4.

Huron, A. (2015). Working with strangers in saturated space: Reclaiming and maintaining the urban commons. Antipode, 47(4), 963-979. 
COMMUNITY ORCHARDS AS NEW URBAN COMMONS

doi: 10.1111/anti.12141

Hyde, L. (2007). The gift: Creativity and the artist in the modern world ( $2^{\text {nd }}$ ed.). Toronto: Random House.

Hyslop, K. (2014, December). Gardens grow another day on the Arbutus Corridor. Megaphone: Change that Works (p. 7). Retrieved from http://d3n8a8pro7vhmx.cloudfront.net/megaphone/mailings/6/attachment s/original/141203_Megaphone_166_Final_WEB_SPREADS.pdf?1417735685 International Assessment of Agricultural Knowledge, Science and Technology for Development (IAASTD). (2009). Agriculture at a Crossroads. Retrieved from http://www.unep.org/dewa/agassessment/reports/IAASTD/EN/Agriculture\%20at $\% 20 \mathrm{a} \% 20$ Crossroads_Executive $\% 20$ Summary $\% 20$ of $\% 20$ the $\% 20$ Synthesis $\% 20 \mathrm{R}$ eport $\% 20 \% 28$ English $\% 29 . p d f$

Jacke, D. \& Toensmeier, E. (2005). Edible Forest Gardens - Volume One: Ecological vision and theory for temperate climate permaculture. White River Junction, VT: Chelsea Green. Retrieved from http://library.uniteddiversity.coop/Permaculture/ Agroforestry/Forest_Gardens/Edible_Forest_Gardens_Vol.1-Vision_and_ Theory.pdf

Janzen, R. (2014). Guatemalan ex-combatant perspectives on reintegration: A grounded theory. (Doctoral dissertation). The Qualitative Report 19(41), 1-24. Retrieved from http://www.nova.edu/ssss/QR/QR19/janzen41.pdf

Jarosz, L. (2008). The city in the country: Growing alternative food networks in metropolitan areas. Journal of Rural Studies, 24, 231-244. doi: 10.1016/j.jrurstud.2007.10.002 
COMMUNITY ORCHARDS AS NEW URBAN COMMONS

Jerven, T.G. (2012, Summer). Putting down roots. Montecristo Magazine. Retrieved from http://www.copleycommunityorchard.com/media/

Jessop, B. (2002). Liberalism, neoliberalism, and urban governance: A state-theoretical perspective. Antipode, 34(3), 452-472. doi: 10.1111/1467-8330.00250

Johnston, J. (2003). Who cares about the commons? Capitalism, Nature, Socialism, 14(4), 1-41. doi: 10.1080/10455750308565544

Johnston, J. (2008). Counterhegemony or bourgeois piggery? Food politics and the case of FoodShare. In W. Wright and G. Middendorf (Eds.), The fight over food: Producers, consumers, and activists challenge the global food system (pp. 93120). University Park: Pennsylvania State University Press.

Kaethler, T.M. (2006). Growing space: The potential for urban agriculture in the city of Vancouver. Retrieved from http://communitywealth.org/content/growing-spacepotential-urban-agriculture-city-vancouver

Kato, Y., Passidomo, C. \& Harvey, D. (2014). Political gardening in a post-disaster city: Lessons from New Orleans. Urban Studies, 51(9), 1833-1849. doi: $10.1177 / 0042098013504143$

Kemshaw, M. (2011). Spring Ridge learning [Video file]. Retrieved from https://www.youtube.com/watch?v=IBEHwoV5zzA\&feature=player_embedded

King, A., \& Clifford. S. (2011). Community Orchards Handbook. Dorset, England: Green Books.

Kingsley, J.Y. \& Townsend, M., (2006). 'Dig In' to social capital: Community gardens as mechanisms for growing urban social connectedness. Urban Policy and Research, 24(4), 525-537. doi: 10.1080/08111140601035200 


\section{COMMUNITY ORCHARDS AS NEW URBAN COMMONS}

Klein, N. (2014). This changes everything: Capitalism vs. the climate. Toronto: Knopf Canada.

Klinenberg, E. (2018, Feb 9) Is loneliness a health epidemic? New York Times Sunday Review. Retrieved from https://www.nytimes.com/2018/02/09/ opinion/sunday/loneliness-health.html

Knigge, L. (2009). Intersections between public and private: Community gardens, community service and geographies of care in the US City of Buffalo, NY. Geographica Helvetica, 64(1), 45-52. Retrieved from https://www.geogrhelv.net/64/45/2009/gh-64-45-2009.pdf

Kurtz, H. (2001). Differentiating multiple meanings of garden and community. Urban Geography, 22(7), 656-670. doi: 10.2747/0272-3638.22.7.656

Lang, T. (1999). Food policy for the 21 st century: Can it be both radical and reasonable? In M. Koc, R. McRae, L. Mougeot, \& J. Welsh (Eds.), For Hunger Proof Cities: Sustainable Urban Food Systems (pp. 216-224). Ottawa, Canada: International Development Research Centre. Retrieved from https://www.idrc.ca/en/book/hunger-proof-cities-sustainable-urban-food-systems

Lang, T. (2003). Food industrialisation and food power: Implications for food governance. Development Policy Review, 21(5), 555-568.

Lave, J. \& Wenger, E. (1991). Situated learning: Legitimate peripheral participation. Cambridge, UK: Cambridge University Press.

Lawson, L. (2005). City bountiful: A century of community gardening in America. Berkeley: University of California Press. 
Lee, S., \& Webster, C. (2006). Enclosure of the urban commons. Geojournal, 66(1-2), 27-42. doi: 10.1007/s10708-006-9014-3

Lefebvre, H. (1991). The production of space. (D. Nicholson-Smith, Trans.). USA, UK, Australia: Blackwell. (Original work published 1974)

Lepofsky, J. \& Fraser, J. (2003). Building community citizens: Claiming the right to place-making in the city. Urban Studies, 40, 127-142. doi: $10.1080 / 00420980220080201$

Levkoe, C. (2006). Learning democracy through food justice movements. Agriculture and Human Values, 23, 89-98. doi: 10.1007/s10460-005-5871-5

Lifecycles. (2018). About us. Retrieved from http://lifecyclesproject.ca/about-us/

Lincoln, Y., \& Guba, E. (2000). Paradigmatic controversies, contradictions, and emerging confluences. In N. K. Denzin \& Y. S. Lincoln (Eds.), Handbook of qualitative research (2nd ed.) (pp. 163-188). Thousand Oaks, CA: Sage.

Linebaugh, P. (2010). Enclosures from the bottom up. Radical History Review, 108. doi:10.1215/01636545-2010-007

Linebaugh, P. (2009). The Magna Carta manifesto: Liberties and commons for all. Berkeley and Los Angeles: University of California Press.

Linn, K. (1999). Reclaiming the sacred commons. New Village, 1, 42-49. Retrieved from http://www.newvillage.net/Journal/Issue1/1 sacredcommon.html

Linn, K. (2007). Building commons and community. Oakland, CA: New Village Press.

Loopstra, R. \& Tarasuk, V. (2009). Food insecurity and participation in community food programs among low-income Toronto families. Canadian Journal of Public 
COMMUNITY ORCHARDS AS NEW URBAN COMMONS

Health, 104(1), e55-e59. Retrieved from http://www.jstor.org/stable/canajpublheal.104.1.0e55

Lyson, T. (2004). Civic agriculture: Reconnecting farm, food, and community. Lebanon, NH: University Press of New England.

Mackenzie, F. (2012). Places of possibility: Property, nature and community land ownership. Oxford: Wiley-Blackwell.

Magdoff, F. (2012). Food as a commodity. Monthly Review, 63(8). Retrieved from http://monthlyreview.org/2012/01/01/food-as-a-commodity

Mallet, A. (2012). Youth, food justice and the practice of everyday politics: A case study of agricultural resistance in the Spring Ridge Commons (Masters thesis). University of Victoria, Victoria, BC.

Mares, T. \& Peña D. (2010). Urban agriculture in the making of insurgent spaces in Los Angeles and Seattle. In J. Hou (Ed.), Insurgent public space: Guerrilla urbanism and the remaking of contemporary cities (pp. 241-254). New York: Routledge.

Margalit, R. (2014, Nov 5). "The Giving Tree” at fifty: Sadder than I remembered. The New Yorker. Retrieved from https://www.newyorker.com/books/pageturner/giving-tree-50-sadder-remembered

Martin, C. (2006). The apple: A history of Canada's perfect fruit. Toronto: McArthur \& Co.

Massey, D. (2005). For Space. London: Sage.

Mattei, U. (2012). First thoughts for a phenemonology of the commons. In D. Bollier \& S. Helfrich (Eds.), The wealth of the commons: A world beyond market and state (37-44). Amherst, MA: Levellers Press. 


\section{COMMUNITY ORCHARDS AS NEW URBAN COMMONS}

McCarthy J. (2005). Commons as counter-hegemonic projects. Capitalism Nature Socialism, 16(1), 9-24. doi: 10.1080/10455750532000335348

McClintock, N. (2010). Why farm the city? Theorizing urban agriculture through a lens of metabolic rift. Cambridge Journal of Regions, Economy and Society, 3, 191207. doi:10.1093/cjres/rsq005

McClintock, N. (2014). Radical, reformist, and garden-variety neoliberal: Coming to terms with urban agriculture's contradictions. Local Environment: The International Journal of Justice and Sustainability, 19(2), 147-171.

doi: $10.1080 / 13549839.2012 .752797$

McClintock, N., Mahmoudi, D., Simpson, M., \& Santos, J.P. (2016). Socio-spatial differentiation in the sustainable city: A mixed-methods assessment of residential gardens in metropolitan Portland, Oregon, USA. Landscape and Urban Planning, 148, 1-16. doi: 10.1016/j.landurbplan.2015.12.008

McClintock, N. (2017). Cultivating (a) sustainability capital: Urban agriculture, ecogentrification, and the uneven valorization of social reproduction. Annals of the American Association of Geographers, 0(0), 1-12.

doi:10.1080/24694452.2017.1365582

McClintock, N., Miewald, C. \& McCann, E. (2018). The politics of urban agriculture: Sustainability, governance, and contestation. In A. Jonas, B. Miller, K. Ward \& D. Wilson (Eds.), SAGE handbook on spaces of urban politics (pp. 361-374). Abingdon, UK: Taylor \& Francis. 


\section{COMMUNITY ORCHARDS AS NEW URBAN COMMONS}

McClintock, N., \& Simpson, M. (2014). A survey of urban agriculture organizations and businesses in the US and Canada: Preliminary results. Retrieved from http://www.urbanfood.org

McCue, D. (2014, July 22). Vancouver's Oppenheimer Park protest raises question of Aboriginal title to urban centres: Protesters hand City of Vancouver eviction notice over park occupied by homeless. $C B C$ News. Retrieved from http://www.cbc.ca/news/indigenous/vancouver-s-oppenheimer-park-protestraises-question-of-aboriginal-title-to-urban-centres-1.2714731

McCulloch, S. (2013, October 9). How about these apples? Old orchard to be restored. Times Colonist. Retrieved from http://www.timescolonist.com/news/local/howabout-these-apples-old-orchard-to-be-restored-1.655010

McCracken, K. (2012, July 30). Fresh, local, and financially sound: Community supported agriculture in Canada. Retrieved from http://activehistory.ca/2012/07/ fresh-local-and-financially-sound-community-supported-agriculture-in-canada/ McKay, G., (2011a) Radical gardening: politics, idealism and rebellion in the garden. London: Frances Lincoln.

McKay, G. (2011b, May 2). Radical plots: The politics of gardening. The Independent. Retrieved from http://www.independent.co.uk/property/gardening/radical-plotsthe-politics-of-gardening-2277631.html

McLain, R., Poe, M., Hurley, P., Lecompte-Mastenbrook, J., \& Emery, M. (2012). Producing edible landscapes in Seattle's urban forest. Urban Forestry and Urban Greening, 11(2), 187-194. Retrieved from https://doi.org/10.1016/j.ufug.2011 .12 .002 


\section{COMMUNITY ORCHARDS AS NEW URBAN COMMONS}

McLain, R. J., Hurley, P., Emery, M.R., \& Poe, M.R. (2014). Gathering “wild” food in the city: Rethinking the role of foraging in urban ecosystem planning and management. Local Environment: The International Journal of Justice and Sustainability, 19(2), 220-240. Retrieved from http://dx.doi.org/ $10.1080 / 13549839.2013 .841659$

McMurtry, J. (2001). The life-ground, the civil commons and the corporate male gang. Canadian Journal of Development Studies, 22, 819-854. Retrieved from https://doi-oorg.proxy.library.carleton.ca/10.1080/02255189.2001.9669944

Meenar, M. (2012). Community food security via urban agriculture: Understanding people, place, economy, and accessibility from a food justice perspective. Journal of Agriculture, Food Systems, and Community Development, 33(1), 143-160. doi: https://doi.org/10.5304/jafscd.2012.031.013

Menzies, H. (2014). Reclaiming the commons for the common good. Gabriola Island: New Society Publishers.

Mies, M. \& Bennholdt-Thomsen, V. (2001). Defending, Reclaiming and Reinventing the Commons. Canadian Journal of Development Studies, XXII (Special Issue), 9971023.

Milbourne, P. (2012). Everyday (in)justices and ordinary environmentalisms: Community gardening in disadvantaged urban neighbourhoods. Local Environment: The International Journal of Justice and Sustainability, 17(9), 943-957. Retrieved from https://doi-org.proxy.library.carleton.ca/10.1080/13549839.2011.607158

Miller, S. (2008). Edible action: Food activism \& alternative economics. Halifax and Winnipeg: Fernwood. 


\section{COMMUNITY ORCHARDS AS NEW URBAN COMMONS}

Mincyte, D. \& Dobernig, K. (2016). Urban farming in the North American metropolis: Rethinking work and distance in alternative food networks. Environment and Planning A: Economy and Space, 48(9), 1767-1786. doi: $10.1177 / 0308518 X 16651444$

Mitchell, D. (2003). The right to the city: Social justice and the fight for public space. New York: Guilford Press.

Neo, H. \& Chua, C.Y. (2017). Beyond inclusion and exclusion: Community gardens as spaces of responsibility. Annals of the American Association of Geographers, 107(3), 666-681. doi: 10.1080/24694452.2016.1261687

Nettle, C. (2014). Community gardening as social action. Surrey, UK: Ashgate.

Nguffio, S. (1998). In defense of the commons: Forest battles in southern Cameroon. In M. Goldman (Ed.), Privatizing Nature: Political Struggles for the Global Commons (102-119). London: Pluto Press/Transnational Institute (TNI).

Night soil. (2012). CollinsDictionary.com. Retrieved from https://www.collinsdictionary.com/dictionary/english/night-soil

Nordahl, D. (2009). Public produce: The new urban agriculture. Washington, Covelo, London: Island Press.

Nordahl, D. (2014). Public produce: Cultivating our parks, plazas, and streets for healthier cities. Washington, Covelo, London: Island Press.

O'Brien, R. (1998). An overview of the methodological approach of action research. Retrieved from http://www.web.ca/ robrien/papers/arfinal.html\#_edn1 
COMMUNITY ORCHARDS AS NEW URBAN COMMONS

On the Commons Team (OTC). (2011). Observations from the 2011 Farming Commons

Gathering. Retrieved from http://onthecommons.org/work/observations-2011farming-commons-gathering

Ostrom, E. (1990). Governing the commons: The evolution of institutions for collective action. Cambridge University Press: Cambridge, UK.

Ostrom, E. (2009, December 8). Beyond markets and states: Polycentric governance of complex economic systems (Nobel Prize Lecture). Retrieved from http://www.nobelprize.org/nobel_prizes/economic-sciences/laureates/2009/ ostrom_lecture.pdf

Palmer, D. (2013, August 8). Community orchards take root in Victoria West. Victoria News. Retrieved from http://www.vicnews.com/news/218857551.html

Palmer, P.J. (2007). The courage to teach: Exploring the inner landscape of a teacher's life. San Francisco: Jossey-Bass.

Parkhouse, P., Christl, A., Baigent, J., Johnson, G., Krawczyk, T., Meredith, J., Roessler, H., \& Rombs, R. (2013). Banfield Park community orchard proposal. Retrieved from http://isssuu.com/victoriawestcommunitycentre/docs/banfield_community -com

Passidomo, C. (2016). Community gardening and governance over urban nature in New Orleans's Lower Ninth Ward. Urban Forestry \& Urban Greening, 19, 271-277. Retrieved from http://dx.doi.org/10.1016/j.ufug.2016.01.001

Perkins, H. (2009). Out from the (green) shadow? Neoliberal hegemony through the market logic of shared urban environmental governance. Political Geography, 28(7), 395-405. doi: 10.1016/j.polgeo.2009.09.007 
COMMUNITY ORCHARDS AS NEW URBAN COMMONS

Perkins, H. (2010). Green spaces of self-interest within shared urban governance. Geography Compass, 4(3), 255-268. doi:10.1111/j.1749-8198.2009.00308.x

Pickerill, J. \& Chatterton, P. (2006). Notes towards autonomous geographies: Creation, resistance and self-management as survival tactics. Progress in Human Geography, 30(6), 730-746. doi: 10.1177/0309132506071516

Pierce, J. (2010). Reinvigorating the concept of land tenure for American urban geography. Geography Compass, 4(12), 1747-1757. Retrieved from https://doi-org.proxy.library.carleton.ca/10.1111/j.1749-8198.2010.00402.x

Pimbert, M. (2009). Towards food sovereignty: Reclaiming autonomous food systems. London: International Institute for Environment and Development.

Pink, S. (2009). Urban social movements and small places. City, 13(4), 451-465. Retrieved from https://doi-org.proxy.library.carleton.ca/ $10.1080 / 13604810903298557$

Plant, D. (n.d.). BCW Project: British civil wars, Commonwealth \& protectorate 16381660. Retrieved from http://bcw-project.org/church-and-state/sects-andfactions/diggers

Poitevin-DesRivières, C. (2018). Hidden Harvest: A case study. Retrieved from http://nourishingontario.ca/the-social-economy-of-food/case-studies-subversionsfrom-the-informal-and-social-economy/hidden-harvest/

Poizner, S. (2014, November 4). The story of Copley Community Orchard [Video file]. Retrieved from https://vimeo.com/110880282 


\section{COMMUNITY ORCHARDS AS NEW URBAN COMMONS}

Pollan, M. (1998, Nov 5). Breaking ground: The call of the wild apple. The New York Times. Retrieved from http://michaelpollan.com/articles-archive/breakingground-the-call-of-the-wild-apple/

Polanyi, K. (1944). The great transformation: The political and economic origins of our time. New York, Toronto: Farrar \& Rinehart.

Poppendieck, J. (1999). Sweet charity: Emergency food and the end of entitlement. New York: Penguin.

Porter, C. (2009, May 2). Neighbours war over urban orchard. Toronto Star. Retrieved from https:/www.thestar.com/news/gta/2009/05/02/neighbours_war_over_ urban_orchard.html

Porter, C. (2013, July 11). Thieves rake community orchard clean: Porter. Toronto Star. Retrieved from https://www.thestar.com/news/insight/2013/11/ thieves_rake_community_orchard_clean_porter.html

Poteete, A., Janssen, M.A., Ostrom, E. (2010). Working together: Collective action, the commons, and multiple methods in practice. Princeton \& Oxford: Princeton University Press.

Pottinger, L. (2013). Ethical food consumption and the city. Geography Compass, 7(9), 659-668. doi:10.1111/gec3.12064

Pudup, M. B. (2008). It takes a garden: Cultivating citizen-subjects in organized garden projects. Geoforum, 39, 1228-1240. doi:10.1016/j.geoforum.2007.06.012

Purcell, M., (2002). Excavating Lefebvre: the right to the city and its urban politics of the inhabitant. GeoJournal, 58(2), 99-108.

doi: 10.1023/B:GEJO.0000010829.62237.8f 


\section{COMMUNITY ORCHARDS AS NEW URBAN COMMONS}

Purcell, M., \& Tyman, S.K. (2015). Cultivating food as a right to the city. Local Environment: The International Journal of Justice and Sustainability, 20(10), 1132- 1147. doi: 10.1080/13549839.2014.903236

Quastel, N., (2009). Political ecologies of gentrification. Urban Geography, 30(7), 694 725. Retrieved from https://doi-org.proxy.library.carleton.ca/10.2747/02723638.30.7.694

Quilligan, J. (2012). Why distinguish common goods from public goods? In D. Bollier \& S. Helfrich (Eds.), The wealth of the commons. A world beyond market \& state (pp. 73-81). Amherst, MA: Levellers Press.

Ravenscroft, N., Moore, N., Welch, E., \& Hanney, R. (2013). Beyond agriculture: The counter-hegemony of community farming. Agriculture and Human Values, 30, 629-639. doi:10.1007/s10460-013-9437-7.

Rayner, J. (2012, Fall). Copley Community Orchard. Cider Press. Retrieved from http://www.bcfta.ca

Rabinowitz, D. (2012). Residual residential space as commons. International Journal of the Commons, 6(2), 302-318. Retrieved from doi: http://doi.org/10.18352/ijc.300

Reed, M.G. \& Peters, E.J. (2004). Using an ecological metaphor to build adaptive and resilient research practices. ACME: An International E-Journal for Critical Geographies, 3(1), 18-40. Retrieved from https://www.acmejournal.org/index.php/acme/article/view/724.

Renfrew-Collingwood Food Security Institute. (2017). About us. Retrieved from https://rcfood.wordpress.com/about/ 
COMMUNITY ORCHARDS AS NEW URBAN COMMONS

Reynolds, K. (2015). Disparity despite diversity: Social injustice in New York City’s urban agriculture system. Antipode, 47(1), 240-259. doi: 10.1111/anti.12098

Richer, C., Htoo, J., Kamizaki, K., Mallin, M., Goodmurphy, B., Akande, A., \& Molale, A. (2010). Beyond bread and butter: Toward food security in a changing Parkdale. Retrieved from http://parkdalecommunityeconomies.wordpress.com /resources/beyond-bread-and-butter-toward-food-security-in-a-changingparkdale/

Rilling, R. (2011). The commons, the public and the left. Retrieved from http://rosaluxeuropa.info/userfiles/file/Rilling_Commons_2011.pdf

Ristau, J. (n.d.). What is Commoning, Anyway? Activating the power of social cooperation to get things done-and bring us together. On the Commons. Retrieved from http://www.onthecommons.org/work/what-commoninganyway\#sthash.xjJGdq2C.dpbs

Robbins, P. (2006). Research is theft: Environmental inquiry in a postcolonial world. In S. Aitken \& G. Valentine (Eds.), Approaches to Human Geography (pp. 311324). London, Thousand Oaks, CA, New Delhi: SAGE Publications.

Rodgers, N. (1995). Modern commons: Place, nature, and revolution at the Strathcona Community Gardens (Master's thesis). Simon Fraser University, Burnaby, BC.

Romero, J. \& Melo, C. (2015). Spanish Mediterranean Huertas: Theory and reality in the planning and management of peri-urban agriculture and cultural landscapes. WIT Transactions on Ecology and The Environment, 193, 585-595.

doi:10.2495/SDP150501 


\section{COMMUNITY ORCHARDS AS NEW URBAN COMMONS}

Rose, G. (1997). Situating knowledges: Positionality, reflexivities and other tactics. Progress in Human Geography, 21(3), 305-320. Retrieved from http://journals.sagepub.com.proxy.library.carleton.ca/doi/pdf/10.1191/030913297 673302122

Rosol, M. (2011). Community volunteering as neoliberal strategy? Green space production in Berlin. Antipode, 44(1), 239-257. doi: 10.1111/j.14678330.2011.00861.x

Ross, G. S. (2010). A tale of two cities: The Vancouver you see, and the one you don't. The Walrus, (March). Retrieved from http://thewalrus.ca/a-tale-of-two-cities/

Rosset, P.M. (2006). Food is different: Why the WTO should get out of agriculture (Global Issues). London, UK: Zed Books.

Rupp, R. (2014, July 22). The history of the "forbidden" fruit. The Plate. Retrieved from http://theplate.nationalgeographic.com/2014/07/22/history-of-apples

Ryerson University. (n.d.). Centre for Studies in Food Security. Retrieved from https:/www.ryerson.ca/foodsecurity/

Saldivar-Tanaka, L. \& Krasny, M. (2004). Culturing community development, neighborhood open space, and civic agriculture: The case of Latino community gardens in New York City. Agriculture and Human Values, 21(4), 399-412. doi: $10.1007 / \mathrm{s} 10460-003-1248-9$

Salomone, G. (Producer). (2013, June 21). Sharing backyards: A popular Canadian innovation in urban farming. [Audio podcast]. Retrieved from http://www.rcinet.ca/en/2013/06/21/sharing-backyards-a-popular-canadianinnovation-in-urban-farming/ 


\section{COMMUNITY ORCHARDS AS NEW URBAN COMMONS}

Schiavoni, C. (2009). The global struggle for food sovereignty: From Nyéléni to New York. In R. Patel (Ed.) Grassroots Voices: Food sovereignty (pp. 682-689). Journal of Peasant Studies, 36(3), 682-9. doi: 10.1080/0306615093143079

Schmelzkopf, K. (1995). Urban community gardens as contested space. Geographical Review, 85(3), 364-381. doi: 10.2307/215279

Schmelzkopf, K. (2002). Incommensurability, land use, and the right to space: Community gardens in New York City. Urban Geography, 23(4), 323-343. doi: $10.2747 / 0272-3638.23 .4 .323$

Sharma, N. \& Wright, C. (2008/9). Decolonizing resistance, challenging colonial states. Social Justice, 35(3), 120-138. Retrieved from http://proxy.library.carleton.ca/login?url=https://search-proquestcom.proxy.library.carleton.ca/docview/231927761 accountid=9894

Shatkin, G. (2004). Planning to forget: Informal settlements as 'forgotten places' in globalizing metro Manila. Urban Studies, 41(12), 2469-2484.

doi: 10.1080/00420980412331297636

Shore, R. (2012, July 7). Vancouver's urban fruit orchard blossoms in city parks, golf courses” Vancouver Sun. Retrieved from http://vancouversun.com/news/staffblogs/vancouvers-urban-fruit-orchard-blossoms-in-city-parks-golf-courses

Silverstein, S. (1964). The Giving Tree. New York: Harper and Row.

Sinoski, K. (2015, October 21). B.C. Court rules homeless have right to camp. Vancouver Sun. Retrieved from http://www.vancouversun.com/life/ court+rules + homeless + have + right + camp/11456602/story.html 


\section{COMMUNITY ORCHARDS AS NEW URBAN COMMONS}

Slocum, R. (2007). Whiteness, space, and alternative food practice. Geoforum, 38(3), 520-533. doi: 10.1016/j.geoforum.2006.10.006

Slocum, R. (2008). Thinking race through corporeal feminist theory: Divisions and intimacies at the Minneapolis farmers’ market. Social \& Cultural Geography, 9(8), 849-869. doi: 10.1080/14649360802441465

Slocum, R., Cadieux, K.V., \& Bloomberg, R. (2016). Solidarity, space, and race: Toward geographies of agrifood justice. justice spatiale | spatial justice 9 (January) Retrieved from http://www.jssj.org/article/solidarite-espace-et-race-vers-desgeographies-de-la-justice-alimentaire/

Smith, A. \& MacKinnon, J.B. (2007). The Hundred-Mile Diet: A Year of Local Eating. Toronto: Vintage Canada.

Smith, C. M. \& Kurtz, H. E. (2003). Community gardens and politics of scale in New York City. Geographical Review, 93(2), 193-212. Retrieved from https://wwwjstor-org.proxy.library.carleton.ca/stable/30033906

Soja, E. (2010). Seeking spatial justice. Minneapolis: University of Minnesota Press.

Solnit, R. (2004). Hope in the dark. New York: Nation Books.

St Jean, J. (2003, September 18). Community gardening in the City of Ottawa. Retrieved from http://ottawa.ca/calendar/ottawa/citycouncil/hrssc/2003/09-18/ACS2003PEOIDP0020\%20Community\%20Gardening\%20in\%20the\%20City\%20of\%20Ot tawa.htm

Staeheli, L. (2008). Citizenship and the problem of community. Political Geography, 27(1), 5-21. doi: 10.1016/j.polgeo.2007.09.002 


\section{COMMUNITY ORCHARDS AS NEW URBAN COMMONS}

Staeheli, L. A., Mitchell, D. \& Gibson, K. (2002). Conflicting rights to the city in New York's community gardens. GeoJournal, 58(2-3), 197-205.

doi: 110.1023/B:GEJO.000010839.59734.01

Stephen, L. (1998). Between NAFTA and Zapata: Responses to restructuring the commons in Chiapas and Oaxaca, Mexico. In M. Goldman (Ed.), Privatizing nature: Political struggles for the global commons (pp. 76-101). London: Transnational Institute.

Teitelbaum, S. (Ed.). (2016). Community Forestry in Canada. Vancouver: UBC Press. Thornton, A. (2017). “The Lucky country”? A critical exploration of community gardens and city-community relations in Australian cities. Local Environment: The International Journal of Justice and Sustainability, 22(8), 969-985. doi: $10.1080 / 13549839.2017 .1317726$

Tornaghi, C. (2016). Urban agriculture in the food-disabling city: (Re)defining urban food justice, reimagining a politics of empowerment. Antipode, 49(3), 782-801. doi: 10.1111/anti.12291

Tornaghi, C. (2014). Critical geography of urban agriculture. Progress in Human Geography, 38(4), 551-567. doi: 10.1177/0309132513512542

Tornaghi, D. \& Van Dyck, B. (2015). Research-informed gardening activism: Steering the public food and land agenda Local Environment: The International Journal of Justice and Sustainability, 20(10), 1247-1264.

doi:10.1080/13549839.2014.949643. 


\section{COMMUNITY ORCHARDS AS NEW URBAN COMMONS}

Travaline, K. \& Hunold, C., (2010). Urban agriculture and ecological citizenship in Philadelphia. Local Environment: The International Journal of Justice and Sustainability, 15(6), 581-590. doi: 10.1080/13549839.2010.487529

Tsing, A. L. (2012). Empire's salvage heart: Why diversity matters in the global political economy. Focaal - Journal of Global and Historical Anthropology, 64, 36-50. doi: $10.3167 /$ fcl.2012.640104

Twiss, J., Dickenson, J., Duma, S., Kleinman, T., Paulsen, H., \& Rilveria, L. (2003). Community gardens: Lessons learned from California healthy cities and communities. American Journal of Public Health, 93, 1435-1438. Retrieved from https://www.ncbi.nlm.nih.gov/pmc/articles/PMC1447988/

UK Government (n.d.). The law and allotments. Retrieved from https://www2.canterbury.gov.uk/media/892659/the-Law-and-allotmentssummary-Appendix-28.pdf

Van Laerhoven, F., \& Ostrom, E. (2007). Traditions and trends in the study of the commons. International Journal of the Commons, 1(1), 3-28. Retrieved from http://doi.org/10.18352/ijc.76

Van Slyke, B. (2013, March 1). Canada's co-operative movement is on the rise.

Retrieved from http://rabble.ca/news/2013/03/canadas-co-operative-movementrise

Vancouver Foundation. (n.d.). Neighbourhood Small Grants. Retrieved from http://neighbourhoodsmallgrants.ca/ 
COMMUNITY ORCHARDS AS NEW URBAN COMMONS

Vancouver Public Space Network (VPSN). (2008). A Manifesto on public space policy...for the years 2008-2011. Retrieved from http://www.vancouverpublicspace.ca/uploads/Manifesto.pdf

Vivero Pol, J.L. (2013). Food as a commons: Reframing the narrative of the food system. SSRN Working paper series. Retrieved from http://papers.ssrn.com/sol3/papers.cfm?abstract_id=22555447

Vivero Pol, J.L. (2015). Transition towards a food commons regime: re-commoning food to crowd-feed the world. Retrieved from http://ssrn.com/abstract=2548928

Voicu, I. \& Been, V. (2008). The effect of community gardens on neighbouring property values. Real Estate Economics, 36(2), 241-283. Retrieved from https://doiorg.proxy.library.carleton.ca/10.1111/j.1540-6229.2008.00213.x

Wakefield, S., Yeudall, F., Taron, C., Reynolds, J. \& Skinner, A. (2007). Growing urban health: Community gardening in South-East Toronto. Health Promotion International, 22(2), 92-101. doi:10.1093/heapro/dam001

Wekerle, G. (2004). Food justice movements. Journal of Planning Education and Research, 23(4), 378-386. doi: 10.1177/0739456X04264886

Wekerle, G. \& Classens, M. (2015). Food production in the city: (Re)negotiating land, food and property. Local Environment: The International Journal of Justice and Sustainability, 20(10), 1175-1193. doi: 10.1080/13549839.2015.1007121

Welsh, J. \& MacRae, R. (1998). Food citizenship and community food security: lessons from Toronto, Canada. Canadian Journal of Development Studies/Revue Canadienne d'Etudes du Développement, 19(4), 237-255. doi: 10.1080/02255189.1998.9669786 
COMMUNITY ORCHARDS AS NEW URBAN COMMONS

White, M.M. (2011a). D-Town Farm: African American resistance to food insecurity and the transformation of Detroit. Environmental Practice, 13(4), 406-417. doi: $10.1017 / \mathrm{S} 1466046611000408$

White, M.M. (2011b). Sisters of the soil: urban gardening as resistance in Detroit. Race/Ethnicity: Multidisciplinary Global Contexts, 5(1), 13-28. Retrieved June 25, 2018, from Project MUSE database.

Williams, M. J. (2018). Urban commons are more-than-property. Geographical Research, 56(1), 16-25. doi: 10.1111/1745-5871.12262

Wilson, P.L. \& Weinberg, B. (Eds.). (1999). Avant gardening: Ecological struggle in the city and the world. Brooklyn, NY: Autonomedia.

Wilson, R. (2010). Cultivating the city and its citizens: The creation of corporation allotments in York. The International Journal of Regional and Local Studies, 6(1), 38-57. doi:10.1179/jrl.2010.6.1.38

Wilson, A.D., (2013). Beyond alternative: Exploring the potential for autonomous food spaces. Antipode, 45(3), 719-737. doi: 10.1111/j.1467-8330.2012.01020.x

World Population Review (2018) Vancouver Population 2018 Retrieved from http://worldpopulationreview.com/world-cities/vancouver-population/

Ybarra, M. (2014). Don't just pay it back, pay it forward: From accountability to reciprocity in research relationships. Journal of Research Practice, 10(2), Article N5, 1-7. Retrieved from http://jrp.icaap.org/index.php/jrp/article/view/407/358

Young, I. M. (1990). Justice and the Politics of Difference. Princeton, NJ: Princeton University Press. 
COMMUNITY ORCHARDS AS NEW URBAN COMMONS

Yuen, J. (2014, April). City farms on CLTs: How community land trusts are supporting urban agriculture. Retrieved from https://www.lincolninst.edu/sites/default/files/ pubfiles/2376_1716_city_farms_on_clts_041411.pdf

Zukin, S. (2010). Naked City: The Death and Life of Authentic Urban Places. Oxford, UK: Oxford University Press. 


\section{Appendix A - Letter of Introduction and Informed Consent}

\section{Letter of Introduction/Email Invitation}

Subject: Invitation to participate in a research project on community orchards

Title: The Giving Trees: Community Orchards as New Urban Commons

Funding Source: Joseph-Armand Bombardier Doctoral Fellowship, Social Sciences and Humanities Research Council (SSHRC)

Dear Sir or Madam,

My name is Jennie Barron and I am a PhD student in the Department of Geography and Environmental Studies at Carleton University. I am working on a research project under the supervision of Prof. Patricia Ballamingie.

I am writing to you today to invite you to participate in a study on community orchards. The purpose of the study is to understand the ways in which some community orchards are creating new forms of commons - i.e., lands and resources that are shared, governed and managed by an identifiable community, separate from government. The study also seeks to understand how well such a model can work as a vehicle for enhancing equity and sustainability in the local food system.

My research will involve visiting various community orchards in Canada and the U.S., studying publicly-available documentation related to them (newspaper articles, blogs, videos, promotional materials, signage, minutes of meetings etc), and speaking with people who are involved in various capacities with community orchards - volunteers, coordinators, advocates, and those who provide training, funding, coordination or other services, such as municipal staff. I hope also to participate in events organized by or at various community orchards, including harvesting, maintenance and celebratory events.

Your participation would include one interview of approximately 90 minutes. The duration of the interview will be largely dependent on the length of interviewees' responses. If you have only one hour, I can limit the number of questions I ask.

The interview will take place in a mutually convenient, safe location (alternatively, by Skype or telephone if necessary). I will then transcribe this interview and send it to you for your review and approval. I may also need to contact you again to ask clarification or follow-up questions.

With your consent, interviews will be audio-recorded. Once the recording has been transcribed, the audio-recording will be destroyed. If you are not comfortable consenting to audio-recording, I will take notes on a portable computer while we are talking. 
I would also like to take some photographs, but only with the explicit consent of any persons who would appear in them.

The foreseeable risks of participating in this study are minimal. These might include personal discomfort related to discussion of food insecurity and hunger, and/or potential social-emotional risks having to do with sharing information or opinions related to issues that might be contentious within your organization or related networks. To mitigate these risks, and to respect participants' confidentiality wishes, I will offer you the chance to be identified by a pseudonym if you wish, and/or to request that certain responses not be included in the final project, or be included only in such a way that they are not associated with any particular individual, orchard, or community. This can be done before or during the interview, or after you read the transcript of our interview, up until two months after the interview date.

You will have the right to end your participation in the study at any time, for any reason. If you choose to withdraw, all the information you have provided will be destroyed.

As a token of appreciation, I will be offering a small gift or gift certificate. If we meet in person, I will provide refreshments. Transportation costs incurred to meet with me will be reimbursed. No other compensation will be provided.

All research data, including audio-recordings and any notes will be encrypted. Any hard copies of data (including any handwritten notes or USB keys) will be kept in a locked cabinet in my office. Research data will only be accessible by the researcher and the research supervisor.

The ethics protocol for this project was reviewed by the Carleton University Research Ethics Board, which provided clearance to carry out the research. Should you have questions or concerns related to your involvement in this research, please contact the REB Chair, Professor Louise Heslop at ethics@carleton.ca or at 613-520-2517.

If you would like to participate in this research project, or have any questions, please contact me at (250) 352-5740 or jenniferbarron@cmail.carleton.ca.

Sincerely,

Jennie Barron 


\section{Carleton U N I V E R S I T Y Consent Form \\ Canada's Capital University}

Title: The Giving Trees: Community Orchards as New Urban Commons

Funding Source: Joseph-Armand Bombardier Doctoral Fellowship, Social Sciences and Humanities Research Council (SSHRC)

Date of ethics clearance: Aug 25, 2015 (renewed July 6, 2016)

Ethics Clearance for the Collection of Data Expires: Aug 31, 2017

I , choose to participate in a study on community orchards. This study aims to understand the ways in which some community orchards are creating new forms of commons, and to explore how well such a model can work as a vehicle for enhancing equity and sustainability in the local food system. The researcher for this study is Jennie Barron in the Department of Geography and Environmental Studies. She is working under the supervision of Dr. Patricia Ballamingie in the same department.

This study involves one interview of approximately 90 minutes, and possible follow-up communication for clarification, where needed. With my consent, the interview will be audio-recorded. Alternatively, the researcher will take notes while we speak. Once the recording has been transcribed, the audio-recording will be destroyed.

I understand that I will be given an opportunity to review the transcript (or notes) of my interview and to retract or revise statements should I choose to do so. I will also have the option of requesting that certain responses not be included in the final project, or that they be included only in such a way that they are not associated with a particular individual, orchard, or community. I am aware that I can request to be identified by a pseudonym instead of by my real name.

I understand that I have the right to end my participation in the study at any time, for any reason, up until two months after the interview date. I can withdraw by phoning or emailing the researcher or the research supervisor. If I withdraw from the study, all information I have provided will be immediately destroyed.

All research data, including audio-recordings and any notes will be encrypted. Any hard copies of data (including any handwritten notes or USB keys) will be kept in a locked cabinet in the researcher's office. Research data will only be accessible by the researcher and the research supervisor. 
The ethics protocol for this project was reviewed by the Carleton University Research Ethics Board, which provided clearance to carry out the research. If I have questions or concerns related to my involvement in this research, I can contact:

\section{REB contact information:}

Professor Louise Heslop, Chair

Professor Andy Adler, Vice-Chair

Research Ethics Board

Carleton University

511 Tory

1125 Colonel By Drive

Ottawa, ON K1S 5B6

Tel: 613-520-2517

ethics@carleton.ca

Researcher contact information:

Name Jennie Barron

Department of Geography

Carleton University

Tel: $\quad$ XXX-XXX-XXXX

Email: jenniferbarron@cmail.carleton.ca
Supervisor contact information:

Name Dr. Patricia Ballamingie

Department of Geography

Carleton University

Tel: 613-520-2600, ext. 8566

Email: patriciaballamingie@carleton.ca

I agree to be audio-recorded: _ Yes _ No

I agree to be photographed: —Yes — No

I agree to be identified by my real name: __ Yes ___ No

$\underline{\boldsymbol{O R}}$, I would prefer to be identified using a pseudonym: __ Yes _ _ No 


\section{Appendix B - Questions for Interviewees}

\section{Questions for community orchardists:}

Tell me how and why you became involved in [your community orchard]. What word would you say best describes your role: are you a volunteer, a participant, a member, an activist, or something else?

Purpose

What needs and desires do you think drive this project (community orchard)?

Who is the orchard for?

Has the sense of the community orchard's purpose evolved at all since it was first envisioned?

How much would you say it's about food security?

Is there appeal in the idea of free - non-commodified - fruit?

Are you involved in any other food security type work or activism?

\section{Harvest}

How much fruit (estimate) has been produced and shared to date?

Do you (collectively) track where the food goes and whom it reaches? Why or why not? Ideally, how would you like to see the harvest distributed?

Has there been any theft (or vandalism)? Is this a concern? What do you do if/when there is theft?

How do expectations about give-and-take and sharing get communicated?

What signage do you have and what does it communicate?

Work

Tell me how the work of caring for the orchard is organized - work parties? How often? Tell me how you feel when you're doing that work, and after you see the results of your labour?

How does it get decided who does what?

Do you feel there is a balance between the responsibilities and the benefits of volunteering/membership?

Does all the work get done in a satisfactory way? If not, what happens? (Is this sustainable in the long run?)

Are there any issues with the union(s) regarding volunteer labour on City land?

Space

How has the space been transformed? Is it safer? Is it different aesthetically?

Would you say there is any sense of greater psychological "ownership" over the space now by the community? Or by the gardeners who do the work? Or attachment? Would you say it feels the same or different from other public spaces or parks? 


\section{Community}

How do you define the "community" of the CO? (geographic/neighbourhood, intentional/voluntary, or all of the city, anybody-and-everybody?)

What do you think might be the advantages of a membership model in a community orchard? (as opposed to a more casual, drop-in model, or NGO-run program model)

Has the orchard changed the way neighbours relate to each other?

Tell me about who is involved in this $\mathrm{CO}$ (demographic characteristics). Is it your sense that the volunteers or the membership in the Community Orchard reflect the composition and diversity of the neighbourhood/community? If not, why not?

Tell me about any community-building events you've had - e.g., celebrations?

Has there been attrition since the beginning? (If so) To what do you attribute people dropping out?

Governance (including relationships to other governing bodies - City, NGO)

Where do you think the drive for more community gardens and orchards is coming from - the city administration or residents?

What do you think the City's main interests are in having more community gardens and orchards? (and other "food assets" such as boulevard gardening etc.)

What does the City contribute to the community orchard? (e.g., direct funding, equipment, expertise, water, mulch, wood chips, workers' time)

Has that changed over time?

What does the community orchard do for the City?

Do you think it's a fair exchange?

How would you characterize the relationship of the community orchard with the associated nonprofit group, if there is one (e.g., Lifecycles, EYA)?

How free do you feel to suggest changes to the way things are done in the orchard, or to initiate something new?

Can you tell me about any notable conflicts that have arisen and how they have been handled? Has this been satisfactory?

\section{Commons}

Do you think this community orchard can be understood as a commons, and in what sense? (What does a commons mean to you?)

Greatest successes of $\mathrm{CO}$ to date?

Lessons learned?

Is there anything else you'd like to say? 


\section{Questions for City Councilors and/or Staff:}

1. What is your role relative to the community orchards?

2. What needs and desires do you think most drive these projects?

How much would you say it's about food security? (cf. community building, other) In what way is it about food security? (Food system re-localization, hunger relief, reskilling etc?)

Ideally, how (and among whom) would you like to see the harvest shared?

3. What do you think the City's main interests are in having more community gardens and orchards? (and other "food assets" such as boulevard gardening etc.)

4. Do you think that the community orchards have changed the nature of the space at all? (made it safer, changed the aesthetics, brought more people to the spaces etc.)

Do they seem more like community-run spaces now, or are they the same as any other public space or park, just with trees that happen to bear fruit?

5. Who cares for the fruit trees? Did they come to you or did you ask for their help?

6. Has the City initiated any of these fruit tree plantings in City parks?

Are these orchards different in any way from ones that community groups have initiated?

7. How would you characterize the relationship between the community orcharding or tree caretaking group and the City? (Partnership? Sub-contracting? Formally independent and autonomous of each other?)

8. Has anything changed in this relationship over the years? (i.e., the City providing more or less of something, or granting more or less autonomy to community groups)

9. Does all the work seem to get done in a satisfactory way?

10. Are there any issues with the union(s) regarding volunteer labour on City-owned land?

11. How do you define "the community" when it comes to community gardens and orchards?

12. Do community gardening and orcharding groups tend to reflect the composition of the population in general, or do they tend to be a fairly homogenous sub-population? (please describe)

Why do you think that is? 
13. What does the City contribute to these arrangements? (direct funding, equipment, expertise, water, mulch, workers' time)

14. What does the City get in return from these arrangements?

Do you think it's a fair exchange?

Where do you think the drive for more community gardens and orchards is coming from - the City administration or residents?

15. What restrictions, if any, does the City place on community orcharding groups - what they can do and what they can't?

16. How is your relationship with the [supporting non-profit] structured?

17. Has theft been a problem? What do you think can be done about it?

18. Do you think that these community orchards can be described as commons? In what sense? 


\section{Appendix C - Community Orchards by Physical \& Organizational Characteristics}

\section{Community Orchards by Physical Characteristics}

\begin{tabular}{|c|c|c|c|c|}
\hline Orchard & Location & Size & $\begin{array}{l}\text { Number of } \\
\text { trees }\end{array}$ & Varieties grown \\
\hline $\begin{array}{l}\text { Copley } \\
\text { Community } \\
\text { Orchard }\end{array}$ & $\begin{array}{l}3590 \text { Copley } \\
\text { St., Vancouver }\end{array}$ & $\begin{array}{l}4,856 \mathrm{~m}^{2} \\
(1.2 \text { acres })\end{array}$ & $\begin{array}{l}65 \text { trees and } 100 \\
\text { shrubs planted } \\
\text { in first year }\end{array}$ & $\begin{array}{l}\text { apples, cherries, } \\
\text { pears, plums, } \\
\text { walnuts and figs, as } \\
\text { well as strawberries, } \\
\text { raspberries, } \\
\text { blueberries, } \\
\text { currants, } \\
\text { honeyberry, jujubes } \\
\text { and kiwi vines }\end{array}$ \\
\hline $\begin{array}{l}\text { Strathcona } \\
\text { Community } \\
\text { Gardens }\end{array}$ & $\begin{array}{l}857 \text { Malkin } \\
\text { Ave., } \\
\text { Vancouver }\end{array}$ & $\begin{array}{l}\text { Orchard - } \\
4,047 \mathrm{~m}^{2} \\
(1 \text { acre }) \\
\text { Gardens, } \\
\text { total - } \\
13,517 \mathrm{~m}^{2} \\
(3.34 \\
\text { acres })\end{array}$ & 363 & $\begin{array}{l}\text { Over } 130 \text { varieties } \\
\text { of apple and } 14 \\
\text { varieties of pear; } \\
\text { walnut, persimmon, } \\
\text { plum, cherry, paw- } \\
\text { paw, Asian pear, } \\
\text { peach, olive, sea } \\
\text { berry, nectarine, } \\
\text { Chinese date, } \\
\text { salmonberry, fig, } \\
\text { currant, mulberry, } \\
\text { goumi, quince, } \\
\text { crabapple, hazelnut, } \\
\text { grape, loquat, } \\
\text { chestnut, } \\
\text { boysenberry }\end{array}$ \\
\hline $\begin{array}{l}\text { Jonathan } \\
\text { Rogers Park }\end{array}$ & $\begin{array}{l}110 \text { West } 7^{\text {th }} \\
\text { Ave., } \\
\text { Vancouver }\end{array}$ & $\mathrm{n} / \mathrm{a} *$ & 8 & $\begin{array}{l}\text { Apple, plum, and } \\
\text { pear }\end{array}$ \\
\hline $\begin{array}{l}\text { Norquay } \\
\text { Learning } \\
\text { Orchard }\end{array}$ & $\begin{array}{l}2732 \text { Horley } \\
\text { St., Vancouver }\end{array}$ & $\begin{array}{l}566 \mathrm{~m}^{2} \\
0.14 \text { acres }\end{array}$ & 11 & $\begin{array}{l}2 \text { heritage varieties } \\
\text { of apple, } 5 \text { varieties } \\
\text { of pear, } 2 \text { plum, } \\
\text { cherry, blackberry, } \\
\text { laurel, fig, }\end{array}$ \\
\hline
\end{tabular}




\begin{tabular}{|c|c|c|c|c|}
\hline & & & & $\begin{array}{l}\text { blueberry, kiwi, } \\
\text { kiwiberry, red and } \\
\text { white grapes, black } \\
\text { and white currants, } \\
\text { and a dozen } \\
\text { varieties of edible } \\
\text { berries native to } \\
\text { Western Canada }\end{array}$ \\
\hline $\begin{array}{l}\text { Spring Ridge } \\
\text { Commons }\end{array}$ & $\begin{array}{l}\text { Corner of } \\
\text { Chambers St. \& } \\
\text { Gladstone Ave., } \\
\text { Victoria }\end{array}$ & $\begin{array}{l}2023 \mathrm{~m}^{2} \\
(0.5 \text { acre })\end{array}$ & $\begin{array}{l}50 \text { trees/shrubs } \\
\text { and herbaceous } \\
\text { layers (food } \\
\text { forest) }\end{array}$ & $\begin{array}{l}\text { Apple, pear, figs, } \\
\text { buckthorn, goumi } \\
\text { berries, mulberries, } \\
\text { goji berries, kale, } \\
\text { arugula, lima beans, } \\
\text { herbs, miners' } \\
\text { lettuce }\end{array}$ \\
\hline $\begin{array}{l}\text { Banfield Park } \\
\text { \& Commons }\end{array}$ & $\begin{array}{l}521 \\
\text { Craigflower } \\
\text { Road, Victoria }\end{array}$ & $\begin{array}{l}485 \mathrm{~m}^{2} \\
(0.04 \\
\text { acre })\end{array}$ & 21 & $\begin{array}{l}\text { Apples (about half } \\
\text { of total), figs, } \\
\text { mulberries, plum, } \\
\text { pear, nuts }\end{array}$ \\
\hline $\begin{array}{l}\text { Fernwood } \\
\text { Community } \\
\text { Orchard }\end{array}$ & $\begin{array}{l}1240 \text { Gladstone } \\
\text { Ave., Victoria }\end{array}$ & $\begin{array}{l}250 \mathrm{~m}^{2} \\
(0.12 \\
\text { acre })\end{array}$ & 25 trees & Fruit and nuts \\
\hline $\begin{array}{l}\text { Welland } \\
\text { Legacy Park }\end{array}$ & $\begin{array}{l}1215 \text { Stancil } \\
\text { Lane, View } \\
\text { Royal (Greater } \\
\text { Victoria) }\end{array}$ & $\begin{array}{l}3035 \mathrm{~m}^{2} \\
(0.75 \\
\text { acre })\end{array}$ & Over 230 trees & $\begin{array}{l}\text { Over } 100 \text { varieties } \\
\text { of heritage apples as } \\
\text { well as a selection } \\
\text { of: pears, plums, } \\
\text { figs, paw-paw, } \\
\text { hazelnut, medlar, } \\
\text { quince, cherry, } \\
\text { grapes, kiwi, } \\
\text { persimmon }\end{array}$ \\
\hline $\begin{array}{l}\text { Ben Nobleman } \\
\text { Orchard }\end{array}$ & $\begin{array}{l}1075 \text { Eglinton } \\
\text { Ave., West } \\
\text { Toronto }\end{array}$ & $\mathrm{n} / \mathrm{a}^{*}$ & 14 trees & $\begin{array}{l}\text { Apples, plums, } \\
\text { apricot, sweet } \\
\text { cherries, paw-paw, } \\
\text { Asian pear }\end{array}$ \\
\hline
\end{tabular}

* Size is not applicable to trees planted within City parks because the area is not simply an orchard; the fruit trees are part of multi-functional space and it is difficult to calculate what proportion of the area of the park they take up. 


\section{Community Orchards by Organizational Characteristics}

\begin{tabular}{|c|c|c|c|c|}
\hline Orchard & $\begin{array}{l}\text { Year of } \\
\text { inception }\end{array}$ & Leaseholder & $\begin{array}{l}\text { Property } \\
\text { Classification }\end{array}$ & \begin{tabular}{|l} 
Sources of \\
funding
\end{tabular} \\
\hline $\begin{array}{l}\text { Copley } \\
\text { Community } \\
\text { Orchard }\end{array}$ & 2011 & $\begin{array}{l}\text { Environmental Youth } \\
\text { Alliance (to 2016); } \\
\text { Copley Community } \\
\text { Orchard Society (as of } \\
\text { 2017) }\end{array}$ & $\begin{array}{l}\text { City-owned } \\
\text { land (not a } \\
\text { park) }\end{array}$ & $\begin{array}{l}\text { Memberships, } \\
\text { grants, } \\
\text { donations }\end{array}$ \\
\hline $\begin{array}{l}\text { Strathcona } \\
\text { Community } \\
\text { Gardens }\end{array}$ & 1985 & $\begin{array}{l}\text { Strathcona } \\
\text { Community Gardens } \\
\text { Society }\end{array}$ & $\begin{array}{l}\text { City-owned } \\
\text { land - Urban } \\
\text { farm }\end{array}$ & $\begin{array}{l}\text { Memberships, } \\
\text { grants }\end{array}$ \\
\hline $\begin{array}{l}\text { Jonathan } \\
\text { Rogers Park }\end{array}$ & (unknown) & $\begin{array}{l}\text { Elizabeth Rogers } \\
\text { Community Gardens }\end{array}$ & City park & (unknown) \\
\hline $\begin{array}{l}\text { Norquay } \\
\text { Learning } \\
\text { Orchard }\end{array}$ & 2006 & $\begin{array}{l}\text { Renfrew-Collingwood } \\
\text { Food Security } \\
\text { Institute }\end{array}$ & City-owned lot & $\begin{array}{l}\text { Grants, } \\
\text { donations }\end{array}$ \\
\hline $\begin{array}{l}\text { Spring } \\
\text { Ridge } \\
\text { Commons }\end{array}$ & 1999 & $\begin{array}{l}\text { Fernwood } \\
\text { Neighbourhood } \\
\text { Resource Group }\end{array}$ & $\begin{array}{l}\text { School District } \\
61\end{array}$ & $\begin{array}{l}\text { Grants, } \\
\text { donations, Go- } \\
\text { Fund-Me } \\
\text { campaigns, sale } \\
\text { of donated items }\end{array}$ \\
\hline $\begin{array}{l}\text { Banfield } \\
\text { Park \& } \\
\text { Commons }\end{array}$ & 2013 & $\begin{array}{l}\text { Vic West Food } \\
\text { Security Collective }\end{array}$ & City park & $\begin{array}{l}\text { Grants; City of } \\
\text { Victoria }\end{array}$ \\
\hline $\begin{array}{l}\text { Fernwood } \\
\text { Community } \\
\text { Orchard }\end{array}$ & 2013 & $\begin{array}{l}\text { Fernwood } \\
\text { Neighbourhood } \\
\text { Resource Group }\end{array}$ & City park & $\begin{array}{l}\text { Grants; City of } \\
\text { Victoria }\end{array}$ \\
\hline $\begin{array}{l}\text { Welland } \\
\text { Legacy Park }\end{array}$ & 2013 & $\begin{array}{l}\text { LifeCycles } \\
\text { (since 2013) }\end{array}$ & $\begin{array}{l}\text { City park (land } \\
\text { trust) }\end{array}$ & $\begin{array}{l}\text { City grants \& } \\
\text { operational } \\
\text { funding } \\
\text { (contractual } \\
\text { basis) }\end{array}$ \\
\hline $\begin{array}{l}\text { Ben } \\
\text { Nobleman } \\
\text { Orchard }\end{array}$ & 2009 & Informal & City park & $\begin{array}{l}\text { Grants, } \\
\text { rummage sales }\end{array}$ \\
\hline
\end{tabular}




\section{Appendix D - Maps Showing Locations of Community Orchards}

\section{Vancouver Community Orchards}

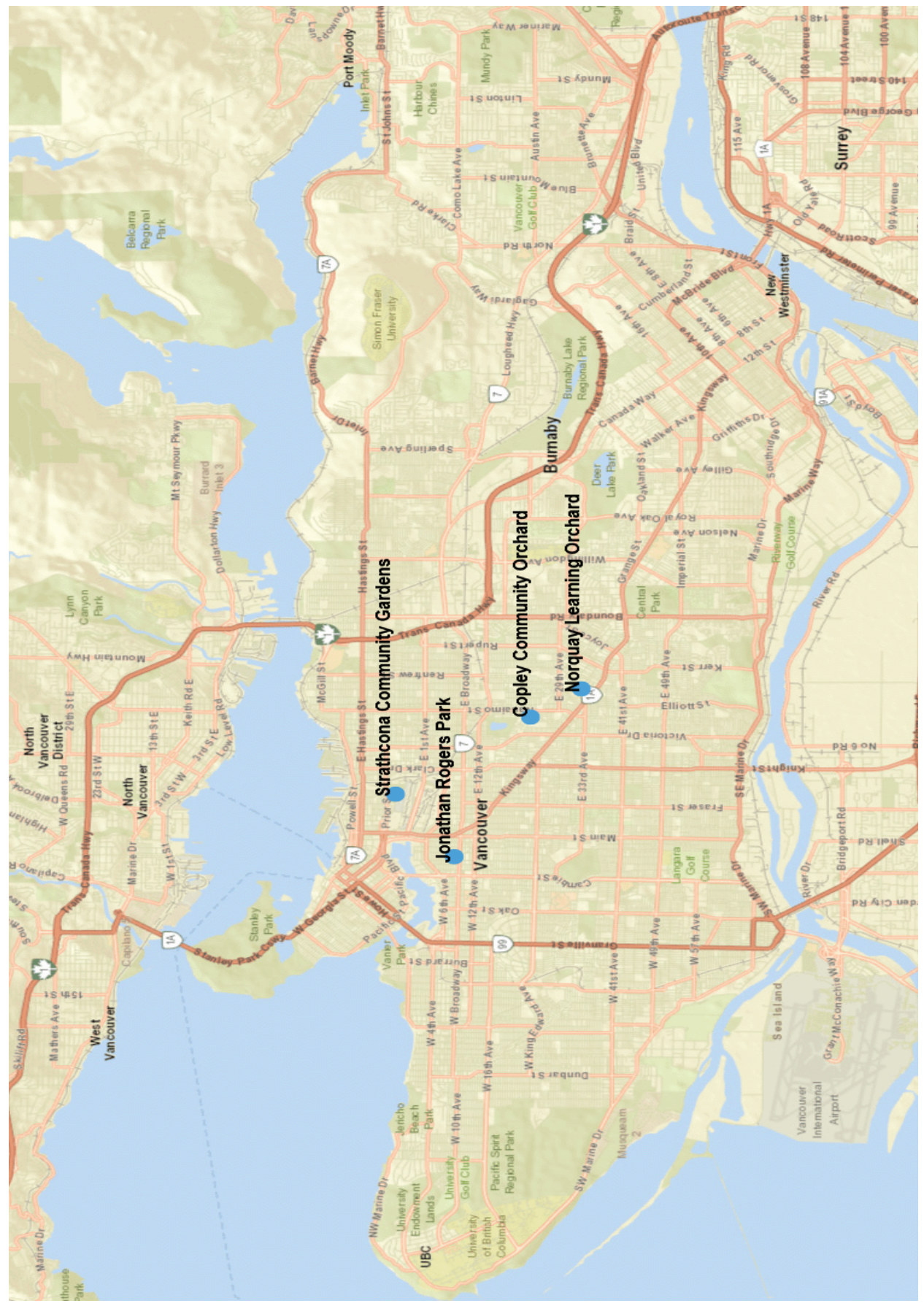

Map made using iMapBC. Available at https://maps.gov.bc.ca/ess/hm/imap4m/ 


\section{Greater Victoria Community Orchards}

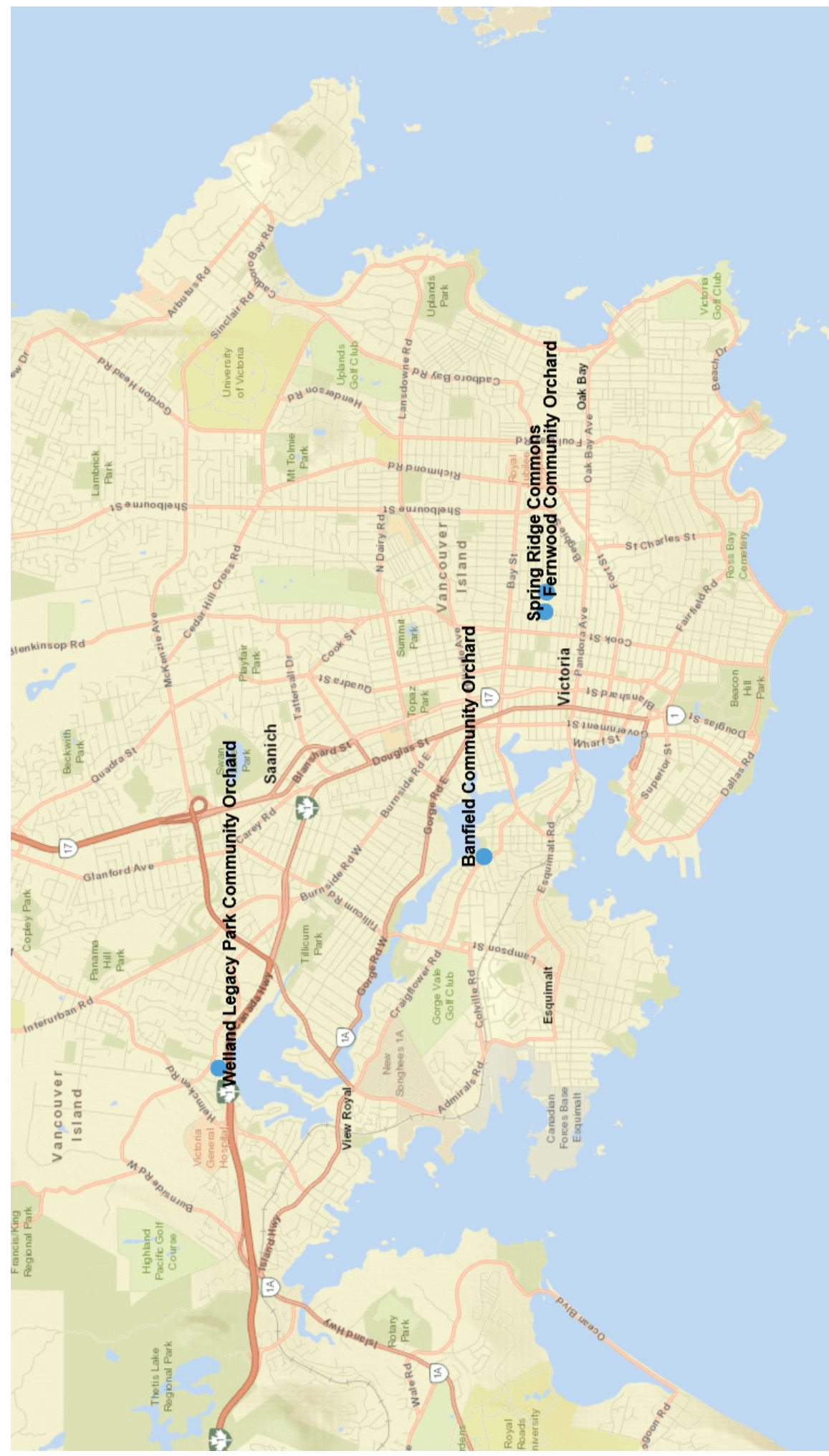

Map made using iMapBC. Available at https://maps.gov.bc.ca/ess/hm/imap4m/ 


\section{Toronto - Ben Nobleman Community Orchard}

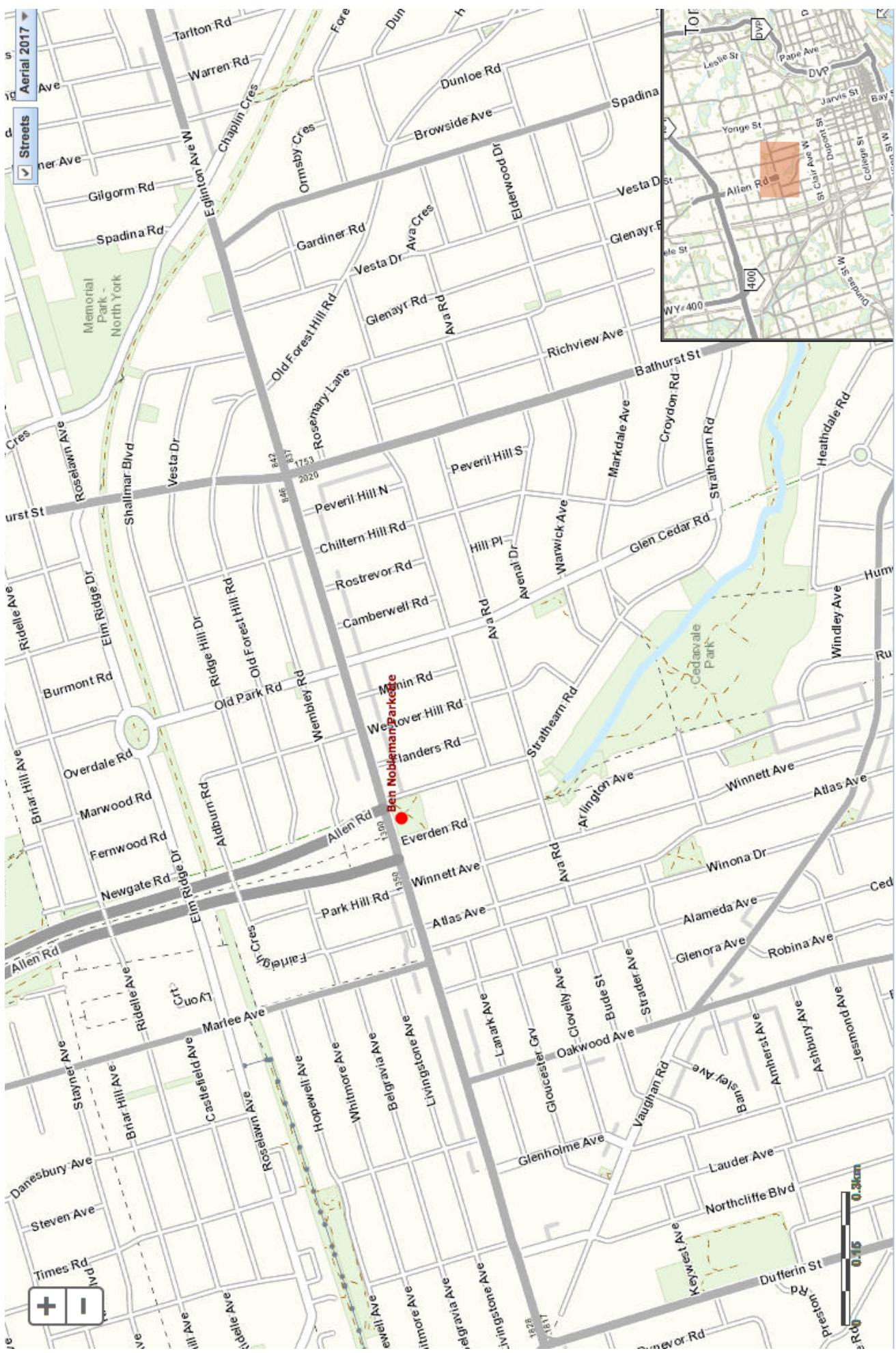

Map made using the Interactive Toronto Map. Available at https://www.toronto.ca/citygovernment/data-research-maps/maps/interactive-toronto-map/ 